
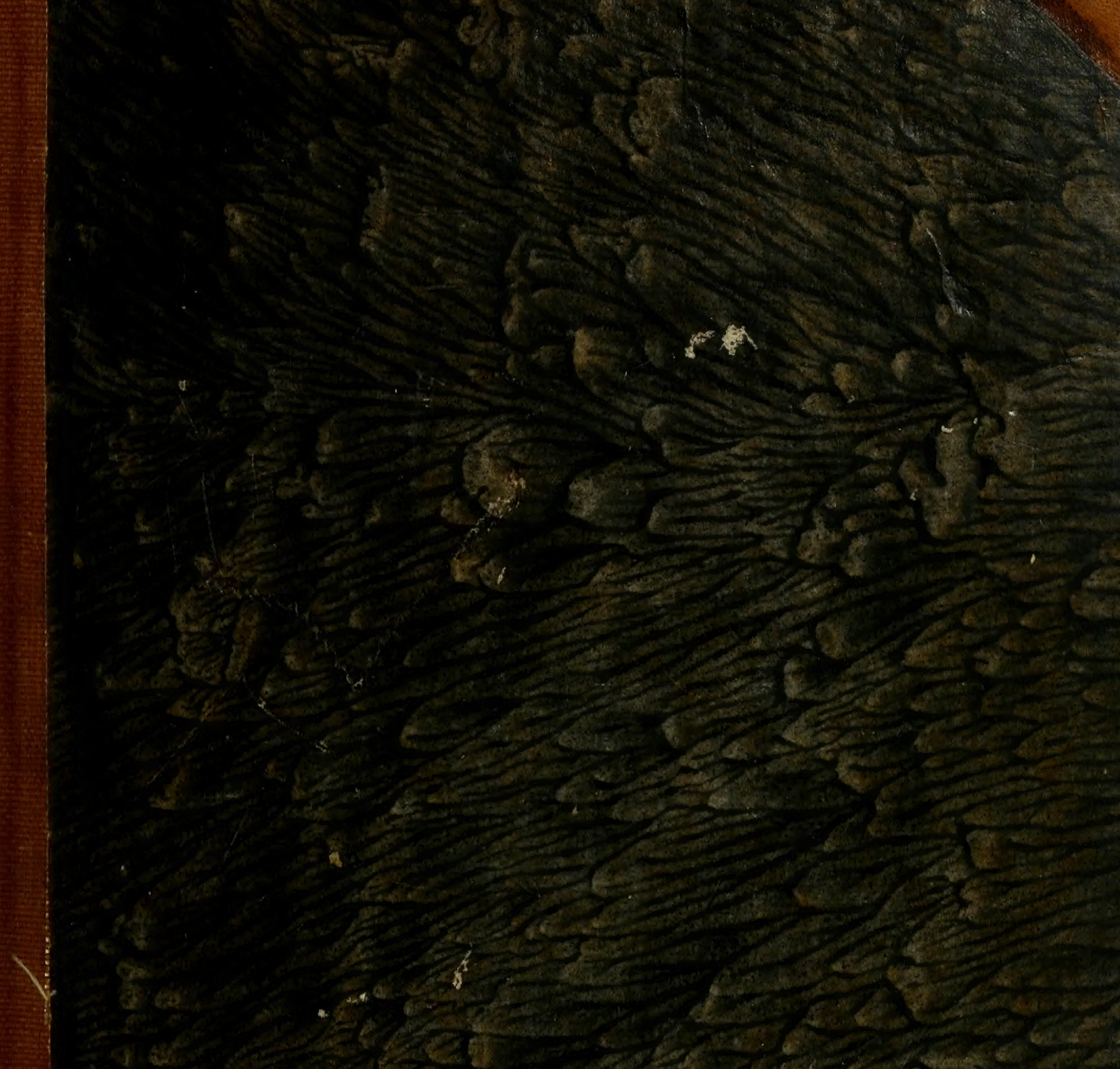

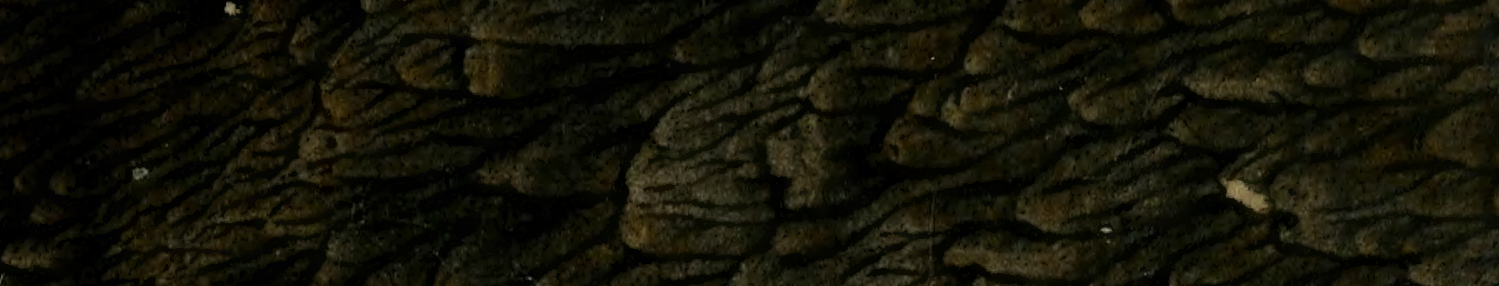
(3)

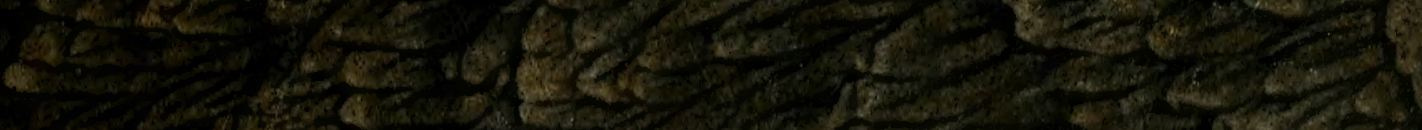

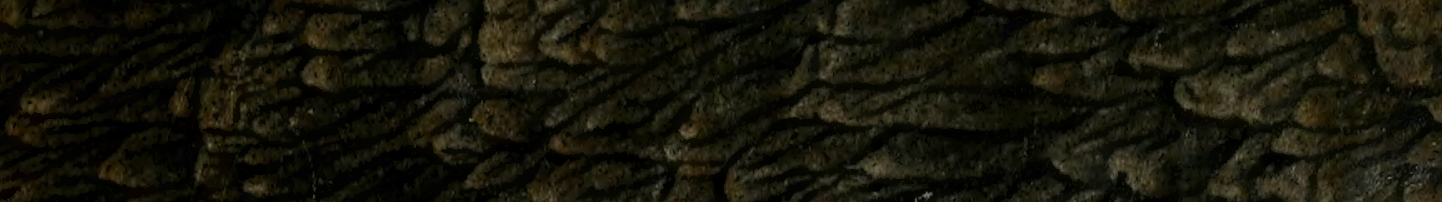

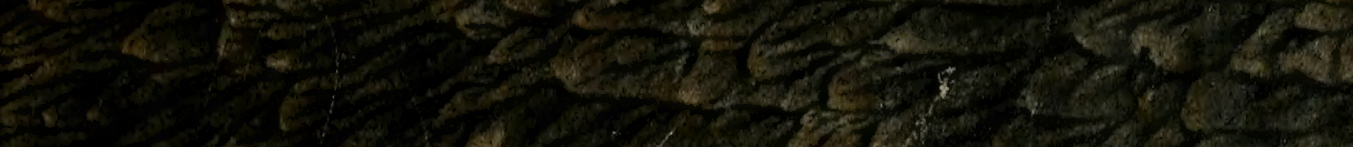

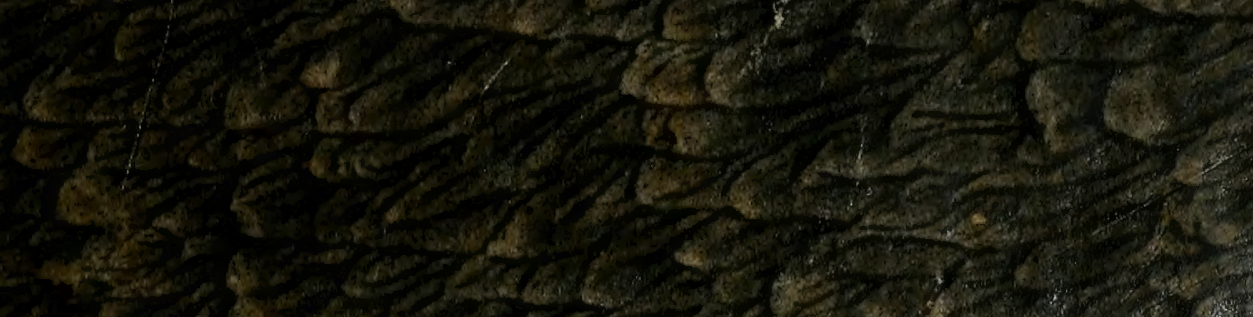

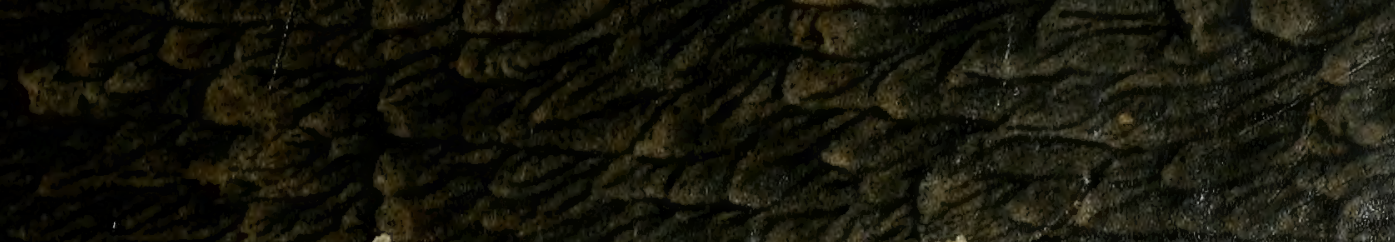





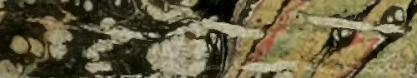

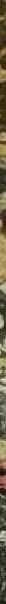

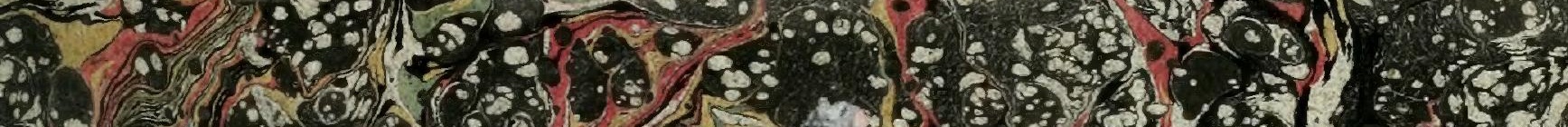

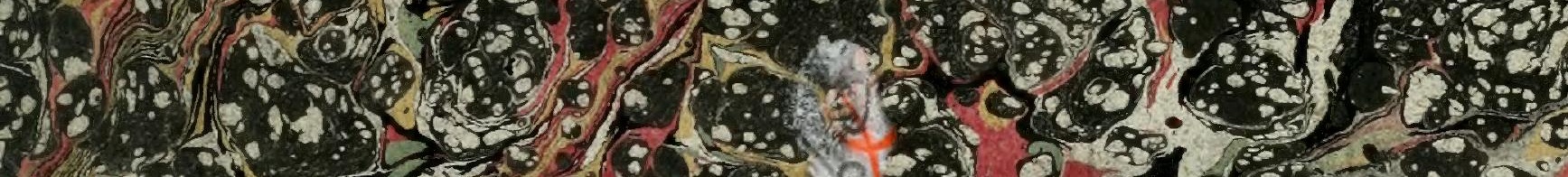
6. a. 930 - 3 .

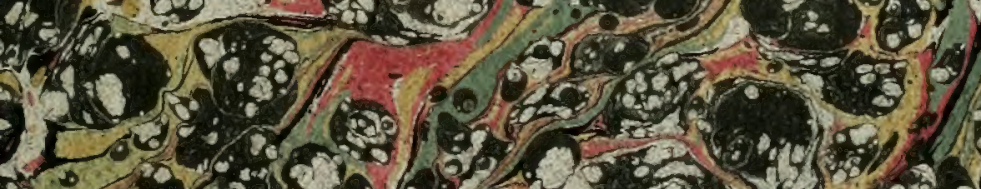
3.

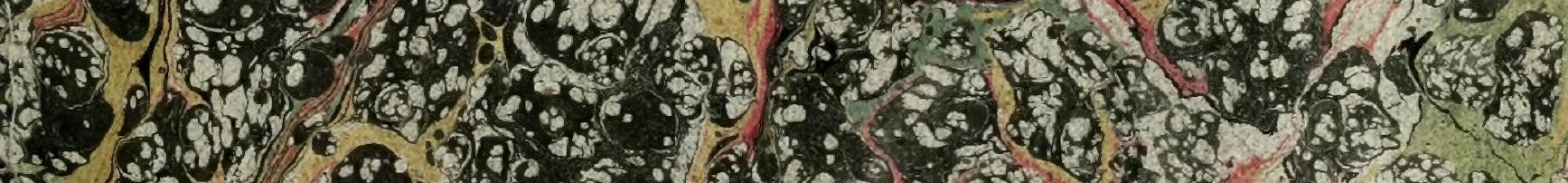

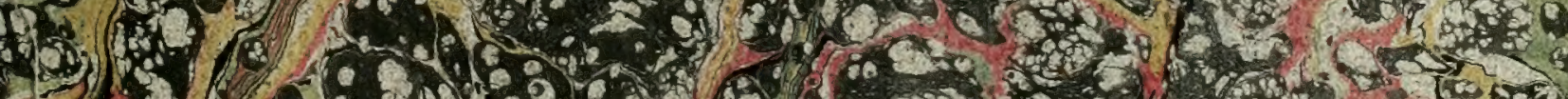

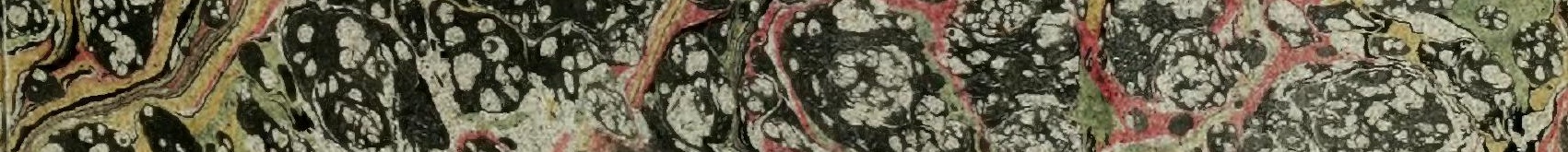

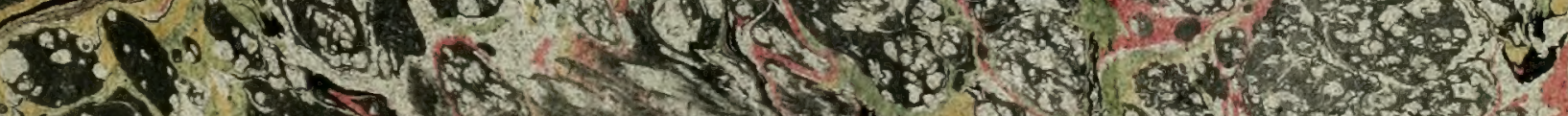

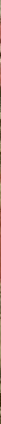




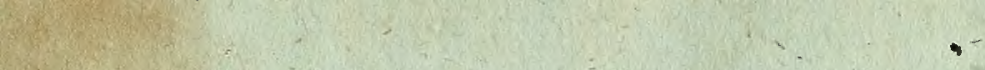






\section{A N T I S S A}

\section{N S E C T O R U M}

EXHIBENS SPECIES NUPER IN ETRURIA

$$
\text { C O L L E C T A S }
$$

A

\section{P E T RO ROS S I O}

ADIECTIS FAUNAE ETRUSCAE ILLUSTRATIONIBUS, AC EMENDATIONibUS .

\section{P I S I S}

EXTY TOGRAPH IA POLLONI PRAESIDUM FACULTATE M D C C X C I I. 
Digitized by the Internet Archive in 201.1 with funding from University of Illinois Urbana-Champaign

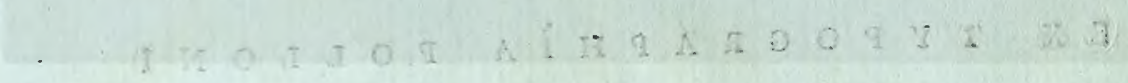

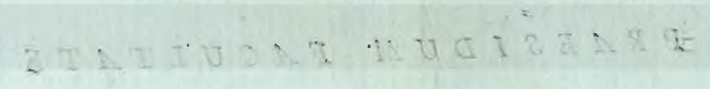

http://www.archive.org/details/mantissainsector00ross 


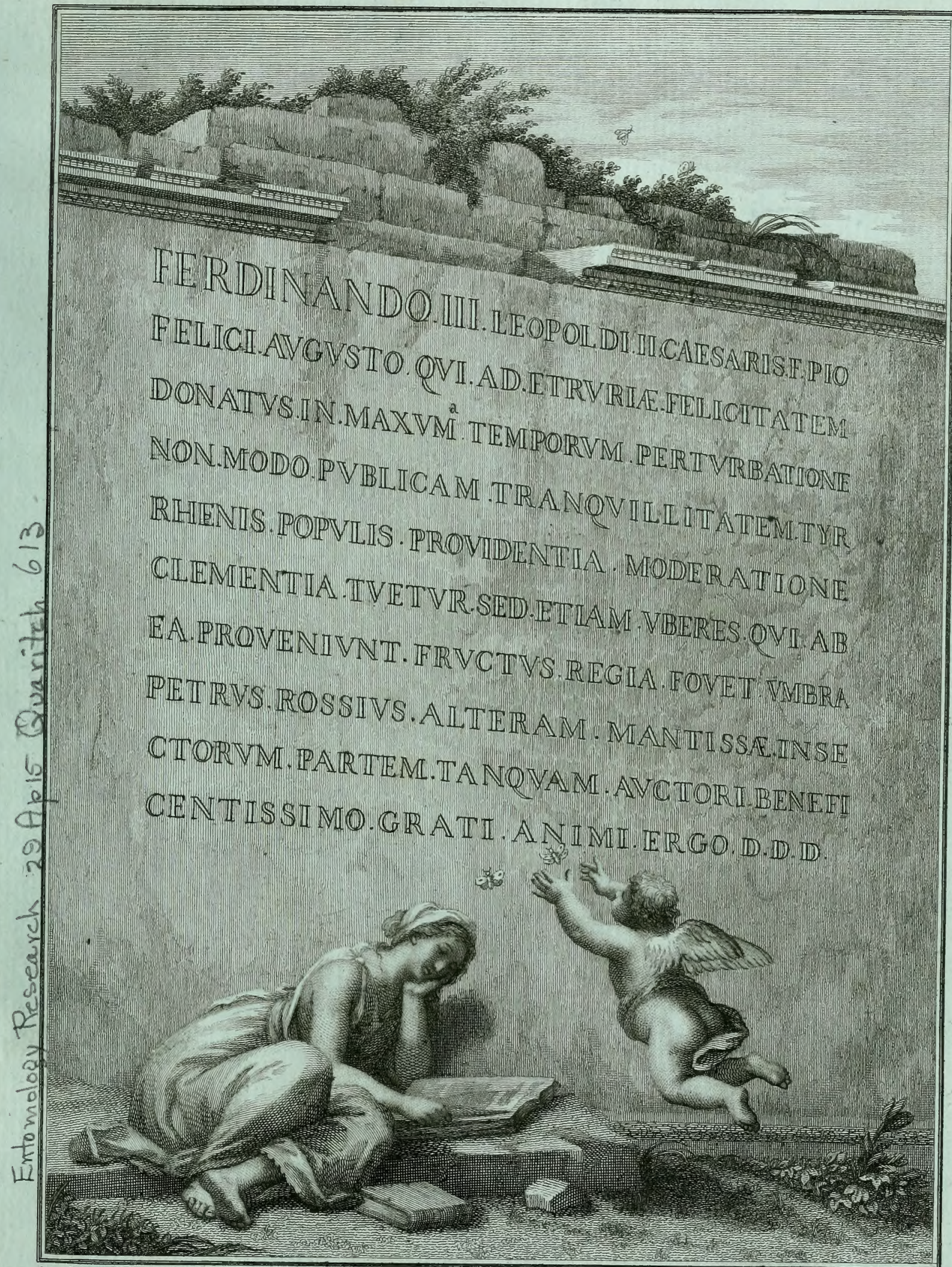

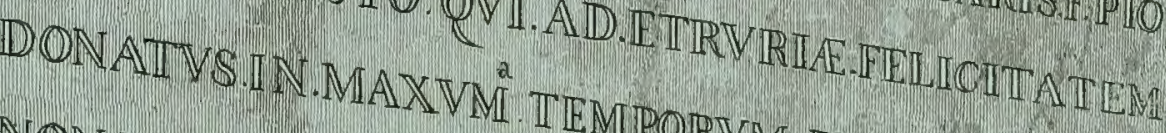

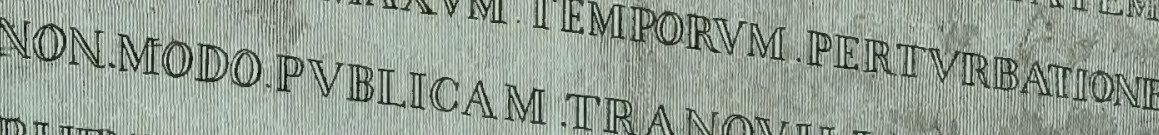

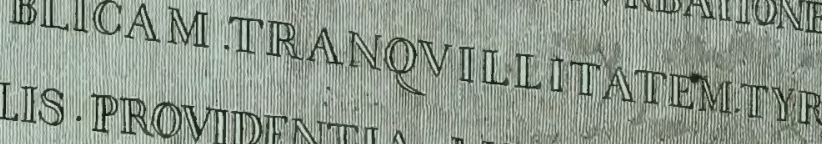

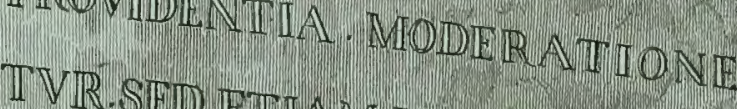

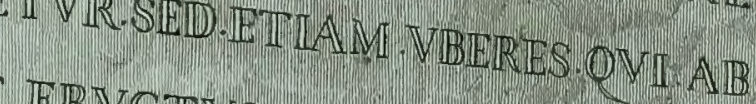
C YS. REGIA. EOVIU WMBRA ILIRAL MLANTISSA INSE AM. AV CTORT.RENETII 


\section{$\checkmark$}


MA N T ISSA I N S E C T O R U M 
Curiosum nobis ingenium Natura dedit, \& artis sibi ac pulchritudinis suae conscia spectatores nos tantis rerum spectaculis genuit, perditura fructum sui, si tam magna, tam clara, tam subtiliter ducta, tam nitida, \& non uno genere formata solitudini ostenderet.

SENEC. de otio. 


\section{E C T O R I.}

$\mathrm{H}_{\mathbb{N}}$ tibi, Entomophile, Insectorum species a me nuper in Etruria collectas, quas oro excipias animo ipso indulgenti quo superiores labores meos complexus es. Illustrationes, ac emendationes specierum in Fauna Etrusca editarum addidi, easque partim occasione data, suo loco, partim in Operis calce, quemadmodum et Icones praestantiora Insecta exhibentes ibidem indicatas invenies. Vale.

Dabam Pisis Prid. Kal. Mart. 1792. 



\section{L A S S I S P R I M A.}

E L E U T E R A T A.

I. $L U C A N U S$.

Penicilli duo sub labio palpigeri. Antemnae pectinato-fissiles.

$$
\begin{aligned}
& \text { I. L? V I R E S E N S. } \\
& \text { Long. 7. 1. Lat. 2. } 1 .
\end{aligned}
$$

Viridi-aeneus, maxillis tridentatis. F. Syst. App. $81 \%$.

Trogossita virescens. Oliv. Ent. $12.19 .8 . t$. I. $f .5$.

Major L. Caraboide, et oblongior. Antennae aeneo nigrae, $\mathrm{Ca}^{-}$ pite longiores, undecim articulatae, articulis tribus ultimis extrorsum crassioribus. Maxillae crassae, prominentes, capite breviores, tridentatae. Caput viridi aeneum punctulatum depressum, antice canaliculatum clypeo apice obtuse quadridentato. Thorax viridi-aeneus depressus, postice rotundatus. Scutellum inconspicuum. Elytra viridi-aenea punctato substriata. Subtus omnino concolor.

Lectus in silvis Pisanis.

\section{III. $S C A R A B A E U S$.}

Palpi quatuor filiformes. Labium elongatum : apicibus elongatis, palpigeris.Antennae clavato-lamellatae.

2. S. Punctulatus.

Scutellatus, muticus, mandibulis laciniatis, clypeo triangulari, 
thorace punctato, elytris sublineatis, punctisque majusculis inordinate excavatis. Fin. Etr. 1. 9. 1.9. $t$. I. f."

S. Punctatus Villers Ent. 1. 40. 88. t. 1. f. 3 .

Statura et magnitudo feminae $S$. Sileni. Elytra late lineata, lineis laevibus, vix elevatis, obliquis, convergentibus. Femora postica crassa. Niger immaculatus. Magnit. variat.

Habitat silvas, et hortos frequentissimus.

$$
\begin{aligned}
& \text { 3. S. Fos SOR. } \\
& \text { Lozg. 4. 1. Lat. 2. } \frac{1}{3} 1 .
\end{aligned}
$$

Scutellatus, thorace inermi retuso, capite tuberculis tribus, medio subcornuto. F. $\int p .15 .59 . F n . \int v .384$.

Geoff. Ins. 1.. 82. 20.'

De Geer Ins. 4. 264. 8. t. 10. f. 7 .

Villers Ent. 1. 17. 15.

Scaeff. Icon. t. 144. $f: 7$ ?

Habitat in montuosis .

$$
\begin{aligned}
& \text { 4. S. SORDIDU.S. } \\
& \text { Long. 2. } \frac{x}{2} \text { 1. Lat. 1. } \frac{x}{3} 1 .
\end{aligned}
$$

Scutellatus, capite tuberculato, thorace nigro, margine pallido puncto nigro, elytris griseis. $F a b . / p .17 .68$.

Statura $S$. Conspurcati, at paullo major. Clypeus rotundatus, integer, niger, macula utrinque pallida, tuberculisque tribus intermedio subcornuto. Thorax laevis, glaber, ater margine pallido: punctum utrinque nigrum in margine pallido. Elytra striata grisea sutura obscuriore. Subtus nigro griseoque variegatus pedibus pallidis. F.

Habitat cum congeneribus.

\section{S. Rubidus.}

Niger, abdomine elytrisque ferrugineis, thorace antice vix excavato, capite tuberculis tribus. Oliz. Ent. 3. 81. 77. t. 26 . - f. 224 . 
Similis S. Fimetario, at triplo major. Caput nigrum antice subemarginatum, lateribus angulatum, supra tuberculis tribus, intermedio elevato acuto. Thorax inermis, punctatus, antice, vix excavatus, niger lateribus ferrugineis. Scutellum nigrum. Elytra ferruginea striata. Corpus subtus, pedesque nigra, tarsis abdomineque obscure ferrugineis. Oliv.

Habitat Florentiae.

$$
\begin{aligned}
& \text { 6. S. I R R O R A } \mathrm{T} U \mathrm{~S} \text {. } \\
& \text { Long. 8. 1. Lat. 4. 1. }
\end{aligned}
$$

Scutellatus, thorace rugoso fossula utrinque impressa, capite subcornuto, elytris rugoso sulcatis nigris, rufo-submaculatis. Fn. Etr. 1. 7. 16.

Clypeus marginatus, carinatus, et in medio corniculo brevissimo armatus. Antennae nigrae. Thorax subrugosus margine crenulato. Scutcllum parvum. Elytra antice coarctata, late rugoso-6ulcata, maculis, seu punctis plurimis obsoletis rufis, vix distinguendis aspersa. Femora antica duobus denticulis interne instructa. Tibiae anticae quadridentatae .

Habitat Florentiae, et Pisis rarus .

$$
\begin{aligned}
& \text { *7. S. F U R C I F E R, } \\
& \text { Long. 8. 1. Lat. 4. } 1 \text {. }
\end{aligned}
$$

Scutellatus, muticus, niger, elytris rugosis, femoribus anticis lamina, et dente valido instructis, pectore bifurcato.

Statura, ct magnitudo S. Irrorati. Totus niger obscurus. Clypeus marginatus, carinatus, corniculo, seu potius lineola vix apparente. Thorax magnus circularis, convexus, subrugosus fossula laterali. Elytra subrugosa ad latera angustata. Scutellum parvum fere nullum. Tibiae anticae longae, arcuatae, quadridentatae absque tarsis. Femora antica intus, et inferne appendice, seu lamina cuneiformi porrecta, utrinque dentata; denteque altero acuto supcrne instructa. Pectus spinis duabus validis instar furcae armatum. Cum a 
praecedente differat tantum pectore bifurcato, et lamina cuneiformi femorum anticorum, alterum esse sexum asserere posse videtur.

Raro lectus.

$$
\text { 8. S. R U F I P E S . }
$$

$$
\text { Long. 4. 1. Lat. } 2.1 .
$$

Scutellatus, muticus ater, thorace glabro, nitido, elytris striatis. F. $\int p .20 .84$.

S. Rufipes muticus ater, antennis pallidis, elytris laevibus. Linn. Syst. Nat. 559. 86. Fn. Sv. 403 .

De Geer Ins. 4. 263. 7. t. 10. f. 6.

Geof: Ins. 1. 83. 21. Scbrank E. I. 30.

Habitat in stercore, infrequens.

$$
\begin{aligned}
& \text { 9. S. P L A G I A T U S . } \\
& \text { Long. 2. 1. Lat. 1. } 1 \text {. }
\end{aligned}
$$

Scutellatus, muticus niger, elytris plaga rufescente $F \cdot \sqrt{p} .21$. 87. Limn. Syst. Nat. 539. 85.

Scbrank E. I. 28.

Affinis S. Subterraneo, et forte mera varietas. In singulo elytro macula oblonga rufescens juxta suturam.

Habitat in stercore bovino.

$$
\text { * 10. S. Fuscus. }
$$

Scutellatus supra fuscus, subtus niger, elytris tomentosis, striatis .

Paulo minor $S$. Quisquilio, et totus supra obscure fuscus pube subferruginea: subtus niger nitidus. Clypeus rotundatus, marginatus, tuberculo solitario vix apparente. Antennae capitulo trifido. Tibiae anticae tridentatae. Elytra subtilissime, atqque obsolete punctato-striata. Tarsi subrufi.

Habitat sub corticibus.

$$
\text { 11. S. LU NARIS. }
$$

Excutellatus, thorace tricorni intermedio obtuso bifido, capitis 
cornu erecto, clypeo emarginato $F . \int p .24 .108$. Limm. Syst. Nat. 543. 10, mas.

Copris capitis clypeo lunulato, margine elevato, corniculo denticulato. Geof. Ins. 1. 88. 1. femina . Hunc Clar. D. Olivier speciem diversam esse a praecedente credit, et distinguit sub nomine S. Emarginati t. 8. f. 64. a. 6. Mihi tamen liceat, venia Celebris Viri, in pristina manere sententia, donec res aliter se commonstret ac visa pluries. Confer $F n$. Etr. 1. 11.24.

Junior variat colore castaneo.

Habitat uterque simul in stercore bovino pascuorum.

$$
\text { IV. } T R O X \text {. }
$$

Palpi quatuor capitati. Maxilla bifida. Antennae clavatoJamellatae.

$$
\text { * 12. T. NigER. }
$$

Long. 3. $\frac{1}{3}$ 1. Lat. 2. 1. vix.

Njger, thorace marginato inaequali, elytris punctato striatis, lineis elevato spinosis.

Insectum idem quod dedimus in Frr. Etrusca sub dubio nomine $T$. Luridi qui diversus .

Corpus totum obscure nigrum. Thorax marginatus, inaequalis, villo brevi rufescente ciliatus, late dorso sulcatus, at haud spinosus. Elytra marginata, punctato-striata, lineis tantum quinque in singulo elytro elevato-spinosis. Videtur novus.

Flabitat Florentiae .

$$
\text { V. MELOLONTHA. }
$$

Maxilla brevis cornea : apice multidentata. Antennae lamellatae. 


\section{M. R U FIC O R N I S.}

Villosa testacea abdomine albiçante. $F_{0} \iint_{0}, 37.8$. Mant. 20. 12.

Yoet. Scar t. 6. f. 50 .

Statura M. Solstitialis . Caput nigricans antennis rufis. Thorax et pectus villis densis albis tecta. Elytra testacea inmaculata. Abdomen albidum, ano nigricante. Pedes nigri. F. Variare saepe videtur magnitudine, et colore obscuriori.

Habitat in plantis rarior.

\section{M. A B DOMIN ALIS. \\ Long. 4. 1. Lat. 2. $\frac{1}{2}$ 1. vix.}

Capite thoraceque ceruleo-pilosis, elytris testaceis, abdomine albo-villoso. F. Jp. App. 496.

Paula minor $M$. Hurticla, et thorax magis rotundatus. Species distincta.

Habitat Pisis rarior.

$$
\begin{aligned}
& \text { 15. M. A R G E T T A. } \\
& \text { Long. 4. 1. Lat. 2. 1. et ultra. }
\end{aligned}
$$

Clypeo marginato nigra, subtus argenteo-nitens, elytris test2ceis. F. Jp. 44. 48 ?

S. Farinosus scutellatus, muticus niger, polline virescente, elytris abbreviatis Fu. Sv. 399.

S. Argentens Scop. Ent. Carn. 9.

S. Argenteiss Pud. M. G. 20.

S. Farinostis. Vill. Eat. 1. 30. 46.

Statura, et magnitudo fere $S$. Squamosi. Vill. Thorax et elytra squammis, seu polline luteo-virescente tecta, nonnihil abbreviata. Abdomen fupia nigrum, subtus viridi-argenteum. Tibiae anticae bidentatae. Pedes plerumque testacei, sed interdun nigri. Variat magnitudine duplo minori, unde forsan in hac specie determinanda orta confusio. Tibiae 
anticae bidentatae, et dorsum sub elytris nigrum visac sunt norae constantes. Varietas minor, forte est alter sexus.

Habitat in plantis, et floribus.

$$
\begin{aligned}
& \text { 16. M. S Q U A M O S A. } \\
& \text { Long. 4. L. Lat. } 2.1 \text {. }
\end{aligned}
$$

Searat. Squamosus scutellatus, violaceus, squammis subtus argenteis, supra violaceis, tibiis anticis tridentatis.Villers Ent. 1. 30. 47 .

M. Farinosa F. Mant. 23.60.

Geolf. Ins. 1. 13. l'Ecailleux violet.

Statura praecedentis. Color elytrorum laete violaceus, splendidus. Abdomen subtus argenteum, supra lutescens. Tibiac anticae tridentatae. Tarsi nigri.

$$
\text { * 17. M. D U в I A. }
$$

Nigra, cinereo hirta, corpore virescenti-argenteo, elytris testaceis.

Descriptio $M$. Pulverulentae $\mathrm{F}$. huic nequaquam competere videtur. Statura praecedentium, sed duplo minor. Caput, et thorax nigra, squanmis viridi-argenteis vix aspersa, et pilis densis cinereis longioribus hirta. Elytra testacea abdomine breviora, pilosa. Corpus subtus viridi-argenteum pilosum, supra nigrum. Tibiae anticae bidentatae. Pedes nigri. Obs. In hac antennae, et palpi omnino nigri; in praecedentibus rufi, antennaeque ad basin rufae.

Habitat in plantis.

\section{HISTER.}

Maxilla unidentata. Labium corneum, cylindricum integrum. Antennae clava solida.

18. H. $M$ A J O R .

Ater, elytris, substriatis, thoracis marginibus ciliatis $F$. Syst. 52. 1. Mant. 32. 1. Limm. Syst. Nat. 566. 2. 
Voet. Coleopt. t. 3 i. f. 6 .

Simillimus $H$. Unicolori, at duplo major, et thorax pilis ferrugineis densis ciliatus. $\mathrm{F}$.

Gaudeo hanc speciem indigenam esse etiam Etruriae, sic enim magis magisque asserere possum quod manifeste differt $a b$ H. Laevo Fz. Etr. 1. 28 . 63. forma corporis magis subquadrata, minusque depressa; capite minus exserto, imo fere toto in thoracem retracto; labio superiori, seu clypei apice emarginato, excavato, neque elongato uti in $\dot{H}$. Laevo; mandibulis diversis, et aequalibus; clava antennarum subrufa; thorace antice, et lateribus pilis ferrugineis dense ciliato, absque foveola utrinque impressa; sterno antice acuto, aliisque notis quas referre supervacuum.

Habitat in stercore bovino larus.

$$
\begin{aligned}
& \text { 19. H. C Y A N E U S. } \\
& \text { Long. 4. I. Lat. 2. } 1 .
\end{aligned}
$$

Thorace aeneo, elytris cerulescentibus $F$. $\int p$. 60. 3 .

Descriptio Fabricii Syst. Ent. compctit nostris speciminibus * quae omnino conveniunt cum is e Svecia a $D$. de Paykull acceptis. Color aeneus thoracis, quadam tantum incidentia Iucis conspicuus.

Habitat $\mathrm{Pisis}$ in stercore bovino noin rarus.

$$
\text { * 20. LI MA C U E A T U s. }
$$

Niger nitidus, elytris pallide rubris, striis curvis, anterioribus obsoletis, macula magna baseos nigra ad suturam communi .

Descriptio H. Bipustulati Silbrakkiz E. I. 67. cum nostris minime convenire videtur.

Statura H. Quadrimaculati a quo tamen differt elypeo capitis magis prominulo, magisque ad apicem coangustato, acuminato. Differt antennis clava rufa, non nigra; thorace linea ante marginem destituto; clytrisque omnino pallide-rubris, praeter maculam, et suturam quae nigra sunt. Abdomen in loc magis globosum, ${ }_{2}$ es tibiae anticae quadridentatac in $H$. 
Quadrimaculato rarius, et profundius tridentatae. Macula baseos elytrorum inaequalis, unica, et ita ad suturam posita, ut junctis elytris formam referat subquadratam. Ab H. Binaculato magis etiam difier, cujus, praeter alias, nota constans est foveola sea punctum impressum ad latera antica thoracis.

Habitat cum congeneribus in stercore bovino.

$$
\begin{aligned}
& \text { *21. H. M I N O R: } \\
& \text { Long. I. 产 I. Lat. I. 1. }
\end{aligned}
$$

Ater nitens, elytris subdepressis striatis, striis tribus integris, binisque interioribus abbreviatis, clava antennarum ferruginea.

Statura, et magnitudine fere convenit cum figura a Villers Eatt. t. 1.f: 7. exhibita ad indicandum H. I 2-striatum Sibrankii, scilicet $H$. Depresso paulo major, magisque convexus. Caput parum prominens fronte impressa, apice attenuatum. Antennae clava ferruginea. Thorax Iaevis. Elytra abdomine paulo breviora, striata, striis in singulo tribus vix obliquis, integris; ct duabus suturac proximis abbreviatis ab apice usque ad medium diductis. Tibiae anticae quadridentatac. Differt ab H. Depresso, praesertim magnitudine, et corpore elytrisque minus depressis.

Habitat sub ligno putrido, et sub corticibus frequens.

$$
\text { * 22. H. Decemstriatus. }
$$

Ater nitens, elytris punctato-striatis, striis suturae proximis antice coenntibus.

Accedere videtur ad $H$. Abbreviatrim F. Statura rotundo-globosa. Magnitudo fere $H$. Sulcati, at saepe major. Ater nitidus. Antennae totae nigrae. Caput post mortem intra thoracem retractum. Thorax omnino laevis. Elytra apice truncata, punctato-striata striis in singulo quinque, prima marginis exterioris obliqua abbreviata, sccunda, tertia, et quarta parum obliquis, et ad apicen productis, quinta suturae proxima recta, et cum praecedente antice adeo juncta, 
quasi ac una eademque esset stria recurrens. Nota hacc constans et singularis, etsi quid simile in $H$. Aeneo interdum observetur. Inter quartam vero et ultimam striam, alia interior abbreviata $a b$ apice elytri extenditur usque ad dimidium. Posteriora abdominis elytris paulo longiora. Habitat cum congeneribus frequens.

*3. H, DUODECIMSTRIATUS?

$$
\text { Long. 1. 1. Lat. } \frac{2}{3} 1 \text {. }
$$

Ater, nitens, elytris duodecim striatis, antennis ferrugineis.

Duac obversantur difficultates ne mihi suadcam hunc esse verum $H, 12$-striatum Scbrankii E. I. 70. Villers Ent. t. 1.f. 7 . nempe magnitudo minor, et color antennarum a Scbrankio praetermissus, qui in nostris specimin. ferrugineus est: at cum nullum alium noverim cui magis $\mathrm{Cl}$. Viri descriptio competat, nomen idem servandum esse duxi.

Statura omnino praecedentis, sed paulo minor. Antennae ferrugineac. Caput retractum fionte non impressa. Thorax laevis. Elytra abdomine breviora, convexa, striata striis minutissime punctatis. In singulo sex a basi ad apicen decurrunt ita ut aequalibus a se distantes spatiis discum totum occupent. Pedes nigri interdum picei.

Habitat in truncis a borum emort. non rarus.

$$
\text { 24. H. S U L C A T U S . }
$$

Ater, thorace, elytrisque punctato-sulcatis, apice retusis. Fn? Etr. 1. 30. 70. t. 11. f. 3 .

H. Striatus Forster N. I. C. \#. II.

H. Globulosus. Olivier. Ent. t. 2. f. I5. a. b.

Habitat in stercore equino pascuorum, primo vere.

$$
\begin{aligned}
& \text { 35. H. P A R V U U S. } \\
& \text { Long. } \frac{3}{4} \text { 1. Lat. } \frac{1}{3} 1 .
\end{aligned}
$$

Ater, clongatus, elytris lacvissimis nitidis, antennis, pedibusque ferrugincis: 
Minor semine Oryzae. Statura corporis elongata. Laevis, nitidissimus, ater, pedibus exceptis, antennisque a fractura ad clavam ferrugineis. Elytra admodum abbreviata, convexa. Abdomen apice attemratum .

Habitat in ligno putrescente, hieme non rarus.

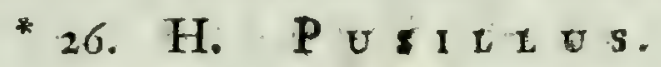

Niger, subnitidus, elytris punctatis; thorace utrinque ad matrginem sulco longitudinali impresso.

Minor Pediculo, eodemque modo longiusculus. Niger subnitidus. Antennarum clava ferruginea. Thorax sulco utrinque ad marginem longitudinali profunde excavato. Elytra abbreviata, undique punctulata punctis impressis, armato oculo manifeste conspicuis, unde nitoris defectus.

Habitat sub arborum cortice cum congeneribus, rarior.

$$
\text { * 27. H. А т о м } \text { о . }
$$

Ater laevissimes nitiỏus, clytris subintegris, capite toto exserto . Vix major semine Papaveris. Cum H. Minimutm in Fn. Etr. 1. 30. 71. dedinus, eo minorem nullum inveniri posse visum, at revera hic duplo minor, et statura diversus. Corpus subrotundum, globosum, atrum, laeve, nitidum; iit H. Minimo ovatum. Differt etiam antemnis nigris clava concolori, capire parvo toto exserto, elytris vix abbreviatis. Habitat sub cortice Ulmi mens. Februar. (a)

(a) Claracteres indicati in speciebus a me descriptis constanter observati in pluribus individuis. H. Pygmaeum, qui apud nos etian babitare videtur, cum autbrres in eo describendo nimis dissentiant, erroris periculo praetermisimas, itemque alios, quorum differentiam oculis snagis distinguere, quam verbis exprimere datum. 
$\mathrm{X}$. DERMESTES.

Palpi quatuor filiformes. Maxilla bifida. Labium corneum, obtusum, integrum. Antennase clavato-perfoliatae.

$$
\begin{aligned}
& \text { 28. D. V U I P I N U } 5 \text { ? } \\
& \text { Long. 4. } \frac{2}{3} \text { 1. Lat. I. } \frac{x}{2} 1 \text {. }
\end{aligned}
$$

Oblongus laevis niger, thoracis lateribus cinereo-villosis, subtus albidus. F. $\int p$. 64. 9 .

D. Cadaverinus Fn. Etr. 1. 33. 77. vídetur huc referendus . Mea specimina conveniunt cum descriptione Fabricii. Femo-

ra postica etiam basi cinereo-fasciata. Magnitudo variat. Speciem e descriptionibus tuto determinare non potui. Habitat cadavera.

$$
\begin{aligned}
& \text { 29. D. T в I F A S С I A T U } 8 \text {. } \\
& \text { Long. I, } \frac{1}{3} \text { 1. Lat. } \frac{1}{3} \text {. } 1 \text {. }
\end{aligned}
$$

Ovatus, niger, elytris fasciis tribus undatis cinereis. F. Mant. 34. 7 .

Byrrbus fuscus, fasciis elytrorum transversis cinereis. Geof. Ins. 1. 112.5 .

Vill. Illustr. 4. 219.

Magnitudo, et statura D. Undati . Caput nigrum. Thorax niger margine baseos cinereo. Elytra nigra fasciis tribus undatis, punctoque apicis cinereis . Corpus nigrum. F.

Elytrorum fasciae interdum obliteratae. De genere dubitat $D$. Villers $l$. $c$.

Habitat in plantis rarus.

$$
\text { 30. D? DE N T A T U S . }
$$

Elongatus hirtus, niger, elytris testaccis. Frt. Etr. 34. 82. t. 3. f...2. et add. Insectum forte novi generis. An. Cantharis Serraticomis Scop. E. Casm. 135? Sed antonnae difierun paullulum a descript. Siopoline. Variat magnitudine. 
Nidulatur in ligno antiquo. Mens. Jun. et Jul. saepe inveni in postibus fenestrarum, et januis domesticis exeuntem c factis foraminibus; sed ruri etiam lectus in floribus.

$$
\begin{aligned}
& \text { 3I. D. F O R I C A T U S. } \\
& \text { Long. 2. 1. Lat. 1. l. et ultra. }
\end{aligned}
$$

Fuscus obscurus, corpore ovato laevi fornicato, antennis longissimis: clava subulata. De Geer. 4. $216.9 . t$. 8. f. 15. Villers. Ent. 1, 57. 46.

Genus incertum, at facies Dermestis. Antennac clava elongata apice subulato, capite thoraceque paulo longiores. Habitat in truncis cariosis.

$$
\text { * 32. D. F U I I GIN OS US. }
$$

Ovatus ater, antennis ferrugineis.

Statura, et magnitudo $D$. Lardarii. Totus ater, et veluti fuligine obductus. Antennae subrufae. Alae fuscescentes. Accedere videtur ad D. Atruin de Geer. Iis. t. 4. 223. 1. t. 18. $f .7$ at differt colore aterrimo, et statura breviori.

Habitat in arborum carie frequens.

$$
\text { 33. D. B I C OLOR. }
$$

Oblongus niger, subtus testaceus, elytris striatis. $F \cdot \sqrt{p} .64 .8$. Statura D. Murini, sed paullo major. Totus superne niger, capite, thoraceque praesertim ad latera villis fulvo luteis tectus; inferne testaceus. Elytra substriata.

Habitat in truncis arborum exsiccatis.

$$
\begin{aligned}
& \text { 34. D. D U в I U S. } \\
& \text { Long. 4. } \frac{1}{3} \text { 1. Lat. 1. } 1 \text {. }
\end{aligned}
$$

Cyaneo-niger subhirtus, elytris rubris.

Insectum forte novi generis. Primo intuitu Cantbaris, aut Lagria, aut Clerus videtur. Corpus totum cyaneo-nigrum, elytris exceptis rubris. Statura D. Sanguinicollis, at paullo major. Caput exsertum hispidulum. Palpi quatuor inaequales 
subfiliformes. Antennae porrectae, thorace breviores, clavatae clava ex articulis tribus composita, primo, et secundo apice oblique truncatis, extimo acuminato. Thorax rotundatus, emarginatus, punctulatus, subhirtus, lateribus posticis paullulum reflexis. Elytra integra tenuissime punctulata, rubra nitida, ejusdemque coloris elytrorum Bostr. Capucimi. Alae nigrae. Tarsi quatuor.

Lectus juxta sepes in silvis April. $m$.

\section{XII. $B O S T R I C H U S$ :}

Maxilla cornea . Labium cylindricum integrum, apice palpigerum. Antennace clava solida.

$$
\text { 35. B. C A L C O G R A P H U S . }
$$

Ater, elytris praemorso-dentatis rufis. $F . \int p .64 \cdot 4$.

Dermestes Chalcograpbus ater, elytris praemorso-dentatis rufis, lateribus, basique nigricantibus . Linn. Syst. Nat. 562. 8. Fn. Sv. 417.

Duplo, aut triplo minor $B$. Typograpbo. Antennae testaceae. Corpus glabrum. Colore variat.

Habitat sub arborum cortice.

$$
\text { 36. B. } P Y G M A E U S \text { : }
$$

Ater nitidus, elytris integris rufis, abdomine retuso . F. Mant. 37. 11 .

Statura, et summa affinitas $B$. Scolyti, at triplo minor, et elytra rufa. F.

Habitat intra cortices arborum cmortuarum.

$$
\text { 37. B. CR E N T U S . }
$$

Glaber ater, elytris integris piceis, crenato-striatis. F. Mant. 37. 10.

Statura, et magnitudo B. Scolyti. Caput, et thorax laevia, atra, immaculata. Elytra integra picea, crenato-striata. Pedes picei: F.

Iabitat in truncis arborum. 
Villosus testaceus, corpore nigricante, tibiis quatuor posticis serratis. F. Mant. 37. 12.

Paullo major $B$. Piniperda. Caput nigricans antennis testaceis, articulo primo longiori, crassiori incurvo, ultimo clavato. Thorax, elytra, abdomen villosa testacea immaculata. Elytra striata. Pedes breves validi testacei, tibiis quatúor posticis serratis. Optime F.

Habitat in ligno.

39. B. VA PIUS :

Subvillosus, corpore nigro, cinereoque vario. $F . \int p .64 .8$. Statura, et magnitudo B. Piniperilae, sed paulo latior, et brevior. Antennarum clava acuminata .

Habitat cum praecedentibus.

$$
\text { * 40. B. A T } E \text { R. }
$$

Glaber niger nitidus, elytris integris, antennis pedibusque rufis. Statura B. Piniperdae, at minor, et ab eo distinctus etian colore magis atro, magisque glabro, laevi, nitido.

Habitat in ligno.

$$
\mathrm{XV}: A N O B I U M \text {. }
$$

Palpi quatuor clavati. Maxilla obtusa dentata. Labium integrum. Antennae filiformes.

$$
\begin{aligned}
& \text { 4I. A. P U N C T A T U M. } \\
& \text { Long. 1. } \frac{1}{3} \text { 1. Lat. } \frac{2}{3} 1 .
\end{aligned}
$$

Griseo-fuscum, elytris striatis, punctisque excavatis, thorace in medio gibboso .

Ptinus Punctatus griseo-fuscus elytris striatis, punctisque excavatis. De Geer Ins, 4. 230. 3. 
Statura omnino $A$. Pertinacis, cujus forte varietas. Antennae fuscae, tres articuli ultimi majores. Thorax in medio gibbus, margineque postico parum reflexo. Elytra punctatostriata.

Habitat in ligno.

XVI. PTINUS.

Palpi quatuor filiformes. Maxilla bifida. Labium bifidum. Antennae filiformes:

$$
\text { 42. P. L O NGI P E S. }
$$

Testaceo-flavus pilosus, antennis, pedibusque longissimis.

Statura, et magnitudo P. Furis. Totus testaceo-flavus pilosus, alatus. Antennae corpore fere duplo longiores . Oculi nigri. Thorax elevatus, tuberculosus. Elytra laevia. Pedes longissimi .

Habitat Florentiae.

$$
\text { * 43. P. VA IR I E G A T US. }
$$

Thorace bituberculato, elytris nigris albo-fasciatis, antennis, pedibusque cinereo nigroque variis.

Statura P. Furis, at fere duplo major. Antennae corpore breviores fuscae, articulis apice cinereo-tomentosis. Thorax bituberculatus, cinereo rufescens. Scutellum cinereum . Elytra nigra laevia, nitida, punctato-striata fasciis duabus, altera baseos, altera apicis undulatis candidis. Pectus, abdomen, pedes cinerei femoribus nigro annulatis .

Habitat Florentiae.

$$
\text { 44. P. L A T R } 0 \text {. }
$$

Thorace bidentato testaceus, immaculatus. $F \cdot \int p \cdot 73 \cdot 6$.

Statura, et magnitudo $P$. Furis. Antennae longitudine corporis. Thorax angustus dentibus dorsalibus binis. Elytra punctato-striata .

Habitat in ligno. 
XIX. SPHAERIDIU $M$.

Palpi quatuor filiformes. Labium quadratum emarginatum. Antennae clava perfoliata.

45. S. FI M E TAR I U M.

Atrun immaculatum, elytris laevissimis. $F . \int p .79 .9$.

Parvum, et vix magnitudine seminis Oryzae. Statura oblongior quam in congeneribus. Totum atrum nitidissimum . Species quidem distincta, non varietas uti errore dictum in Fu. Etrusca.

Habitat in stercore bovino rarius.

$$
\begin{aligned}
& \text { 46. S. P U I I C A R I U M. } \\
& \text { Long. } \frac{3}{4} \text { I. Lat. } \frac{1}{2} \mathrm{I} \text {. }
\end{aligned}
$$

Nigrum oblongum, elytris abbreviatis, abdomine acuto. $F$. jp. 79. I2.

Synonymia Authorum errata. Derm. Pulicarius Linn. et Anthribus Geof. Ins. 1. 308. 4. Sph. Pulicarium non indicant. Corpus oblongo-globosum, atrum, laeve, nitidissimum. Antennae tenues longitudine thoracis clava perfoliata. Elytra armato oculo vix marginata, abbreviata. Abdomen apice acutum. Pedes subrufi.

Saepe lectum hieme in truncis arborum emort.

$$
\text { 47. S. L U T E U M. }
$$

Luteum, elytris pubescentibus laevibus. F. Mant. App. 378. 3-4. N. Veris. Fn. Etr. 1. 60. 147. t. 2. f. 12, nomen delendum, et huc referenda descriptio .

Habitat medio vere in floribus Crataegi.

$$
\text { XX. } T R I T O M A \text {. }
$$

Palpi anteriores securiformes. Labium emarginatum. Antenznae clavato perfoliatae. 


\section{T. B I P U T U L T $\mathrm{T}$.}

Atra, elytris macula laterali coccinea. F. Syst. 68. 1.

Tritoma Incerta Fn. Etr. 1. 48. 119.

Synonymia Geoffroyana falsa, occasionem in Fn. Etr. dubitan. di praebuit .

Habirat sub arborum cortice. Mox lecta frequentior.

$$
\text { 49: T. S E R I E A . }
$$

Nigricans holosericea, pedibus testaceis. $F . \int p .44 .6$.

Statura, et magnitudo Coc. Minntissimat. Corpus totum $\mathrm{ci}$. nereo holosericeum. Antennae, pelesque testacei.

Habitat in arborum truncis.

\section{I P S.}

Papp breviscimi aequales articulo ultimo ohtuso. Maxilla bitida. Labiniz breve emarginatum. Antemate perfoliatae.

$$
\text { * 50. I. F A L L A X. }
$$

Picea laevis nitida: antennis pedibusque rufis.

An. I. Ruficomis Olivier?

Statura, et facies omnino I. Taxicomis Fn. Etr. Herbst Arch. 21. sed dimidio minor, et color elytrorum obscurior. Antennae ad apicem tantum clavatae clava perfoliata, diversae ab antennis I. Taxicomis, cam ab illa plane distinguunt, Habitat sub corticibus .

$$
\text { * 51. I. T E S T A C E A. }
$$

Oblonga testacea immaculata.

Statura I. Crenatae, et paulo oblongior. Corpus depressum, immaculatum. Antennae testaceae. Oculi nigri. Thorax subquadratus, testaceus sulco medio impresso longitudinali obsoleto. Elytra laevissima, et abdomen nigrum praecipue distinguunt a $N$. Ferruginen.

Eecta in arculis insectorum. 


\section{* 52. I. A T R A .}

Atra, oblonga nitida, elytris striatis, thorace puncto utrinque impresso, antennarum clava, pedibusque subrufis.

Minor I. Crenata, et minus depressa. Antennae longitudine thoracis clava rufa pilosa. Thorax ater nitidus, latitudine elytrorum, emarginatus, punctulatus, punctoque utrinque majore excavato . Elytra atra nitida, subdepressa laeviter striata. Pedes subrufi .

Habitat in ligno putrido.

\section{S I L P H $A$.}

Labium cordatum, cmarginatum, crenatum. Antemae perfoliatae.

53. S. L A E $V$ V I G A

Long. 6. 1. Lat. 3. 1.

Atra, elytris laevibus, subpunctatis $. F . \int p .87: 13$.

Peltis nigra tota elytris laevibus, punctis minimis excavatis: Geoff. Ins. I. 122. 8.

Raj. Ins. 90. 9.

Silpha Polita Sulz. Hist. Ins. t. 2. f. 16.

Habitat in hortis, et silvis frequens:

\section{XXVI $N I T I D U \mathrm{~L} A$.}

Palpi quatuor filiformes. Maxilla cylindrica membranacea. Labium cylindricum. Antennae clava solida.

-54. N. M a c U l a t A.

Long. 1. $\frac{1}{3}$ 1. Lat. 1.1 .

Testacea pubescens, elytris maculis tribus fuscis, pone medium transversim positis.

Antennae longiusculae. Oculi nigri. Thorax subquadratus, 
angulis posticis acutis. Elytrorum maculae oblongae, obsoletae; in singulo elytro una, et media suturac communi. Femora crassiuscula.

Habitat sub corticibus rara.

$$
\text { 55. N. } S T R I G A T A \text {. }
$$

Ovata fusca, thoracis margine, elytris margine, lineola baseos, strigaque apicis fulvis. F. Mant. 51. 7.

Media. Caput fuscum antennis clavatis, clava apice ferruginea. Thorax laevis, fuscus margine pallide-fulvo. Elytra laevia, nitida, margine, lineola baseos lunata, strigaque apicis incurva fulvis. Corpus nigrum. Pedes fulvi. F. Color elytrorum fusco-niger lineolis fulvis circumscriptus, si illum oculi tantum advertant, eleganter pictus apparet.

Lecta Pisis in horti pariete.

$$
\text { 56. N. D I S C O I D E A. }
$$

Thorace marginato nigra, elytrorum disco-ferrugineo. $\pi$. $\hat{y}$. 92. 11 .

Statura, et magnitudo N. Bipustulatae. Antennae ferrugineae clava fusca. Caput nigrum. Thorax inaequalis, margine dilatato obscure-ferrugineo . Elytra nigra, macula magna orbiculata communi pallide ferruginea. Pedes picei. Lectae duae in equi cadavere insepulto.

$$
\begin{aligned}
& \text { * 57. N. C } \mathrm{C} \text { R Y S O M E I O I D E S. } \\
& \text { Long. 1. 1. Lat. } \frac{1}{2} .1 \text {. }
\end{aligned}
$$

Obscure-testacea subglobosa pubescens, elytris laevibus, thorace vix obscurioribus.

Duplo major N. Aestiva . Corpus totum obscure-testaceum . Antennae brevissimae, admodum clavatae. Oculi nigri. Thorax laevis, gibbus latitudine clytrorum vix marginatus, et pube tenuissima, certo situ, ferruginco micanti. Elytra gibba laevia, vix pubescentia, thorace obscuriora .

Habitat in ligno putrido. 


\section{N. H A E M O R R HO I D A L I S?}

Nigra, elytris apice ferrugineis. F. Mant. 52. 12.

Statura N. Colon, at vix minor. Caput, antennae, palpique rufi. Antennae hujus generis, clava solida, breves. Palpi antici apice subclavato, et oblique truncato. Thorax niger margine antico et laterali rufo. Elytra laevia, nigra, apice late rufa. Abdomen obscure nigrum. Pedes omnes rufi. Lecta sub corticibus M. Mart.

\section{XXVII. $C O C C I N E L L A$.}

Palpi antici securiformes : postici filiformes . Labiums cylindricum. Antennae clava solida.

59. C. T R I P U N C T A T A .

Coleoptris rubris, punctis nigris tribus.F. Mant. 54. 17. Limn. Syst. Nat. 580. 8. Fn. Jv. 472?

C. Tripunltata. Vill. Eut. I. 75. 5.

Ea quae rarissime occurrit apud nos, certe mera varietas est C. 5-punctatate, cui fortuito in elytris deest punctum posticum marginale: reliqua omnia similia. In Fn. Etrusca dubitatum, at erroce calani, aut Typograph. irrepsit praecedentis pro sequentis.

Habitat in plantis.

$$
\text { 6o. C. NIGROFA S C I A T A. }
$$

Coleoptris rubris punctis nigris octo, fascia media atra. Fro. Etr.. 1. 62. 155.

Fenina $C$. 9-punctatue, cum qua copula junctam saepius reperi. Habitat in plantis.

$$
\text { 6r. C. 23-P U NCTATA. }
$$

Coleoptris rubris, punctis nigris viginti tribus distinctis. $F$ : Sp. 101. 46. Limm. Syst. Nat. 582. 27.

Villers. Ent. 1. 104. 25. 
Parva. Thorax ruber punctis tribus nigris. Elytra rubra. Puncta 3. nigra; dein 4; tum 3; ultimo, punctum transversum ex duobus connatum. Accedit punctum scutellare commune. Puncta omnia rotunda, distincta. Subtus etiam rufa una cum pedibus ,

Habitat in plantis,

$$
\text { 62. C. } 12-P \cup N C T \text { A T A. }
$$

Coleoptris flavis, punctis nigris duodecim, extimis linearibus repandis. F. Sp. 98. 32. Linn. Syst. Nat. 581 . 19. Villers Ent. 1. 100. 17. Fig. Scbaefferi non rite citata. Minuta. Thorax flavus, punctis, maculisque duabus nigris . Elytra flava. Puncta quinque nigra praeter exteriorem quasi ex quatuor punctis connatum, lineare repandum ad marginem exteriorem, inter primum, et ultimum punctum. Sutura longitudinalis nigra. Subtus nigra tibiis flavis. Puncta thoracis variare videntur. In nostris saepe duo sunt baseos composita ex aliis duobus.

Habitat in hortis minus frequens.

$$
\text { 63. D. I } 4-M \text { A C U L A T A : }
$$

Colcoptris luteis : sutura, punctisque quatuordecim nigris, distinctis. F. Mant. 58. 57 .

Praecedente major. Caput albidum. Thorax albidus, nigropunctatus, fere uti in C. 12-punctata, sed punctis plerumque distinctis. Elytra lutea punctis 3. 3. 1. anterioribus in semicirculo positis, distinctis, oblongis, praeter penultimum rotundum suturae proximum. Pedes lutei femoribus posticis apice nigris.

Habitat ruri sat frequens.

$$
\begin{aligned}
& \text { 64. C. 14-G U T T A T A } \\
& \text { Long. 2. } \frac{1}{4} \text { 1. Lat. I. } \frac{1}{4} 1 \text {. }
\end{aligned}
$$

Coleoptris rufis, punctis albis quatuordecim . F. $\sqrt{p} \cdot 102.52$. Linn. Syst. Nat. 583. 34. Fn. Sv. 492.

Geoff: Ins. 1. 327.13 . 
Scop. E. Carn. 248.

De Geer. Ins. 5. 385.20.

Scbaeff. Ic. t. 9. $f .11$.

Dantur aliae dimidio minores huic omnino similes, quae sane referendae sunt ad C. 12-guttatam Geoff. Pod. Schrank. E. I. 3 il. at quamvis elytrorum puncta sint tantum duodecim, de varietate praecedentis dubito.

Habitat in Salice frequens.

$$
\text { 65. C. 14-P US T U L A T A. }
$$

Coleoptris nigris, punctis albis quatuordecim. $F . \int p \cdot 106.68$. Lisn. Syst. Nat. 585. 46. Frz. Sv. 502.

Coccinella coleoptris nigris maculis quatuordecim aequalibus flavis. De Geer. Ins. 5. 391. 27.

Geoff. Ins. I. 330. 18.

Coc. 14-maculata Pod. M. G. 26.

Scbrank. E. I. 122.

Villers. Ent. 1. 114.58.

Schaeff. Ic. $t$. $30 . f$ i 10.

Statura, et magnitudo C. 2-punctatae. Thorax niger puncto utrinque marginali arcuato flavo; saepius tamen margo etiam anticus totus flavescit. Puncta elytrorum 2. 2. 2. 1. interdum flava, interdum rubra.

Habitat in floribus frequens.

\section{XXVIII. $C A S S I D A$.}

Palpi antici clavati : postici filiformes. Labium elongatum integrum. Antennae moniliformes.

$$
\text { 66. C. } M \text { A R G A R I A C E A. }
$$

Virens, elytris viridi-argenteis nitidis, capite, pectoreque nigris. F. Mant. 6.3. 22.

Statura C. Nebulosae, at paulo minor. Caput, et pectus nigra. Abdomen, pedes, antennaeque pallide viridia. Color elytrorum viridi-argenteus perit cum vita .

Habitat apud nos sat frequens. 
XXX. CHRYSOMELA.

Palpi sex extroisum crassiores. Labium corneum integrum. Antennae moniliformes .

$$
\begin{aligned}
& \text { 67. C. G O E T T I G E S I S } \\
& \text { Long. 4. 1. Lat. 2. } 1 .
\end{aligned}
$$

Ovata, atra, pedibus violaccis. $F . \int p$. I 6 6. 2. Linn. Syst. Nat. 586. 4. Fn. Sv. 506.

De Geer. Ins. 5. 298. 8.

Laichart Ins. Tyr. 1. 143. 2. C. Coriaria.

Roes. Inss. 2. Scar. 3. t. 5 ?

C. Haemzoptera panlo major, globosior, obscurior. Plantae stbrufae.

Habitat in Gramine frequens.

$$
\begin{aligned}
& \text { 68. C. F A S T U O } 5 \text { A. } \\
& \text { Long. 3. 1. Lat. I. } \frac{1}{2} \text {. }
\end{aligned}
$$

Ovata aurea, coleoptris lineis tribus caeruleis. F. $\int p \cdot 124.48$. Linn. Syst. Nat. 588 . 18.

Chrysomela viridis nitida, thorace antice excavato, fasciis elytrorum longitudinalibus caeruleis. Geoff. Ins. 1. 26 1. 11. Le petit vertú bleu (a)

Scop. E. Carn. 532. Scbrank. E. I. I 75.

Grontor. Zooph. $56 \mathrm{I}$.

Vill. Ent. 1. 122: 14.

(a) Citatio Geoffroyana quam authoritate Linnaci in synonymia C. Aeneac dedimus, v. Fn. Etr. 1. 196. ad bauc referenda esse videtur; C. Aenea enim bac major est, et caret fasciis caeruleis: In C. Fastuosa alae rubrae, in $\mathrm{C}$. Aenca nigrae; qua nota baec etiam distinguitur a $\mathrm{C}$. Graninis cui sunt rubellae. 
Aurato-virens fulgida. Linea caerulea longitudinalis in medio elytroum, et unica communis in sutura. Alae rubrac. Colore admodum variat.

Habitat in lamio albo, et urticis frequens.

$$
\begin{aligned}
& \text { *6. C. V I O I A C E A. } \\
& \text { Long. 3. } \frac{8}{3} \text { 1. Lat. I. } \frac{2}{3} 1 \text {. }
\end{aligned}
$$

Orata violacea, antennis plantisque fuscis .

C. Violacea. Panzer Journ. Allem.

Statura, et magnitudo fere C. Politae. Tota laete violacea nitida, unicolor. Thorax ac elytra punctulata punctis inordinate sparsis. Antennae, et plantae fuscae.

Raro inveni.

$$
\text { * 70. C. NI g R I c o r N Is. }
$$

Long. 4. $\frac{1}{3}$ 1. Lat. 2. 1. vix.

Oblongo-ovata violacea nitens; thoracis lateribus incrassatis, prominulis, antennis nigris.

An. C. Nitens. Mus. Lesk. p. 13. n. 261?

Statura ovato-oblongior quam in nostratibus omnibus. Tota violacea nitida colore $C$. Alni; Antennae tantum nigrae, et longiusculae. Thorax fere latitutine elytrorum, antice excavatus, postice rotundatus, in medio convexus, margine laterali crasso, prominulo. Elytra laevia, vix subpunctata. Plantae fuscae. Affinis C. Gloriosae, at omnino distincta .

Habitat Florentiae rara.

$$
\begin{aligned}
& \text { 71. C. G L O R I O S A. } \\
& \text { Long. 4. } \frac{1}{3} \text { 1. Lat. } 2 . \frac{1}{4} 1 \text {. }
\end{aligned}
$$

Ovata viridis nitida, elytris linea caerulea. F. $\int p . A p p .497$. Duplo major C. Fastuosa. Color viridis nitens, linea unica caerulea in medio elytrorum. Frons puncto impressa. Thorax latus. Elytra nonnihil utrinque angustata, postice 
latiora. Antennarum articulus ultimus, plantaeque griseafuscae .

Habitat apud nos rarior.

$$
\begin{aligned}
& \text { * 72. C. G E M I I A } \\
& \text { Long. 2. } \frac{1}{2} \text { 1. Lat. } 1 . \frac{3}{2} 1 \text {. }
\end{aligned}
$$

Viridis, punctis elytrorum per strias gemellas digestis. $\mathbb{E}_{n}$. Paris. 110. 22. La Cbrysom. ¿i stries jumelles.

Villers. Ent. I. 138. 63.

Statura, et magnitudo fere C. Fastuosae. Supra aeneo-viridis. Antennae nigrae. Thorax brevis laevissimus lineola abbreviata postica marginali. Elytra laevia punctis duplici ordine quasi in strias gemellas inordinate digestis. Subtus aeneo-cacrulescens plantis fuscis. Alae albae.

Habitat apud nos rarior.

$$
\begin{aligned}
& \text { 73. C. V U L G A T I S S I M.A. } \\
& \text { Long. I. } \frac{2}{3} \text { 1. Lat. } \frac{3}{4} 1 \text {. }
\end{aligned}
$$

Oblonga caerulea, antemnis basi ferrugineis. F. $\int p .{ }^{1}$ 130. 79. Linn. Syst. Nat. 589. 22. Fur. Sv. 517.

Cbrysomela caerulea Betulae. De Geer. Ins. 5. 317.23.

Coccinella Vulgatissina. Scoṕ. E. Carn. 222.

Scbrank. E. I. I 26.

Corpus magis oblongum quam ovatum. Antennae nigrae longiusculae. Thorax subquadratus margine laterali saepius in riedio nonnihil coarctato, angulis posticis acutis. Elytra punctis longitudinaliter digestis .

Habitat in Salicibus frequentissima cum C. Vitellinae.

$$
\begin{aligned}
& \text { 74. C. A R M O R A C I A E. } \\
& \text { Long. 1. } \frac{1}{3} \text { 1. Lat. I. 1. vix. }
\end{aligned}
$$

Ovata caerulescens nitida, subtus nigra. $F, \sqrt{ } \mathrm{p} .127 .66$. Limm. Syst. Nat. 588, 16. Fn. Sv. 515 . 
C. Plantaginis subglobosa supra violacea nitida, subtus nigra, punctis excavatis striatis. De Geer. Ins. 5. 322. 25.

Similis C. Betulae, at corpore magis globoso. Abdominis apex obscure flavescit.

Habitat in Armoracia, Plantagine, aliisque.

$$
\text { *75. C. PY R I TOSA. }
$$

Fusco-aenea nitida, antennis crassiusculis, thorace laevi, elytris punctato-striatis.

Statura, et magnitudo praecedentis . Antennae pone medium crassiusculae. Subtus etian tota fusco-aenea. Differt a $C$. Armoraciae colore diversissimo; et a C. Metallica Fn. Etr. colore minus nitido, et forma thoracis antice latiori.

Habitat in pratis silvaticis, mens. Maj. saepe lecta .

$$
\text { 76. C. RUIIO OLIS. }
$$

Oblonga viridi-aenea, thorace, pedibusque rufis . F. Syst. Ent. App. 820.

Chrysomela nigra, elytris caeruleo-viridibus, thorace, pedibus, antennarumque basi rufis. Geof. Ins. 1. 263. 16.

Statura C. Betulae. Antennae rufae apice fuscae. Caput viridi-aeneum ore rufo. Thorax rufus immaculatus. Corpus viride. Pedes rufi. F.

Valde affinis C. Polygoni. Nonnulla individua possideo capite toto rufo, et alia quae forte referenda sunt ad C. Ruficcllem. F. Mant. 55.

Habitat in plantis non rara.

ALTICAE saltatoriae femoribus posticis incrassatis.

$$
\text { 77. C. NEMORU M . }
$$

Saltatoria, atra, elytris flavis margine omni nigro. $F . \int_{p}$. 136. 114. 
Chrysomela Nemorum saltatoria, elytris linea flava, pedibus pallidis. Linn. Syst. Nat. 995. 62. Fn. Sv. 543.

Cbrysomela Fasciata. De Geer. Ins. 5. 347. 55. Altica Nemorum. Geoff. Ins. 1. 247. 9.

Siop. E. Carn. 21.5. Scbrank. E. I. 154.

Sulz. Hist. Ins. $t$ 3. $f$. 11 .

Magnitudo maximi Pulicis. Thorax niger. Elytra flava undique margine nigro cincta. Pedes pallidi.

Habitat in Pulmonaria, in Lepidio latifolio frequens, copiosa mens. Maj.

$$
\text { - 78. C. P U L E X. }
$$

Saltatoria, nigro-aenea nitens, antennarum basi, tibiisque rufis. An. C. Pulex. Schrank. E. I. 160.

Magnitudo praecedentis, et facies veri Pulicis. Oblonga, tota aeneo-nigra nitens. Thorax, elytraque subtilissime, ac inordinate punctata. Tibiae, tarsique rufi.

Habitat in plantis minus frequens.

$$
\text { 79. C. V. I O L A CE O-P U N C T A T A. }
$$

Saltatoria, ovata, thorace punctato virescenti-caeruleo, elytris violaceis punctato-striatis, pedibus rufis. De Geer. Inls. 5. 343.48.

Magnitudo praecedentis, supra laete violacea, subtus nigra; antennae, pedesque rufi.

Habitat in plantis.

$$
\text { 80. C. D O R S A L I S . }
$$

Saltatoria, luteo-livida, elytris sutura nigra. An C. Dorsalis F. varietas?.

Statura C. Atricillae. Antennae subluteae . Oculi nigri . Caput, thorax, ac elytra pallide flava. Elytra subpellucida, laevia, sutura nigra. Abdomen, et femora postica nigra. Tarsi pallidi. Variat pedibus anticis interdum totis pallidis. Habitat in Verbasco non rara. 
XXXI. CR Y P T OCE P H ALUS.

Palpi quatuor filiformes. Maxilla unidentata. Labium corneum integrum. Antemane filiformes.

$$
\begin{aligned}
& \text { 81. C. } \mathrm{M} \text { О R A Е I. } \\
& \text { Long. I. } \frac{8}{2}, \text { 2. 1. Lat. } \frac{3}{4} 1 \text {. }
\end{aligned}
$$

Ater, elytris maculis duabus flavis marginalibus. $F$. $\int p$. $144.3 \%$ Cbrysomela Moraei cylindrica, thorace nigro, elytris nigris, maculis duabus rubris marginalibus. Limn. Syst. Nat. 597. 82. Fin. Sv. 550 .

Cryptocepbahis niger, capite, thoraceque antice luteis, elytro singulo externe macula duplici flava. Geof. Ins. 1. 234. 5. Buprestis. Moraei. Siop. E. Cam. 202.

Fin. Etr. 1. 95. 232.

Schaef. Ic. t. $238 . f$. 2. t. 30. f. 5 ?

Variat elytris apice, et macula marginali rubris, flavisve. Maculae in masculo flavae, in femina rubrae. Thoracis margo anticus in femina plerumque immaculatus. In utroque thoracis anguli postici albidi.

Habitat in Hyperico perforato. Mens. Jun. sub vesperum frequens copiosus, et sacpe copula junctus.

$$
\text { * 82. C. T R I C O L O R. }
$$

Niger, thorace atro, maculis sex inaequalibus luteis, clytris rufis, punctis tribus nigris .

Statura ac magnitudo $C$. Bipunctati. Antennae nigrae thorace longiores. Caput nigrum totum intra thoracem reconditum. Thorax ater laevissimus nitidus, maculis duabus in medio dorsi postice, obliquis majoribus; itemque duabus utrinque ad marginem exteriorem fere contiguis, eademque parte similiter emarginatis, luteis . Elytra rubra inordinate, ac subtilissime punctulata. In singulo ad basin puncta duo rotunda, et aliud fere in medio elytri quasi ex binis compositum nigra. Subtus totus niger. 
Missus ab ill. ac egregio Viro Com. Leopoldo Galli, qui Entomologiae etiam amantissimus, Insecta multa in Etruria collegit, et benevole mihi communicavit

Habitat Florentiae in montuosis; frequens loco vulgo dicto Montespertoli.

\section{C I STE LA.}

Cistela Gigas, et Tenebrio Dubius Fn. Etruscae ad novum genus retulit $\mathrm{Cl}$. Olivierus sub nomine Ceb. Longicornis, et Ceb. Brevicornits.

\section{C $\quad E \quad B \quad R \quad I \quad O$.}

Antemae filiformes subserratae corpore paullo breviores, II-articulatae, articulo 2. 3-q. brevissimis . Labizm superius corneum breve antice ciliatum. Mandibulae porrectae, corneae, arcuatae, simplices, rotundatae, ciliatae. Labizun inferius breve, subcorneum, integrum. Palpi quatuor filiformes inaequales : anteriores longiores, quadriarticulati, articulo primo breviori, aliis aequalibus, \&c.

$$
\text { 83. C. L O NGICOR I : }
$$

Pubescens fuscus, elytris, abdomine, femoribusque testaceis. Oliv. Ent. p. 5. n. 1. t. 1. f. 1. a. b. c. t. 1. f. 1. a. b.c. C. Gigas. Fn. Etr. 1. 100. 256.

Habitat Pisis, et Florentiae non rarus.

$$
\text { 84. C. BREVICORNIS. }
$$

Apterus, testaceus mandibulis exsertis nigricantibus, antennis brevissimis. Oliv. Ent. 5. 12. 2.t. 1. f. 2. a. b. c. T? Dubius. Frt. Etr. 1. 234. 583 . t. 1. $f .2$. Habitat Florentiae, et Pisis rarissimus. 
XXXIII.: C R IOCERIS.

Palpi quatuor filiformes. Maxilla bifida. Labium corneun integrum Antennae filiformes.

$$
\text { 85. C. C A P R E A E. }
$$

Long. 2. $\frac{3}{2}$ 1. Lat. 1. $\frac{2}{2} 1$.

Thorace nigro maculato, elytrisque griseis, antennis nigris .

F. $\int p$. 150.4 .

Cbrysomela Capreae. Linn. Syst. Nat. 600. 100. Fn. Sv. 516. Chrysomcla grisea Alni ovata grisea opaca, thorace angusto, puncto nigro, antennis variegatis. De Geer. Ins. 5. 325. 30. Galleruca nigra, thorace, elytrisque luteo lividis. Geof: Ins.

1. 254. 5. la Galleruque Grisette.

Abdomen, et femora ante apicem nigra, tibiis, tarsisque elytro concoloribus.

Habitat in Salice.

\section{$\mathrm{XXXV} L A G R I A$.}

Palpi quatuor inaequales : antici securiformes; postici extrolsun crassiores. Labium membranacéum integrum. Antemnae filiformes.

$$
\text { 86. L. A EN E A. }
$$

Antennis serratis, hirta obscure-aenea . F. Mant. 94. 23.

Affinis L." Atrae, et minor, tota hirta , obscure-aenca nitida. Pedes, et antennae atrae. Variat rarius tibiis testaceis, $F$.

Habitat in floribus frequens.

$$
\text { * 87. L. V I R I D IS. }
$$

Aeneo-viridis hirta, thorace marginato, antennis aeneis.

Praecedente minor. Tota aeneo viridis nitida ad cyaneum vergens. Antennae aeneo-nitidae longitudine thoracis. Thorax lateribus, posticeque marginatus, planiusculus, seu 
minus quam in superiore convexus, hirtus. Elytra uti thorax aeneo-viridia punctulata marginata, minus hirta. Abdomen, et pedes toti elytris concolores. Variat magnitudine duplo minori, colore viridi subaurato.

Habitat in floribus frequens.

$$
\text { XL. } \quad C U R C U L I O \text {. }
$$

palpi quatuor filiformes. Maxilla cylindrica unidentata. Labium integrum. Antennae clavatae insidentes rostro corneo.

* Longirostres fem. simpl.

88. C. B A $\mathrm{D}$ A N A E .

Longirostris, cylindricus, griseo-tomentosus, pedibus anticis elongatis . F. Mant. 104. 84 .

Statura, et magnitudo fere C. Paraplectici. Junior totus tomento griseo tectus; adultior niger, et glaber evadit. Elytra rotundata, obtusa. Pedes anteriores parum elongati. F. In hoc elytra subtilissime ac laeviter punctato-striata; in $C$. Pulverulento Scop. qui forte est C. Angustatius F. transversim rugosa .

Habitat in Arctio Lappa, aliisque plantis non rarus.

$$
\text { * 89. C. S A N G U I N E U S. }
$$

a basi rostri ad apicem elytrorum. Long. 4. 1. Lat. I. 1.

Longirostris cylindricus, ruber, oculorum supercilio, thoracisque lateribus flavescentibus.

Statura, et magnitudo C. Ascaniii, at clytra apice obtusa . Rostrum thoracis longitudine, totum superne sanguineum, inferne cinereum. Antennae breves, fractae, cinereo fuscae. Caput sanguineum quod ubique inflectit. Oculi nigri supercilio flavo. Thorax laevis sangumeus, margine laterali flavo-lineato. Elytra lacvia, sanguinea, apice obtuso. Sternum, et abdonen cinerea. Pedes cinerei femoribus dilute 
sanguineis. Color idem qui in Call. Sanguineo, et cum in tenuissima pube consistat, facile attritu deletur; et tunc niger evadit.

Lectus Pisis in Verbasci foliis d. 24. Mart.

$$
\text { 90. C. C U PRIROSTRIS. }
$$

Longirostris, oblongus, viridi-aeneus, elytris striatis, rostro cupreo . F. Mant. 100. 43.

Magnitudo C. Granarii. Corpus oblongum nitidum . Rostrum arcuatum cupreum. Thorax viridi-aeneus, laevissimus nitidus. Elytra subtilissime striata, viridi-aenea nitida. Abdomen viride. Pedes fusci.

Habitat in Alno non rarus .

$$
\begin{aligned}
& \text { 91. C. C A E R U L E C E N S. } \\
& \text { Long. I, } \frac{1}{1} \text { Lat. } \frac{2}{3} \text { l. }
\end{aligned}
$$

Longirostris, obscure caeruleus; elytro singulo decemstriato, rostro deflexo. Schrank. E. I. 202.

C. Caerulescens. Scop. E. Carn. 87.

Statura praecedentis, at latior. Rostrum tenue longum, deflexum. Thorax excavato-punctatus, etiam inferius. Elytra subtilissime striata striis decem-impunctatis. Femora mutica. Raro lectus.

$$
\text { * 92. C. T I M I D U S. }
$$

Longirostris, ater laevis, nitidus : elytris substriatis, rostro crassiusculo incurvo .

Magnitudo fere C. Betulae, at paullo oblongior, et corpore ovato globoso. Totus ater nitidus. Rostrum crassiusculum incurvatum antennis nigris. Thorax latus. Elytra subtilissime punctato-striata. Femora inermia. Alatus.

Habitat in pratis silvaticis frequens. 


$$
\begin{aligned}
& \text { *93. C. P E R P E N S US. } \\
& \text { Long. I. 1. Lat. } \frac{1}{2} 1 \text {. }
\end{aligned}
$$

Longirostris, griseo-fuscus, thorace, elytrisque hispidis, cinereo nigroque obsolete punctatis.

Statura C. Antbirrini. Fn. Etr. Rostrum tenue, porrectum. Elytra striata. Femora mutica. Tibiae testaceae. Habitat in silvis.

$$
\begin{aligned}
& \text { 94. C. R U M I C Is. } \\
& \text { Long. 3. 1. Lat. 1. } 1
\end{aligned}
$$

Longirostris, griseus, nigro-nebulosus, antennis fuscis. $F \cdot \int p$. 170. 55. Linn. Syst. Nat. 614. 6o. Fn. Sv. 590 .

Curculio longirostris, femoribus muticis, antennis fractis, corpore oblongo griseo, fusco-nebuloso, thorace fasciis duabus nigricantibus. De Geer. Fins. 5. 231.20. t. 7. f. 10. II. Magnitudo variat..

Habitat in Rumice frequens.

$$
\text { * } 95 \text { C INFIDU. }
$$

Longirostris, piceus, nitidus; thorace punctato, femoribus clavatis, compressis.?

Statura C. Granarii, cui valde affinis, at major, et disținctissimus. Differt a $C$, Granario praeter magnitudinem quae fere dupla, colore piceo nitidiore; rostro magis porrecto; thorace diversimode punctato punctis rotundioribus. Elytra in hoc thorace longiora nitida, manifeste punctato-striata. Femora mutica, clałata clava compressa.; imprimis antica. Tibiae breves, compressae . Subtus concolor nitidus, punctulatus.

Habitat Pisis .

$$
\text { 96. C. C I N C TUS. }
$$

Longirostris globosus rufus, elytris striatis fascia transversa alba. Geoff. Ins. 1. 289. 28. Ent. Par. 124. 27.

C. Erytroleucos. Ed. Linn. 13. 
Magnitudo C. Rufirostris. Rostrum tenue nigrum. Antennae ferrugineae clava apice cinereo.

Habitat in plantis non frequens.

* Longir. fem. dentatis.

\section{* 97. C. B I N O T A T U S.}

Longirostris, fuscus, elytris subdepressis, pone medium puncto albo notatis.

Statura C. Colon, at major. Rostrum mediocre crassiusculum carinatum longitudine thoracis. Thorax fuscus, subcarinatus, linea laterali cinerea obsoleta. Elytra basi subdepressa, obsolete punctato-striata, fusca, pone medium angustata, gibba, puncto utrinque albo. Antennae, pedesque fusci femoribus subdentatis. Apterus. Color fuscus in testaceum vergit.

Habitat in silvestribus paludosis; hieme in truncis arborum putridis minime rarus.

$$
\text { * 98. C. T I G R A T U S. }
$$

Longirostris? femoribus dentatis, bruneus fulvo maculatus, thorace depresso, carinato, elytris sulcatis, punctatisque. Magnitudo C. Abietis. Totus bruneus maculis laete ferrugineis aspersus. Antennae fractae, pilosae clava subrotunda crassiuscula. Rostrum mediocre carinatum sulcis tomento fulvo contectis . Thorax rotundatus, depressus, carinatus maculis, fasciisque ferrugineis ordine dispositis . Elytra sulcata lineis elevatis, abdominis latera admodum involventia, coalita, fulvoque undique maculata. Femora omnia dentata annulo fulvo. Inter singulos sulcos striae duae punctorum impressorum .

Habitat in silvis non frequens.

$$
\text { * 99. C. B I P U S T U L A T US. }
$$

Longirostris, femoribus dentatis, niger subpilosus, elytris striatis, plaga utrinque rufescente,

Statura $C$. Verbasci quo paulo minor . Rostrum tenue antennis 
nigris. Elytra late striata, subpilosa, maculam in medio gerentia insignem rotundam rufescentem. Femora dentata, crassiuscula .

Lectus raro.

**** brevirostres fem. muticis.

\section{* 100. C. C A N E S C ENS.}

Long. 4. 1. Lat. 1. $\frac{x}{2}$ :

Brevirostris, cinereus nitidus subpilosus, elytris nigro mactlatis .

Minor C. Incano, et corpus magis ovatum, magisque globosum . Caput cinereum rostro crasso brevissimo. Antennae brevissimae fractae cinereae clava subrufa. Thorax cinereus in medio obscurior. Elytra cinerea subpilosa, leviter punctato-striata, punctisque inaequalibus nigris aspersa, coalita, apiceque parum acuminato. Color totius corporis albido cinereus nonnihil ad aeneum vergens.

Lectus pluries sub arborum cortice tempore hiberno.

$$
\begin{aligned}
& \text { 10r. C. C A U D A T U s. } \\
& \text { Long. 6. 1. Lat. 2. 1. et ultra }
\end{aligned}
$$

Ovato-oblongus, thorace, elytrisque scabris, apice acuminatis pilosis .

Major C. Armadillo, et oblongior totus niger subobscurus. Rostrum breve crassum, bisulcatum, apice dilatatum. Antennae in medio fractae longiores. Thorax, ac elytra punctis elevatis scabra, eaque magnam partem abdominis obtegentia, minime striata, apice acuminato, pilisque subferrugineis hirto, quasi penicillato. Abdominis basis inferne compressa, retusa. Femora omnia clavata inermia. Alae nullae. Apex elytrorum nunc magis, nunc minus pilosus. Dubitavi de C. Nigrita, at descriptio minime convenit, et species nova videtur.

Habitat Florentiae. 


\section{C. C OS T A T US.}

Brevirostris cincreus, thorace nigro: lineis quatuor cinereis. F. Mant. 115. 194.

C. Bilineatus. Fn. Etr. 1. 110.281.

Magnitudo C. Incani. Antennae in medio fractae, basi ferrugineae. Rostrum apice incrassatum nigrum dorso cinereo. Thorax rotundatus niger linea dorsali paullulum elevata atra. Elytra, pedesque cinerea. $F$.

Habitat in pratis frequens.

$$
\begin{aligned}
& \text { * 103. C. V I A T O R. } \\
& \text { Long. 2. } \frac{1}{2} \text {. 1. Lat. 1. } 1 .
\end{aligned}
$$

Brevirostris? niger oblongus, thorace, elytrisque squamosoaeneis subnitidis .

Magnitudo fere C. Pyri, at statura distinctus, et colore etiam minus nitido. Rostrum mediocre crassiusculum longitudine thoracis. Antennae breves fractae fuscae clava subcinerea. Thorax lateribus squamoso-aeneis obscuris. Elytra mutica. Ademta pube aeneo-rufescente totus niger apparet .

Lectus Pisis.

$$
\begin{aligned}
& \text { 104. C. S C A B R I C U L U S } \\
& \text { Long. I. } \frac{1}{2} \text { 1. Lat. 1. 1. vix. }
\end{aligned}
$$

Brevirostris, corpore cinereo hispido. $F . \int p .189 .159$.

C. Scabriculus brevirostris, femoribus muticis, cinereus, elytris hispidis . Linn. Mant. 531 .

Bonsd. Curc. Svec. 2. f. 21 .

Magnitudo C. Cervini: Totus cinereus. Rostrum breve canaliculatum. Antennae crassiusculae vix longitudine rostri. Elytra striata hispida, praesertim postice. Femora inermia.

Raro lectus in locis arenosis Pisani nemoris. 
Brevirostris, ater subnitidus, elytris punctato-sulcatis, rostro latitudine capitis

Paullo major C. Granario, a quo praecipue differt thorace elytris breviore, rostro brevissimo crasso latitudine capitis. Ater nitidus, sed minime lucens, glaberrimus. Antennae brevissimae nigrac apice cinereo. Caput punctulatum, at respectu thoracis laeve. Thorax excavato-punctatus . Elytra punctato sulcata, connata. Femora subclavata inermia. Habitat in agro Pisano.

$$
\text { * 106. C. L I M O S U s. }
$$

Brevirostris, niger obscurus, thorace, elytrisque limo exsiccato obductis, antennis rufis. An. C. Lutosus. Mus. Lesk. p. 22. n. 482?

Statura C. Lineati, quo duplo major . Niger, sed totus semper crusta terrea contectus. Rostrum breve crassum nigrum. Antennae rufae clava fusco-nigra. Thorax subglobosus. Elytra ademto limo, nigra striata. Femora mutica : antica subclavata. Abdomen cinerascens.

Habitat Florentiae, et Pisis sat frequens.

$$
\text { * 107. C. V I s u s. }
$$

Brevirostris, fuscus, elytris fasciis duabus marginalibus cinereis, antennis, pedibusque testaceis .

Medius inter C. Lineatum, et C. Argentatum. Antennae fractae testaceae clava obscuriori, apice cinereo. Rostrum brevissimum. Caput, et thorax tomento flavo lucido subaureo tecta. Elytra convexa striata, flavo-tomentosa dorsa fusco, fasciis duabus cinereis, prima obliqua prorsus marginali; altera apicis usque ad suturam producta. Abdomen fusco nitidum. Pectus macula utrinque cinerea. Pedes testacei tenues, femoribus muticis, et versus apicen cinereo annulatis . Alatus .

Habitat in plantis non rarus.

**** brev. fem. dentatis. 


\section{Clas. 1. Eleuterata, Curculio. \\ \$108. C. A R M A D I L I 0. \\ Long. 4. $\frac{1}{3}$. Lat. $2 . \frac{3}{4} 1$.}

Brevirostris, femoribus subdentatis, niger elytris crenato-striatis, striarum fossulis cinereo-flavescentibus .

Corpus ovato-globosum nigrum. Antennae fractae articulo primo praelongo. Rostrum breve crassum bisulcatum. Thorax subrotundus punctis elevatis scaber. Elytra connata, admodum convexa, crenato-striata pilis soidide cinereis brevissimis in striarum foveolis hic inde aspersa, unde cinereo veluti pulvere inquinata apparent. Femora clavata, subdentata. Alae nullae.

Descriptio C. Nigritae Fu. Etr. ad hunc male pro C. Nigrita assumtum referenda.

Habitat in silvis frequens.

$$
\text { 109. C. S U I C A T U S. }
$$

Brevirostris, femoribus dentatis ater, elytris striatis, ferrugineo-maculatis . F. $\int p .197 .212$.

Femora omnia apice clavata, postica etiam acute dentata. Differt a $C$. Armadillo praesertim statura oblongiori, et macularum colore non sordide cinereo, sed ferruginco fiavescente : Elytra crenato-striata . Magnit. variat.

Raro lectus hicme sub arborum cortice.

$$
\text { XLI. } R H I N O M A C E R \text {. }
$$

Palpi quatuor extrorsum crassiores articulo ultimo truncato. Antemne setaceae rostro insidentes,

$$
\text { IIO. R. BRE T T I D E S. }
$$

Glaber piceus, thorace punctato, elytris punctato striatis. D. D. Antic. Soc. Limn.

Fn. Etr. 1. 135. 347. t. 3. f. 14.

Pimelia Angustata. F. Sp. 320. 24. Mant. 209. 28?

Habitat sub arborum cortice obvius. 


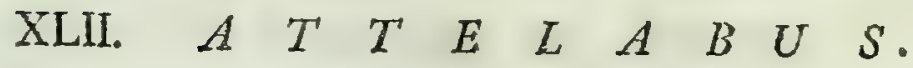

Palpi quatuor filiformes. Maxilla bifida. Labium corneum palpos tegens. Antennae moniliformes insidentes rostro.

$$
\text { * III. A. B I } \subset \text { OL O R. }
$$

Cuprens, hirtus, elytris saturate testaceis .

Statura, et magnitudo $A$. Pubescentis, at paulo latior. Rostrum tenue elongatum longitudine fere dupla thoracis, subrufum, apice dilatato, bifido. Antennae subrufae, rectae moniliformes, medio rostri insidentes, clava fusca. Oculi prominuli nigri . Caput, thorax, abdomen, femora cuprea, quasi subaurata hirta. Thorax punctulatus. Elytra punctato-striata hirta saturate testacea. Tibiae subrufae.

Habitat Florentiae rarus.

\section{XLIII. $C L E R U S$.}

Palpi quatnor; antici filiformes: postici longiores, securiformes. Antennae moniliformes.

\section{* 112. C. UNI VITTA T U .}

Niger, elytris fascia media unica alba.

Statura C. Unifasciati, at paulo minor. Antennae nigrae basi ferrugineae. Caput, thoraxque nigra pilosa, minus tamen quam in C. Unifasciato. Elytra nigra, nitida, striato-punctata, fascia media recta unica alba. Abdomen nigrum. Pedes ferruginei femoribus nigris. Alae fuscescentes. Habitat Pisis rarus . 


\section{XLIV: NOTOXUS.}

Palpi quatuor securiformes. Maxilla unidentata. Antenziae filiformes.

* 113. N. T r I F a S c i a T U S.

Thorace in cornu supra caput protenso, elytris trifasciatis. Fr. Etr. 1. 139. 354. 月. t. 2. f. 14.

Notoxus quem habet. To. Moraeus. Upl. Nov. Sp. Ins. 1789. $\mathrm{ab}$ hoc diversus. Noster in Svecia non habitat.

Statura, et habitu omnino similis $N$. Monocero, at species sane distincta. Differt magnitudine paulo minori; elytris nigro trifasciatis; abdomine fusco. Elytrorum apex fascia nigra terminatus .

Habitat mens. Jun., et Jul. in Salice, Bignonia radic. aliisque plantis frequens copiosus. A mare videtur folia glabra, umbraque tecta, quae velociter cursitando huc, illuc percurrit.

$$
\begin{aligned}
& \text { * 114. N. P E D E S T R Is. } \\
& \text { Long. I. } \frac{1}{3} 1 \text {. Lat. } \frac{3}{3} \text { l. }
\end{aligned}
$$

Niger, thorace elongato rufo, elytris pubescentibus, puncto utrinque baseos subrufo.

C. Pedestris. Fur. Etr. 1. 224. 557.

Proximus Cantharidi Geoff. I. 344. 8. La Cantharide fourmi, quae forte hujus generis.

Magnitudo N. Trifasciati. Antennae nigrae filiformes longitudine dimidii corporis, articulis brevibus ultimo oblongo acuminato. Palpi quatuor securiformes nigri. Caput paullulum a thorace remotum collo tenuissimo, nigrum nitidum, defexum, et conformatum ut in N. Monocero, ac Trifasciato. Thotax clongatus rotundatus, antice latior latitudine capitis, postice angustatus, punctulatus, rufus. Elytra integra convexa, thorace duplo latiora, postice praesertim albo pubescentia, nigra, puncto baseos utrinque subrufo. Pedes nigri femorum basi tenui ferruginea. Alae albae. Habitat in terra, arena, ligno putrescente frequens. 
Niger, thorace elongato, elytris macula utrinque baseos, cruceque postica suturae communi subrufis .

Statura magis quam in praecedente cylindrica, et paullo minor. Caput nigrum thorace vix latius. Palpi antennaeque nigrae. Thorax niger antice rotundatus, postice nonnihil angustatus, emarginatus, vix latitudine longior. Elytra thorace duplo latiora, minutissime punctata, integra convexa, nigra, macula ad basin utrinque fere trigona, posticeque cruce ad suturam communi saturate testaceis notata. Basis ad scutellum, atque apex nigra. Abdomen nigrum. Pedes nigri tibiis pallide ferrugineis. Elytra paulo minus quam in praecedente convexa.

Habitat sub corticibus rarus.

$$
\text { * I } 16 . \text { N. H I S P D } 0 \text { S. }
$$

Niger hispidus, tibiis antennisque testacco-pallidis, elytris macula baseos flava.

Facies N. Pedestris, at paulo minor. Antennae testaceo-fuscae moniliformes. Caput nigrum nitidum deflexum, punctulatum, latitudine thoracis. Oculi prominuli . Thorax niger hispidus, admodum convexus, subglobosus. Elytra obscure nigra hirsutissina, integra, macula magna baseos flavescente. Subtus totus niger hispidus, demtis tibiis pallidetestaceis. Alatus.

Lectus sub foliis disiectis .

\section{* I6. N. M Y R I C O C E P HALUS.}

Ferrugineus laevis, glaber, capite thorace latiore, elytris apice obtusis .

Statura, ac magnitudo N. Pedestris : Caput magnum obscure-ferrugineum. Palpi, antennaeque ferrugineac apice crassiori uti in praecedente. Thorax ferrugineus, elongatus, capite angustior, convexus, stibpunctatus. Elytra ferruginea 
laevia convexa integra apice obtuso. Subtus ferrugineus abdomine obscuriori. Alae albae.

Habitat . . . .

$$
\text { * II8. N. H I S P I D U L U S. }
$$

Hispidus, thorace, elytrisque obscure-testaceis, capite punctulato nig errimio.

Statura, et magnitudo $N$. Non plus ultra. Antennae, palpique testacei. Caput nigerrimum punctulatum, latitudine thoracis. Thorax angustus, elongatus, convexus, fere cylindricus, immarginatus, punctulatus, obscure-testaceus, pilosus. Elytra testacea pilosa, integra punctulata. Subtus omnino obscure-testaceus. Differt a $N$. Non plus ultra, colore, forma thoracis angustiori, magisque elongata, capitc nigro, ac hirsutia magis conspicua.

Habitat sub arborum cortice hieme.

$$
\text { * 119. N. Non plus ultra. }
$$

Flavus, oculis nigris, elytris, antennisque pilosis subclavatis. C. Non plus ultra. Fn. Etr. 1. 227. 566.

Pédiculo aequalis corpore toto flavo. Statura, et habitus praecedentium. Antennae ad apicem crassiores articulis fere rotundis, approximatis pilosis, ultimo majore acuminato. Thorax minus quam in superioribus elongatus, convexus praesertim basi. Elytra punctulata, pilosa.

Habitat in quisquiliis non frequens.

$$
\text { * 120. TEN U I C O L L IS. }
$$

Laevis, capite, thoraceque nigris, antennis, elytrisque obscure-testaceis, pedibus pallidis.

Duplo minor N. Pedestre. Corpus totum tenuissima pube subobscurum. Antennae longiusculae filiformes, apice vix crassiores obscure-testaceae. Caput nigrum thorace fere majus. Thorax convexus rotundatus, postice paulo angustior 
niger. Elytra integra, laevia, capite thoraceque longiora te staceo-fusca . Abdomen nigrum . Pedes pallidi. Alae albae. Lectus tempore hiberno sub corticibus, at aestate etian in plantis .

$$
\text { 121. N. 4-G U T T A T U S . }
$$

Hispidus, antennis, pedibusque testaceis, elytris maculis quatuor obscure-flavis.

Statura praecedentis, magnitudo N. Trifasciati. Palpi, antennaeque obscure-testaceae. Caput nigrum hirtum. Thorax subglobosus, minus elongatus, postice vix angustior, latitudine capitis, punctulatus, niger hirtus. Elytra integra hirta, tenuissime punctulata, basi nigra, mox macula utrinque obscure-flava fere marginem attingente, dein fascia nigra, tum macula altera minori obscure-flava rotunda, apice denique nigro. Abdomen nigrum. Pedes testacei.

Aliud specimen habeo quod differt a praecedente palpis, antennis, pedibusque nigris; elytris maculis quattor subrufis paullo majoribus, quasi in fasciam connatis, corpore non hispido sed pubescente: An satis distinctus?

Occurrit cum aliis.

\section{* I22. N. B I F A S C I A T U.S.}

Glaber, nitidus, thorace antice nigro, postice ferrugineo, elytris nigris, fasciis duabus luteis in medio interruptis.

Habitus, ac statura fere $N$. Cinctelli, at dimidio minor. Caput nigrum laeve, nitidissimum . Palpi, antennaeque ferrugineae. Thorax capite paullo ninor, elongatus, convexus, postice nonnihil angustatus, forma magis cylindrica, lacvis, nitidus, antice niger, postice ferrugineus. Elytra laevia, nitida, punctulata, nigra, fasciis duabus luteis in medio late interruptis, seu maculis quatuor luteis, binis prope basin, et binis pone medium notata : hae maculae tamen marginem exteriorem attingunt, et apex summus ad 
suturam flavescit. Pedes ferruginei femoribus apice nigris . Lectus sub arborum cortice. Mart. m. (a)

\section{XLVII. $C E R A M B Y X$.}

Palpi quatuor filiformes. Maxilla obtusa midentata. Labium bifidum. Antennae setaceac.

\section{C. FA S I C U T $A$ U S. Long. 2. $\frac{7}{4}$ 1. Lat. $\frac{3}{3}$ 1. vix.}

Thorace spinoso, elytris integris, punctis tribus hispidis, antennis mediocribus hirtis. $F$. Mant. 134. 37.

Paulo major C. Hispido. Antennae longitudine corporis, articulis basi cinereis, apice fuscis, hirtae. Caput, et thorax fusca hirta. Elytra fusca hirta lineolis elevatis; versus basin pallidiora, quasi fasciata fascia ad marginem exteriorem diducta usque ad elytri basin, fasciculis, seu punctis tribus nigris hispidis, apice omnino integra. Pectus, et abdomen cinerea. Pedes grisei.

Raro lectus.

G

(a) Ad species Notoxi quod attinet supra relatas, monenduin summan differentiam consistere in antennis articulis tribus ultimis crassioribus; reliqunm, palpi in ommibus securiformes, omniwmque facies, ac babitus idem qui in N. Pedestre peritiorum etiam sententia babito pro vero Notoxo. Etsi tamen de affinitate inter eos maxima dubitari nequeat, si in aliquem ex descriptis, fortasse generis error irrepserit, gratia. praesertim impotentiae eos rectius examinandi, (cumn nomnulli in Sueciam missi ad consulendum D. De Paykull Gasu perierint, ) indulgeant mibi Entomologi. 


\section{XLVIII. $L A A: M \quad I \quad A$.}

Palpi quatuor filiformes. Maxilla cornea bifida. Labium corrieum bifidun. Astrtinae setaceae.

$$
\text { 124. L. UN I F A S C I A T A. }
$$

Thorace inermi ovato, sordide nigro, elytris fuscis nigropunctatis, fascia media atra fiexuosa flavo marginata. Fn. Etr. 1. 147. 370. t. i. f. 5.

Cerambyx Fasciatus. Villers Ent. 1. 239. 38. videtur omnino diversus, uti figura Schaefferi ab co citata apertissime ostendit. Thorax in meis specimin. nullo modo spinosus. Elytrorum fascia non fusca, sed atra, et flexuosa.

Habitat sub arborum cortice rara .

\section{LII. $S A P E R \quad D A$.}

Palpi quatuor filiformes. Maxilla membranacea bifida.

Labium cordatum, truncatum. Antennae setaceae.

$$
\text { 125. S. ER Y T H R O C E P H A I A. }
$$

Thorace rotundato villoso, rufa, antennis, pectore, elytrisque nigris. F. Mant. I 48. 13.

Cerambyx Erythrocepbalus. Schrank. E. I. 270.

Herbst ap. Fuesl. Arcb. Ins. 5, t. 26. f. 3.

Villers Ent. 1. 243 . 51. t. 1. f. 28.

Media inter S. Oculatan, et Cylindricam; statura eadem. Caput rufum maxillis, antennisque nigris mediocribus. Thorax cylindricus villosus rufus, margine antico, et postico nigris. Elytra glabra cinereo-nigra colore elytrorum $S$. Octtlatae, eodemque modo punctulata. Pectus nigricans. Abdomen rufum macula magna baseos nigra. Pedes rufi. Alac nigrae .

Lecta in sepibus mens. Jun. 
Clas. I. Eleuterata, Saperda . 126. S. L I I N $\quad$ E A $A$ R I $\quad$ S .

Cylindrica nigra, pedibus luteis, antennis mediocribus. $F$. $\int p$. 132. 6.

Cerambyx Linearis thorace cylindrico mutico niger, peäibus omnibus totis luteis, antennis mediocribus. Linn. Syst. Nat. 632. 58. Fn. $\int v .663$.

Leptura Parallela Scop. E. Carn. 153.

Herlst ap. Fuesl. Arcb. Ins. 5. t. 26. f. I.

Scbaef. Icon. t. $55 . f$ : 6 .

Paullo major $S$. Cylindrica, et magis nigra . Abdominis doesum supra testaceum.

Saepe lecta ruri in floribus.

$$
\text { 127. S. L I N E O I A. }
$$

Nigra, thoracis linea dorsali, femoribusque apice rufis. $F . \int p$. 235 . 26.

Herbst ap. Fuesl. Arch. Ins. 5. t. 26. f. 4.

Statura S. Cylindricae, at paullo minor. Nigra villosula. Antennae longitudine corporis, apice non attenuatae nigrae. Linea rubra in dorso thoracis. Elytra concoloria. Abdominis apex, femora omnia apice, uti et tibiae anticae rubra. Variat abdomine, pedibus secundi, et tertii paris totis nigris: femina .

Habitat in pratis silvaticis mens. Jun. non frequens.

\section{LIII. $C A L L I D I U M$.}

Palpi quator clavati . Maxilla membranacea bifida. Labium bifidum : laciniis tenuissimis . Antennae setaceae.

$$
\text { 128. C. S A I I C I S. }
$$

Thorace tuberculato, spinosoque rufum, pectore, elytrisque nigris . F. Mant. 154. 38.

Steviocorus Ruficollis. Herbst Arch. Ins. 5. 92. 3. t. $25 . f .13$. Generis in hoc Insecto incertitudo, summaque apud nos raritas, cum unum tantum specimen habuerim colore antennarum, 
elytrorumque paullulum diversum a $C$. Salicis $F$. occasionem dedit mihi assumendi in Fro. Etrusca 1. 149. 373. t. x. f. 4 . pro nova specie. Ad hoc igitur referantur descriptio, et figura 1. c. exhibitae, et falsum $R$. Etrusci nomen deleztur. Videtur Stenocorus.

Lectum Florentiae.

$$
\begin{aligned}
& \text { 129. C. C L A V I P ES. } \\
& \text { Long. 8. 1. Lat. 2. } \frac{3}{2} 1 .
\end{aligned}
$$

Nigrum opacum, femoribus omnibus clavatis, antennis longioribus . F. $\int p .236 .4$.

$$
\text { Herbst ap: Fuesi. Arib. Ins. 5. t. 26. } f \text {. } 9 .
$$

Statura, ct magnitudo C. Bajuli. Nigrum opacum. Antennae in nostris ( fortasse feminis ) corpore paulo breviores, crassae, articulis apice interno spina terminatis. Thorax subrotundus, depressus, uti totum corpus. Femora omnia valde clavata. Alae fuscae.

Habitat in silvis rarum.

$$
\begin{aligned}
& \text { 130. C. V A R I A B ILE. } \\
& \text { Long. 4. } \frac{2}{3} 1 . \text { Lat. 1. } 1 .
\end{aligned}
$$

Thorace glabro, corpore fusco-aeneo, antennis, pedibusque fuscis. F. $\sqrt{p} \cdot 237 \cdot 9$.

Cerambyx Variabilis thorace mutico subrotundo inaequali glabro, pectore, anoque ferrugineis, antennis ferrugineis. Linm. Syst. Nat. 635. 74. F. Sv. 669.

Cerambyx Scaber. Pod. M. G. p. 36.

Frisch. Ins. 12. $34.5 . t$. 6. $f: 3.4$.

Schaef: Ic. t. 4. f. 1.2 .

Simile C. Violaceo, sed minus. Variat colore : alterum violaceum; thorax subferrugineus, pedes ferruginei, femora clavata, nigra. Alterum thorace, elytrisque lividis, femoribus similibus. Frt. Sv. 669. Habitat in Pinetis. 


\section{I. C. $\mathrm{G}$ I Long. 4. 1. Lat. $\frac{3}{4}$ l.}

Thorace rotundato nigrum, elytris cinereo-fasciatis, basi bituberculatis, apice acuminatis. F. Mant. is6. 62.

Nostrum Insectum variare in multis videtur a $C$. Gibboso $F$. Utrum sit nova species, a descriptione periti judicabunt . Statura C. Mystici, at fere dimidio minus. Antennae corpore paulo breviores, subpilosae, articulis basi obsoletecinereis, apice ferrugineo-fuscis, spinaque laterali parum perspicua instructis. Caput, et thorax nigra obscura immaculata tomentosa, uti totum corpus. Thorax non tantum rotundatus, sed globosus, et in medio valde convexus. Elytra basi obscure-nigra, et prope suturam utrinque valde tuberculosa fere uti etiam in C. Mystico observantur. In medio elytrorum fascia terminat lata cinerea, cui superius incumbit striga linearis arcuata nigra : mox sequitur fascia atra latitudine praecedentis cinereae: et demum aequele spatium cinereum terminat elytra apice obtruncato, et in spinam validam margine externo excurrente. Pedes $f_{a-}$ sco-nigri tarsis subferrugineis.

Lectum in montuosis.

$$
\text { 132. C. } P \cup \& \perp I L U M \text {. }
$$

Thorace rotundato nigrum, antennis tibiisque testaceis. $\boldsymbol{E}$. Mant. I 55.39.

Corpus C. Alni minus, obscure nigrum. Antennae corpore longiores testaceae pilosae. Thorax rotundatus, subdepressus, muticus. Pedes femoribus clavatis fuscis, tibiis, tarsisque testaceis. Alae albae.

Habitat Pisis .

$$
\text { LV. LEPTURA. }
$$

Palpi quatuor filiformes. Maxilla unidentata, apice setosa : Labizsm membranaceum bifidum. Antennae setaceae. 


$$
\begin{array}{llllllllll}
* & \text { 133. L. E } & \text { L } & \text { O } & \text { N } & \text { G } & \text { A } & \text { T } & \text { A. }
\end{array}
$$

Nigra, elytris testaceis: punctis duobus, cruce, fasciisque nigris . Fn. Sv. Ed. 2. 2275.

Nigra, corpore elongato, elytris flavis: maculis sex nigris, pedibus, antennisque nigro flavoque maculatis. De Geer. Ints. 5. 134. 10.

Leptura nigra elytris testaceis : punctis duobus, cruce faciisque nigris. Geoff. Ins. 1. 224. 5. Le Stencore janne à bandes noires.

Schaef. Iconr. t. 58. f. 10.

Descriptiones De Geeriana, et Geoffroyana optimae. Magnitudo L. Quadrifasciatae, at corpus magis elongatum, magisque apice attenuatum. Antennae corpore subbreviores nigrae articulis basi flavescentibus. Caput nigrum. Palpi flavi apice nigri. Thorax niger flavo-pubescens, antice angustatus, utrinque tuberculosus angulis posticis acutis. Elytra flava antice nigro-punctata, posticeque fasciis tribus nigris, prima late interrupta, apice attenuato truncato. Pedes primi, et secundi paris flavi tarsis nigris: postici femoribus, tibiisque basi dimidiato-flavis. Tibiae posticae saepius, at non semper latere interno versus apicem deficientes, quasi mutilatae, dentatae; forte distinctio sexus.

Habitat flores in silvis non rara.

$$
\text { LVII. } P Y R O C H R O A \text {. }
$$

Palpi quatuor subfiliformes. Maxilla integra . Labium corneum. lineare integrum. Antennae filiformes .

$$
\text { 134. P. C O C C I N E A. }
$$

Long. 8. 1. Lat. unius elytri ad apicem desumta 1. $\frac{1}{2} 1$.

Nigra, thorace, elytrisque sanguineis immaculatis. F. $\int p .254$. I. De Geer. Ins. 4. 47. 4. Villers Ent. t. 2. f. 35 . Schrank. E. I. 323 . 
In nostris caput semper nigrum, fronte foveola ampliuscula impressa. Elytra nullo modo striata .

Habitat Florentiae, et Pisis in sepibus non frequens. Lecta ineunte Aprili .

\section{LXI. $\quad C U C U I U S$}

Palpi quatuor aequales, articulo ultimo truncato, crassiori. Labium breve bifidum: laciniis linearibus distantibus . Antennae filiformes.

\section{C. TES T A C EUS :}

Long. 1. $\frac{1}{6}$ 1. Lat. $\frac{1}{4} 1$.

Thorace subquadrato mutico testaceus, femoribus compressis. F. Mant. 166. 7 .

Triplo, aut quadruplo minor C. Flavipede; statura fere eadem . Antennae longitudine fere corporis filiformes, testaceae, graves. Corpus elongatum depressum testaceum immaculatum. Pedes breves testacei femoribus compressis .

Habitat sub corticibus.

LXII. $C A N T H A R I S$.

Palpi quatuor filiformes. Maxilla bifida . Labium integrum. Antennae filiformes.

$$
\begin{aligned}
& \text { 136. C. P A L L I D A. } \\
& \text { Long. 2. } \frac{1}{2} \text { 1. Lat. } \frac{8}{2} 1 .
\end{aligned}
$$

Thorace marginato, atra, elytris, pedibusque pallide-testaceis . F. Mant. 167. 12.

Parva. Caput atrum antennarum basi, palpisque pallidis. Thorax marginatus ater immaculatus. Corpus atrum pedibus pallidis. F. Femora nigra. Alae albae .

Habitat in plantis frequens. 


$$
\begin{aligned}
& \text { 137. C. P E U B I A. } \\
& \text { Long. 2. 1. Lat. } \frac{2}{2} \text { 1. vix. }
\end{aligned}
$$

Plumbeo-nigra . Ent. Par. 63. 15.

Antennae maris vix thoracem aequant, in femina dimidii corporis longitudinen. Nigra nitida. Villers Ent. 4. 320.20. Habitat in floribus.

\section{NECYDALIS.}

Palpi quatuor filiformes. Maxilla unidentata. Labisins membranaceum late emarginatum. Antennae. filiformes.

138. N. H Y B R I DA.

Thorace teretiusculo rufo, elytris subulatis, basi, suturaque testaceis, margine, et apice nigris .

Tuto determinare haud potui. Sub hoc nomine peritioribus judicandam relinquo.

Statura, et magnitudo omnino $N$. Caeruleae. Caput, antennaeque nigrae. Thorax punctis duobus impressis, teretiusculus rufus. Elytra lineis tribus elevatis striata, subulata, basi suturaque usque ad medium testacea, toto margine externo, apiceque nigra. Pectus atrum, Femora postica clavata, arcuata, tota atra nitida. Alae nigrae.

Lecta in Pastinacae floribus.

$$
\text { 139. N. F L A V E S E N S. }
$$

Elytris subulatis testaceis, corpore nigro, femoribus posticis clavatis arcuatis. Lizin. Syst. Nat. 642. 8.

Necydalis Flavescens nigra, elytris testaceis subulatis, femoribus posticis clavatis. De Geer. Ins. 5. 155. 4. La Necydale ianne .

Cantbaris Femorata. Scop. E. Carm. 145. 
Cantharis Fulva. Geoff. Ins. 1. 343. 4. La Cantbaride fauve, à grosses cuisses.

Cantburis Flavescens, subvillosa elytris attenuatis. Geof. Ins. 1. 343. 5. varietas.

Schrank. E. I. 315 ?

Hanc unam eamdemque speciem esse cum $N$. Podagrariae Fabricii $\int p$. 264. 8. asserere haud dubitamus. Saepe codem tempore, et loco in silvestribus tantum, plura hujus speciei lecta individua, semperque observatum variare femoribus posticis nunc clavatis, nunc simplicibus, clava modo ad basin testacea, modo tota nigra. In iis quibus pedes omnes 'simplices sunt, color pedum semper testaceoflavus, femorum anticorum apice, tibiis, tarsisque subnigris; thorax semper testaceo-flavus, elytrisque concolor, ad fulvum quandoque vergens, uti etiam maxima abdominis pars: Caput nigrum. Antennae nigrae basi testaceae. Alae fuscae. Quae vero femoribus gaudent clavatis, corpus totum aeneo-nigrum, primi, et secundi paris pedibus tantum, clytrisque exceptis testaceo-flavis. In omnibus thorax, ac elytra pubescunt. Apex elytrorum interdum niger. In hac Necydali femora postica clavata marem designare videntur.

Necydalis Podagrariae elytris subulatis testaceis corpore nigro, femoribus posticis clavatis, basi testaceis. $F . / p$. 26́4. 8. si species omnino distincta est a $N$. Flavescente, uti judicat Cl. Villers Ent. 1. p. 281., ego etiam fateor me numquam vidisse. Certum tamen est Necydales admodum variare. Valde variat $N$. Rufa, et ex observationibus nostris ( conf. Fn. Etruscam ) constat esse masculum N. Atrae : N. Ruficollis forte una eademque species est cum $N$. Caerulescente: N. Viridissima, et Caerulea etiam variant saepe colore, et occurrunt apud nos frequenter femoribus posticis nunc simplicibus, nunc clavatis: Erraret ne igitur Entomologus, qui diceret in hoc genere species nimis auctas? Habitat in sepibus ubi Podagraria crescit. 


\section{E L A T E R .}

Palpi quatuor securiformes. Maxilla unidentata, obtusa. Labitum bifidum. Antennae filiformes.

$$
\text { * i40. E. L I T I G I O S.U S. }
$$

Long. 6. 1. Lat. I. 1. et ultra

Testaceo-rufus, oculis solis nigris, antennis vix thorace longioribus .

Magnitudo, et statura E. Lineati Vill. Elytra laeviter striata. Alae fuscae. Videtur nova species affinis E. Austriaco Scbranz$k i i$, at difficillime distinguenda . Magnitudine variat minori. Habitat in plantis obvius.

$$
\begin{aligned}
& \text { 14I. E. L I N E T U S } \\
& \text { Long. 4. 1. Lat. 1. I. }
\end{aligned}
$$

Niger, elytris obscurc-lividis, fusco sublineatis. Villers, Ent. I. 304. 6 .

Corpus. mediocre fuscum. Antennae subferrugineae. Elytra obscure-livida lineis duabus nigricantibus versus suturam dorsalem positis. Vill.

In nostris speciminibus sane multis, pedes testacei, et elytrorum lineae omnes fuscae quasi in strias gemellas digestae. Habitat in plantis frequens.

$$
\text { * 142. E. C Y I IN D I I C U. }
$$

Aenco-niger tomentosus, elytris laeviter puctato-striatis.

E. Cylindricus D. de Paykull.

Magnitudo praecedentis . Totus nigro-aeneus pubescens. Antennae thorace longiores .

Habitat ruri frequens. 


\section{E. T HOR A C I C U S.}

Niger, thorace toto rufo. $F . \sqrt{p} .270 .32$.

Elater niger thorace rufo. Geof. Ins. 1. 132: 5 .

E. Gramineus Scop. E. Carn. 290. In E. Ruficolli Frr. Etr. Synonymia Scopolina delenda; hunc enim sub nomine $E$. Graminei indicare videtur Scopoli.

Statura E. Ruficollis, at duplo major. Antennae nigrae thorace subbreviores. Caput nigrum nitidum. Thorax latitudine elytrorum admodum convexus, globosus, superne totus rufus nitidus, inferne rufus septo, seu fascia longitudinali nigra ab ore diducta. Elytra subtilissime striata, nigra, nitida, scutello valde excavato, nigro. Abdomen, pcdesque nigra. Alae fuscae. Differt ab E. Rufficolli magnitudine duplo majori, antennis brevioribus, minusque serratis; thorace supra toto rufo, subtus diversimode maculato, pedibus totis nigris ( in $E$. 'Ruficolli, rufis), femoribus aliter conformatis, brevioribus, et non ita uti in illo depressis. Habitat Florentiae.

\section{* 144. E. B I N O T A T U S.}

Long. 1. $\frac{1}{2}$ 1. Lat. $\frac{1}{2} 1$.

Niger, ferrugineo-pubescens, elytris ad apicem macula pallideflava.

Affinis E. Bimaculato. Fn. Etr. Totus niger fuscus, pube subferruginea tomentosus. Antennae fusco-nigrae longitudine thoracis. Thorax angulis posticis, seu dentibus admodum acutis, elytris nitidior. Elytra striata macula ad apicem pallide-flava. Pedes testacei femoribus fuscis. Alae albae. Occurrit sed rarissime elytris alio puncto flavo anteriore obsolete notatis.

Habitat sub arborum cortice. 


\section{LXVI. $\begin{array}{llllllllll} & B & U & P & R & E & S & T & I & S .\end{array}$}

Palpi quatuor filiformes, articulo ultimo obtuso truncato. Maxilla obtusa unidentata. Labium cylindricum acuininatum. Anstennae filiformes serratae.

$$
\text { 145. B. 9-M A C U L A T A. }
$$

Elytris serratis, nigra, fronte puncto unico, thorace quatuor, elytris tribus flavis. F. Mant. I 79. 36 .

Elytris integerrimis nigris, maculis tribus flavis longitudinalibus fronte, thoracisque lateribus luteis. Limn. Syst. Nat. 66z ${ }^{7} 7$.

Fn. Etr. I. 187.463.

Variat thorace maculis 2., 4., nullis, fronte immaculata, elytris semper maculis tribus. F.

Numquam vidi thorace quadrimaculato. Inter mea specimina sane plura, nam frequens est apud nos, habeo varietates fronte, thoraceque immaculatis, elytris maculis tantum quatuor posticis : aliasque quae praeter novem maculas ordinarias ulterius habent punctum flavum in elytrorum apice. Abdomen immaculatum. Elytra subtilissime serrata .

Habitat etiam in hortis.

$$
\begin{aligned}
& \text { * 146. B. C Y A N } 1 \text { C } 0 \text { R N I S. } \\
& \text { Long. 5. 1. Lat. I. } \frac{3}{4} \text {. } 1 \text {. }
\end{aligned}
$$

Elytris integris, viridis, antennis cyaneis, femoribus anticis subtus aureo-ignitis, posticisque clavatis .

An B. Femorata. Villers Ent. 1. 338. 34. t. 1. f. 40. quae forte non rite satis descripta?

Paullo major b. Manca. Antennae thoraci subaequales basi, seu articulo primo longiore, clavato, viridi, reliquis cordato-orbiculatis, compressis, cyaneis . Caput viride. Oculi nigri. Thorax planus lateribus rotundatis, dilatatis, antice posticeque truncatus, viridis. Elytra viridia, subpunctata, ad latera coarctata, ad apicem attenuata, apice ipso obtuso. Abdomen sub elytris caeruleum. Subtus tota 
viridi-aurea nitidior. Femorum anticorum apophyses, ac latus internum fere totum aureo-ignitum, splendidum. Femora postica vix pilosa, admodum incrassata, unde ampla cavitas utrinque in abdomine ad ea recipienda idonea. Alae obscurae costa obscuriori.

Habitat in plantis rara.

$$
\text { 147. B. DE A U R A TA. }
$$

Supra obscure-viridis, thoracis, elytrorumque margine aureo. An B. Aurulentae, seu potius Deauratae varietas. F. Mant. i 82.67 ?

Magnitudo praecedentis . Antennae nigrae . Caput obscure viridi-aeneum, pilosum villo albicante tenuissimo. Thorax fere planus, subpilosus, lateribus rotundatis, in medio viridis, margine exteriore late, et obscure viridi-aeneo. Elytra integra, viridia, nitidiora margine exteriore aureo-rubro, nitidissimo, angustiori. Subtus tota cuprea splendida. Lecta in silvis.

$$
\text { 148. B. R U T I I A N S . }
$$

Elytris tridentatis, viridibus, nigro maculatis, margine aureo. F. Mant 177.16.

Buprestis Fastuosa. Jaqu. Misc. Austr. 2. t. 23. f. 2.

B. Rutilans. Villers. Ent. I. 336. 22.

Statura, et magnitudo fere praecedentis. Antennae serratae, nigrae. Caput, thoraxque viridia. Thorax auro late marginatus, punctatissimus. Elytra striata, ad suturam viridissima, ad marginem ignea, punctis nigris lucidis aspersa. Corpus aurato-viride. Elytra apice serrata .

Habitat Florentiae rara.

$$
\begin{aligned}
& \text { 149. B. E L A T A. } \\
& \text { Long. 2. } \frac{5}{3} \text {, 3. 1. Lat. } \frac{3}{4} 1 .
\end{aligned}
$$

Elytris integerrimis, linearibus, corpore elongato zeneo nitido . F. Mant. 184.84 . 
Statura $B$. Atrae oblonga, at minor, et tota aenea nitida. F. Antennae thorace brevicres serratae. Thorax antice valde convexus, postice depressus, sinuatus, marginatus. Elytra ante medium ad latera angustata, punctata, sutura prominula. Corpus elongatum .

Habitat in silvis.

$$
\text { 150. B. L A E T A. }
$$

Elytris integris viridibus, capite thoraceque aureis. $F \cdot \int p$. 282. 59 .

Statura, et magnitudo B. Nitidulae . Caput, thorax, pectus, abdomen aurea-nitida. Elytra, pedesque viridia. Thorax aureo ignitus, utrinque depressus uti in $b$. Nitidula. Descriptio F. Syst. Ent. nullo modo cum meo specimine convenit; corpus enim non lineare, non statura $B$. Viridis, pedes demum non rufescentes .

Habitat Florentiae rara .

$$
\text { * 15I. B. C A E R U I. E. }
$$

Elytris integerrimis laevibus, corpore supra cyaneo, subtus plumbeo, oculis nigris .

Primo intuitu videtur varietas $B$. Cyaneae, statura enim, et color superius idem, at distincta. Corpus sublineare nitidum. Differt a $b$. Cyanea magnitudine interdum plus quam duplo minori, oculis nigris, elytris non rugosis, thorace convexiore, posticeque magis lato, corpore subtus plumbeo. Lectae quatuor in planta silvae Pisanae.

$$
\text { 152. B. } \mathrm{P} Y \mathrm{G} M \mathrm{~A} \mathrm{E} \text {. }
$$

Elytris integris cyaneis, capite, thoraceque aeneis nitidis. $F$. Mant. 183.78.

Statura et magnitudo B. Minutae. Caput, et thorax laevia, aenea, nitidissima. Elytra cyanea nitida, immaculata. Corpus obscure-nitidum .

Habitat in Umbellatis frequens. 


\section{B. $M$ I N U T A .}

Elytris integerrimis transverse rugosis, thorace subtrilobo laevi, corpore ovato nigro. Vill. Ent. I. 334 . 15.

In Ed: XIII. Linn. praetermissa.

Minor altera B. Minuta. Geoff. Ins. 1. 128. 6. Cuculjus fusco cupreus triangularis \& $c$., cui similis, sed elytra sine fasciis undulatis, villoso-albidis. Hanc Villers credit veram $B$. Mimutam Linnaei.

Habitat in plantis rarior.

$$
\begin{aligned}
& \text { * I 54. B. N I T I D A. } \\
& \text { Long. 2. } 1 \text { vix. Lat. } \frac{3}{4} \text { l. }
\end{aligned}
$$

Elytris integerrimis, viridis, nitens, thorace foveola postica utrinque profunda excavato.

Statura B. Salicis, at fere dimidio minor. Caput viride. Frons impressa. Antennae nigrae thorace subbreviores. Oculi fusci. Thorax viridis, nitens, antice convexus, postice marginatus, et fossula magna utrinque profunde excavatus. Elytra viridia, nitida, integerrima, scabriuscula, acute-marginata, anticeque parum coarctata. Subtus tota subaencoviridis. $\beta$. Variat elytris aureo-rubris. Differt a B. Salicis magnitudine qua vix aequat $B$. Nitidulam, fossula thoracis valde profundiore, coleoptrisque (etiam in varietate $\beta_{.}$, ) numquam aureis basi viridibus, sed totis aureis. A B. Nitidula vero differt praecipue forma thoracis omnino diversa. Habitat in floribus compositis frequens.

\section{E LAPHR US.}

Palpi sex filiformes. Labium rotundatum, acuminatun, integrum . Antemnae setaceae :

$$
\begin{aligned}
& \text { 155. E. C A R A B O I D E S. } \\
& \text { Long. 2. } \frac{1}{2} \text { 1. Lat. 1. } \frac{1}{2} 1 \text {. }
\end{aligned}
$$

Cicindela Caraboides thorace cordato hemisphaerico, marginato, 
elytris nigro-aeneis, punctis copiosis impressis. Scbrank. E. I. 193.360.

Villers Ent. 1. 326. 14. t. 2. f. 39.

Caput, et thorax nigro-aenea. Oculi exserti, et maxillae insignes. Thorax perfecte cordatus, marginatus uti in Carabis, sed margo angustus linea longitudinali excavata. Elytra nigro-aenea maculis viridi-aeneis variegata, minutissime punctata; ad utrumque marginem puncta excavata lata in lineam longitudinalen disposita. Pedes fusci. Pectus nigroaeneum. Abdomen atrum nitens. Schr.

Habitat in sabulosis non rarus.

$$
\text { * 156. N E B U L o S U S. }
$$

Obscure-aeneo-viridis, elytris cinereo nebulosis .

Statura E. Flavipedis, at triplo major. Antennae fuscae. Thorax cordatus linea longitudinali impressa. Elytra obscureaenco-viridia, laevia, ad suturam interdum bipunctata, et sparsim cinerea pube nebulosa. Subtus aeneo niger tibiis, tarsisque ferrugineis .

Habitat in locis arenosis frequens.

$$
\text { * 157. E. P Y R I T O S U S : }
$$

Aeneus, elytris punctis duobus majusculis profunde impressis, pedibus atro-aeneis.

Proximus E. Alpino D. de Paykull, et praecedente paullo ninor. Caput aeneum. Thorax aeneus, convexus, vix marginatus. Elytra aenea, subtilissime striata, punctis duobus valde conspicuis pone medium prope suturam, inter striam secundam, et tertiam impressis, altero anterius, altero posterius. Color supra prorsus aeneus, subtus atro-viridiaeneus, nitidus. Pedes concolores nitidi.

Habitat cum praecedentibus rarior. 


\section{Clas. 1. Eleuterata. Hydrophilus . \\ LXIX. H $H$ D $R$ O P H I L U S.}

palpi quatuor filiformes. Maxilla bifida. Labium corneum subemarginatum. Antennae clava perfoliata.

\section{I58. H. C A R A B O I D E S .}

Niger nitidus, elytris substriatis. F. Jp. 289. 3. Limm. Syst. Nat. 664. 2. Fn. Sv. 765.

Hydropbilus Nigricornis. De Geer Ins. 4. 376. 2.

Geoff. Ins. 1. 183. 2.

Roes: Ins. 2. Aquat. 1. t. 4. f. 1.2.

Schaeff. Ic. t. $33, f$. 10.

Fin. Etr. 1. 185.482.

Niger laevis convexus, elytris punctato-striatis, capitulo antennarum perfoliato nigro, capite thoraceque striis punctorum abbreviatis recurvis.

Mas pedibus anticis absque palmulis, omnino feminae similis, mens. Mart. et April. coire solet. Penis insidet medius inter duo cornicula, seu poțius appendices corneas, lamelliformes, apice attenuatas, quae ad introductionem, firmioremque copulam sustentandam accomodatae videntur. Ova magnitudine vix cedunt is $B$. Pavoniae Majoris. Datur alus, mihi varietas, qui magnitudine excepta triplo, aut quadruplo minori, nulla alia nota distinguitur a praecedente, simulque frequens occurrit, nempe $H$. Picipes. F. Mant I 88. 6:

Habitat in aquis frequens :

\section{H. ORBICULATUS.}

Subrotundus, corpore glabro.F. $\int_{\text {p. }}$ 290. 6.

Statura fere H. Scarabaeoidis, at minor, et fere orbiculatus. Antennae perfoliatae. Totus laevissimus, nitens. F. Habitat in aquosis. 
160. H. P A L I I D U S.

Pallidus laevis, abdomine, oculis, femoribusque subnigris. Statura, et magnitudo omnino $H$. Lutridi, sed caput, thorax, et elytra laevia, pallida, subdiaphana, interdum tamen fuscedine quadam aspersa. Abdomen, et femora obscure-nigra. Tibiae, tarsi, antennarum basis, et palpi pallide-rufi; hique porrecti, longiusculi. Variat quandoque elytrorum colore obscuriori .

Habitat in aquis stagnantibus .

\section{DYTISCUS.}

palpi sex filiformes. Labium corneum, truncatum, integrum. Anteninie setaceae.

\section{D. D Is SIMILIS.}

Niger, depressus, thoracis, elytrorumque margine exteriore ferrugineo-flavescente, elytris, in femina obscurioribus, minus laevibus fibrosis, neque striato-punctatis . Fn. Etr. 1. 199. 489.

Cum in determinando pro $D$. Costali varia sit Entomologorum sentenitia, nomen $D$. Disparis jam usurpatum mutavi.

Valde affinis $D$. Costali, cui femina hujus praesertim simillima. Differt tantum magnitudine paullo minore, corpore toto subtus ferrugineo, striaque costali ferruginea apicen haud attingente, caetera aequalia. Obs. Fascia supra os puncto utrinque impressa, flavescens, supra quam aliud punctum majus adest similiter utrinque impressum. Mas vam riat colore testudineo-nigro, at rarissime .

Habitat in Arni aquis, etiam in fossis.

$$
\begin{aligned}
& \text { 16. D. B I P U S T U L A T U S. } \\
& \text { Long. 3., 4. 5. 1. Lat. I. } \frac{1}{2}, 2 ., 2 . \frac{1}{2} 1 \text {. }
\end{aligned}
$$

Ater lacvis, capite postice punctis duobus rubris. F. $\int p .294 .15$. 
Dytiscus totus niger laevis. Geoff. Ins. 1. 189. 6. Le Dytique en deuil.

Mull. Linn. Nat. Cl. v. p. 350.

Dytiscus Immaculatus. Sibrankii E. 1. 377 .

Dytiscus Luctuosus. Ent. Par. 1. 67. 6.

Dytiscus Gronovi. Gron. Mus. 2. p. 164. n. 555. an?

Schaef: Ic. t. 8. $f .9$ ?

Dytiscus ater corpore convexo nigro toto, pedibus, antennisque rufo-fuscis. De Geer Ins. 4. 401 . 8. et variet. $\beta$. major elytris rufo bipunctatis. Confer.

Anceps diu haesi an varietas a De Geerio indicata quac gaudet elytris rufo bipunctatis, distinguenda foret a D. Bipustulato F. Ut veritas, quam sequimur, clarius, certiusque innotescat, liceat observationes nostras in medium afferre, et peritioribus Entomologis subiicere.

Hi duo Dytisci qui eodem tempore, et loco apud nos etiam frequenter occurrunt, primo intuitu fere similes sunt, toti atri, unus altero minor, et in utroque caput postice punctis duobus rubris, vix oculo inermi conspicuis, notatur.

Minor: $D$ ater laevis capite posterius punctis duobus rubris; sane est D. Bipustulatus Fabricii, uti magnitudine ab Authoribus allata, aliisque notis constare videtur.

Major: Varietas est elytris rufo-bipunctatis a De Geerio tantum 1. c. supra indicata, scilicet $D$. Ater corpore convexo nigro toto, pedibus, antennisque rufo-fuscis; Varietas .

Observatum igitur D. Minorem . scilicet Bipustulatum constanter differre a $D$. Majore, seu var. De Geerii practer magnitudinem, corpore, elytrisque minus convexis; inmaculatis; apice magis depresso, et obtuso; pedibus quatuor anticis nigris, raro piceis. In $D$. Majore palpi, antennaeque rufae, et caput postice punctis duobus rubris uti in $D$. mizori notatum, sed elytra magis convexa, apice magis elongato, et punctis in singulo binis rufis; altero pone medium versus marginem exteriorem oblongo; altero ad apicem rotundo, quae etiam nudis oculis in Insecto praesertim vivo aspiciuntur, et avulsis elytris si inferna parte observentur, eo quod pellucida, manifestissime apparent. Pedes quatuor 
antici subrufi, tarsis tribus primis pilis canis hispidis, quasi fasciculatis. Alde in hoc uti in praecedente albohyalinae, ad costam marginemque tenujorem fusco-nebulosae. Hae notae, cum nemo adhuc asserat observasse $D$. minorem copula junctum cum $D$. majore, sufficientes videri possent ad declarandos eos specie distinctos. Attamen nos, rebus omnibus bene perpensis, cum De Geerio credimus unam eamdemque speciem esse, quae variat magnitudine majori, elytrisque magis convexis, rufo bipunctatis .

Habitat in aquis frequens.

$$
\text { 163. D. TRANSVERSALIS. }
$$

Ater, thorace antice ferrugineo, elytrorum margine, strigaque baseos abbreviata flavis. F. Manit. 191. 23.

Dytiscus niger, thorace utrinque, fasciaque antica, elytris margine, lineaque transversa baseos flava. Mztll. Zool. Dais. prodr. 7 1. 668.

Pontop. Atl. Dan. 1. t. 29. Bergstr. Momencl. 1. t. 29. Habitat in aquis.

$$
\text { * 164. D. PUS T U e a T US. }
$$

Niger laevis, macula frontis lunulata rufa .

Statura, et magnitudo D. Striati. Os, antennae, palpique rufi. Caput nigrum mactia magna frontis rufa, in Insecto vivo, praesertim natante maxime conspicua, post mortem certo tantum situ visibili. Thorax imo margine laterali subrufo. Elytra nigra laevia immaculata. Subtus piceus pedibus anticis subrufis. Capitis clypeus antice utrinque punctis duobus impressis, uti in D. Striato, sed in hoc disiunctis, in illo contiguis. Aqua extractus, digitisque ad examinandum leniter contrectatus, vitam quae in aliis diu permanet, deserit brevi .

Habitat cum praecedente.

$$
\text { 165. D. H Y B N E R 1. }
$$

Laevis ater, ore, thoracisque margine ferrugineis, elytris linea marginali flava. F. Mant. igo. $2 \mathrm{I}$. 
Magnitudo, et statura D. Ttransversalis. Caput nigrum, ore, antemnis, palpisque pallide-ferrugincis . Thorax niger margine imprimis antice ferruginco. Elytra laevia, atra, striata, striis in singulo tribus punctatis vix oculo inermi con. spicuis, lineaque flava marginali, quae tamen apicem haud attingit. Subtus niger pedibus quatuor anticis flavis; et primi paris in masculo patellatis.

Habitat in aquis sat frequens.

$$
\text { * 166. D. T A E N.I A T U S. }
$$

Supra niger laevis nitidus, subtus ferrugineus, ore, verticis punctis duobus, thoracis margine, fasciaque media flavis. Statura D. Cinerei, magnitudo D. Transversulis . Caput nigrum ore, lineola trigona media, punctisque verticis duobus transversis flavis, fere uti in $D$. Cinereo. Antennae palpique rufi . Thorax antice, posticeque niger nitidus margine laterali, fasciaque transversa media marginem utrinque attingente flavis . Elytra glabra, laevia, nigra nitida, pun* ctis minutissimis flavis undique irrorata, sed oculo tantum armato conspiciendis. Subtus totus flavo-ferrugineus. Caput antice utrinque punctis duobus impressis, distantibus. Habitat in aquis rarus.

$$
\text { 167. D. B I P U N C T A T US? }
$$

Ater, thorace flavo, punctis duobus nigris, elytris flavo-fuscoque variis. F. Mant. 190. 19.

Statura D. Fenestrati, et vix major . Caput nigrum ore subferrugineo, fronte, armato oculo, rufo bipunctata. Thorax pallide-flavus punctis duobus dorsalibus atris . Elytra laevia, glabra, pallide-flava, nigro variegata. Pectus nigrum. Abdomen, pedes, antennae testaceae. Anceps diu haesi, anne potius referendus esset ad D. Irroratum. F. Color abdominis magis convenit, at magnitudo removet.

Lectus super herbam in prato palustri.

$$
\begin{aligned}
& 167 .^{2} \text { D. U L I G I N O S U S. } \\
& \text { Long. 2. } \frac{\pi}{3}, \text { 3. 1. Lat . I. } \frac{1}{4} \text {. }
\end{aligned}
$$

Ater, nitidus, antennis, pedibus, elytrorumque latere exteriore 
ferrugineis . F. Sp. 295. 21. Linn. Syst. Nat. 667.20. Fn. Sv. 776 .

Mull. Limn. Nat. cl. v. p. 350.

Scop. E. Carn. 296.

Scbrank. E. I. 378.

Magnitudo G. Natatoris . Caput, palpi, antennae, pedesque rufi. Thorax rufus margine antico obscuriori. Elytra nigricantia punctulis excavata, latere exteriore rufo flavescente. Abdomen nigrum.

Habitat in aqua stagnante.

\section{D. MINUTUS.}

Flavescens, elytris fuscis, margine flavo-maculato $F$. $f_{p}$ 297. 36.

Dytiscus Minutus elytris fufcis bafi, lateribus pallidis, thorace flavo immaculato, corpore ovato. Limn. Syst. Nat. 667 . 23. Fn. $S v_{\text {.. }} 778$.

Dytiscus Ruficollis rufus, elytris Atriatis, flavo-grifeis, maculis nigris. De Geer Ins. 4. 404. 18. t. 16. f. 9. 10. descr. optima

Geof. Ins. 1. 12.

Ad basin abdominis lamina magna mobilis femorum partem obtegens. Variat capite nigro, elytris modo maculis nigris, modo immaculatis .

Habitat in aquofis.

LXXII. $C A R A: B U S$.

Palpi sex articulo ultimo obtuso, truncato . Labiun integrum truncatum. Antennae filiformes .

$$
\text { 169. C. PUPURASCE NS. }
$$

Niger thoracis, elytrorumque marginibus violaceis, elytris rugose punctato-sriatis . Mon. Car. no 4 . 
C. Purpurascens. F. Mant. 195. 6 .

Scbaeff: Ic. t. 88. f. .

Statura, et magnitudo $C$. Violacei. Caput nigrum . Antennae apice fuscescentes. Thorax niger margine acute elevato, violaceo, obcordatus, subpunctatus, longitudine latior, lineola longitudinali, dorso convexo postice retuso. Elytra nigra convexa, rugose punctata, margine violaceo purpurascente. Subtus totus niger.

Habitat apud nos rarior; bis tantum inventum cadaver in silvis .

$$
\text { 170. C. HORTEN SIS. (a) }
$$

Apterus, niger, elytris subrugolis, punctis aeneis excavatis triplici ferie, margine cyaneo . F. Mant. 196. 16.

C. Hortensis. Limn. Syst. Nat. 668. 3. Fn. Sv. 783.

C. Violaceus. De Geer Ins. 4. 89. 3.

C. Hortensis niger, thorace latiore, elytris subrugofis, margine, punctisque triplici serie excavatis aeneis . Mons. Car. 17.7 .

Scbaef. Icon. t. iा $f$. 2 .

Statura C. Glabrati. Latitudo C. Violacei, sed brevior . Capue nigrum . Oculi pupillati. Antennae apice fuscescentes. Thorax niger convexus, linea longitudinali, obcordatus, latitudine fere baseos elytrorum, margine parum prominulo, aeneo-purpurascente. Elytra nigra, convexa, margine subaeneo, minime striata, rugis vix nudis oculis conspicuis, punctis aeneis triplici serie excavatis. Sternum, abdomen, pedes nigra nitida. Differt a $C$. Gemmato cui affinis, latitudine thoracis, et elytris haud striatis. Mon. Car. l. c. Habitat in putridis. Apud nos minime frequens.

(a) In Fn. Etr. 1. 205. 506. deleatur nomen C. Hortensis, et ad C. Auropunctatum referantur descriptio, et figthra l. c. exbibitae. 


\section{C. C O N V X X U S.}

Apterus, convexus, ater, laevis, thorace postice emarginato . F. Mant. $197,22$.

C. Convexus, niger, thorace semirotundato, elytris convexis, subtilissime punctato-striatis, margine exteriore subviolaceo. Mon. Car. n1. 13.

Scbaef. Icon. t. 3. $f$ : 2.

Magnitudo C. Aturati, vel C. Violaceo dimidio minor. Caput nigrum. Thorax totus niger margine concolore, convexus, subtilissime punctatus, semirotundatus. Elytra nigra, convexa, subtilissime punctato-striata; summo margine exteriore subviolaceo, nitido. Subtus totus niger. Differt a $C$. Violaceo, et Purpurascente magnitudine duplo minori, thoraceque unicolore semirotundato, non obcordato, Mon. Car.

Lectus in Pisano nemore.

\section{* 172. C. P A Y K U L L I I.}

Niger nitidus, capite maximo exserto, thorace obcordato, elytris laevibus, tenuissime punctato-striatis .

Magnitudo C. Spinigeri. Caput nigrum maximum latitudine fere thoracis, uti in C. Interrupto, at magis exsertum. Maxillae, oculique nigri. Palpi picei. Antennae crassiusculac, capite, thoraceque breviores fuscescentes, primis quatuor articulis nigris nitidis. Thorax niger cordatus, marginatus, convexus, antice latitudine elytrorum, postice paullo angustior, linea longitudinali, striaque magna postica utrinque late, ac profunde excavata. Elytra nigra laevia, connata, convexa, tenuissime punctato-striata, punctis discoidalibus majoribus nullis, summoque margine exteriore impunctato. Sternum nigrum. Abdomen nigrum, interdum piceum. Pedes nigri, breviores femoribus incrassatis. Alae nullae. Forma thoracis latior quam in C. Spinigero magisque subquadrata.

Insectum dicatum Nobil. ac celeberrimo viro Gustavo de $P_{a y-}$ kull ad universam Naturalem Historiam locupletandam nato, 
Entomologo summo, et in ordinandis, illustrandis, describendisque miro successu variis Insectorum generibus nulli secundo .

Habitat Florentiae rarus .

\section{C. GRANUIATS.}

Apterus, nigricans, elytris aeneis striatis, interiectis punctis elevatis longitudinalibus. F. Mant. 197. 25.

Apterus, niger supra aeneus, elytris tuberculis elevatis tri-plici ordine, sulcisque elevatis. Mon. Car. n. 9.

C. Gramulatus. Linn. Syst. Nat. 668, 2. Var. \%. Fin. Sv. 78i. Var. $\gamma$.

C. Convexepunctatus. De Geer Ins. 4. 88. 2.

Villers. Ent. 1. 367. in calce Observ.

Schaef. Icon. t. 18. f. 6. t. 46. f. 4. parva, et male picta. Magnitudo C. Clathrati, saepius minor. Caput nigrum nucha aenea. Thorax supra aeneus, subtus obscure aenco-niger, obcordatus, subtilissime punctatus, lincola longitudinali. Elytra aenea thorace latiora; sulcis tribus elevatis, intericctis tuberculis elongatis triplici serie : margine exteriore dilatato, punctato. Alarum rudimenta paulo quam in reliquis hujus familiae maiora, sed tamen volando minime idonea. Sternum, abdomen, pedes nigra. Variat basi antennarum, femoribusque ferrugineis . Mon. Car.

Var. B. Niger, elytris subvirescentibus, tuberculis clongatis triplici ordine, sulcisque elevatis. Mon. Car.

C. Gramulatus . Linn. Syst. Nat. 668. 2. var. B. Fn. Sv. 781 . var: $\beta, C$. Granulatiss.

Habitat cum praecedente cui simillimus. An var. sexus?

Var. $\gamma$. Niger elytris tuberculis clongatis, elevatis, triplici ordine, sulcisque elevatis.

C. Granulatus. Linnz. Syst. Nat. 11. 668, 2. var. \%. Fn. Sv. 781 . var. a. C. Granulatus.

Habitat cum praecedentibus, et apud nos frequentissimus. 


\section{C. LE U C O P H T H A L M U S.}

Apterus, niger, elytris decemftriatis, difco quadripunctatis, thorace femirotundato, poftice utrinque biftriato . Mom. Car. 22. 16.

C. Leucopbthalmus. F. Syst. Ent. 240. 23.

C. Leucopbthalmus. Linn. Syst. Nat. 668. 4. Fnr. Sv. 784. Geoff. Ins. 1. 146.7.

Scop. Ent. Carn. 266. Sclbrank. E. I. 396.

Fn. Etr. 1. 207. 511 .

Caput nigrum nitidum. Antennae apice fuscescentes. Thorax niger nitidus, convexus, marginatus, semirotundatus, antice latitudine fere elytrorum, postice angustior, utroque angulo bistriato. Elytra nigra, thorace opaciora, capite, thoraceque longiora, subconvexa, decemstriata striis profundioribus; in stria secunda a sutura utrinque puncta bina minutissima excavata, vix nudis oculis conspicua, quorum alterum fere in medio, alterum apici propius. Sternum nigrum nitidum. Abdomen dimidio corpore longius, nigrum nitidum. Pedes nigri. Obs. Carabus a De Geer Ins, 4. 26. I2. et a Fal. $\int p$. 304. 29. et Mant. Ins. 198. 41. sub nomine Leucophthalmi descriptus, C. Striatum, vel Nigritam sistere videtur, quia alatus. Mire hi omnes Carabi nigri ob negligentiam Authorum confusi sunt, licet certe specie differant, ct optimas differentias specificas praebeant. Nescio etiam qua ratione Auctores octo tantum strias hujus speciei numerant, et strias binas ultimas in margine exteriore omittunt, leviores quidem, nudis tamen oculis bene perspicuas . Mon. Car. l. i.

In meis speciminibus quae aptera sunt, et omnino conveniunt cum allata Monographiac descriptione, thorax non tantum postice utrinque bistriatus ( nota constantissima, qua a plerisque suae gentis optime distinguitur, ) sed etiam sulco Jongitudinali profunde exaratus, et margo elytrorum exterior conspicue' punctatus .

Habitat in putridis, et sub lapidibus frequens. 


\section{C. A U R O-P U N C T A T US.}

Alatus, niger, laevis, thorace postice emarginato, elytris subtilissime punctato-striatis, punctisque paullo majoribus triplici serie excavatis. Mon. Car. 21. 41.

C. Auro-punctatus. Herbst.

C. Indagator. F. Mant. 197. 35 ? affinis videtur, sed apterus ille, hic alatus; an a Cel. Auctore oculo modo fugitivo descriptus?

Fn. Etr. t. 1.f. 3. ad hunc Carabum pertinet. v. C. Hortensis.

Caput totum nigrum. Antennae apice fuscescentes. Thorax niger, laevis, marginatus, obovatus, longitudine fere duplo latior, lateribus rotundatis, antice truncatus, postice subcmarginatus. Elytra nigra thorace paullo latiora, subtilissime punctato-striata: punctis paullo majoribus, triplici serie excavatis. Sternum, abdomen, pedes nigra. Tibiae curvatae. Femina mari simillima, sed colore supra subvirescente punctis aeneis triplici serie; abdomine paulo latiore, tibiisque anticis brevioribus. Mon. Car.

In Svecia variat magnitudine paullo minore.

Habitat in pratis silvaticis, frequens $\mathrm{m}$. Jul. post focnisecium.

$$
\text { 176. C. TERRICOLA. }
$$

Niger, abdomine longiore, elytris subviolaceis, striatis, disco impunctatis, thorace obcordato, utrinque postice impunctato. Mon. Car. n. 17.

C. Terricola. Herbst. ap. Fuesl. Arch. Ins. 6. p. 140. 51. t. 29. $f: 14$.

Magnitudo C. Leacophtbalmi. Caput nigrum nitidum . Palpi, antennaeque fuscescentes. Thorax niger nitidus, obcordatus; lineola longitudinali, punctoque utrinque postice excavato. Elytra subviolacea, subdepressa, striata, difco impunctata, margine exteriore punctata, capite, thoraceque multo longiora. Sternum nigrum nitidum. Abdomen nigrum nitidum. Pedes nigri tarsis fuscescentibus. Mon. Car. l. c. 
Inter C. Apteros a Cl. Authore numeratus, at mea specimina semper alata.

Habitat cum aliis frequens.

\section{C. P U N C T U L A T U S.}

Niger, thorace quadrato, elytris ftriatis punctis plurimis longitudinalibus impreffis. Fr. Etr. 1. 2 1 5.530 .

Buprestis ater laevis, pedibus, antennarumque bafi ferrugineis. Geof. Ins. เ. I 6 I 39.

Car. Flavipes, niger, fubtus piceus, pedibus rufis, thorace subquadrato, elytris arcte juncto, elytris novem-striatis : ftriîs quatuor punctatis. Apterus. Mon. Car. n2. 2 I.

Habitus, et ftatura C. Melanocepbali, at duplo major. Descriptio Monograpbiae optima. Pedes in noftris plerumque rufo fuscescentes .

Habitat sub terra, et in ligno putrido obvius.

$$
\text { 178. C. ST R I A T U S . }
$$

Niger, tharace poftice foveola utrinque biloba, elytris ftriis novem profundioribus: punctis tribus difcoidalibus. Monz. Car. 21.26.

C. Nigro-striatus, alatus totus niger nitidus, elytris ftriatis. De Geer. Inss. 4. 96. 12.

C. Leucophthalmuss. F. Manit. 198. 4 r.

Caput nigrum. Maxillae, palpique picei . Antennae apice fufcefcentes : Oculi pupillati. Thorax niger nitidus, cordatus, marginatus, parum convexus, lineola longitudinali profundiori, foveolaque biloba utrinque in angulo pofteriore excavata. Elytra nigra convexa, marginata, novemftriata: punctis tribus minutiffimis in ftria tertia a margine interiore, quorum primum ad basin, fecundum in medio, et tertium apici propius est. Alae albohyalinae nervis flavescentibus. Sternum, abdomen, pedes nigra. Paullo minor $C$. Spinigero, seu C. Obsoleto. Fur. Etr. Magnitudo non variat. Confusus curn $C_{0}$ Leucophthalmo, ct C. Nigrita qui sane 
diversi. Differe enim a $C$. Lencoplothalmo magnitudine majori, thorace cordato, et clytris utrinque dilico tripunctato ; a C. Nigrita, magnitudine duplo majore, et thorace cordato ... Mon. Car l. . c.

Thorax in medio nonnihil complanatus, et corpus ac elytra minus quam in C. Leucopbtbalmo convexa; Nontrates tamen vix eum magnitudine superant, et pedes habent, forte ratione aetatis, fubrufos, in reliquis conveniunt omnino cam Svecis .

Habitat sub terra Martio $\mathrm{m}$. frequens .

\section{C. C I N C T U.S.}

Fufcus, capite, thoraceque viridi-aeneis, elytrorum margine, pedibusque pallidis. $F . \int p$. 310.62 .

Frr. Etr: 1: $212.523 . t$. 4. f. 9 .

Color capitis, thoracisque viridi-aeneus, elytrorum profundecyaneus. Magnitudo semper eadem. Confer Fn. Etr. lo.c.

Habitat hieme fub cortice Roboris; mox faepe lectus etiam in Ulmo.

\section{I80. C. RUFIGORNAS.}

Alatus, niger, antennis, pedibusque ferrugineis, thorace bafi fubretuso, fubrugoso, elytris ftriatis, fubtilifime punctatis, fubvillofis. Mon. Car. n. 74 .

C. Ruficornis. F. Mant. 199. 48.

Geoff. Ins. 1. 160. 38. Le Bupreste noir velouté.

Fn. Etr. 1. 213 . 526. t. 3. f. 7. C. Pulverulentus.

C. Cupreo longior, et latior. Caput nigrum punctis duobus frontalibus impreffis. Maxillae piceae. Antennae, palpique ferruginei. Thorax niger elytrorum latitudine, lineola longitudinali, antice glaber, poftice loco punctorum ordinariorum fubretufus, levifime rugofus. Elytra nigra ftriata, oculo armato undique fubtiliffime, confertifimeque punctata apparent; e puncto fingulo pilus brevifimus fubflavescens oritur : hinc elytra undique fubtilifime villofa, certo fitu 
flavicantia, micantia: margini infunt puncta nulla diftincta majora. Sternum, et abdomen piceo-nigra. Pedes flavoferruginei . Mas feminae fimillimus. Mon. Car. Habitat in ligno putrefcente, et fub lapididus rarior.

\section{C. VESTITUS.}

Subtus niger, fupra viridi-aeneus, antennis, pedibusque pallidis, elytris pubefcentibus, punctato-striatis, punctis majoribus nullis, limbo exteriore pallido poftice latiore. Mon. Car. n. 44 .

C. Marginatus. Linn. Syst. Nat. 670. 16.

Geoff. Ins. 1. 162. 41. Le Bupreste vert à bordure.

C. Marginatus. F. Mant. 202. 84. ab hoc diverfus, et a Linnaeo in Fn. Sv. 804 defcriptus.

Magnitudo C. 6-punctati . Caput nigrum fupra viridi aeneum, nitidiffimum, glaberrimum . Oculi nigri . Palpi pallide-ferruginei. Antennae pallidae longitudine dimidii corporis. Thorax latitudine longitudinis, fubtus niger, fupra viridi-aeneus pube tenuiffima linea longitudinali, punctoque utrinque bafeos. Elytra viridia ftriata, fubtiliffime punctata pube tcnuiffima certo fitu ferrugineo micanti penitus tecta; punctis difcoidalibus majoribus nullis limbo exteriore pallido, apice latiore. Alae albohyalinae. Sternum nigrum pube tenuiffima . Abdomen nigrum pube tenuiffima certo. fitu ferrugineo micanti. Pedes pallidi . Obs. Differt a C. Marginato, cui habitu, et ftatura fimilis, corpore pubefcente, elytris punctis difçoidalibus nullis, limbo poftice latiore teftaceo; $\mathrm{pe}-$ dibusque totis pallidis. Hanc fpeciem illuftris a Linné inz Syst. Nat. l. c. defcripfit; Marginatum vero in Fn. Sv. fub eodem nomine licet certe diverfae fint. Mon. Car.

Carabus hic cui competit omnino allata defcriptio, et magnitudo C. 6-puntciati rarior habitat apud nos. At contra occurrit alius frequens, in Fn. Etrusca fub nomine C. Margimati non recte defcriptus, qui mihi modo erit varietas $\beta$. C. Vestiti, nam si species ( uti videtur) diftincta, fane admodum proxima eft $C$. Vestito, cum differat tantum 
magnitudine duplo majori, thorace magis fubquadrato, elytrisque limbo exteriore pallido, poftice vix latiori .

Habitat fub lapidibus, et in truncis arborum cariofis. Var. $\beta$. quae in Mon. Car. defcribitur, mihi prorfus ignota.

\section{* 182. C. S P O L I A T U S.}

Long. 7. 1. Lat.: 2.: $\frac{2}{3} 1$.

Capite, thoraceque aeneis, elytris viridi-cupreis, limbo exteriore pallido, undique aequali, futura aeneo lucida.

Magnitudo C. Vestiti var. major ß., ejusdemque ftaturae, at thorax paullo anguftior, fere obcordatus. Caput aeneum nitens. Palpi rufi. Antennae in vivo piceae tribus primis articulis pallide rufis. Thorax aeneus nitens fere obcordatus, linea longitudinali, punctisque oblongis majufculis poftcis profundius excavatis. Elytra viridi-cuprea, ftriata, punctis difcoidalibus nullis, limbo exteriore pallido undique aequali, et ad imum suturae marginem aeneo lucida. Sternum, et abdomen etiam sub elytris nigrum. Pedes pallidi . Alae albae. Differt a C. Vestito var. major $\beta$.; antennis piceis primis articulis pallide-rufis; in C. Vestito totae pallidae rufae. Differt thorace paullo anguftiore, magis obcordato, elytris non pubefcentibus, non viridi-holofericeis, magis convexis, magisque ad cupreum vergentibus, futura aeneo-lucida, thoracique concolori; demum differt abdomine etiam in dorfo toto nigro; In C. Vestito var. $\beta$. Abdomen nigrum margine tamen fub elytris late pallido. Praetereaque in C. Spoliato elytrorum limbus exterior, pedesque paullo pallidiores, et fere albidi . Coloris diverfitas, thorax longior, et anguftior, et abdominis dorfum omnino nigrum, practer alias notas, differentiam conftantem fpecificam ftatuere videntur. Addendum quod C. Spoliatus rarior, et numquam inventus cohabitare cum C. Vestito.

Habitat in truncis putrefcentibus minime frequens. 


$$
\begin{aligned}
& \text { 83. C. N I G R I C O I N I S } \\
& \text { Long. 4. } \frac{3}{3} \text { 1. Lat. 2. 1. }
\end{aligned}
$$

Niger, thorace cupreo, elytris friatis, viridibus, pedibus piceis . F. Mant. 202.82.

Niger, laevis, thorace, capiteque aeneis, elytris ftriatis viridibus, punctis discoidalibus nullis: Mon. $C_{a} \%$. $\pi \%$. 70 .

Caput fupra viridi-aeneum nitidissimum, fubtus nigrum. Oculi, maxillae, palpique nigri. Antennae longiores nigrae primo articulo rufo. Thorax fupra aeneus, fubtus nigro violaceus, capite multo latior, oculo armato fubtilifsime punctatus, lineola longitudinali, punctisque ordinariis pofticis profundius excavatis . Elytra viridia ftriata, convexa medio thoracis antice haud latiora, punctis discoidalibus nullis'. Sternum nigrum . Abdomen, etian sub elytris, nigrum; rarius fubviolaceum. Pedes variant; interdum toti nigri: faepius femora rufa, tibiae, tarfique fuscescentes, interdum tibiae rufae. Mon. Car.

Statura, et habitus fere $C$. Holosericei, fed apud nos paulo minor, laevis, elytrisque uti in C. Vestito certo fitu ferrugineo-micantibus .

Habitat in pratis humentibus fat frequens.

$$
\text { * I 84. C. R } \mathrm{R} \text { F U s: }
$$

Obfcure rufus, thorace obcordato, elytris fubstriatis . Magnitudo C. Germani var. major. Totus obfcure-rufus, unicolor. Thorax obcordatus, convexus, poftice coarctatus, truncatus, vix marginatus, lineola longitudinali, angulisque pofticis impunctatis. Flytra convexa, fubstriata, non nitida, latitudine fere thoracis absque punctis marginalibus. A C. Ferrugineo diverfissimus.

Habitat in filvis, raro lectus.

$$
\text { 185. C. H U M E R A I I S . }
$$

Niger, thorace obcordato, elytris striato-punctatis, truncatis, antice rufis, pedibus rufo-flavis . Mon. Car. 23. 23. 
Magnitudo C. Excavati. Caput nigrum latitudine thoracis fubtilifime punctatum. Antennae, palpique rufi. Oculi prominuli, nigri. Thorax niger, cordatus, acute marginatus, antice, pofticeque truncatus, maxime convexus, fubtilissime punctatus, fine ullis punctis majoribus in angulo pofteriore excavatis. Elytra nigra antice ad quartam circiter partem totius longitudinis obfcure rufa, thorace latiora fubsilifsime punctato-striata, apice truncata, abdominis vix longitudine uti in C. Truncatello. Sternum, et abdomen obfcure rufa. Pedes rufo-flavi.

Var. $\beta$. niger, thorace obcordato rufo, elytris macula bafeos rufo-flava in margine exteriore, ore, antennis, pedibusque rufo-flavís. Mon. Car.

Noftrum fpecimen differt tantum magnitudine paullo majori, at in reliquís convenit.

Lectus in ligno putrefcente.

\section{* 186. C. S MA:A G U I U.}

Viridis, nitidus, thorace subquadrato, elytris striatis .

Magnitudo C. Aterrimi. Caput viride-nitidum, laeve, punctis duobus impreffis. Palpi, antennaeque fufcae primo articulo rufo. Thorax latitudine elytrorum, viridis nitidus, laevis, fubquadratus, poftice fubdepressus, lineola longitudinali vix apparente, ftriaque, feu potius puncto utrinque excavato. Elytra viridia, nitida, laevia, fubtilissime ftriata, impunctata, convexa. Subtus totus ater nitidus, plantis exceptis ferrugineo pilofis. Alatus. Variat magnitudine, pedibusque interdum rufis. Differt a $C$. Lepido femper aptero, alis, thorace una tantum ftria poftica impressa, et colore elytrorum laete viridi : qui in C. Lepido ad cupreum vergit .

Habitat fub lapidibus, et in ligno putrido frequens. 
187. C. S E X-P U N C T A T U S. Long. 4. 1. Lat. 1. $\frac{2}{3} 1$.

Capite, thoraceque viridibus, elytris cupreis. $F . \int p .309 .60$. Linn. Syst. Nat. 672. 35. Fn. Sv. 807.

De Geer. Ins. 4. 99. 16.

Geoff. 1. 149. 14.

Scbrank. E. I. 402.

Vill. Ent. 1. 372.6.

De Paykull Mon. Car. 21. 42.

Magnitudo C. Marginati. Caput viridi-aeneum, fubtus obscurius. Oculi, maxillae, antennae, palpique nigri. Thorax supra viridi-aureus, marginatus, fubtus nigro-caerulescens , longitudine paullo latior, poftice fubangustatus, puncto utrinque in angulo. Elytra rubra aenea, nitidifima, fubstriata; inter ftriam fecundam, et tertiam puncta utrinque fex longitudinalia excavata, margine virefcente punctulato. Alae albohyalinae puncto magno marginali fufco. Femora fusco-aenea. Tibiae, tarsique nigri. Var. B. Viridi-aeneus, elytris concoloribus, statura, et magnitudine omnino similis. Mon. Car. Haec apud nos frequentior.

Habitat in locis apricis. Inventus etiam fub arborum cortice tempore hiberno :

\section{* I88. C. TEN E B R I O I D E S. Long. 7. 1. Lat. 3. 1.}

Ater, thorace lato, elytrorum ftriis punctatis. Geoff. Ins. I. 15. 34. Le Bupreste paresseux.

C. Tenebrioides. Linn. Ed. XIII. 1986. 213.

C. Piger. Ent. Par. 42. Vill. Ent. 1. 377.63.

Statura lata undique fere aequalis, et magis convexa quam in plerisque fuae gentis. Caput nigrum, nitidum, minus exlertum. Palpi, antennaeque breves, fubrufae. Thorax niger, nitidus, latitudine elytrorum, valde convexus, fubquadratus, marginatus, antice laevis, postice punctulatus. foveola utrinque leviter imprella. Elytra nigra, admodum 
et aequaliter convexa, ftriata, ftris novem minutifsime punctatis, extremo apice emarginato. Sternum, et abdomen nigra nitida. Pedes nigri, breves, praefertim antici tibiis apice latiufculo, fpinisque crafsis inftructo. Alatus. Variat magnitudine, abdomine, tibiis, tarfisque fubrufis .

Habitat in arenosis, et fub lapidibus frequens.

\section{C. DEN T A T US .}

Cyaneus, thorace cylindrico fubaequali, ore, antennis, pedibusque rufis. Fn. Etr. 1. 222. 55 I. t. 2. f. 11.

Curabum hunc ad Cicindelae genus referendum efse credant alii; mihi est, femperque erit Carabus; nam facies, habitatio, vivendi modus, incefsus, aliaque inter Carabos naturaliter ftatuere videntur.

Habitat fub Ulmi cortice in truncis emortuis .

$$
\text { * 190. C. DISTINCTUS. }
$$

Teftaceus fubpilosus, abdomine, elytrorumque fafcia longitudinali futurae communi atro-caeruleis.

Statura, et magnitudo C. Dentati. Caput teftaceum . Oculi nigri. Palpi, antennaeque teftaceae articulo primo praelongo apice nigro uti in C. Dentato. Mandibulae pariter uti in illo exfertae, clongatae, teftaceae. Thorax anguftus elongatus, fere cylindricus, emarginatus, teftaceus. Elytra punctato-ftriata, integra, teftacea, fafcia longitudinali futurae communi atro-caerulea. Pectus, pedesque teftacea. Abdomen atro-caeruleum. Alae albae. Etsi habitu, et magnitudine fere fimilis C. Crepitanti, Caraboque Dentato; attamen ab iis omnino diftinctus. Differt enim a $C$. Crepitante forma capitis, antennaramque articulo primo longifsimo, thorace emarginato, elytris teftaceis, fafcia \&c. A C. Dentato differt colore prorfus diverfo, thorace non canaliculato, elytris integris .

Habitat cum aliis exefas arbores. Raro lectus hieme. 


\section{C. $G$ E $M A$ N U S . \\ Long. 3. $\frac{1}{3}$ 1. Lat. 1. $\frac{1}{2}$.}

Cyaneus, capite, elytris, pedibusque teftaceis, elytris apice violaceis . F. Sp. 312. 71. Mant. 204. 102. Linn. Syst. Nat. 672. 26.

C. Germanus. Scop. Ent. Carn. 273.

Scbrank. E. I. 403.

Poda M. G. p. 273.

Fir. Etr. 1. 212.522.

Schaef. Ic. t. 31. f. 13. citata a Fab. aliisque pertinet ad C. Viridanum.

Defcriptio Scopolina optima, at in noftris, pedes non thoraci, fed femper elytris concolores, fcilicet teftacei. Diximus in Fr. Etr. l. c. variare interdum capite nigro ; nunc autem, re melius confiderata, non omittendum dubium, fere ad certitudinem redactum, hunc Carabum huc usque a nobis pro varictate $C$. Germani habitum, fpeciem fortas$s e a b$ eo effe diftinctam : Hic enim quamvis habitu, et ftatura $C$. Germano fimillimus, attamen revera conftanter differt magnitudine, capite atro, thoracis lateribus pofticis non extrorfum, neque acute angulatis ati in Germano, fed obtufis; macula elytrorum violacea non acuminata, maximamque eorum parten occupante. Praeterea C. Germannss frequens hieme fub arborum cortice, lignoque putrido; hic eo tempore raro, ant numquam inventus, etsi alio occurrat faepifsime: Addendumque quod in hac fpecie, aut varietate vidi, et allervo fimile cum fimili copula junctum. Habitat in filvis frequens.

$$
\text { 192. C. EXHALANS. }
$$

Capite, thorace, pedibusque rufis, elytris truncatis, nigro caeruleis, maculis duabus flavis .

Statura, et magnitudo omnino. C. Crepitantis, cujus videtu efle varietas elegantifsima, ac fingularis : Differt enim tantum elytris maculatis, maculis in fingulo elytro binis, altera 
pope bafin, altera pone medium fubrotundis flavis. In $C$. Crepitante qui apud nos frequens copiosus occurrit, abdomen obfervatur in vivo modo obfcure-nigrum, modo rufum. In individuis magnitudine ninoribus, rufum; in majoribus ( fortafle feminis ) opacum nigrum. In hac noftra varietate tamen, quamvis minores aequiparet, abdomen opacum nigrum.

Habitat fub terra cum C. Crepitante Mart. m. rarus .

$$
\text { * 193. C. PS M M ODES. }
$$

Niger, fubdepreffus, capite, thorace, limbo elytrorum, antemnis, pedibusque livide-rufis .

Statura C. Arenarii, at minor. Caput rufum . Oculi nigri . Palpi, antennaeque rufae longiores. Thorax fuperne, et inferne rufus, obcordatus, convexus, fubmarginatus, lineola obsoleta longitudinali, punctisque pofticis ordinariis impressis. Elytra nigra, fubdeprefsa, ftriata, ftriis oculo armato punctatis, limbo exteriore, pofticogue rufo. Abdomen nigrum. Pedes rufi. Alatus. Limbus rufus poftice latior. Differt a C. Sabuloso. F. Mant. 47. a Car. Livido. Linn. Fn. Sv. 791. et a C. Sabuloso. Mon. Car. n. 28. cum in noftris caput, thoraxque fint omnino rufa, et elytra nullo modo dici possint fubtilifsime friato-punctata, punctis quibufdam difcoidalibus, uti in Mon. Car. lo c. afseritur.

Habitat Florentize rarus.

$$
\begin{aligned}
& \text { 194. C. A } \times \times R R 1 M U S \text {. } \\
& \text { Long. 6. } 1 . \text { Lat. } 1 . \frac{3}{4} 1 \text {. }
\end{aligned}
$$

Niger, nitidifsimus, thorace convexo, elytris levifsime punctato-ftriatis: punctis utrinque tribus difcoidalibus majori* bus. Mon. Car. n. 78 .

C. Aterrimus. Herbst ap. Fuesl. Arch. Ins. 6. 140. 50. t. 29. $f .13$.

C. Oblongo-punctatus. Fin. Etr. 1. 214.528.

Caput nigrum moch nitidifsima. Thorax dorfo nitidifsimus, 
convexus, marginatus, antice acute, poftice obtufe angulatus, lineola longitudinali ; poftice loco punctorum ordinariorum profunde excavatus. Elytra nigra nitidifsima, thorace vix latiora, convexiora, levifsime friato-punctata : striis opacioribus, unde nudis oculis perfpiciuntur; in fingulo elytro puncta tria profundiora nudis oculis optime perfpicua, quorum duo in ftria fecunda a margine interiore, alterum in medio, alterum poftice, et tertium bafi propius in fria tertia: margo exterior etiam punctis nunoribus, inermi tamen oculo confpicuis adornatur. Sternum, abdomen, pedes nigra nitida. Obs. Totus fupra nitidifsimus, quafi oleo unctus. Cacterum etiam a $C$. Striato differt thorace fubquadrato ; et a $C$. Nigrita elytris convexioribus, levifsime punctato-striatis, punctisque difcoidalibus majoribus, nudis ocu lis optime perfpicuis. Mon. Car. l. c:

Habitat in filvis primo vere non rarus.

$$
\text { 195. C. P O T E U }
$$

Lacvis, cylindricus, thorace punctis ordinariis laevioribus, elytris ftriatis, difco impunctatis . Mon. Car. n. 72.

$$
\text { C. Aeneus. F. Mant. 202.81. }
$$

Paulo minor C. Cupreo. Caput crafsum ferrugineum bafi ad collum aeneum. Antennae, palpique teftacei. Maxillae validae ferrugineae apice obfcuriores . Oculi cinerefentes. Thorax undique elytrorum latitudine, fubtus teftaceus, fupra aeneus linea longitudinali, punctoque poftico utrinque unico leviter excavato. Elytra friata, capice, thoraceque vix longiora, viridi-acnca punctis difcoidalibus nullis. Alae albohylinae nervis fufcefcentibus. Sternum, abdomen, pedes teftacea. Mon. Cár.

Habitat in Svecia Aufrali . Mihi numquam lectus.

Hic Carabus admodum variat, uti videre est in Mon. Car l. l. ca Varietates in.ea indicatae, quae apud nos occurrunt, et quas ego inveni, funt fequentes.

Var. \&. Subtus niger, fupra cyaneus, antennis, pedibusque rufis : $M: C$. 

C. Azureus . F. Mant. 201. 71.
C. Azureis. Fin. Etr. 1. 222. 550.

Pedes, et antennae interdum fufcelcentes. De hoc tamen licet ne mihi dubitare an revera fit $C$. Protei varietas? Forma thoracis paullulum diverfa, punctaque poftica magis $\mathrm{ex}$ cavata :

Habitat in locis arenosis non frequens .

$V a r . \epsilon_{\text {. Niger }}$, pedibus, antennisque rufis . M. C.

Car. Latus. De Geer. Ins. 4. 100.

Geoff. Ins. 1. 160. 37.

Schrank. E. I. 211. 397. C. Latus, sed major.

Communis .

Var. и. Niger, thorace fupra, elytrisque viridi-aeneis, pedibus, antennisque rufis. $M$. $C$.

C, Affinis. Schrank. E. I. 2 I 2. 399.

Variat pedibus antennisque piceis. Long. 5. $\frac{x}{2}$ 1. Lat. 1. $\frac{2}{3} 1$. Habitat fub lapidibus, et in truncis arborum fat frequens.

$$
\begin{aligned}
& \text { 196. C. A S S I M I L Is. } \\
& \text { Long. 4. } \frac{1}{2} \text { 1. Lat. 2. 1. vix. }
\end{aligned}
$$

Niger, thorace capite longiore, poftice impunctato, elytris ftriatis, margine punctato. Mon. Car. 2.32.

Habitus, et ftatura $C$. Nivalis $M$. C. Caput, palpi antennaeque nigra. Thorax capite longior, antice, non vero poftice latior, convexus, acute marginatus, lineola longitudinali in nostris impressa, angulisque pofticis impunctatis. Elytra nigra, fubconvexa, ftriata, margine exteriori punctulato, punctis utrinque tribus minutifsimis in Atria tertia a futura. Abdomen, pedesque nigra. Alae albae. Mon. Car.

Habitat cum praecedentibus frequens.

$$
\text { 197. C. O в S C UR Us. }
$$

Niger, fupra obfcure nigro-fubaeneus, elytris ftriatis, difco utrinque tripunctato. Var. Morr. Car. 2.45 . fufe, optimeque defcriptus. Conf. 
Statura, et magnitudo C. Mendacis Fn. Etr. et fere C. Picipedis. Thorax laevifsimus longitudine paulo latior, convexus, vix marginatus, lineola longitudinali, punctisque pofticis excavatis. Inter ftriam fecundam, et tertiam elytrorum, puncta tria minutifsime excavata, margine etiam externo punctato. Pedes nigri. Variat colore interdum magis nigro, interdum magis cyaneo.

Habitat cum C. Crepitante, Viridane, aliisque juxta fepes tempore hiemali fub terra degens.

$$
\begin{aligned}
& \text { I98. C. I NEIDUS. } \\
& \text { Lonig, 5. } \frac{1}{4} \text { Lat. 2. } \frac{3}{4} \text {. }
\end{aligned}
$$

Niger, nitidus, thorace femirotundato, elytris fubdeprefsis, punctato-striatis, antennis, tibiisque ferrugineis .

An C. Depressus. Mon. Car?

C. Pilicornis. Fn. Etr. qui omnino delendus .

Facies C. Spinibarbis, fed duplo major . Palpi, antennaeque ferrugineae, bafi nitidiores, pilis longioribus hirtae. Thorax fufco-niger nitidus, orbiculatus, antice, pofticeque anguftatus, marginatus, punctulatus, fulco longitudinali convexitatem quafi in duos lobos dividente. Elytra fufco-nigra nitida, fubdeprefsa, 9-striata friis confertifsime punctatis, punctis quatuor utrinque in tria fecunda paulo majoribus longitudinaliter excavatis, interdum vix perfpicuis. Pedes fubrufi. Femora plerumque nigra. Alae albae Junior variat colore fufco-rufo. Variat etiam magnitudine minori. Habitat fub corticibus, et in truncis cariofis primo vere frequens .

\section{C. A G I wis.}

Thorace rotundato, rufus, elytris, abdomineque nigris. $F$. Mant. 204. 99.

C. Agilis, rufus, abdomine poftice fufco, elytris deprefsis fuscis, truncatis, ftriatis. Mon. Car. 3. 64. 
Magnitudo C. Viridanum aequiparat . Caput rufum. Oculi nigri. Thorax rufus, marginatus, lineola levifsina longitudinati, pilis quibusdam majoribus, longioribus marginalibus . Elytra fufca deprefsa, ftriata, truncata, abdomine brevio$\mathrm{ra}$; angulo pofteriore obtufo, anteriore acuto. Alae albae macula marginali fufca. Sternum rufum. Abdomen rufum apice fufco. Pedes rufo-flavi. Admodum variat. Confer Mon. Car. l. c.

Var. $\gamma$. Fufcus, fubtus abdomine excepto, maxillis, antennis, pedibusque rufo-flavis, elytris puncto medio pallido; apud nos frequens.

Habitat in foliis arborum convolutis,

$$
\text { 200. C. O } \vee \text { A T U s . }
$$

Ovarus, thorace antice capitis, poftice elytrorum latitudine, utrisque adnato, elytris friatis, punctis difcoidalıbus nullis . Mon. Car. 21. 81 .

C. Vulgaris. Var. ß. Linn. Fn. Sv. 799.

C. Vulgaris . Fn. Etr. 1. 209. 515.

Caput nigrum. Oculi pupillati. Antennae faepius bafi rufefcentes . Thorax bafi latitudine capitis poftice latitudine elytrorum convexus, vix marginatus, lineola longitudinali, punctisque ordinariis rarius duplicibus, laevioribus. Elytra nigra, antice truncata, thorace arcte juncta, ftriata, dimidio corpore longiora; margine exteriore fubpunctato, punctis difcoidalibus nullis. Alae albae venis nigris macula marginali fufca. Subtus totus niger .

$V a r$. $\beta$. Supra obscure-aeneus, fubtus cum antennis, pedibusque piceus. C. Vulgaris var. a. Limn. Syst. Nat. 675. 27. Ed. XI. Fn. Sv. 799 .

Var. $\gamma$. Supra viridi-aeneus, fubtus niger.

Var. \&. Supra nigro-caerulefcens, fubtus niger nitidus. C. Aemeus. De Geer Ins. 4. 98. 15.

Obs. Omnes hae varietates habitu, et ftatura fimillimae, fed magnitudo fpeciei variat. Jam longitudo C. Protei, jam duplo fere brevior; femper vero ratione magnitudinis multo latior eft. Mon. Car. l. G. 
C. Metallicus. Scop. E. Cam. 270. videtur referendus ad varietatem $\delta$.

Habitat fub lapidibus frequens.

$$
\text { * 20I. C. V OTIVUS. }
$$

Niger, nitidus, thorace vix marginato, elytris ftriatis, punctis difcoidalibus nullis, antennis ferrugineo-flavis .

C. Nigritae affinis, fed minor. Caput nigrum nitidum . An: tennae flavefcentes. Thorax niger, nitidus, vix marginatus, fubquadratus, lineola longitudinali, punctisque pofticis ordinariis impreffis. Elytra nigra nitida, ftriata, punctis difcoidalibus nullis. Sternum, et abdomen nigra. Femora nigra. Tibiae, tarfique ferruginei. A C. Nigrita diftinguitur thorace vix marginato, punctisque difcoidalibus nullis. Habitat in truncis arborum cariolis .

$$
\begin{aligned}
& \text { *202. C. V E L O C I P E } 6 \text {. } \\
& \text { Long. 2. 1. Lat. } \frac{3}{4} 1 \text {. }
\end{aligned}
$$

Ater fubaeneus, elytris punctato-ftriatis, antennis nigris, pedibus pallide-rufis .

C. Rufppedi M. C. affinis, cujus forte varietas. Antennae nigrae primis duobus articulis rufis. Caput atrum fubaeneum nitidiffimum. Thorax ater fubaeneus, nitidus, cordatus, lineola longitudinali, punctoque poftico utrinque excavato, latitudine dimidia elytrorum. Elytra atra fubaenea, nitida, punctato-feriata. Femora atra fubaenea. Tibiae, tarfique pallide-rufi. Alae nigrae.

Habitat fub corticibus .

$$
\text { 203. C. R U F I P E S. }
$$

Supra obfcure-subaeneus, fubtus niger pedibus rufis, thorace glaberrimo, elytris integris, fubtilifime punctato-ftriatis. Mon. Car. n. 63. 
Magnitudo C. Bipunctati. Antennae nigrae. Caput totum nigrum occipite obfcuro fubaeneo. Thorax glaber vix marginatus lineola dorfali levifime impreffa, punctisque ordinariis impreffis. Elytra obfcure-subaenea fubtilifsime punctato-ftriata. Femora rufa tibiis, tarfisque pallidioribus .

Habitat cum praecedentibus.

$$
\text { 204. C. D O R S I IS. }
$$

Thorace rotundato nigro, coleoptris pallidis, macula magna dorfali nigra. F. Mant. 205 . 116.

Parvus; Caput atrum, nitidum . Thorax ater nitidus, orbiculatus, margine tenuiffime pallefccnte. Elytra fubtilifime ftriata, nitida, pallida, macula dorfali nigra fere communi. Corpus nigrum. Pedes ferruginei. Antennae, in noftris, fufcae, bafi ferruginea. Confer C. Meridianum var. $\gamma$. Mon. Car. D. de Paykull.

Habitat fub foliis putridis frequens.

$$
\text { *205. C. ER R A T U S }
$$

Niger, thorace orbiculato rufo, coleoptrisque flavis, fafcia media nigra ad utrumque marginem dilatata .

Statura C. Turcici, at major. Caput nigrum nitens. Antennae fufcefcentes articulo primo, et fecundo ferrugincis. Thorax rufus, orbiculatus, marginatus, angulis pofticis paullulum productis, lineolaque dorfali vix impreffa. Elytra minus convexa, tenuifime fubftriata, apiceque oblique truncata, flavva; fafcia media tranfversa nigra, quae ad futuram, et marginem exteriorem, apicemque adeo extenditur ut fpatium margine nigro cinctum, feu maculam fubrotundam flavam utrinque conftituat. Abdomen nigrum. Pedes faepius rufi, interdum nigri. Differt a C. Turcico magnitudine majori, colore, macula poftica apicis flava . A C. C. Minori, differt etiam ftatura, capite anguftiore, thorace magis orbiculato, fafcia minus lata, elytris truncatis. \&c. 
Heic autem fatendum hunc Carabum male a me affumptum fuiffe in Fn. Etrusca pro C. Andreae, cui thorax juxta Cl. Fabricii diagnolin niger est, non rufus; proindeque mirum videri me nec poffidere, nec umqquan vidifle hanc fpeciem, quae pró Italica habetur.

Habitat cum aliis rarior.

\section{LXXIII. $S C A R I T E S$.}

Palpi sex filiformes. Labium corneum dentatum. Antennae moniliformes.

$$
\text { * 206. S. D A M A. }
$$

Niger, thorace obcordato, capitis clypeo bafi bituberculofo, apice utrinque cornuto, cornibus erectis, excavatis, compreffis, biramofis .

Diximus in Fn. Etrusca. 1. 228. 571. Sc. Calydonium variare magnitudine minori, maxillis cornutis; at re melius perpenfa, varietas ibi indicata modo fpecies diftincta videtur; nam etfi ftatura eadem, magnitudo tamen quadruplo minor, et caput, uti in diagnofi, omnino diverfum. Reliqua omnia in utraque fpecie fimilia.

Habitat in arenofis.

\section{TENEBRTOV}

Palpi quatuor inaequales; antici fubclavati, postici filiformes. Maxilla bifida . Labium truncatum, integrum . Antennat moniliformes.

$$
\begin{aligned}
& \text { *207. T. C O R N IF R O N } \text {. } \\
& \text { Long. 2. } \frac{2}{2} \text { 1. Lat. I. } \frac{1}{5} \text { l. }
\end{aligned}
$$

Oblongus, ruber, nitidus, elytris nigris: capite bicorni .

Statura, et magnitudo omnino S. Rezssicae Fn. Etr. 1. 136. cui primo intuitu adeo fimilis, ut facillime cum ea confundatur. 
Conf. fig. pag. 3. Tom. I. Conf. etiam A. Rubrum. De Geer Ins. 5. 283 . 1. t. 8 . $f$ : 12. Caput rufum fronte admodum excavata, et corniculis duobus elevatis rufis inftructa. Palpi quatuor inaequales, antici fubclavati, poftici filiformes, rufi. Antennae breves, rufae, moniliformes. Oculi nigri . Thorax rufus, nitidus, laevis, convexus, fubmarginatus. Elytra nigra, nitida, extremo apice rufa, convexa, fubtilifinme punctato-ftriata, ftriis in fingulo elytro novem. Sternum, abdomen, pedes rufa. Alae albae. Frons in altero fexu inermis. Differt a $S$. Russica, capite cornuto, antennis brevioribus, apiceque minus clavato, ftriis elytrorum diftinctioribus, abdomine toto rufo. \&c.

Habitat in quifquiliis, et truncis arborum cariofis, rariflimus.

$$
\text { 208. T. MA U R I T A I C U S . }
$$

Alatus niger, fubtus piceus, thoracis marginibus antice, pofticeque dente angulatis. Linn. Syst. Nat. 674. 4.

Trogossita Mauritanica nigricans, fubtus picea, elytris ftriatis. Oliv. Ent. 19: 2. 1. t. 1. f. 2. A. B.

Geoff: In. 1. 64.5 .

Dorth. Mem. d'Agric. a. $1787 \cdot$ p. 64. f. 1.2.

Fn. Etr. 1. 232. 579. t. 7. f. 15 .

Habitat fab arborum cortice frequens.

\section{LXXXIV. $M Y L A B R I S$.}

Palpi quatuor filiformes. Maxilla cornea, compreffa, bifida. Labium membranaceum, fubemarginatum. Antennae moniliformes. 209. M. TESTACEA:

Teftacea, pectore, elytrorumque apicibus nigris. F. Manto 217.8.

Praeter ea quae diximus de $L$. Afra, et $M$. Testacea in Fn. Etr. 1. 240. 594. et in Append. addendum varietatem elytris 
94 Clas. 1. Eleuterata. Mylabris.

totis nigris variare interdum etiam capite, pedibusque nigris .

Habitat in floribus Dipfaci Fullonum frequentiffima .

$$
\begin{aligned}
& \text { *210. M. F U L V A. } \\
& \text { Long. 5. } \frac{x}{2} \text { 1. Lat. I. } \frac{3}{4} \text { 1. }
\end{aligned}
$$

Nigra, thorace rufo-flavefcente, elytris faturate-teftaceis.

Statura $M$. Testaceae, at dimidio major, ac diftinctiflima. Caput atrum nitidum, glabrum, tenuifime punctulatum, inflexum. Palpi quatuor inaequales, filiformes nigri . Antennae nigrae filiformes i 1 -articulatae. Thorax rufo-flavefcens nitidus, glaber, omnino conformatus uti in $M$. Testacea. Scutellum nigrum . Elytra faturate-teftacea, laevia, flexilia, vix pubefcentia, integra, fed abdomine paulo breviora. Sternum, abdomen, pedes atra. Alae obfcurae. Abdomen craflum ventricosum; forte femina?

Non leviter admiranti mihi prodiit e pupa obtecta putamine proprio oviformi ferrugineo, ftigmatibus utrinque longitudinaliter impreflo, quam inveni abrupto nido Ap. Variantis ( $\operatorname{conf} f$. ) in ejus medio litam prope cellulas, ubi nefcio quomodo introducta larva, veluti in apto fibi domicilio una cum Apibus l.c. defcriptis, metamorphofin fubierat.

\section{MORDELLA.}

Palpi quatuor inaequales : antici clavati, postici filiformes. Maxilla bifida. Labium membranaceum bifidum . Antennae moniliformes.

211. M. A B D O M N A I S .

Ano aculeato, nigra, thorace, abdomineque fulvis. $F . \int p$. 333. 10.

Statura M. Aculeatae. Caput, pectus, elytra, fpina analis, pedes atra. Thorax, et abdomen fulva, immaculata, nitida. Lecta in floribus. 
212. M. F R O N T A I I S .

Atra, fronte, pedibusque flavefcentibus. $F \cdot \int p \cdot 333.12$. Limn. Syst. Nat. 682. 4. Fir. Sv. 834.

Parva, frons flava, et pedes praefertim antici flavi.

Habitat in floribus.

$$
\text { *213. M. NIGRA. }
$$

Nigra, unicolor, antennis bafi flavefcentibus,

Statura, et magnitudo $M$. Flavae. Caput, et thorax minora, minusque gibba quam in $M$. Aculeata. Thorax fuborbiculatus. Antennae prorfus moniliformes, nigrae primis articulis flavefcentibus. Anus absque aculeo.

Habitat in floribus.

\section{STAPHYLINUS.}

Palpi quatuor filiformes. Maxilla unidentata. Labium membranaccum, trifidum. Antennae moniliformes.

$$
\text { 2i4. S. H I R T US. }
$$

Hirfutus, niger, thorace, abdomineque poftice flavis. $F . \int p$. 334. 1. Linin. Syst. Nat. 683. 1. Fu. Sv. 839.

Stapbylinus niger, villofus, capite, thorace, anoque pilis flavis aureis. Geoff. Ints. 1. $363 \cdot 7$.

Staphylinus Bombylius. De Geer Ins. 4. 20. 5.

Staphylinus Hirtus. Mon. Staph. 21. 1. descriptio optima. Stilz. Hist. Ins. t. 7. f: 16 .

Scbaef. Icon. t. 36. f. 6. Monog. 1754 t. 2. f. 12.

Inter maximos numerandus, facillimeque dignofcendus. Lanugo aureo-flava interdum aetate deteritur.. Habitat in fimo, et ftercore bovino fat frequens in locis filvaticis arenofis. 


\section{S. C Y A N E U S .}

Long. 7. 1. Lat. 1. $\frac{3}{2} 1$.

Niger, capite, thorace, elytrisque cyaneis. Mon. Stapb. n. 7. S. Atro-caerulescens. Geof. 1, 36 r. 2.

Magnitudo, et ftatura St. Erytbropteri. Caput thorace latius, fupra cyaneum, fubtus nigrum nitidum. Oculi difco nigri, margine pallidi. Maxillae palpique nigri. Antennae filiformes, capite duplo longiores, nigrae. Thorax longitudine capitis, convexus, antice obtufus, poftice rotundatus cyaneus. Elytra cyanea longitudine thoracis. Scutellum nigrum. Sternum nigrum. Abdomen nigrum elytris plus duplo longius. Pedes nigri .

Habitat apud nos rarior.

$$
\begin{aligned}
& 216 . \text { S. B I C I N C T U S } \\
& \text { Long. } 7: \frac{x}{3} 1 \text { Lat. 1. } \frac{1}{2} 1 .
\end{aligned}
$$

Niger, capite, thorace, elytrisque profunde cyaneis, abdomine atro, ultimis duobus fegmentis basi late aureo holofericeis :

Praecedenti proximus, ejufdemque magnitudinis ac ftaturae, at magis affinis St. Morsitanti Fn. Etr. 1. 614.

Caput bafi latitudine fere thoracis, ad latera poftica fubangulatum, punctulatum fufco-cyaneun . Palpi rufi . Antennae filiformes, nigrae bali rufa, apice acuto cinereo-rufo, capite vix duplo longiores. Thorax fufco-cyaneus, punctulatus, capite longior, et paulo latior, antice truncatus, angulatus, poftice rotundatus. Elytra fufco-cyanea, punctulata, thorace paulo longiora. Scutellum nigrum. Abdomen elytris plus duplo longius, atrum, ultimis duobus fegmentis bafi, lanugine aurea nitente late fafciatis. Subtus totus niger pedibus exceptis omnino rufis. Fafciae vix marginem exteriorem attingunt, et in mortuo, fegmentis contractis, maximam partem occulțantur.

Lectus in Fraxini Orni ligno putrefcente. 
217. S. P U B E S C E N S .

Pubefcens, capite flavo, thorace, elytrisque fufco, nigroque nebulolis; punctis imprefsis. Geoff. Ins. 1. 363. 8.

S. Pubescens niger nebulofus, capite, femoribusque annulo flavo-ferrugineo, abdomine obfcuro . Mon. Staph. n. 9.

S. Pubescens. De Geer Ins. 4. 17. 2.

S. Ocbrocepbalus. Ed. XIII. Linn. 2034.85.

S. Chrysocephalus. Ent. Par. 1. 166.8.

Statura, et magnitudo fere S. Murini . Caput flavun, pubescens, deprefsum, latitudine thoracis, collo pariter flavo. Palpi, maxillaeque nigrae. Antennae capite paullo longiores, extrorfum crafsiores, bafi flavae, fex ultimis articulis nigris. Thorax capite longior, antice truncatus, poftice rotundatus, fufco, nigroque nebulofus, lanugine fubferruginea. Elytra thorace longiora, fufco nigroque nebulofa. Abdomen elytris vix duplo longius, dorfo nigro fubferrugineo, apice obtufo, ad latera lanuginofum. Subtus cinereo-pubefcens, nigro punctulatum, pube certo fitu holofericea, et ad fegmentorum margines laciniata. Pedes fufco-nigri, femoribus ferrugíneo-annulatis .

Habitat in fimo rarus.

\section{S. TOMENTOSUS.}

Fufcus, pubefcens, pedibus, thoracis lateribus, elytrorumque bafi pallidis, penultimo fegmento abdominis, reliquis haud longiore. Mon. Car. App. pag. 138.

Caput thorace anguftius, nigrum, minutum. Palpi pallidi. Antennae capite, thoraceque longiores. Thorax magnus, convexus, fufcus lateribus pallidis, undique hirfutia brevisfima tectus. Elytra capitis, thoracisque longitudine, fufca, 
tenuifsime villosa; bafi macula pallida futuram haud attingente. Sternum fufcum. Abdomen fulcum, in vivo conicum, acuminatum longifsimum. Pedes pallidi. Magnitudo, et ftatura $S$. Disparis, a quo differt corpore omnino pubefcente, et penultimo fegmento abdominis breviore.

Var. B. Fufcus, pubefcens, pedibus pallidis : habitat cum varietate praeced. cui fimillimus, ut feparari nequeat. Mosz. Car. l. c.

Habitat uterque apud nos in putridis .

\section{S. CANAIICULATUS.}

Flavus, capite, abdominisque cingulo atris, thorace canaliculato. F. Mant. 221.29.

S. Canaliculatus rufo-flavus, capite, abdominisque apice nigris, thorace poftice canaliculato. Mon. Staph. iz. 23.

P. Impressus . Fu. Etr. 1. 254. 627. Corrige S. Camaliculatus. Parvus; Caput nigrum thoracis latitudine. Antennae extrorfum crafsiores, capite, thoraceque longiores, bafi rufo-flavefcentes, apice fufcae. Palpi aequalcs, filiformes, rufoflavefcentes. Thorax flavo-rufescens, rotundatus, poftice medio canaliculatus, elytrorum longitudine. Sternum rufoflavefcens. Elytra breviora, flavo-rufescentia. Abdomen marginatum, reliquo corpore longius, bafi rufo-flavum, apice nigrum. Pedes rufo-flavi. Color rufo-flavus interdum magis obfcurus. Mon. Staph. l.. .

Habitat in ligno putrido, frequens .

\section{S. C L A V I OR NIS.}

Niger immaculatus, thorace rotundato laevi, antennis extropfum cralsioribus. F. Mant.221.21.

Staph. Juno ater oculis prominentibus crafsis. Geoff. Ins. I. 371. 24 .

Staph. Buphtbalmos. Niger immaculatus, oculis magnis exfertis. Scbrank. E. I. 445 . 
Stapb. Juno. Niger oculis nagnis prominentibus antennis clavatis. Moni. Staph. 3n. 25.

Fn. Etr. 1. 252623 .

Caput nigrum breve, thorace latius, fubtilifsime punctatum. Oculi magni valde prominuli. Palpi aequales longiores. Antennae nigrae longitudine thoracis, bafi tenuifsimae; interdum flavicantes, quatuor ultimis articulis crafsioribus. Thorax niger, cylindricus, fubtilifsime punctatus capite, et elytris praefertim anguftior. Sternum nigrum. Elytra breviora nigra poftice retufa, fubtilifsime punctata. Abdomen nigrum cylindricum longitudine dimidii corporis. Pedes nigri, interdum flavi, geniculis modo nigris; rarius flavi immaculati. Variat elytris puncto flavo. Monz. Stapjb. l. c. Magnitudo praecedentis, at paulo latior.

Habitat fub arborum cortice frequens.

\section{* 221 . S. P A L I I D U S .}

Pallide-flavus, pilofus, capite, elytrorumque pofticis nigris. Statura, et magnitudo S. Tomentosi. Caput nigrum nitidum, thorace anguftius. Antennae nigrae, basi flavae, ad apicem crafsiores, longitudine capitis, atque thoracis. Thorax pallide-flavus, parum convexus, rotundatus, emarginatus angulis obtufis, poftice latior, fed magnitudine cedit thoraci S. Tomentosi. Elytra pallide-flava, laevia, pilofa, capitis, thoracisque longitudine, apice macula magna nigra, quae tamen marginem interiorem haud attingit. Abdomen rufoflavum, pilofum, incurvum, apice obtulo. Subtus una cum pedibus omnino pallide-flavus.

Habitat in putridis, et fub arborum foliis disiectis.

$$
\text { 222. S. } O \text { R B I C U L A T U S : }
$$

Niger, thorace convexo, orbiculato, antennis, palpis pedibusque fuffo rufefcentibus. Mon. Staph. n. 26 .

Caput nigrum, fupra infraque convexum, orbiculatum thorace latius. Antennae filiformes vix capitis thoracisque 
longitudine . Palpi fufco rufefcentes. Thorax niger, orbiculatus, convexus, capite elytrisque anguftior, profunda incifura $a b$ illis difiunctus, ut tenuifsine illis adhaereat. Elytra nigra quadrata, thorace longiora, et latiora. Sternum nigrum. Abdomen nigrum vix thorace, elytrisque longius. Pedes fufco-rufefcentes. Magnitudo St. Canaliculati, fed anguftior. Ab omnibus Stapbylinis nigris optime diftinguitur thorace convexo, orbiculato a capite majori valde difiuncto. Mon. Staph.

Habitat cum aliis rarior.

\section{S? S A N G U I E US.}

Niger, elytris fanguineis, abdomine gibbo antennis longioribus. Morr. Staph. n2. 29.

St. Sanguineus. Linn. Syst. Nat. 689. 19. Fn. Sv. 853.

Statura, ac habitu a Staphylinorum genere diverfus, magisque capitis forma, atque thoracis Notoxis proximus. Jure ad novum genus fub nomine Pselapbi a $\mathrm{Cl}$. D. Herbst relatus. Hist. Ins. p. 106. t. 39. f. 9. Minor St. Sulcato, quo magis gibbus, et globolior. Caput thoracis latitudine, inflexum nigrum, interdum piceum, in medio tuberculofum, vix rugofum. Palpi flavefcentes. Antennae fufcae, longitudine dimidii corporis, moniliformes, articulis tribus ultimis crafsioribus, ultimoque clavato rufo. Thorax rotundatus, convexus, niger nitidus, puncto in medio bafeos interdum imprefso, abdomine multo anguftior. Elytra teftacco-rufa, admodum convexa, valde abbreviata, et veluti dorfo arctifsime adnexa, medium tantum abdomen obtegentia. Reliqua pars abdominis nuda, magis etiam gibba, globofa, nigra. Pedes longiufculi rufi femoribus apice crassioribus, bafi tenui nigra. Occurrunt alii praecedenti fimiles, qui variant magnitudine, et colore corporis interdum. toto faturate teftaceo.

Habitat in terra arenofa, et in arborum carie non sarus. 


\section{$\begin{array}{lllllllll}\text { LXXXIX. } & P & A & E & D & E & R & U & S .\end{array}$}

Palpi quatuor inaequales: antici clavati; postici filiformes. Labium lineare integrum. Antemae moniliformes.

\section{P. EIONGATUS.}

Niger, elytris poftice, pedibusque fulvis. $F . \int p \cdot 339.3$.

Staphylinus Elongatus. Linn. Syst. Nat. 685. 14.

Staphylinus Elongatus. Mons. Staphyl. n. 17.

Caput thoracis latitudine nigrum fubpunctatum . Antennae filiformes, rufefcentes, capitis thoracisque longitudine. Palpi anteriores clavati, pofteriores filiformes. Thorax niger, fubpunctatus, antice, pofticeque rotundatus, inangulatus longitudine capitis . Elytra thoracis longitudine, antice nigra, poftice obfcure-rufa. Sternum nigrum . Abdomen cylindricum nigrum, vix longitudine dimidii corporis. Pedes rufi. Mon. Stapb. l. c.

Magnitudo media .

Habitat in ftercore, et ligno putrido, obvius. 


\title{
CLASSIS SECUNDA.
}

\author{
UL O N A T A.
}

\section{XGII $M A N T S S$.}

Palpi subaequales, filiformes . Labium bifidum, lacinis fixis; pinnis aequalibus. Anteninae setaceae.

$$
\text { 225. M R O S S A. }
$$

Baculiformis, aptera. Fn. Etr. 1. 259. 636. t. 8. f. 1. Variat magnitudine minori, et colore toto ferrugineo-fufco, antennis longioribus, articulis 16 . ultimo longiore. Mas. Iconem exhibet etiam D. Cyrillus in Frz. Neapolitara fub nomine $M$. Filiformis . F.

Habitat in sepibus ad folsas aquarum, et in Ericetis frequens.

$$
\text { *226. M. S P A I L A N Z A N I A. }
$$

Viridis, thorace laevi, elytris, alisque brevifsimis, alis externe rubris, interne violaceis.

Statura M. Oratoriae, cujus pupa primo intuitu videtur, at sextuplo minor. Tota viridis, immaculata. Caput magnum. Frons punctis duobus imprefsis. Antennae letaceae, mediocres. Oculi magni oblongi. Thorax laevis. Abdomen latum, reflexum. Elytra brevifsima rudimentis tantum alarum brevifsimis, fupra dimidiato-ferrugineis; fubtus exteriore parte rubris, interiore violaceis . Femora antica valde incrafsata. Incedit pectore erecto, abdomineque reflexo; 
et ponit ova congesta, agglutinata quemadmodum $M$. Oratoria; v. Roes. Ins. 4. t. 12. $f: 1$. 2. 5. e quibus anno posteriore mens. Aug. Larvae mihi domi exclufae, capite maximo, fronte lata, concava, femoribus albo obsolete annulatis. Specimen mifsum etiam ad $\mathrm{Cl}$. virum $D$. Giornce Taurin . Entomologum magni nominis cui Naturalis Historia amplificata plúrimum debet.

Habitat prope aquas in silvis, rara .

\section{XCVI. $L O C U S T A$.}

Palpi inaequales, filiformes. Maxilla apice tridentata. Labium bifidum; laciniis seta subulata . Antennae setaceae.

\section{L. T T B E R U I A T A}

Thorace planiufculo, vertice tuberculato laevi, elytris elongatis, anguftis, antennis fetaceis longitudine elytrorum. De Geer Ins. 3. 444. 5. t. 38. f. 1 .

Flavo-viridis, capitis vertice tuberculato laevi, elytris elongatis; maxillis flavis.

L. Tuberculata. Fn. Etr. 1. 269.'651.

Statura fere L. Viridissimae, at dimidio minor : Caput flavoviride, vertice leviter tuberculato. Antennae flavae, elytro paulo minores. Oculi cinerei fafcia, feu lineola longitudinali nigra. Maxillae flavae. Thorax planiufculus, flavo-viridis. Elytra flavo-viridia, angufta, abdomine duplo longiora, apice obtufo. Alae subvirides, hyalinae, reticulatae, elytro aequales. Abdomen flavo-viride . Cauda cnsifera recta, bivalvis, longitudine abdominis, flavefcens, costa media fusca. Pedes flavo-virides, antici, et fecundi paris breves; poftici longifsimi, et elytris subaequales. Tarsi omnes in vivo pallidiores, et fere cinerei.

Habitat in pratis, fed frequens etiam in hortis. 


\section{CLASSIS TER TIA. \\ S Y N I S T A T A.}

CIV. PHRYGANEA.

Maxillae totae connatae cum labio. Antennae setaceae.

$$
\text { 228. P. B I M A C ULA TA. }
$$

Alis fuscis, macula laterali duplici flava. F. Jp. 390. 13. Linns. Syst. Nat. 909. 9. Fn. Sv. 1487.

Antennis longioribus, alis fuscis, maris cinereo fafciatis, feminae macula grifea. De Geer Ins. 2. 567. t. 15.f: 1. Geoff. Ins. 2. 248 . 5 .

Antennae corpore fere duplo longiores. Mas a femina diverfus. Habitat in aquosis.

\section{P. G R I S E A .}

Alis anticis nebulosis, macula marginali grifea. $F . \int p .389 .11$. Linn. Syst. Nat. 909. 6. Fu. Sv. 1484.

Antennis longitudine corporis, grifea, punctis, maculisque nigricantibus, alis fuperioribus poftice rotundatis, angulo cxteriore linea nigra. De Geer Ins. 2. 543. t. 13. $f$. 21 . Praecedente major, seu mediae magnitudinis. Alae poftice comprefsae, macula parva nigra ultra medium marginis exterioris. Color ad teftaceum vergens. Larva intra cylindrum e culmis graminum, et juncorum compactum. Habitat ad aquas frequens. 
Clas. III. Synistata. Phryganea.

$$
\begin{aligned}
& \text { 230. P. L O N G I G O R N I S. } \\
& \text { Long. 3. } \frac{1}{2} 1 .
\end{aligned}
$$

Alis fufcis, ftrigis duabus undatis obfcurioribus, antennis lon" gifsimis. F. $\dot{j} .391 .21$.

P. Longicornis. Limn. Syst. Nat. 910. 15. Fn. Sv. 1492.

$P$. alis fuperioribus nebulofis nigro punctatis, antennis triplo longioribus. Geoff. Ins. 2. 249. 7 .

Parva: Alae anticae nigro-punctatae, pofticae albidae margine piloso.

Habitat juxta aquas rarior.

$$
\text { * 231. P. O в s c U R A. }
$$

Alis anticis, cinerco-punctatis, pilofis, pofticis albidis fubpellucidis, margine pofteriore, et interno nigro ciliatis. Species forte nota, at non fatis bene diffincta. Magnitudo $P$. Bimaculatae. Caput pilofum. Antennae fubferrugineae, fufco-annulatae, corpore paullo longiores. Oculi aterrimi. Alae anticae fufcae cinerco inaequaliter punctulatae, pilofae pilis decumbentibus. Pofticae albidae, impunctatae margine pofteriore, et interno in omnibus nigro ciliato. Abdomen fubviridéfcens. Pedes pallide-ferruginei .

Lecta Florentiae.

$$
\begin{aligned}
& \text { *232. P. E V I T A T A. } \\
& \text { Long. } 4 \cdot \frac{2}{3} 1 .
\end{aligned}
$$

Fufco-grifea alis cinereo, nigroque reticulatis, obfufcatis, antice hirtis, areola ad marginem exteriorem, ftrigaque ante apicem albidis .

An P. Inconspicua. Lesk. 51. 38? An P. Hirta. F? Cum defcriptionibus tamen omnino non convenit. Transmifsa ad D. D' Antic. Paris. refpondit eam se polsidere fub dubio nomine $P$. Hirtae. 
Statura $P$. Griseae, at minor, et omnino diverfa. Antennae corpore paullo longiores, albo fuscoque annulatae, primo articulo haud longiore. Palpi pallidi articulis apice nigris. Caput et thorax grifea, immaculata pilis cinereis hirta . Alae anticae hirtae, cinereo minutifsime reticulatae, et nigredine afperfae, areola ad marginem exteriorem, ftrigaque ante apicem arcuata albidis, margineque poftico, in Insecto recens exclufo, albo punctato. Alae pofticae hyalinae, ad apicem vix obfcuriores. Pedes pallidi tibiis apice, tarsisque fufco annulatis.

Habitat juxta aquas frequens, et faepe in feneftris occurrit.

\section{HEMEROBIUS:}

Maxilla recta, apice fissa. Labium corneum, fornicatum. Antennae setaceae .

\section{H. P U I S A TORIUS.}

Long. $\frac{1}{2}$ 1. vix .

Apterus, ore rubro, oculis luteis : $F \cdot \int_{p}$. 394. 15. Mant. 248. 19.

Termes Pulsatorium. Linn. Syst. Nat. 101 5. 2. Fn. Sv. 1937. Scop. E. Carn. 1032. Schrank. E. I. 1019.

Termes Lignorum. De Geer Ins. 7. 41. 1. t. 4. f. 1. An varietas?

Pediculus Ligni antiqui. Geoff. Ins. 2. 601. 12. Derb. Theol. 119. Villers. 4. 14. 1. t. 11. $f .3$. Schaeff. Elem. t. 126.

Habitat in herbariis, et inter Insecta afservata, velociter currens, et ubique se abfcondens, holtis ab Entomologe collectore prae aliis pertimefcendus . 
Clas. III. Synistata. Termes.

CVI. $T E R M E S$.

Labium corneum quadrifidum : laciniis lineraribus acutis . Antennae moniliformes.

*234. T. L U C I F U G U M.

Long. a capite ad apicem alae 1. 4. $\frac{3}{4}$. A capite ad anmm

1. I. $\frac{1}{2}$. Latitudo major abdominis $1 . \frac{5}{2}$

Fufco-nigrum, capite nitido, pedibus pallide-rufis, alis incumbentibus fufcis, corpore triplo longioribus.

Hoc nostrum Termes habitu omnino fimile T. Fatali, at quintuplo minus, et proximum H. Testaceo. Linm. Syst. Nat. 912. 8. et T. Fusco. De Geer Ins. 3. 567.1 . t. 27. f. 4 . 5. quorum defcriptiones huic etiam quodammodo competere videntur, sed diverfum, et novum judicio etiam peritiorum.

Caput nigrum laeve nitidum. Antennae moniliformes, fufcae, articulo fecundo longiori . Oculi exigui. Thorax niger latitudine capitis, at brevifsimus orbiculatus, inangulatus, utrinque deprefsus. Abdomen fufco-nigrum. Pedes nigri tibiis, tarfisque pallide-rutis . Alae fubrugofae fufcescentes, corpore triplo longiores. Occurrunt alia capite fubrufo, thoraceque antice albido, ejusdemque ftaturae, ac magnitudinis, quae numquam visa cohabitare cum praecedente. An varietas? An species?

Habitat mens. Jun. sociatim in truncis filvarum putrefcentibus, in quibus cum apteris vivere vidi etiam facpius innumera alata. Oeconomia videtur eadem quae in aliis fuae gentis. Alae is facile exsiccantur, et decidunt, quo forte fit, ut detectis, ac expofitis eorum acervis, domicilium relinguant, nec amplius poftridie in is reperiantur. 
108

Clas. III. Synistata. Myrmeleon ,

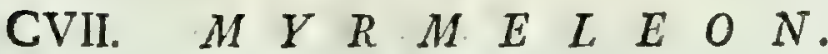

Palpi sex inaequales; postici multo longiores, articulis ulcimis duobus extrorsum crafsioribus . Anteninae extrorsum crassiores .

235. M. $\mathrm{P}$ I S A $\mathrm{N}$ U $\mathbf{S}$.

Villosus, alis grifeis immaculatis, nervis nigro-punctatis, thorace rubro cinereo, linea nigra duplici longitudinali, corpore toto nigro, albo marginato, ungulis tibiarum recurvis. Fn. Etr. 2. 14. 690. t. 9. f: 8. femina.

$M$. Occitanicum alis hyalinis, nervis albo nigroque variegatis, abdomine annulato, cauda maris hirsuta. Villers Ent. t. 3. 63. 9. t. 7.f: 1 o. mas.

Habitat Pisis, rarus .

\section{T E N T H R E D O.}

Palpi filifornes . Labium trifidum.

$$
\text { 236. T. P A D I. }
$$

Antennis septemnodiis, atra, femoribus, tibiisque albis . Linn. Fri. Sv. 1544 .

Villers Ent. 3.91. 29.

Antennae, caput, thorax, abdomen atra. Alae glaucae pur-

cto marginali oblongo atro. Femora, et tibiae albae, fed palmae praefertim pofticae nigrae. Antennae antrorsum exfertac 7. vel 8. articulis, acuminatae. Fzr. Sv.

Parva, et fere duplo minor $T$. Rosae. Femora interdum basa nigra, et palnae pofticae fuperius fufcae. Habitat in Pruni Padi foliis.

$$
\begin{aligned}
& \text { 237. T. N I G R A. } \\
& \text { Long. 3. } \frac{1}{2} \text { 1. Lat. } \frac{3}{4} \text { I. }
\end{aligned}
$$

Antennis feptenmodiis, corpore toto nigro, $F . \sqrt{p} .416 .49$. Linn. Syst. Nat. 925. 34. 
Scbranck. E. I. 677.

Viil. Ent. 3. 98. 44 .

Corpus totum nigrum pubefcens. Alae fufco-hyalinae: fuperiores nervis, cofta, punctoque marginali nigris.

Habitat ruri, frequens primo vere.

$$
\text { 238. T. V, A A . }
$$

Antennis feptemnodiis, nigra, ventre, pedibusque flavis. $F$. fp. 415.46.

Parva. Caput nigrum ore flavo. Thorax niger. Abdomen fupra nigrum ftrigis aliquot obfoletis flavis, fubtus, uti et pedes flavum. F.

Antennae nigrae. Abdomen fingulo fegmento macula nigra fcmicirculari tecto, margine poftico, et laterali pallido. Semel inveni.

$$
\text { 239. T. V I R I D I S? }
$$

Pallide-lutea ${ }_{2}$ fubtus pallidior, capite, thoraceque fupra cha: racteribus atris .

Videtur varietas notatu digna $T$. Viridis . Statura, et magnitudo eadem quae in Viridi. Differt colore, thoraceque luteo, fubtus pallidiore, abdomine toto luteo, antennis, pedibusque faturatius luteis, immaculatis, alis puncto oblongo nigro, marginali. Caput, et thorax picta characteribus atris uti in $T$. Viridi. Mas.

Capta ruri in Alno.

$$
\begin{aligned}
& \text { 240. T. H A E AI A T O DE S. } \\
& \text { Long. 3. } \frac{2}{3} 1 \text { Lat. } 1 \text {. } 1 \text {. }
\end{aligned}
$$

Antennis feptemnodiis, nigra, thorace antice utrinque rubro. Schrank. E. I. 678.

Vill. Ent. 3. 105.63.

Tota nigra. Thorax utrinque ante alas ruber. Alae hyalinae, fuperiores cofta fusca, punctoque marginali nigris .

Habitat in plantis non rara. 


\section{T. $R$ U B I I D A E I.}

Capite, thoraceque nigris, abdomine flavo, antennis duplicibus, laquei inftar conniventibus. Fn. Etr. 2. 31. 731. t. 9 . f: 9 .

T. Furcata, antennis ciliatis, exarticulatis, furcatis in mare, capite, thoraceque nigris, abdomine flavefcente. Vill. Ent. 3. 86. 19. t. 7. f. 16. mas. f. 17. femina.

Anterinae vere fingulares, et numquam in alio Insecto ob. fervatae .

Habitat in hortis; laecta faepius in foliis Rubi Idaci.

$$
\begin{aligned}
& \text { 242. T. R A P A E } \\
& \text { Long. 3. } \frac{2}{3} \text {. Lat. } \frac{2}{3} 1 \text {. }
\end{aligned}
$$

Antennis feptemnodiis, corpore atro, ventre, pedibus, fcutelloque albidis. Linn3. Syst. Nat. 242. 35.

Scbrank. E. I. 676 .

Vill. Ent. 3. 99. 45.

Mull. Linn. Nitt. Cl. v. p. 83 .

Abdomen nigrum margine fegmentorum tenuifsime flavo. Pedes albidi, exterius nigri.

Habitat in Rapae foliis :

$$
\begin{aligned}
& \text { 243. T. D E P R E S A } \\
& \text { Long. 5. 1. Lat. 1. } \frac{1}{4} \text {. }
\end{aligned}
$$

Capite, thoraceque nigro, characteribus flavis, pedibus, abdo: mineque ferrugineis. Geoff. Ins. 2. 28i. 2I. Schrank. E. I. 691 .

De Geer Ins. 2. 2. 1040. t. 40. f. 22.

Vill. Ent. 3. 124. 131.

T. Betulaie valde affinis.

Ruri degit . 
Clas. III. Synistata. Ichneumor.

\section{I C H N EUMON. (a)}

Labium cylindricum, apice membranaccum, emarginatum, medio palpigerum ..Antemae setaceae.

* Scut. albido, ant. albo anmulatis.

$$
\text { 244. I. Q U A E S I T O R I U S. }
$$

Scutello flavicante, thorace maculato, abdominis tribus ultimis fegmentis macula dorfali alba. F. $\int p \cdot 421.5$. Linn. Syst. Nat. 930. 5. Fri. Sv. 1582.

Medius. Antennae nigrae ante medium albo annulatae. Caput nigrum immaculatum. Thorax niger puncto minutissimo albo fub basi alae. Scutellum flavicans. Petiolus niger. Abdominis fegmentum fecundum, et tertium rufa, reliqua atra nitida, macula dorfali alba. Pedes ferruginei, pofticique femoribus, tibiarum apice, tarsisque nigris. In noftris fegmenta abdominis nigra plerumque quatuor, et quatuor plerumque funt maculae albae dorfales. Mas. Feminam numquam vidi.

Habitat in truncis arborum cariofis hieme frequens.

$$
\begin{aligned}
& \text { *245. 1. I N F L I C T O R I U } 8 . \\
& \text { Long. } 7 \cdot \frac{1}{2} \text { L. Lat. 1. } \frac{8}{3} \text { I. }
\end{aligned}
$$

Scutello flavicante, thorace immaculato, abdomine atro, fegmento fecundo utrinque macula, apiceque puncto minutissimo flavis.

(a) Species bujus generis ob coloris, et sexus varietatem nimis multiplicantur in dies, et scientia inutili nominum farragine oneratur; buic malo ne ad infinitum crescat, partim succurreretur figuris, et descriptionibus accuratioribus quae semper affinitatem, ac sexum indicarent, nulla propemodum babita in multis ratione ( sunt enim notae incostantes) antennarum fasciae, scutellique concoloris, aut non; sic forte luxurie compressa, facilius speranda aliquando foret certior generis instauratio . 
I. Niger, pedibus ferrugineis, thoracis apice, maculisque $a b-$ dominis quatuor albis, antennarum medio albo. Geoff. Inss. 2. 345 . 54. varietas?

Antennae nigrae annulo dimidiato albo, abdomine paullo breviores. Caput nigrum linea ante oculos tenuifsime alba. Thorax niger immaculatus, fcutello flavicante. Abdomen atrum nitidum fegmento fecundo basi utrinque macula, fummoque apice puncto minutifsimo flavefcentibus. Pedes pri$\mathrm{mi}$, et fecundi paris toti ferruginei, fed poftici, tarfis, $\mathrm{fe}$ moribus, tibiisque apice nigris. Alae hyalinae puncto oblongo fulvo marginali. Mas.

Authores in defcribendo I. Sugillatorio parum confentanei funt, et hic nofter nimis differre videtur a deferiptionibus pracfertim Linnaei, et Fabricii.

Habitat in silvis; lecti plures, at femper inventi mares, et inter se fimillimi.

$$
\begin{aligned}
& \text { * 246. 1. M A C H I N A T O R I U S. } \\
& \text { Long. 9. 1. Lat. 1. } \frac{2}{3} 1 .
\end{aligned}
$$

Ater, fcutello, tarfis, tibiarumque basi albidis, abdomine immaculato.

Antennae nigrae, apice pallidae, annulo dimidiato albo, articulis brevibus. (a) Caput, thorax, abdomen atra imma-

(a) Ichneumonum antennae quae praeter formam, et modos a De Gcer Ins. 1. p. 558. jam descriptos, variare etiam observantur boc triplici modo, scilicet 1 . in antennis articulis conicis brevibus, uti videre est in I. Crispatorio, aliisque multis . 2. In antennis, articulis elongatis, uti in I. Gladiatore. 3. Et in antennis articulis brevibus, compressis, internoque latere subcrassioribus, vel subserratis, uti in I. Arrogato: re; novun suppeditare possent cluaracterem minus ammulo, fasciaque alba incostantem ad distribuendas fumilias, rognitionemque specierum faciliorem reddendam. 
culata. Scutellum album. Pedes nigri tarfis, tibiarumque basi albidis. Aculeus brevifsimus.

Quamvis experientia apprime edoctus quasdan Icbneumonturi fpecies interdum variare magnitudine eximia, tamen cum hic meus Icbnenmon differat ab $I$. Molitorio etiam defectu puncti albi in apice abdominis, ut pro varietate hujus assumatur, non facile afsentior.

Prodiic mihi e pupa $P$. Bombycis.

$$
\begin{aligned}
& \text { *247. I. V A C I L L A T O R I U S } \\
& \text { Long. 5. } \frac{1}{3} \text { 1. Lat. } \frac{2}{3} 1 \text {. }
\end{aligned}
$$

Niger, scutello albo, abdominis fegmentis margine tenuifsimo albis, tibiis anticis brevibus, dilatatis .

Accedere videtur ad I. Nutatorium. Totus armato oculo, cinereo-pilofus. Antennae porrectae, articulis elongatis, nigrae, annulo lato albo-fafciatae. Caṕut nigrum puncto fub oculis utrinque ninutifsimo albo, labiique emarginatura albo-punctata. Thorax niger lineola alba ante alas. Scutellum parvum lineolaque poftica minutifsima alba. Abdomen - nigrum apice reflexun, fegmentis omnibus margine tenuissimo albis. Pedes ferruginei nigro ungulati. Anticorum tibiae brevifsimae, gibhae, dilatatae, comprefsae fenoribus paullo crafsiores: pofticorum vero femora, tibiaeque apice nigrae, tarsi nigri ante apicem albi. Femorum apophyfes nigrae. Aculcus exsertus, rufus dimidio brevior abdomine, valvis nigris fuhrecurvis, conitnrtis, et fub aculeo fpina brevis, armato oculo, tantum confpicua.

Lectus in silvis.

$$
\begin{aligned}
& \text { 248. I. S A R C I T O R I U S . } \\
& \text { Long. } 5, \frac{1}{2} 1 \text {. Lat. 1. } \frac{3}{4} 1 \text {. }
\end{aligned}
$$

Scutello albido, thorace immaculato, abdominis fegmento tertio pofterius, fecundoque ferrugineis, fexto flavo. F. $\int p$. 421. 3. Limm. Syst. Nat. 930. 3. Fn. Sv. 1580. 
Raj: Ins. 255.15.

Sulz. Ins. t. $18 . f$. 15 .

Antennae longitudine abdominis, fubtus fulvae, apice nigrae, annulo dilute luteo, articulis brevibus. Aculeus in femina brevifsimus .

Habitat in hortis frequens.

\section{I. F U N E R E U S? \\ Long. 7. 1. Lat. 1. 1.}

Niger, thoracis apice antennarumque medio albis. Ent. Par. 406.40.

Villers Ent. 3. 141.21.

Afinis $I$. Deliratorio. Antennae articulis brevibus, nigrae; ante medium annulo dimidiato albo, longitudine abdominis. Caput nigrum linea ante oculos albida. Thorax niger puncto fub alis albido: Scutellum triangulare albidum. Abdomen petiolatum obfcure nigrum. Pedes nigri introrfum pallidi, praefertim quatuor antici. Alae puncto marginali ferrugineo. Mas. Macula alba in fenorum origine a Villers adnotata, nil aliud fane est, faltem in meo fpecimine, quam ipfa junctura intus albida.

Occurrit in plantis non rarus.

$$
\text { * 250. I. O B L A T O R I U S. }
$$

$$
\text { Long. 4. 1. vix. }
$$

Ater, scutello albido, capite, thoraceque maculatis, abdomine petiolato, brevifsimo; albo marginato.

An $I$. Porrectorio affinis? E defcriptione periti judicabunt. Inter medios minor. Antennae fere longitudine corporis, porrectae, articulis elongatis, nigrae, ante apicem albae. $\mathrm{Ca}$ put nigrum ore, palpis, puncto fub antennis, binisque in Fertice minutifsimis albis. Thorax niger puncto medio antiço minimo, altero loco fcutelli, lineolaque tranfversa te. nuifsima, et pone hanc ad apicem litura quadrangulari majuscula albis. Abdomen nigrum, petiolatum, porrectum, 
thorace brevius, fegmentis albo marginatis apice quasi obtruncato. Aculeus exsertus longitudine abdominis. Pedes antici obscure rufi fenoribus basi pallidc-annulatis : postici femoribus, tibiisque fuscis, tarsis pallidis.

Captus ruri.

$$
\text { 251. I. M O T A TORIUS: }
$$

Scutello albo, thorace immaculato, abdomine rubro, apice nigro, puncto albo. $F . \int p .423 .14$.

\section{Vill. Ent. 3. 139. 14.}

Parvus. Antennae articulis brevibus, nigrae albo-annulatac. Caput, et thorax atra immaculata fcutello folo albo. Aculeus brevifsimus. Pedes nigri tibiis anticis totis; pofticis basi rufis .

Habitat etiam in hortis.

$$
\begin{aligned}
& \text { 25. I. L U C T A T O } 1 \text { U S } \\
& \text { Long. 5. 1. Lat. } \frac{2}{3} \text {. }
\end{aligned}
$$

Scutello albo, thorace maculato, abdominis fegmento fecundo, tertioque luteis. $F . \int p .423 .15$ ?

I. niger, tibiis, fegmentoque fecundo, tertioque abdominis flavis. Fn. Sv. 983.

Geoff. Ins. 2. 247.59.

Noftra fipecimina differunt a defcriptione Limn. Fn. Sv. 1590. et Geoffroae l. c. defectu macularum in fegmento quarto, et admodum variant. In nonnullis frons nunc flava, nunc immaculata. Femora omnia modo crafsiufcula, modo non. Primum fegmentum, et ultimum femper nigra: fecundum, et tertium flava, et interdum etiam petioli apex flavus. Tibiae flavae apice nigrae, fubtus fulvae. Mares omnes quotquot vidi. Confer I. Elegantulum. Sebr. E. I. 727 .

Habitat Elorentiae.

** Scut albo, antcmis nigris totis. 


$$
\begin{gathered}
\text { * 253: I. P E R F U S O R I U S. } \\
\text { Long } 5 \cdot \frac{1}{3} 1 .
\end{gathered}
$$

Niger, fcutello albido, abdominis apice albo maculato, pedibus, palpis, antennisque basi ferrugineis .

An sit nova species, determinare non potui. Forte varietas, feu alter fexus I. Scirpi. Geoff. Ins. 2. 346. 56 ?

Antennae articulis brevibus, basi ultra medium ferrugineae, apice nigrae. Caput nigrum palpis ferrugineis. Thorax niger immaculatus. Scutellum albidum. Abdomen nigrum, petiolatum, fummo apice macula albida. Pedes ferrugine? tarfis pofticis nigris. Alae puncto marginali ferrugineo. Mas. Habitat ruri.

\section{I. LAETAT $\mathrm{T}$ R I US. Long. 2. 1.}

Scutello albo, niger, thorace maculato, abdomine rufo, apice nigro, tibiis pofticis annulo albo. $F \cdot \int p \cdot 424 \cdot 26$.

I. Dichrous. Scbrank. E. I. 7 iо.

Defcriptio Fabricii optima. Aculeus in femina brevis. An veriat abdomine, antennisque totis nigris?

Occurrit in plantis non rarus.

\section{** Scut. thoraci concolore.} ant. fascia anmulatis.

$$
\begin{aligned}
& \text { *255. I. P R A E D A T O R. } \\
& \text { Long. 6. 1. }
\end{aligned}
$$

Niger, abdominis fegmento penultimo, tarsisque pofticis albo-fafciatis, pedibus rufis; ungulis infolenter apertis, crassioribus .

Ab I. Cinctorio, et Restanratore. F. diftinctifsimus. Antennae articulis elongatis, porrectae, nigrae, annulo albo. Caput, ct thorax atra immaculata. Petiolus crafsus, comprelsus, incurvus, rufus. Abdomen gibbum, atrum, fegmento penultimo fafcia lata alba. Aculeus fufcus cxfertus dimidio 
ninor abdomine, valvis nigris fubincurvatis. Pedes rufi geniculis nigris : poftici tarfis fufcis, fecundo albo annulaío. Ungulae omnes nigrae praeter moren, refpectu magnitudinis Infecti; crafsiufculac, hiantes.

Lectus in Rubo.

$$
\begin{aligned}
& \text { *256. I. O C C U L T A T O R. } \\
& \text { Long. 7. 1. Lat. 1. 1. et ultra. }
\end{aligned}
$$

Niger, capite globofo, majufculo, abdomine fefsili, pedibus ferrugineis, tibiis quatuor anticis comprefsis, latitudine femorum .

I. Ocreatus, niger pedibus rufis, tibiis, plantisque pofterioribus fulcis, aculeo longitudine abdominis . Muss. Lesk. p. co. 22. 183. qui mihi ignotus, prae aliis juxta hanc diagnofin ad noftrum fpecimen accedere videtur.

Gaput nigrum thoraci fere adnatum palpis fufcis longiusculis. Antennae articulis elongatis, nigrae; albo-annulatae. Abdomen fefsile, nigrum, immaculatum, petiolo brevifsimo, aculeoque fufco longitudine abdominis. Pedes ferruginei. Tibiae primi, et fecundi paris comprefsae, latitudine femorum : pofticae una cum tarfis fufcae. Alae hyalinae punctnigro marginali. Differt ab $\boldsymbol{I}$. Manifestatore antennis albofaciatis, forma capitis diverfa, abdomine non cylindrico, neque arcuato, tibiis anticis comprefsis, aculeo breviore. $\mathrm{Ab}$ I. Insignitore Vill. Ent. 3. 164. 90. differt petiolo brevifsimo, tibiis anticis comprefsis, aculeoque corpore non fesquilongiore .

Habitat in filveltribus.

$$
\begin{aligned}
& \text { 257. I. EX HOR T A TOR. } \\
& \text { Long. 3. } \div 1 .
\end{aligned}
$$

Ferrugineus, capite, abdominisque apice nigris, ano albo. F. Mant. 264. 54.

Medius. Antennae articulis elongatis, nigrae albo-fafciatae, basi ferrugineae primo articulo nigro. Caput atrum immaculatum. 
Thorax ferrugineus. Abdomen basi ferrugineum, apice atrum, ultimo fegmento albo. Pedes ferruginei geniculis nigris. Alae albae puncto marginali nigro. $F$. In noftris, qui mares funt, pedes nigri geniculis rufis, et magnitado inter medios minor.

Habitat ruri non frequens.

$$
\text { * 258. I. A M A T OR. }
$$

Long. 4. $\frac{3}{8} 1$.

Ater, abdomine petiolato, apice albo, pedibus nigris, aculeo fere longitudine abdominis .

Statura, et magnitudo I. Gladiatoris. Antennae articulis elongatis, nigrae, albo femifafciatae. Caput, et thorax atra inmaculata. Abdomen petiolatum, oblongo-ovatum, atrum, extimo ano albo. Aculeus niger abdomine paullo brevior. Pedes nigri tibiis, tarfisque quatuor anticis inferne pallidis. Alae puncto nigra marginali.

Ruri degit.

\section{*** Scutello thoraci concolore antenuis nigris.}

\section{* 259. I. I N SI N U A TOR. \\ Long. $5 . \div 1$.}

Niger, abdomine fefsili ferrugineo, aculeo duplo longiore tarsis omnibus albido-flavis, elis ad coftam apicemque nebulosis. Antennae nigrae fetaceae, articulis elongatis . Caput, thoraxque, nigra, immaculata . Abdomen fefsile oblongum, fcrrugineum aculeo rufo duplo longiore. Petiolus rectus, niger. Pedes tenues: antici rufi tarfis albido-flavis; poftici fufci tarsis albidioribus. Ungulae nigricantes. Alae hyalinae puncto nigro marginali, apiceque nebulofis.

Habitat Florentiae. 


$$
\begin{aligned}
& \text { 260. I. I L L E C E } \mathbf{R} \text { A T O R. } \\
& \text { Long. II, 1. Lat. 2. 1. }
\end{aligned}
$$

Niger, nitidus pedibus fulvis. Villers Ent. t. 3. 194. 192.

Facies Siricis; maximus, totusque niger praeter pedes qui fulvi funt, tibiis, tarfisque pofticis fufcis . Antennae longitudine abdominis. Aculeus quatuor lineas longus. Variat magnitudine duplo minore. Mas mihi, et $D$. Villers ignotus. Habitat in silvis.

$$
\begin{aligned}
& \text { 261. I. T UR I O N E L L A E. } \\
& \text { LOng. } 30^{\circ} \frac{1}{2} 1 .
\end{aligned}
$$

Niger, pedibus rufis, tibiis pofticis nigris albo-annulatis. Fab. $\int p .432 .76$.

1. Turionellae niger, abdomine cylindrico, macula alarum fufca albae inferta, tibiis pofterioribus albo annulatis. Linn. Syst. Nat. 935. 40. Fur. Sv. 1615.

Antennae flavefcentes, abdomine dimidio breviores. Caput parvum nigrum. Palpi flavi. Thorax niger immaculatus. Abdomen cylindricum nigrum. Aculeus brevifsimus. Pedes rufi; pofticique femoribus crafsiufculis, tibiis nigris bis albo-annulatis. An varietas?

Raro lectus.

$$
\text { 262. I. R E S I N E L L A:E. }
$$

$$
\text { Long. 6. } 1 .
$$

Niger, pedibus flavis, abdomine fefsili cylindrico incurvo, antennis basi luteis. F. $\int p .433 .81$. Linn. Syst. Nat. 936. 43. Fri. Sv. 16 18.

Niger immaculatus. Antennae nigrae basi fubtus flava. Palpi flavi. Abdomen cylindricum fefsile, apice fubincurvato. Pedes flavi tarfis, tibiisque pofticis apice fufcis. Alae breves. Mas.

Mabitat in Larva P. Resinellae. 


$$
\begin{gathered}
\text { 263. I. B I F A S C I A T U S } \\
\text { Long. 4. 1. Lat. } \frac{2}{3} \text {. }
\end{gathered}
$$

Niger immaculatus, abdomine petiolato, tibiis fubferrugineis, alis albohyalinis fafcia duplici tranfverfa atra, prima marginem exteriorem haud attingente.

Videtur I. Bifasciatus, Ent. Par. 2, 405. 37.

Antennae articulis elongatis nigrae fubtus fufcae. Aculeus niger dimidio brevior abdomine. Reliqua in nomine dicta.

Occurrit in plantis rarus.

$$
\begin{aligned}
& \text { 264. I. OCULATOR. } \\
& \text { Long. 2. } \frac{x}{2} \text {. Lat. } \frac{1}{2} 1 \text {. }
\end{aligned}
$$

Ater, 'abdominis basi utrinque puncto flavo, thorace poftice bidentato. F. Mant. 267.96.

I. Atomos. Fn. Etr. 2. 54. 792.

Crafsiufculus, ater. Antennae porrectae nigrae longitudine abdominis. Caput nigrum. Palpi flavi. Thorax ater poftice bidentatus. Abdomen ovatum, punctulatum fubtus fornicatum, fupra integ:um, hoc est annulis indiftinctum, atrum basi utrinque puncto flavo, at faepe primo fegmento toto flavo. Aculeus rufus abdomine paullo longior. Pedes rufi tibiis pofticis nigris; hi tamen juxta fexum colore variant, et femora interdum omnia nigra. Variat etiam faepius abdomine toto nigro, praefertim in feminis. Alae hyalinae puncto marginali ( nota inconftantifsima) modo nigro, modo flavo.

Habitat in hortis frequens.

$$
\begin{aligned}
& \text { *265. I. C U N I C U I A T O R. } \\
& \text { Long 4. Lat. } \frac{1}{2} 1 .
\end{aligned}
$$

Rufus, abdomine ovato, alis omnibus nigris, puncto majufculo marginali flavo. 
1. Tentator. Fn. Etr. 2. 50. 783 . Ne confunderetur cum I. Teritatore. Villers Ent. 3. 196. 200. nomen pernutavi.

Accedere videtur ad I. Fastidiatorem, at fere dimidio minor, et diverfus. Antennae nigrae longitudine abdominis : Caput rufum oculis, vertice, ocellisque nigris. Thorax rufus nigredine afpersus. Abdomen fubsessile rufum petiolo brevi lato concolore, aculeoque nigro abdomini fubaequali. Pcctus poftice nigrum. Pedes rufi femoribus pofticis, tibiisque apice nigris. Alae omnes nigrae puncto majufculo marginali flavo inter duo nigra .

Defcriptio Fr. Etr. l. c. competit mafculo qui interdam variat abdomine nigricante.

Habitat in filvestribus frequens.

$$
\text { 266. 1. TER RETACTOR; }
$$

Long. 4. 1. Lat. $\frac{1}{2}$.

Teftaceus, capite, thoraceque nigro maculatis, antennis nigris . Vill. Ent. 3. 195. 194. t. 8. f. 6.

Mediocris. Antennae, oculique nigri. Caput teftaceum in medio macula nigra angulata. Thorax teftaceus lineis, feu maculis longitudinalibus, quarum latitudo inaequalis, fupra notatus. Macula nigra fuper petiolum. Aculeus teftaceus corpore duplo longior; vaginae nigrae. Femora teftacea. Tarfi omnes nigri. Tibiae pofteriores nigrae. Vill.

Color, in noftris, rufus, alaeque in medio lunula albida. Proximus I. Impostori, magisque affinis praecedenti, a quo tamen differt praefertim aculeo in hoc multo longiore.

Habitat in filvis, et locis incultis non rarus .

$$
\begin{aligned}
& \text { * } 267 \text { I. C U S P I d A T O } \mathrm{R} \text {. } \\
& \text { Long. 2. 1. Lat. } \frac{x}{3} 1 \text {. }
\end{aligned}
$$

Niger', gibbus', thorace antice rufo, abdomine vix petiolato, rufo; lamina fubtus acuminata. 
Statura diverfa a praecedente, magis contracta, et gibbofior. Totus niger praeter thoracem antice rufum et abdomen, quod tamen faepe dorfo nigrefcit. Caput parvum. Antennae porrectae longitudine abdominis. Thorax gibbus pectore in medio nigro. Abdomen thoraci adnatum, lamina fubtus vomeriformi acuta. Aculeus abdomine paullo longior. Alae nigrae litura vix hyalina.

Lectús ruri.

$$
\begin{gathered}
\text { *268. I. S A G I T T A T R. } \\
\text { Long. } 8 \text { 1. Lat I. } 1 .
\end{gathered}
$$

Niger, abdomine fubfalcato, tibiis, tarfisque quatuor anticis albido luteis; capite fubhirto, punctoque fub antennis flavo. Proximus I. Pugillatori, et Resinellae quamvis ab iis diverfissimus. Antennae mediocres articulis brevibus nigrae. Caput nigrum, villis canis hirtum, oculis parvis, puncto fub antennis flavo, oblongo obfoleto. Palpi lutei vix apparentes. Thorax niger fubhirtus immaculatus. Abdomen fubfalcatum tenue elongatum, lateribus comprefsum, apice vix incurvo, haud crafsiori, fupra nigrum, fubtus flavum. Petiolus tenuifsimus niger. Pedes quatuor antici tenues, femoribus nigris, tibiis, tarfisque albido luteis : Poftici, maximam partem, fufco-nigri, tarfis ( refpectu tibiarum, ac femo. rum ) crafsiusculis, fubtus teftaceis, fupra, primo excepto apice tantum, nig
Habitat Florentiae.

**** Anteninis luteis.

$$
\text { 269. I. L U N U I A T U S . }
$$

Long: 9. 1. Lat. 2. 1. vix."

Niger, abdominis fegmentis flavo cinctis. Vill. Ent: 3. 20.3.224.

I. Variegator. Fn. Etr. 2. $4.6 .772 . t .6 .6$. An I. Variegator. F. Mant. 268. 102? 
Cum maximis certat . Niger flavo variegatus . Antennae abdomini fubaequales nigrae, fubtus fulvae, articulis brevibus. Caput nigrum fronte flava, macula media oblonga nigra. Thorax niger lineola flava ante alas utrinque, poftice lunulatus, lunula flava cornibus abdomen fpectantibus, feu fcutello emarginato-bidentato flavo. Ante lunulam puncta duo flava, poft lunulam, unum; iterumque alia duo ad latera poftica. Pectus nigrum macula magna laterali, punctoque oblongo contiguo fub basi alarum flavis. Abdomen comprefsum, clavatum, atrum, fegmentorum marginibus omnibus flavis. Pedes flavi femoribus introrfum fufco maculatis. Apophyfes omnes nigrae macula media flava. Alae flavefcentes. Mas.

Habitat Florentiae rarus. An hujus tribus?

$$
\begin{aligned}
& \text { 270. I. A M I C T U S. } \\
& \text { Long. 9. } 1 .
\end{aligned}
$$

Nigel, abdomine falcato, antennis, pedibusque ferrugineis. F. $\int$ p. 436.101.

Statura, et magnitudo I. Lutei. Antennae flavae longitudine abdominis. Caput dilute flavum vertice, oculisque nigris. Thorax ater omnino immaculatus. Abdomen falcatum ferrugineum. Aculeus brevis vix lineam longus. Pedes qua. tuor antici ferrugineo flavi, tibiis, tarsisque pallidioribus: poftici ferruginei tibiis fummo apice nigris, tarsisque pallidis. Apophyfes pedum quatuor anticorum dilute flavae; pofticorum vero introrfum ferruginene, extrorfum nigrae. Alae obscurae abdominis medium longitudine paullulum fuperantes.

Habitat Florentiae non rarus.

$$
\begin{aligned}
& \text { 271. I. C I N C T U s. } \\
& \text { Long. 1. } \frac{1}{2} \text { 1. Lat. } \frac{1}{3} 1 .
\end{aligned}
$$

Ater, antennis, pedibusque ferrugineis, alis albis fasciis duabus nigris : F. $\int p \cdot 437.107$. Linn. Syst. Nat. 938. 60. Fn. Sv. 1632. 
Icbnenmon niger, alis albis fafcia duplici nigra, pofteriore majori . Geoff, Ins. 2. 359.85 .

Habitat in hortis, etiam in feneftris frequens.

$$
\text { 272. I. C R A S S I P E . }
$$

Fulvus, flavoque varius, thorace fublineato, femoribus po Aticis clavatis. Fn. Etr. 2. 52. 787. t. 2. f. 15. Permutandum nomen jam ufurpatum.

Femina mari fimillima, aculeo abdomine breviore, fufco, valvis nigris .

Habitat in filveftribus.

$$
\begin{aligned}
& \text { 273. I. L E N O C I N A T O R. } \\
& \text { Long. 5. } 1 \text { Lat. } \frac{1}{3} \text {. }
\end{aligned}
$$

Rufo-albidoque varius, abdomine sefsili, pedibus citrinis . Caput nigrum fronte rufefcente, labio, palpis, orbita oculorum, punctoque verticis flavo-albidis. Antennae corpore breviores, fufcae, fubtus rufefcentes. Thorax antice ufque ad fcutellum, et lateribus rufus, lineolis duabus dorfalibus interruptis fcutellum cingentibus albidis. Post fcutellum lineola brevis albida; poftice niger puncto utrinque laterali albido. Abdomen sefsile, fubcylindricum fegmentis prominulis basi nigris, lateribus late, et ad marginem tenuifsime fulvis. Aculeus lineam longus albidus, vaginis nigris. Pedes pallide citrini femoribus pofticis in medio rufefcentibus, tarsisque nigro geniculatis. Alae albae breves, puncto marginali majufculo ferrugineo .

Mens. April. quatuor mihi prodierunt declarati e folliculis intextis intra nidum Araneale fub arboris cortice inventum, ubi larvae jam confumtis maximam partem ejus ovulis, metamorphofin fubierant : feminae omnes, unaque earum etiam monftruofitate quadam fingularis, fcilicet excrefcentia in medio oculi dextri fita, ab ipfa cornea infolenter qucta efformata.

$$
\begin{gathered}
\text { ****** Minuti, ant. fliformibus } \\
\text { abdomine sessili. }
\end{gathered}
$$




$$
\begin{aligned}
& \text { 274. I. M U T I I I A R I U S. } \\
& \text { Long. 2. 1. }
\end{aligned}
$$

Apterus, rufus, capite, thoracis, abdominisque poftico nigro. F. Mant. 271152.

Major in hoc ordine. Caput nigrum nitidum. Antennae flavefcentes, basi ferrugineae, apice nigrae. Thorax antice rufus, poftice niger. Abdomen rufum, poftice nigrum . Aculeus exfertus abdomine brevior. Pedes rufi femoribus. pofticis nigris .

Lectus ruri .

$$
\begin{aligned}
& \text { *275. I. C Y N I F O म M IS. } \\
& \text { Long. 2. } 1 \text {. }
\end{aligned}
$$

Viridis, abdomine brevi reflexo nigro, petiolo longo, fcutello bifurcato .

Elegantifsimus, et forma paullulum $a b$ aliis diverfus. Caput viride $\mathrm{ab}$ ore ad frontem breve refpcctu latitudinis. Thorax viridis valde gibbus, crafsus, punctis elevatis fcaber, poftice attenuatus. Scutellum prominens apice bifurcatum. Abdomen atrum, nitens, ovatum, fornicatum penitusque reflexum . Petiolus ab imo pectoris derivatus longitudine abdominis. Aculeus brevis fub fornice abfconditus. Pedes lutei . Alae albae puncto marginali fufco. Statura accedit ad $E$. Ediogaster. Fn. Etr. 2. 801. quae inter Ichnewmones amandanda videtur.

Lecti duo Florentiae, quorum unus mifsus ad $D$. d'Antic Paris. an. 1790.

$$
\text { * 276. I. RODO P TH А I U U. }
$$

\section{Long. 2. L.}

Fufco viridi-aeneus, oculis rubris .

Statura, ac habitu accedere videtur ad Ichneumonem De Geer Ins. 2. 2. $897, t$. 31. f. II. at defariptio minime convenit. 
Major 1. Bedeguaris . Caput viride. Oculi rubri. Antennae fractae nigrae, basi flavefcentes capite paullo longiores. Thorax fufco-viridi-aeneus, gibbus. Abdomen breve, ovatum, lateribus fubcomprefsum, fere thoraci adnatum, aeneo niridum. Aculeus exfertus, rufus, longitudine abdominis. Femora poftica crafsiora aeneo viridia. Tibiae fubrufae; pofticae crafsiores. Tarsi albidi. Alae albae puncto marginali nigro.

Lectus in foliis Bignoniae radicantis. m. Jul.

\section{I. $M U$ U C A R U M.}

Auratus, pedibus flavis faltatoriis . F. $\int p .438 .109$. Limm. Syst. Nat. 938. 62. Fn. Sv. 1636 .

De Geer. Ints. 1. 32. f. 19. 20.

Fn. Fridr. 11.621.

Villers Ent. 3. 205.230.

Habitat in larvis Mufcarum Aphidivorarum.

$$
\text { *278. I. MORTUORUM. }
$$

Atro-aeneus, oculis nitidifsimis coralinis .

Minutus. Antennae breveș fubclavatae. Ambulat fuper cadavera in arculis Infectorum.

\section{CXVI. $C H A L C I S$.}

Palpi quatuor acquales. Antennae breves cylindricae, fere fusifornes, articulo primo fubcrafsiori .

$$
\begin{aligned}
& \text { *279. C. I M M A C U I A T A. } \\
& \text { Long. 2. 1. Lat. } \frac{2}{3} 1 \text {. }
\end{aligned}
$$

Nigra, immaculata, puhefcens, abdomine nitido, femoribus pofticis globofis, ferratis, tibiis arcuatis.

An Vefpa nigra femoribus pofticis globofis, ferratis, tibiis arcuatis, alarum basi, genubusque flavis. Gsoff. 
Ins. 2. 38. 15. Varietas? An alter fexus C. Pusillae F? determinare haud potui .

Thorax, et genua, in noftris, omnino nigra immaculata uti totum corpus. Alae albae.

Occurrit cum congeneribus in arborum foliis rarior.

\section{S $\quad P \quad H \quad E$.}

Os lingua inflexa trifida. Labium emarginatum utrinque seta instructum. Antennae filiformes.

$$
\begin{aligned}
& \text { 280. S. P L U M в E A? } \\
& \text { Long. 3. 1. Lat. } \frac{1}{2} 1 \text {. }
\end{aligned}
$$

Plumbea, antennis atris, alis anticis, apice fuscis. F. Mant. 178. 64 .

Plumbea, feu cinereo-fufca. Antennae nigrae thorace longiores. Caput cinereum . Abdominis fegmenta basi atra, apice cinerea. Pedes cinereo-fufci. Alae albae, anticae apice fulcae .

Defcriptio $S$. Cinereae. F. nimis convenire videtur cum defcriptione $S$. Phumbeae, unde dubium.

Habitat in fforibus .

$$
\text { *281. S. NOTA TA. }
$$

Nigra, abdominis fegmento fecundo macula fulva dorfali notato.

Statura, et magnitudo fere S. Rufipedis. Tota nigra immaculata, praeter fegmentum fecundunr abdominis macula fulva oblonga in medio notatum. Alae obfcurae apice fufcae. Lecta in filvis Pifanis.

$$
\text { 282. S. MACULATA. }
$$

Atra, thorace albo maculato, abdominis fegmento primo rufo, reliquis utrinque lineola transverfa alba. F. Mant. 277. 50. 
Vix major C. Uniglumi . Caput nigrum immaculatum. Anterinae nigrae capite paullo longiores. Thorax niger lineola abbreviata marginis anterioris, puncto ante alas, fcutelloque albis. Abdomen ovato-conicum, apice fubincurvatum primo fegmento fupra late rufo, reliquis nigris, utrinque lineola tranfverfa alba. Pedes rufi. Alae albae.

Habitat filvas rarifsima.

$$
\text { 283. S. CARBO NARIA. }
$$

\section{Long. 3. 1.}

Tota nigra, alis hyalinis. Scop. Ent. Carn. $78 \mathrm{~s}$,

Villers Ent. 3. 248: 75.

Pedes huic nigri. Corpus vix pilofum: Antennae thorace lorigiores. Scop. l. $c$.

Non confundenda haec Spbex cum S. Nigra F. nam minor abdomenque aliter conformatum. Vill. $l_{\text {. }} c$.

Sphece Nigra F. ohicurinr, antennaeque longiores. Alae hyalinae. Aculeus turus Magnitudine tamen apud nos faepe aequat $S$. Nigians

Habitat circa $f-c$, in

$$
\begin{aligned}
& 384 \text {. A. O O P S . } \\
& \text { Long. 4. } \frac{1}{2} \text { 1. Lat. 1. } \frac{\pi}{4} \text { 1. vix. }
\end{aligned}
$$

Atra abdominis fegmentis tribus, tarfisque teftaceis. Scbr. E. 1. 777 .

Vill. Ent. 3. 249.82.

Proxima S. Gibbae a qua praefertim difiert oculis magnis fubteftaceis totum fuperne caput occupantibus, fere coalitis, haud tamen exfertis. Abdomen breve ovatum, duplo minus thorace, rufum, apice nigrum. Tarfi teftacei. Alae apice etiam hyalinae. Villosula.

Habitat in floribus Umbcllatis; rarior. 
Clas. III. Synistata: Scolia.

CXIX. SCOLIA.

Os lingua brevi, trifida. Labium porrectum apice membrana. ceum, integrum, medio palpigerum. Antemnae. fubpetiolatae.

285. S. F L A I F O N S.

Atra, fronte flava, abdomine maculis quatuor flavis. $F . S p$. 452. 5 .

Fn. Etr. 2. 69. 832. conf.

Mas duplo minor femina. Antennae in femina nigrae; in mafculo flavae basi nigra, at in utroque fexu breves, apiceque retortae. Abdominis maculae modo disiunctae, modo cohaerentes. Aculeus adeo validus ut in teneriori ligno notan imprimere queat.

Habitat in pratis, et filvis pafsim, frequentans flores.

$$
\text { 286. S. 2-M A C U L A T A. }
$$

Hirta, atra, abdomine maculis duabus luteis, antennis flavis. F. $\int p .452 .7$.

Pet. Ins. Cal. 32. 161.

Fn. Etr 2. 70. 833. conf.

Paullo minor, fed ftatura eadem quae in S. Hortorrm. In omnibus quotquot inveni, antennae flavae, rectae, prismaticae; anus conftanter trifpinofus .

Habitat in filvarum arboribus excavatis, ihique faepe inventa, numero tamen inferior, cum S. Hortortin; lecta etiam fimul in horto cum convolafset ad flores Lilii albi vulgaris. An mas fequentis?

$$
\text { 287. S. HORTORUM. }
$$

Atra, abdomine fafciis duabus flavis, alis ferrugineis, apice cyaneis, F. Mant. $281,12$. 
Scolia hirta, nigra, abdomine maculis quatuor flavis. Pet. Ins. Cal. 32. 160.

S. Interrupta. Scop. Del. Fl. et Fu. Ins. fasc. 2. p. 60. t. 22.f. 3. Frz. Etr. 2. 70. 834. conf.

Non defunt qui judicant hanc noftram efse S. Quadrimaculatam $\mathrm{F}$. Hirta uti praecedens. Alae ferrugineae apice cyaneae. Antennae nigrae, rectae, prismaticae. Anus conftanter trif́pinosus. Variat interdum dorfo thoracis antice, anoque flavefcentibus.

Habitat cum praecedente frequentior.

$$
\text { * 288. S. S EX P U N C T A } \mathrm{TA} \text {. }
$$

Hirta, atra, abdomine maculis fex pallide luteis, alis ferrugineis, apice pone medium fufco-violaceis .

Statura, habitus, color omnino S. 4-punctatae, at dimidio major. Antennae non rectae, breviores, apiceque retortae. Caput nigrum puncto pone oculos albo. Thorax niger immaculatus. Abdomen nigrum maculis sex exalbidis, seu pallide-luteis in 2. 3. 4. fegmento sitis : anticae mediocres, et utrinque emarginatae; mediae majores, orbiculatae; pofticae multo minores, quasi puncta oblonga transversa. Anus nullo modo trifpinosus, fed inermis, retusus. Alae ferrugineae apice fufco-violaceae.

Determinare haud potui in Fn. Etrusca, confer S. 4-pursctatam t. 2. 74. 840. an haec efsct fpecies distincta, feu varietas fexus S. 4-punztatae; peritiorum judicio etiam nunc relinquam : at foret ne femina? Sane etiam in $S$. Bicincte fafciae abdominis flavae variant, nunc enin magis, nunc minus in medio finuatae, margineque emarginatae; Varia-re ea quoque videtur magnitudine paullo minori, antennis prifmaticis rectis, apiceque abdominis trifpinoso, cui varietati, alia ( forte $\mathrm{fp}$. diftincta) habitu, ftatura, ac magnitudine omnino fimillima occurrit, antennis rectis prifmaticis, anoque pariter trifpinoso, diverfa tamen numero fafciarum abdominis, nam in quarto fegmento tertia gaudet fafcia multo anguftiore, ac eleganter fuperius attenuata, et in primo, uth in quinto fegmento interdum, puncto utrinque 
minutifsimo flavis: Infuper in hac thorax femper lateribus anticis macula flava notatus afpicitur: reliqua fimilia. Praererea non omittendum fpecimen aliud quod habeo diftinctum tantummodo fafcia unica abdominis flava. (a)

Lecta femper in filvis cum $S$. 4-punetats eodem tempore, et loco.

$$
\text { * 289: S. } 8-\mathrm{P} \text { U N C T A T A. }
$$

Atra, thorace maculato, abdomine punctis utrinque quatuor albis, alis hyalinis.

Statura, et magnitudo omnino S. Quadriguttatae. Antennae nigrae thorace breviores, apice retortae. Caput nigrum puncto inter antennas albo, armatis oculis tantum perspicuo. Thorax niger antice utrinque albo-punctatus. Abdomen

(a) OBS. Dubitatum an Scoliae quae gaudent ano trispinoso, antesmisque prismaticis, rectis, forent me mares? Quac antemas babent breviores, apice retortas, anumque non Jpinosum, retusum, an plerumque feminae? Quoad species sequentes apud nos abvias, scilicet. S. Insubricam Scop. (quae a monnuldis babetur pro masculo S. Sexmaculatae, ) Bicinctam, Quadripunctatam, observatio baec mibi visa est admodums veritati proxima: Quoad vero S. Flavifrontem, Bimaculatam, Hortorum, Sexmaculatam, Interruptan, visa est att falsa, aut prorsus dubia; nam

In S. Bimaculata, Hortorum, et Interrupta F. Antennae observantur constanter prismaticae, anusque trispinosus.

In S. Flavifronte, et in Sexmaculata; antennae constanter breves, apice retortae, anus absque spinis.

In S. Insubricae variet. majore; entennale constanter bre. ves, apice retortae, anus absque spinis. In varietate minori; antennae constanter prismaticae, anus trispinosus.

Et boc idem quod in Insubrica; constanter etiam in iis quas pro varietatibus babemus Bicinctae, et Quadripunctatae, observatur. 
atrum punctis utrinque quatuor tranfversis, minutifsimis albis, in quatuor ultimis fegmentis fitis. Pedes nigri. Alae hyalinae. Differt a S. 4-guttata, fronte non macula, fed puncto albo vix confpicuo notata; antennis totis nigris duplo brevioribus, apiceque minus crafsiore; thorace maculato; numero punctorum abdominis, quae in hac etiam minufcula, et magis lateraliter pofita .

Lecta ruri in floribus.

\section{CHRYSIS.}

Labium porrectum maxilla multo longius, apice membranaceum . Antennae filiformes.

$$
\text { * 290. C. R O S E A. }
$$

Capite, thoraceque viridi-caeruleis, abdomine rofeo, pone edentato. Frz. Etr. 2. t. 8. f. 7 .

Statura C. Auratae. Geoff. Inss. 2. 383. 21. ejusdemque fere magnitudinis . Antennae nigrae. Caput, thoraxque viridi-caerulea. Thorax poftice utrinque dentatus. Abdomen fere hemisphaericum, laeve, totum pallide-rofeum, fegmentis tribus fubaequalibus. Anus rotundatus, integer. Tibine cacruleae. Alae anticae apice fufcae. In hoc genere, anus dentatus anne fexum ftatueret?

Habitat in filvis rarior.

$$
\text { 291. C. B I D E N T A T A. }
$$

Glabra, nitida, cyanea, thorace bidentato, abdominisque fegmentis duobus primis aureis. F. $\int p$. 456. 9? Linn. Syst. Nat. 947. 2?

Clarysis cyanea nitida, abdomine macula magna nigra, alis apice fufcis. De Geer Ins. 2. 2. 837. 2. t. 29. f. 3. 4 .

Mea fpecimina quae tota cacruleo-viridia, abdomine nacula magna ovata nigra, ano edentaro, alis apice fufcis omnino conveniunt cum defcriptione De Geeriana l.c., differunt tantum tibiis, tarfisque ferrugineis, plantis fufcis.

Habitat in Pinetis non frequens. 


\section{C. C F U L L G I D A .}

Glabra, nitida, thorace, abdominisque primo fegmento eaeruleis, reliquis aureis, ano quadridentato. F. $\int p .455 .7$. Limn. Syst. Nat. 948. 7. Fr. Sv. 1669.

Geoff. Ins. 2. 382.20.

Schrank. E. I. 783 .

Statura, ac magnitudo C. Ignitae a qua tantum differt primo, et interdum fecundo abdominis fegmento caeruleis .

Habitat in muris, et lignis non frequens .

$$
\text { * 293. C. M I C A N S. }
$$

Glabra nitida, capite, thoraceque profunde cyaneis, abdomine viridi-aureo, ano fexdentato.

Paullo major C. Ignita. Antennae nigrae. Caput cyaneum fronte fub antemnis certo fitu albo-pubefcente. Thorax profunde cyaneus, poftice utrinque dentatus. Abdomen viridi-aureum nitidum, punctatifsimum apice concolori, dentibus fex manifeftis inftructo. Pedes virides. Alae anticae fufcae, ad apicem internum hyalinae. Differt a $C$. Smaragdula magnitudine paullo minori, colore thoracis caeruleo, abdomine magis aureo, apice concolore, alis non omnino fufcis. A C. Ignita differt magnitudine majori, colore abdominis non aureo-ignito, fed viridi-aureo, minusque vivido, ano fexdentato .

Lecta faepius in floribus.

$$
\text { * 294. C. E D E N T U I A. }
$$

Viridis glabra, thorace, abdomineque aureis, ano laete cyaneo; antennis fubtus ferrugineis.

Statura, et magnitudo praecedentis. Antennae fupra nigrae, fubtus ferrugineae primis articulis nigris . Caput viride. Thorax fupra aeneo-aureus nitidus, punctulatus; fubtus viridis, poftice inermis. Abdomen aeneo-aureum, nitidum, tertio fegmento, anoque cyaneo-viridibus. Anus veluti obtruncatus, edentatus. Pedes virides. Alae fubobfcurae. Aliud fpecimen habeo huic valde affine, thorace, abdomineque 
aureo-nitidis, quod differt magnitudine paullo minori; 2ntennis nigris, fubtus fufcis; thorace bidentato; colore capitis, corporisque fubtus cyaneis; ano magis integro, fubdentato, forte alter fexus?

Ruri inveni .

$$
\text { 295. C. I N T E G R A. }
$$

Glabra, viridis nitida, abdomine aureo basi, apiceque viridi, ano integro. F. Mant. 283. 11.

Statura, et fumma affinitas C. Ignitae . Caput, et thorax viridia nitida immaculata. Abdomen aureum primo fegmento parum viridi. Anus integer viridis. Abdomen fubtus viride. F.

Habitat in plantis non rara.

$$
\text { 296. C. A U R A A . }
$$

Glabra nitens, thorace viridi, abdomine aureo, ano bidentato. F. $\int p .456,13$. Limn. Syst. Nat. 948. 4. Fn. Sv. 1666.

Corpus parvum magnitudine C. Succinctae, caeruleo-viride, abdomine laevi, aurato fulgidifsimo. Thorax poftice dentatus. Alae apice fufcae. A nonnullis confufa cum Vespa thorace viridi-caeruleo, abdomine aurato cupreo, pone inermi. Geoff. Ins. 2. 383.21. quae valde major est, et varietas videtur ( uti fufpicatur ipfe Geoffroy) C. Ignitae : fortafse alter fexus?

Habitat in plantis parieti innixis.

CXXII. L E U COSPIS.

Palpi quatuor aequales, breves.. Labium maxilla longius, emarginatum. Antemae clavatae.

$$
\text { 297. L. D O R S I E R A . }
$$

Abdomine sessili nigro, fafciis duabus, punctoque flavis. $F$. Mont. 284 . I. 
Sphex Dorsigera. Suiz. Hist. Ins. t. 27. $f$. 11.

L. Coclogaster. Schrank. der. Berl. Naturf. 1. 14. 308. t. 8. f. 4. 5. et 2. p. 307. Coelogaster.

Villers Ent. 3. 260. 1. t. 8. f. 17.

Fn. Etr. 2. 80.856 .

Habitat in hortis, frequens in floribus Pastinacae, La vandulae Spicae, aliisque.

$$
\text { 298. L. G A L } \geq \subset A \text { A . }
$$

Nigra, thorace punctis duobus flavis. Villers Ent. 3. 261 . 2. t. $8 \mathrm{f}$. i 8 . quem confer.

Cynips nigra maculis luteis notata, femoribus pofticis globofis margine interiori dentatis, aculeo triplici fuper abdomen recurvato . D. de la Tourrette Acad. des Sciences Tom. IX. Savans étrangers $p .730$.

Haec conftanter apud nos differt a praecedente magnitudine fere triplo majori, antennarum articulo fecundo rufo, capitis vertice utrinque flavo punctato, thorace punctis duobus mediis fubcontiguis flavis, femorumque pofticorum macula nigra exteriore aliter picta. Macula fcutellaris in hac femper cordiformis, in praecedente non femper; caetera fit milia .

Plures habui, femper in filvis inventas, numquam in hortis. An mera varietas, an fpecies? mihi nunc fpecies. Habitat Pisis .

\section{CXXIV. $V E S P A$.}

Labium porrectum maxilla longius emarginatum, utrinque seta instructum . Antenzzae extrorfum crafsiores.

$$
\text { 299: V. C O N I C A. }
$$

Ferruginea nigro maculata, abdominis fegmento fecundo fafcia atra. F. Mant. 293. 69.

$V$. Coungustata. Frz. Etr. 2. 84. 863. t. 4. f. 10. quae $V$. Conicae varietas profecto est: Differt tantum antennis nigris articulo primo antice flavo; in $V$. Conica $F$. frons, 
nntennaeque totae flavae ; petiolus abdominis in hac, fafcia, in $V$. Coangustata linea longitudinali nigra notatus.

Habitat etiam in hortis flores adiens, non obvia.

$$
\text { 300. V. B I P U N C T A T A. }
$$

Thorace maculato, abdomine fafciis quatuor, punctisque duobus primi fegmenti flavis. Fab. Sp. 465.44.

Media. Antennae nigrae primo articulo fubtus flavo. Caput nigrum maxillis, ftriga, orbitaque oculorum flavis . Thorax niger ftriga antica, puncto fub alis, fcutelloque flavis. Abdomen atrum nitidum, primo fegmento utrinque puncto, reliquis fafcia flavis. Pedes flavi femoribus basi nigris. F. V. Bipuntata Fn. Etr. 875. omnino diverfa : Nomen permutandum ne confundatur.

Habitat ruri .

\section{CXXV. $C R A B R O$.}

Palpi quatuor articulis comprefsis rhombnidaliton. Labium breve corneum apice palpigerum. Antennate filiformes.

$$
\begin{aligned}
& \text { 301. C. F L A V I P E S } \\
& \text { Long. } 5.1 \text {. }
\end{aligned}
$$

Niger, thorace maculato, abdomine flavo, fegmentorum mar-: ginibus anoque nigris. $F . \int p$. 470. 6 .

Antennae breves nigrae. Oculi glauci. Labium flavum. Thorax niger, glaber, margine antico elevato interrupto tenuissime flavo punctis fub alis, pofticeque lineolis duabus approximatis, fere contiguis ( quarum prima latior) usque ad alarum infertionem productis, flavis. Abdomen fiavum basi excavata, fegmentis prominulis margine nigris, ultimoque toto atro. Anus interdum dentatus dente bifurcato. Pedes flavi femoribus basi nigro maculatis, anticis paullo crafsioribus. Nlac hyalinae cofta flava. Linea antica thoracis in nonnullis deest.

Habitat in filvestribus rarus, 


$$
\text { * 302. C. A F I I N I S . }
$$

Niger, thorace maculato, abdominis fegmentis flavis, basi nigris, fecundo, et tertio fpatium in medio dorsi circulare nigrum conftituentibus .

Statura, ac habitus C. Fimbriati. Frr. Etr. 2. 93. 887. a quo differt magnitudine majori, alis apice obfcurioribus, colore flavo aliter diftributo, at facies eadem. Antennae fupra nigrae, fubtus ferrugineo flavefcentes. Caput nigrum fronte fub antennis tota flava . Crabro hic, ut diximus in Fiz. Etrussca quam 1. c. confer, aden variare videtur diftributione coloris flavi, ut imporsibile pene fit fpecies fortafse diftinctas pro varietatibus non afsumere. In omnibus corpus confpisue punctulatum, et petiolus, feu primum abdominis fegmentum reliquis anguftius.

Habitat ruri media aeftate fat frequens.

$$
\text { * 303. C. V E S P O DE } 9 .
$$

Niger thorace maculato, abdomine fafciis quinque flavis interruptis, ore, pedibus, antennisque favis.

$B$ ? Vespoides. Fu. Etr. 2. 82. 859.

Proximus $C$. Flavipedi $\mathrm{F}$. at mihi diversus praelertim magnitudine dimidio majori, antennis fulvis, thorace poftice immaculato, et vix interdum lineola fcutellari flava notato. Habitat in silvis.

$$
\text { *304. C. L U N U I A T U S. }
$$

Niger thorace maculato, abdomine fafciis quinque flavis, tertia, et quarta in medio attenuatis .

Magnitudo C. Fimbriati, cui affinis . Caput nigrum, ore, punctoque pone oculos flavis. Antennae nigrae fubtus ferrugineae. Thorax niger punctis duobus anticis, fcurello linea, punctoque utrinque majufculo ad latera poftica flavis. $\mathrm{Ab}$. domen nigrum fafciis quinque late flavis, fecunda puncto in 
medio dorsi nigro non femper praefente, tertia, et quart ibidem attenuatis, et modo punctum, modo lunulas nigras efficientibus. Anus niger. Pedes toti ferrugineo-flavi. Alae fufcefcentes.

\section{*305. C. A N D R O G N US. \\ Long. 6. $\frac{x}{2}$ 1. Lat. 2. 1. vix.}

Niger, cinereo-pilosus, capite thorace majori, abdomine flavo, primis fegmentis triangulo nigro dorfali.

Caput magnum nigrum cinereo-pilofum, macula oris flava inter antennas producta tridentata. Antennae nigrae. Thorax nigcr cinereo-pilofus, capite anguftior, linea antica, et poftica flavis. Abdomen ovatum, latitudine thoracis, flavum; primo, et fecundo fegmento femper triangulo nigro dorfa1i, interdum etiam reliquis, picto. Pedes flavi femoribus basi nigris. Alae hyalinae nervis flavefcentibus. Triangulorum basis refpicit caput. Variare videtur magnitudine duplo minori .

Habitat in floribus umbellatis rarior.

\section{\#306. C. A n O F A C A T US.}

Niger punctulatus, fcutello laevi nitido, abdomine fafciis quatuor albidis in medio attenuatis, fubinterruptis.

Medius . Corpus fubobfcurum, totum punctulis elevatis fere fcabrum. Antennae nigrae. Caput nigrum orbita antica, punctoque pone oculos albidis. Maxillae basi albidae, apice nigrae. Thorax niger antice puncto utrinque diftanti, calloque alarum albidis; poftice immaculatus fcutello laevi nitido. Abdomen nigrum fegmento primo anguftiori coarctato puncto laterali bafeos albido; 2. 3. 4. 5. fafciis albidis in medio attenuatis fubinterruptis. Anus niger. Pedes ferruginei. Alae anticae flavefcentes apice obfcuriores .

Qccurrit in floribus. 


\section{*307. C. Q U I Q U E F S IATUS.}

Niger villofulus, thorace maculato, abdomine fafciis quinque flavis, prima, et fecunda interruptis.

Statura praecedentis, cui proximus, at paullo minor. Antennae fupra nigrae, fubtus ferrugineae. Caput nigrum cinereo-villofum, labio, orbita antica, punctoque pone oculos flavis. Thorax niger cinereo-villofus, puncto antico utrinque, callo alarum, lineolaque fcutelli loco flavis. Abdomen nigrum primo fegmento coarctato, fafcia feu potius macula utrinque fubcontigua flava; 2.3 .4 . et 5 . fafciis flavis in medio attenuatis, neque fubtus continuatis fafciaque fecundi fegmenti late interrupta. Anus niger. Pedes ferrugineoflavi. Alae flavefcentes apice fufcae. Variare videtur punctis frontis coalitis, feu fronte flava, punctoque loco fafciae primi fegmenti abdominis minutifsimo.

Ruri degit fat frequens.

$$
\text { 308. C. S P I N OS U S. }
$$

Niger thorace postice bidentato, abdomine fafciis tribus favis . F. $\int p .469 .2$.

Medius. Caput, et antennae nigrae ore argenteo. Thorax niger lineola antica flava, poffice utrinque dente valido armatus, fubtus argenteo pubefcens. Abdomen nigrum laeve nitidum fafciis tribus flavis. Pedes nigri femorum geniculis, tarfisque subferrugineis. Alae fufcefcentes.

Habitat in filveftribus rarior.

CXXVII. AP I S .

Os lingua inflexa quinquefida. Palpi brevissimi. Antennae filiformes.

309. A. P A S C U O R U M.

Long. 7. 1. Lat. 4. 1.

Rufa, antennis, pedibusque nigris. Scop. Ent. Carm. 819. 
Apis quae ab Europa Boreali mihi pervenit fub nomine $A$. Agrorum $F a b$. sane huic valde affinis. Magnitudo A. Hortorum . Totum corpus superne pilis luteo-rufis longis, denfisque; inferne nigris hirtum. Tibiae pofticae latae, comprefsae, lateraliter glabrae nitidae. Antennae nigrae. Alae ad apicem fufcefcentes. Variat magnitudine minori. A. $R$ tbfa Sibrank. E. I. 803. foret ne huc referenda?

Habitat ruri, et in hortis obvia.

\section{A. BI C O R N S}

Fronte bicorni, capite nigro, abdomine hirfuto rufo. $F$. $\int p$. 483. 52. Linn. Syst Nat. 954 10. Fn. Sv. 1691.

Villers Ent. t. 3. 288. 9. t. 8. f. 23. An $A$. Rufae faemina? Copula connexas vidit $P$. Forskaebl.

Omnino diftincta ab A. Cormigera. Fn. Etr. 925.

Habitat apud nos rarior.

\section{A. P I P ES.}

Grifea, pedibus intermediis fafciculato pilofis . F. $\sqrt{p} \cdot 484: 34$. Apis Plumipes. Pall. Spicil. Zool. fasc. 9. 24. t. 1. $f$. 14. Apis Plumipes. Sibrain. E. I. 804.

Apis Pilipes. Frt. Etr. 2. 102.910.

Habitat ineunte vere pafsim, Pomonae flores in hortis frequentans. Sub vefperum quaeritat apta parietum foramina ibique pernoctat.

$$
\text { * 312. A. A E M U I A. }
$$

Hirfuta atra, ano albo, tarfis fubrufis .

An $A$. Soroeensis $F$. $\int \hat{p} .476$. 9. varietas? cum qua omnino convenit, magnitudine excepta majore, anoque villo magis albicante, in A. Soroecnse Schaeff. Ic. t. 251.f. G. enim paullulum ad ferrugineun vergit.

Vix minor A. Lapidaria. Tota atra, hirfuta, folo ano albo. Tarsi fubrufi.

Lecta in silvis. 


\section{\% 313. A. P A L M I P E S .}

Hirfuta nigra, oculis glaucis, thorace, abdominisque basi fulvis, tibiis intermediis, comprefso-dilatatis, hirfutis, atris . Statura, et magnitudo omnino $A$. Bicornis. Antennae nigrae thorace breviores, articulo primo fubtus flavo. Caput fronte hirfuta fulva, labio tumido flavo, lincola media nigra tranfversa notato. Oculi glauci. Thorax hirfutia fulva densa contectus. Primum, et fecundum abdominis fegmentum fulva, reliqua quatuor pilis nigris hifpida; fubtus totum nigrum. Pectus flavefcens. Femora, ac tibiae nigrae pilis albidis ciliatae, juncturis, tarfisque albicantibus, nigro ungulatis . Tibiae intermediae comprefso-dilatatae, patelliformes, patella rotunda pilis denfis atris inftucta, albido-ciliata. Femora primi, et fecundi paris apice unispinofa, poftica vero bispinosa. Alae hyalinae nervis fufcefcentibus : Ab A. Pilipede omnino diverfa etiam palmulis tibiarum majoribus, tomento aterrimo denfo veluti intextis, pilisque longis rarioribus deftitutis.

Quamvis non facile fit judicium de Apibus hirfutia rufa, aut fulva veftitis, ob multiplicem earun fpecierum copiam, ac negligentiam auctorum in differentiis adnotandis, tamen cum haec noftra notis gaudeat pene fingularibus, nulla potest dubitatio exoriri de ejus novitate.

Habitat ruri. Lecta m. April.

$$
\begin{aligned}
& \text { 314. A. R E G A L I } 5 \text {. } \\
& \text { Long. 6. 1. Lat. 2. } \frac{2}{3} \text { 1. }
\end{aligned}
$$

Nigra, thoracis abdominisque basi flavis, ano fulvo. Geoff. Ins. 2. 417 . 23. et Var. N. B.

A. Regalis. Ent. Paris. 2. 449. 24.

An A. Arbustorum varietas . F. $\int p$. 477. 16?

A. Terrestri fimilis, fed minor. Frons, thoracis, abdominisque bafis, in meis fpeciminibus, fulphureo-flava. Medium abdominis nigrum . Anus rufus. Quamvis defcriptio Raj. Ins. p. 247. 10. a Geoffroy in synonymia A. Arbustosum. Ins. 
2. 417. 22. allata, huic omnino competere videatur, cum a vera $A$. Arbustorum e Svecia mihi transmifsa, differat magnitudine paullo majore, et abdominis basi flava, ad eam tuto referre haec nostra minime placuit.

Habitat ruri non frequens.

$$
\text { 315. A. S U B T ER A NEA. }
$$

Hirsuta, atra, ano fusco. $F . \int p .26$. Limn. Syst. Nat. 951. 51. Fin. Sv. 1718.

Geoff. Ins. 2. 416.20.

Raj. Ins. 246. I.

Statura $A$. Violaceae, at minor. Tota hirsuta atra folo apice abdominis minus nigro, et pilis quibusdam circa collum fulphureis. Alae atrae.

Habitat fub terra.

$$
\text { * 316. A. A L B O P U N C T A T A. }
$$

Nigra fubhirsuta, abdomine atro, fegmentis primis quatuor utrinque albo-punctatis, alis violaceis .

Statura A. Centuncularis, at major. Caput antennaeque nigrae, breves. Collum paullulum elongatum . Thorax niger fubhirfutus. Abdomen nigrum breve magnitudine thoracis, basi magis hirtum, apice fere glabrum, quatuor primis fegmentis utrinque albo-punctatis, punctis magnitudine decrefcentibus : fubtus obfcurum . Pedes nigri fubhirfuti, plantis fubrufis. Alae praefertim anticae totae violaceae. Differt ab A. Lactuosa Scop. et Scbrank. statura, magnitudine, hirfutia minori, capite thorace pedibus omnino nigris. $\mathrm{Ab} A$. Punctata $F$. magis etiam differt.

Capta in herbidis filveftribus.

$$
\text { *317. A. V A R A N S. }
$$

Mar. Long. 6. $\div$ 1. Lat. 2. 1. Fem. Long 8. 1. Lat. 3. 1. vix.

Nigra, thorace abdominisque basi fuperne hirfuto fulvis, mas: femina tota nigra alis atro violaceis. 
Nigra, thorace, abdominisque basi fuperne lana rufa. Geoff. Ins. 2. 409. 4. L' Abeille macome à poils roux. Mas.

A. Bryorum, nigra, thorace, abdominisque basi hirfuto-fulvis. Schrank. E. I. 8 I 2. Mas.

Descr. Masc. Caput nigrum labio, ac fronte hirfutia flava albicantibus. Maxillac, oculi, antennaeque nigrae. Thorax fupra pilis rufis dentis, fubtus favo-albidis hirtus. Abdomen inferne totum nigrum, fuperne primis tribus fegmentis pilis rarioribus rufis; reliquis tribus nigris hifpidis. Pedes nigri femoribus anticis flavo-albidis hirtis, tibiis, tarfisque minus rufo-pilofis. Alae hyalinae ad apicem fufcefcentes. Ultimum abdominis fegmentum apice nonnihil fubincurvato, et fpinis duris brevibus ferrulato. Anus aculeo deftitutus .

Descr. Fem. Mafculo dimidio major. Colore corporis A.Violaceae adeo fimilis, ut jam antea faepius lecta in floribus, incertus diu, multumque fuerim de $A$. Violacea juniori, recensque exclusa: at revera magnitudo minor, ftatura oblongior, mandibulae porrectae, neque uti in $A$. Violacea incurvatae, pedes minus villosi, et alae magis atro-violaceac breviores. Tota atra hirfuta praeter maxillarum apicenı, digitosque ferrugineo-pilofos. Alae atro-violaceae. Anus non uti in mare incurvatus, et aculeo valido armatus .

Rbeaumurius, Geoffroy, aliique afserunt nidificare in muris - Soli meridiano expofitis: Mihi domi exclusae e nido pyriformi, durifsimo, magnitudine ovi Gallinacei, compofito ex arena minutifsima, agglutinata circum caulem fuffuticofum prope terram, et cellulas 10. , aut 11 . inordinate difpofitas continente, e quibus fub finem Aprilis domicilio communi dentibus ftrenue perforato prodierunt omnes, fcilicet novern masculi, duaeque tantum feminae, quae ultimae fe declararunt. Labor perforandi nidum improbus, afsiduus, fere triduanus. Ad haec, quid novi ulterius in hoc nido mihi obfervare contigerit, jam dictum p. 94. "3. 210.

\section{* 3I8. A. O B S OLETA.}

Nigra; cinereo-pubefcens, abdomine antice teftaceo, poftice nigro, fegmentorum apicibus cinereo-lucidis . 
Proxina And. Etruscae, ejusdemque fere magnitudinis. Caput nigrum pubefcens, fronte, ac orbita oculorum poltica cinereo lucidis. Antennae obfcure-nigrae convolutae. Thorax niger obfcure-cinereus pubefcens. Abdomen fere glabrum, ovatum magnitudine thoracis, primis duobus fegmentis teftaceis, reliquis nigris, et ad apicem cinereo-lucidis. Femora nigra. Tibiae, tarlique teftacei. Alae flavefcentes.

Habitat in filvis .

$$
\text { 319. A. LE U C O Z O N I A. }
$$

Nigra, abdominis fegmentis basi albis. Scbrank. E. I. 819. Tota nigra pilofa, non hirfuta. Abdomen nitidum conftat fegmentis quinque, quorum tria intermedia basi albifsima candore orto ex pilis albis denfis decumbentibus. Pedes rufefcente villo pubefcunt, Schr. l.c. Haec nostra nisi eadem, huic valde proxima.

Occurrit in floribus .

$$
\text { 320. A. A L B I P E S. }
$$

Fufca, abdominis medio rufo, tibiis albis. $F_{0} \int p \cdot 486.78$. Statura parva omnino $A$. Anmulatae . Caput, et thorax fufca, parum pubefcentia. Abdominis fegmentum fecundum apice, tertium totum, quartumque basi rufum. Pedes nigri tibiis albis macula bafeos fusca. Variat interdum fegmento fecundo, tertioque rufis, macula media nigra. F. Corpus oblongum. Habitat in floribus .

$$
\text { * 321. A. S U B A U R A T A. }
$$

Subaurata pubescens, tibiis, tarfisque ferrugineo-flavis . Parva. Tota fubaurata pubefcens, gibba. Antennae breves, fere in medio infractae, nigrae. Abdomen fubauratum fegmentorum marginibus albicantibus, feu minus nitidis. Femora divaricata nigra. Tibiae, tarfique villosuli ferrugineoflavefcentes. Alae albo-hyalinae. Dantur aliae ftatura, ac magnitudine fere And. Aeneae, villofulae, aureo nitidiores, capite majori, antennis longioribus basi infractis pedibus nigris. An varietas And. Aeneae?

Habitat in floribus non rara. 


\section{A. LIN GUARIA?}

Antennis nigris, longitudine corporis, thorace cinereo abdomine nigro. $F$. $\int p .487 .82$.

Statura $A$. Longicornis, et vix minor. Antennae nigrae longitudine corporis. Caput nigrum ore paullulum cinereo-tomentofo. Thorax lateribus, ac inferius praefertim hirfutia tectus. Abdomen nigrum fubrotundum, glabriufculum. Pedes cinereo-hirfuti. Labium in meo fpecimine nigrum, ct lingua ne deftrueretur Infectum, non fatis examinata. Inveni in horto .

$$
\text { *323. A. C U C UR B I T I N A. }
$$

Nigra nitida, labio puncto flavefcente, abdomine obtufo, apice latiori.

Parva. Tota nigra nitida, glabra. Antennae breves. Tibiae cinereo pilofae. Alae albae puncto parvo nigro marginali. Habitat in floribus.

\section{NOMADA.}

Os lingua inflexa trifida. Palpi quatuor inaequales: postici

linguaeformes articulo secundo longissimo. Antennae filiformes.

\section{N. F A B R IC I A \& A .}

Nigra, abdomine glabro ferrugineo, maculis duabus flavis. $F$. jp. 488. 5.

Apis Fabriciana, Linn. Syst. Nat. 955. 17.

Statura N. Ruficornis, at minor. Alae fufcae lunula media apicis alba. Variat abdomine rufo immacuàato. Adit flores in filvis non frequens.

$$
\text { 325. N. G I B B A. }
$$

Nigra, abdomine rufo, apice nigro. $F . \int p .488 .6$.

Nomada Succincta. Scop. Amn. Hist. Nat. IV. 45. 2. Abdomen ellipticum basi rufum. Nervi alarum rufi. Saepitas lecta in floribus. 


\section{Clas. III. Synistata. Nomada. \\ 326. N. C I NG U L A TA.}

Cinereo-villofa, abdomine glabro, nigro, fegmento secundo, tertioque ferrugineis. $F$. $\int p .488 .8$.

Statura praecedentis. Alae albae.

Habitat in filvis.

\section{* 32\%. N. C I N C T A.}

Nigra, abdominis fegmentis basi flavis apice nigris.

Statura, ac magnitudo N. Fabricianae. Antennae luteae interdum fulvae articulo primo fubtus flavo. Caput nigrum pubefcens ore, maxillis, linguaque flavis. Palpi nigri albo annulati. Thorax niger pubefcens, nunc linea, nunc punctis duobus anticis, puncto ante, et fub alis, binisque loco fcutelli flavis. Interdum etiam latera poitica flavo-punctata. Abdomen nigrum glabrum fegmentis omnibus basi tam superius, quam inferius fafcia flava cinctis. Pedes flavi femorum basi nigra. Alae ferrugineae. Fafciae abdominis in medio paullulum attenuatae.

Raro lecta in filvis.

$$
\begin{aligned}
& \text { *328. N. P U S I L L A. } \\
& \text { Long. 2. 1. vix. }
\end{aligned}
$$

Pubescens, abdomine glabro nigro quadrimaculato.

Statura praecedentis, at duplo minor. Caput nigrum vix albo-pubefcens labio margine flavo. Antennae porrectae longiufculae fupra nigrae, fubtus ferrugineae articulo primo nigro. Thorax niger pubefcens puncto unico flavo utrinque ante alas. Abdomen fupra nigrum, glabrum, et. in medio dorsi maculis quatuor flavis oblongis transversis notatum. feu fasciis duabus interruptis approximatis cinctum : fubtus immaculatum fufcum. Pedes flavi femoribus exterius nigris. Alae abdomine longiores, hyalinae, puncto marginali nervisque nigris .

Occurrit in filvestribus rarior. 


\section{CXXIX, $\quad F \quad O \quad R \quad M \quad I \quad C \quad A$.}

$P a l p i$ quatuor inaequales articulis cylindricis . Labium fubmenbranaceum, cylindricum, apice palpigerum.

Anteniae filiformes.

$$
\text { 329. F. F U S C A. }
$$

Nigra, ore, thoracis apice, pedibusque ferrugineis. $F . \int p \cdot 490.9$. Formica Fusca cinereo-fusca, tibiis pallidis. Limn. Syst. Nat. 963. 4. Fn. Sv. 1722. Geoff. Ins. 2. 428. 5 .

Formica nigra nitida fquama petiolari. De Geer Ins. 2. 2. 1082.

t. 42. f. 12 .

Scbrank. E. T. 833.

In ejus acervis habitat Cet. Aurata ante declarationem. Schrank. Habitat in terra arenofa.

$$
\text { 330. F. F L A V I P E S. }
$$

Nigra, antennis, pedibusque flavis. Vill. Ent. 3. 337. 10. t. 8. $f$. 31 .

Nigra. Alae albae breviores quam in $F$. Fusca: Pedes lutei, at antennae in noftris vix flavefcentes. Habitat etiam in hortis .

CXXX. MUTILLA.

Palpi quatuor articulis obconicis. Labium porrectum, corneum, obconicum apice palpigerum. Antennae filiformes.

$$
\begin{gathered}
\text { *31. M. C O R O N A T A. } \\
\text { Long. 4. } \frac{1}{4} \text { 1. Lat. I. } 1 \text {. }
\end{gathered}
$$

Hirta atra, fronte albo maculata, thorace tibiisque rufis, abdomine puncto fasciisque duabus approximatis albis .

Eadem quam dedimus fupprefso nomine una cum M. Rufipe de in Fn. Etr. 2. 115.941.

Differt a $M$. Rufipede, magnitudine triplo majori, fronte albe maculata, antennis fufco rufis, fafcia antica in medio caput verfus protenfa angulata, abdominis fegmentis omnibus fubtus albo villo ciliatis.

Habitat Pisis obvia in filvestribus arenosis. 
Hirta nigra, abdomine basi rufo, apice nigro, fegmentis duobus pilis albis ciliato. Alata.

T? Stridula. Fn. Etr. 2. 68. 830. to 6. f. z. Habitat in filvis frequens .

\section{*333. M. E P н I P P I U M. Long. 4. 1. Lat. $\frac{2}{3} 1$.}

Hirt2 nigra, thorace antice rufo, poftice nigro, abdominis fegmentis tenuifsime albo ciliatis.

Statura praecedentis, at dimidio minor. Caput nigrum pilofum. Anternae nigrae. Thorax pilofus antice rufus, poftice niger, fubtus totus niger. Abdomen nigrum hirtum, fegmentis omnibus albo-ciliatis. Pedes nigri albo-pilosi. Alae apice fufcefcentes.

Variat colore rufo thoracis nunc magis, nunc minus fupra dorfum poftice extenfo, et abdominis apice modo incurvato, acutiufculo, modo magis obtufo, uti etiam magnitudine minori . Habitat in campis sabulosis Pisanis rarior.

$$
\begin{aligned}
& \text { * 334. M. N I G R A . } \\
& \text { Long. 4. 1. Lat. } \frac{2}{3} 1 .
\end{aligned}
$$

Hirta; tota nigra.

Statura, ac magnitudo praecedentis, praefertim varietatis abdominis apice obtuso indicatae. Corpus totum nigrum, pilis albis fubhirtum, capite, thoraceque punctulatis, fere fcabris. Oculi majufculi. Alae apice obfcuriores, puncto nigro marginali .

Rarifsime lecta in iisdem locis. 


\section{A N T I S S A \\ I N S E C T O R U M}

EXHIBENS SPEGIES NUPER IN ETRURIA

C O L L E G T A S

$A$

P E T R O ROS S I O

ADIECTIS FAUNAE ETRUSCAE ILLUSTRATIONIBUS;

AC BMENDATIONIBUS

T о м. II.

P I S I S

Ex Ty Tographa Prosteri

$$
\begin{gathered}
P R A E S I D U M \text { FACULTATE } \\
\text { MDCCXCIV. }
\end{gathered}
$$







\section{G L A S S I S:Q U I N T A. \\ U N O G A T A.}

CXLIII. TR O M B I DIU M.

Palpi incurvi apice acutissimi, os tegentes. Labiun concavum maxillas recipiens.

*335. T. T R I M A C U L A T U M.

Abdomine nigro depresso, tomentoso: maculis tribus aequalibus albis.

Statura, \& magnitudo fere T. Holosericei. Os palpiq. fulvi. Abdomen nigrum depressum tomentosum macula laterali ad basin utrinq. notatum, alteraq. in medio ad apicem albis . Pedes fusci, antice, \& subtus fulvi .

Habitat intra corticem, \& lignum in arboribus putrescentibus. m. Mart. rarum.

\section{CXLIII. $A R A N E A$.}

Palpi incurvi, maris clavati. Labium breve, apice rotundatum,

\section{A. V I R I D I S S I M A.}

Textoria viridis, abdomine oblongo flavescente. De Geer 7. $252.14 .6 .18 . f .6 .16$.

Clerck Aran. t. 6. S. 4. Araneus virescens.

Tota abdomine excepto, viridis; Thoracis latera luteo marginata. Abdomen luteo virescens linea longitudinali viridi, laminaq. squammosa nigra in feminae genitalibus. Oculi pilis albis cincti transverse positi duas lineas formant. Posteriores anterioribus majores. Villers. Magnitudo media. Habitat Florentiae. 
Clas. V. Unogata. Arnnea.

\section{A. P H A L A N G O I D E S .}

Fusco-flavescens, pedibus longis corpore triplo longioribus . Ent. Par. 2. 535. 13. l'Araignẻe domestiquse semblable aus Foucheur?

Species indicata videtur, at diagnosis manca \& descriptione carens dubium relinquit.

Est inter maximas. Tota griseo-fusca unicolor. Palpi pediformes. Oculi in duas lineas dispositi. Thorax antice elongatus, postice rotundus planus abdomine major. Pedes corpore triplo longiores, subaequales villosi.

Habitat in domibus .

\section{A. C A T E S B A E I.}

Tota cinerea pubescens, thoracis dorso fusco, abdomine ov2to fusco, lineis dorsalibus binis longitudinalibus albis. Scop. Carn. 1109.

Vill. Ent. 4. 1 1 2: 65.

Statura ac magnit. A. Sloanii. Palpi aequales. Abdomen subtus sordide flavum. Papillarum regio nigra. Oculorum situs uti in A. Sloanii. Saltatoria.

Habitat passim in muris \& saxis hortorum.

$$
\text { * 339. A. 4-P U N T A T A. }
$$

Abdominis dorso plano nigro, punctis excavatis quatuor; anticis majoribus.

Magnitudo praeced. Nigra nitida. Pedes ferrugineo-fusci. Habitat in arborum truncis.

$$
\text { * 340. A. L T T T E R A T A. }
$$

Abdomine ovato, atra glabra, pedibus quatuor posticis rufis. Parva, \& linea numquam visa major.

Habitat inter libros, \& utensilia domestica (a).

(a) Arancarum species heic entum paucas adiunximus, nam copiosissimum hoc genus singularicer. pertractare est animus. 


\section{Clas. V. Unogata. Phalangium . \\ CXLV. PHALANGIUM.}

Palpi porrecti incurvi. Maxilla superior chelifera.

Abdomine ovato griseo, subtus albo. F. Sp. 547. 2. Limm.

Syst. Nat. 1027. 2. Fn. Sv. 1992. Scop. Carn. 1122.

Pbalangium Parietinum corpore ovato supra griseo-fusco,

subtus albido. De Geer Ins. 7. 166. 1.'t. 10. $f$. 1.

Geoff. Ins. 2. 629. t. 20. f. 6.

Sibrank. E. I. 1088. Faun. Fridr. n. 823.

Mortf. Ins. 234. f. 4. Aldr. Ins. 602. f. 4

Goed. Ins. 2. t. 49. List. Goed. f. 143.

Hoeffin. Ins. 2. t. 9. Raj. Ins. 39. n. 35.

Bradl. Nat. t. 24. f. 2. Clerck. Aran. t. 6. f. 1 0.3.

Sulz. Ins. t. 22. f. 140. Hook Microg. p. 198. t. 31.

Villers. Ent. 4. 80. 2.

Mas minor femina. Oculi duo in capitis vertice fere contigui. Palpi 2. longiusculi apice pallidi Abdomen subtus albidum supra griseo fuscum striga interdum postica alba . Pedes longissimi geniculis quasi duplicatis tibiisq. crassioribus angulosis.

Habitat in muris hortorum . 


\section{L A S S I S E X TA.}

G L O S S A T A.

\section{P A P I L IO}

Palpi duo reflexi. Lingua spiralis exserta. Antenune clavatae.

P. D. C. alis integerrimis angulatis flavis, anticis supra disco fulvo, reliquis puncto ferrugineo. $F . S p .52 .225$. Limmo Syst. Nat. 765.105.

Mull. Syst. Nat. t. 5. p. 594.

Villers Ent. $t$. 2. 15.17.

Fin. Etr. 2. 145.999.

Cyrill. Fu. Neap. specim t. 3, f. 2, male colorata. Discus alarum anticarum nimis obscure fulvus.

P. Cleopatra, \& P. Rhamni aut una eademq. species est quae in masculis variat alis primoribus disco fulvo, aut femina P. Cleopatrae adeo omnino similis feminae P. Rbamsi, at impossibile sit absq. larvae cognitione, frustra hactenus a me quaesita, dubium resolvere. Saepe capti plures P. Cleopatra, semperq. mares inventi, illosq. non vera copula junctos, sed saepissime praeludia Veneris cum ea quae alis pallidioribus habetur pro femina P. Rhamni instituentes vidi, cum frequens hace occurrat eodem tempore \& 10co. Ad assumendum tamen pro varietate, non parum obstare videtur ejus defeetus in variis Europae locis ubi communis invenitur P. Rbamai, quamvis aeris naturam, aliaq. sub calidiore coelo coloris differentiam inducere posse nemo jam dubitet, \& plura non desint exempla etiam in aliis speciebus dari varietates tantum proprias, ac peculiares quarumdam Regionum.

Habitat Pisis。 


\section{P. P H I C. O MON E.}

P. D. C. alis integerrimis rotundatis flavescentibus, atomisq. nigris, omnibus rubro fimbriaris; superioribus fascia maculari in limbo nigro, inferioribus nigricantibus, limbo flavescenti fusco marginato; supra macula pallida, subtus puncto argenteo. Vill. Ent. t. 2. 17. 20.

Pap. d. Eur. t. 89. f. 112. bis.

An $P$. Hyales varietas?

Habitat Pisis rarior.

\section{P. I R I S.}

P. N. G. alis dentatis utrinq. fascia albida interrupta oculoq. unico. F. Sp. 86. 38 2. Limm. Syst. Nat. 775. $16 \mathrm{t}$. Esp.t.71.f. ז.

Ernst. t. 31. f. 62, a. b. c. le grand mars ciangeant. Fn. Etr. 2. 150. 1014:

ค. P. Clytbia. W. S. p. 321 .

Roesel 3.t. $42 . f .3 \cdot$. 4.4.

Esper t. $25 . f .4$.

Ernst t. 32. f. 64. c. 9. 2t. t. 70. f. 64. h.

Schaeff. Ic. t.: 152 . f. 1.2.

Lecta pluries in salice sub finem Julii. Larva viridis lineis albis obliquis, capite bicorni. Pupa alba lateribus compressa bicornis. Imago paucis diebus declaratur.

\%. P. Eos. Le grand Mars Orangé.

Ernst. t. $31 . f .63 . a$ b. u. t. 69. f. 63. c. d. u. t. 70. f. 36. e. Schaef. Ic. t. 152. f. 3 .

Hae tres varietates occurrunt etiam apud nos, sed prior rarissima.

Habitat in Salice, Fraxino.

\section{P. F I D I A 。}

P. N. G. alis dentatis supra fuscis: anticis ocellis duobus, punctisq. duobus albis, posticis subtus striga angulata atra. Fo. Sp. 71. 317. Linn. Syst. Nat. 770. 138.

Ocelli ad marginem exteriorem, inter quos puncta duo alba. Tom. II. 
Alae posticae subtus fusco alboq. variae striga sesquialtera angulata atra.

Habitat in silvis non rar..

346̣. P. F A U. N A.

P. N. G. alis dentatis supra fuscis: anticis ocellis duobus, punctisq. duobus albis, posticis subtus griseis . F. Mant. 35.371 . Esper. t. 29. Supp. 5. t. 63. f. I.

Villers. Ent. 2. 35.50.

Pap. d' Eur. t. 28, 55, a.

P. Fidia dimidio minor, cui affinis.

Habitat cum praeced. minus frequens.

\section{P. M A E R A.}

P. N. G. alis dentatis fuscis, utrinq. anticis sesquiocello, posticis ocellis supra tribus, subtus sex. F. $S p .71,31 \%$. Linn. Syst. Nat. 771. 141. Fu. Sv. 1049.

Schaeff. Ic. t. 58 . f. 2. 3 .

Valde affinis P. Megerae at distincta.

Habitat in Poa annua. Apud nos rarior P. Megeqa.

348. P. I D A .

P. N. G. alis subdentatis fuscis: disco fulvo: anticis utring. ocello nigro bipupillato, posticis subtus griseo-variis. $F$. Mant. 43. 429.

Alis subdentatis, concoloribus fulvis, limbo fusco, primoribus ocello utrinq. bipupillato, posticis subtus fuscis lituris albis. Vill. Ent. 2. 39. 70.

Esper. Pap. tab. 92. f. 2.

Minor P. Pilosellae. Discus alarum anticarum fulvus lituris ad marginem interiorem quibusdam nigris.

Habitat in pratis silvestribus frequens.

\section{P. A G L A 1 A.}

P. N. P. alis dentatis fulvis, nigro maculatis, subtus maculis 21. argenteis. F. Sp. 109. 475. Limn. Syst. Nat. 785.211. Fn. Sv. 1065 . Geoff. 2. 42. 9. 
Roes. Ins. 4. t. 25.

Esp. pap. 1. t. 17. f. 3 .

Schaeff. Icon. t. 7. $f$. 1. 2.

Habitat in Viola tricolore non frequens.

\section{P. A T H A L I A.}

P. N. P. alis dentatis fulvis nigro fasciatim maculatis, subtus fasciis tribus flavescentibus immaculatis nigro inductis, divisisq. Villers. Ent. 2. 58. 96.

Pap. d'Eur. t. 19. f. 31.-t.61.f. 6. Varietas. Geoff: Cinxiae Varietas. B.

Habitat Silvas in Lysimachia vulg. non rara.

\section{P. E U P H R O S Y N E.}

P. N. P. alis dentatis fulvis nigro maculatis subtus maculis 9. argenteis. F. Sp. 111. 482. Limn. Syst. Nat. 786.214。 Fin. Sv. 1069. Geoff. Ins. 2. 44. 31.

Siop. Ent. Carn. 441.

De Geer t. 2. p. 197. t. 1. f. 10. 11.

Esp. t. 18. f. 3. t. 30. f. 1. var.

Pap. d' Eur. t. 16. f. 22. a. b. 23, a. b.

Habitat in Viola montana.

$$
\text { 352. P. B O E T I C U S . }
$$

P. P. R. alis caudatis coerulescentibus, subtus cinereis, albo-undatis, angulo ani ocello gemino aurato. $F$. Sp. 11\%. 529. Linn. Syst. Nat. 789.226.

Geoff. Ins. 2. 57.25.

P. Coluteae Fro. Etr. 2. 155. 1032 .

Esper. t. 37. f. 3 .

Pap. d' Eur. t. 37. f. 76 .

Fuesl. Ins. n. 594. f. 2.

Larva obesa fuscorubra, striis interruptis obliquis albis, capite fere toto intra prinum segmentum retractili. In statu adulto subviridis. Metamorphosin subitura tenui filo se circumligat. Pupa pallida fusco-punctata. Quies 2. haebdomadum. 
Habitat in leguminibus Coluteae Vesicariae semina comedens, mens. Septembris praesertim frequentissim. .

\section{P. A M Y N T A S.}

P. P. R. alis caudatis cyaneis margine nigro subtus cinereis. punctis nigris, posticisq. duobus ferrugineis anguli ani. F. Mant. 70. 666 .

P. Anyntas Wien. Verz. 185.18.

P. Tiresias. Esp. pap. t. 49.f. 2.

Habitat in pratis silvaticis non frequens.

P. P $\mathrm{R}$ alis $\mathrm{P}$. C O R Y D O N.

P. R. alis integris coeruleo argenteis : margine nigro subtus cinereis: punctis ocellaribus, posticis macula centrali alba. Fab. Mant. 74. 693.

P. Corydon. Wien. Verz. 184. 10.

P. Corydon. Esp. pap. t. 33. f. 4 .

P. Corydon. Kleeman. t. 14. f. 3 .

Mas a femina differt.

Habitat silvas .

355. P. D O R Y L A S .

P. P. R. alis integris coeruleis (fuscis) subtus cinereis: anticis puncto medio, strigaq. postica punctorum ocellatorum. F. Mant. 75. 695.

P. Dorylas. Wien. Verz. 322. 19.

$P$. Adonis affinis, at paullo minor .

Habitat in pratis.

\section{P. C Y L L A R U S.}

P. P. R. alis integris coeruleis: margine nigro, subtus fuscocinereis, striga punctorum ocellatorum, posticis basi caeruleis. F. M. 72. 685. Geoff. Ins. 2. 63. $3 \mathrm{I}$.

P. Damoetas W. V. 183.7 .

P. Alexis Pod. M. G.

Esper. Pap. t. 33. f. 1. 2.

Roes. Ins. 3. t. $37 . f .4$.

Habitat in Astragalo Onobrychide . 


\section{Clas. VI. Glossata. Sphinx. \\ 357. P. P A.N I S C U S.}

P. P. V. alis integerrimis divaricatis; posticis utring. fuscis fulvo maculatis. F. Mant. 85. 767 .

P. Brontes. Wiens. Verz. 160. 6.

P. Silvius. $\beta$. Esp. Pap. t. 8\&, f. 5. 6.

Habitat in silvis non rarus.

\section{SP H INX.}

Palpi duo reflexi pilosi. Lingua spiralis plerisq. exserta. Antemae squammatae.

\section{S. A $\mathrm{T}$ R O $\mathrm{P}$ O S .}

S. alis integris, posticis luteis fasciis fuscis, ablomine luteo cingulis nigris. F. Sp. 144. 23. Limn. Syst. Nat. 199. 9. Fn. Etr. 2. 161.1050.

Veritas si admodum a Natura occultata fuerit, nonnisi pluries repetitis observationibus erui potest. Immortalis Rheaumurius asseruit Sphingem Atropon declaratam stridere allidendo palpos ad linguam. Mihi aliter visum in historia quam de hac sphinge dedimus, visumq. deinde comprobandam esse redintegrandamq. cjusdem cl. viri opinionem in Fauna Etrusca. Mox autem cuni non plane adhuc certus, aliquid subesse in factis periculis haud bene animadversum vererer, rursus ad experimenta me contuli, iisq. diversimode centies variatis, persuasere mihi tandem derivare $a b$ ore, aerisq. expiratione in linguae cavitatibus. In Insecto enim recens declarato cum magis viget, ac strijet, si ad tasim lingua amputetur, sonitus non cessat, at fit exilior, \& observantur bullulae ab aere expirato productae ir. extremitatibus abscissis oriri: \& si tum in vase aqua redundante sphingis os vix immergatur, stridor illico cessat, qui renovatur statim ac ab aquae contactu removetur, \& vicissim toties 


\section{Clas. Vil. Grossata. Sphinx .}

auditur, vel non, quoties aut aquae os admovetur, vel ab eadem extrahitur; unde patet sonitum oriri ab aere per linguam immisso, quemadmodum edit fistula inflata, vel alius quicumque tubus cavatus per quem aer spiret. Hic autem sonitus amputata lingua forte non cessat, evaditq. tantum paullo languidior, quod abscissio linguae ad originem imperfecte fit, \& aeris intromissio per tubulorum reliquias, \& oscula continuatur, uti integra cessatio confirmat cum eadem oscula sebo vel alia pingui materia obturantur. Sonitum vero numquam in statu quietis, at molestiae tantum edere observamus, nam tum fit quasi necessarius anhelitus, \& humoris ad os concursus, qui una cum aere ad eum efficiendum idoneum esse plane intelligitur. Ex quibus omnibus concludi posse videtur experimenta jam primum capta, conf. bist. bujus Spbingis, Opusc. di Milano ann. 1782. hisce nuper a me institutis palam respondere, ideoq. veterem confirmandam esse opinionem quam tunc 1 . cit. dubitative dedimus; nempe legem $\mathrm{Na}$ turae universalem non esse stridorem, \& sonitum quemlibet in Insectis caussam semper ab attritu partium repetere, cum Sphinx haec, vera quodammodo voce praedita, regulae, seu potius observationibus hactenus factis exceptionem suppeditet validissimam .

Habitat in Jasmino, aliisq. plantis frequens.

\section{S. L I N E A T A.}

S. alis virescentibus: fascia striisq. albis, posticis nigris: fascia rubra. F. Mant. 96. 37.

Spbinx Koecblini. Arch. Ins. Fyesl. Monog. c. f. 19.

Petiv. Gazoph. t. 12. f. 9.

Habitat in Galio vero sat frequens.

$$
\text { 360. S. G A L I. }
$$

S. alis integris virescentibus: vitta alba, posticis pallidis bosi, strigaq. atris, antennis fuscis. F. Mant. 95. 36.

Wien. Verz. p. 42 .

Esper. Ins. t. 21. 
De Geer t. 2. p. 236.

Scbaef. Ii. t. 78. f. 1. 2.

Habitat in Galio vero.

$$
\text { 361. S. P O R C E L L U S. }
$$

S. alis integris, flavo purpureoq. variis, abdomine subtus sanguineo albo punctato. F. Sp. 149. +4.

S. Pcrcellus alis integris margine rubris, posticis basi fuscis . Linn. Syst. Nat. 801. 18. Fn. Sv. 1090.

Geoff. 2. 88. I 2.

Roes. Ins. 1. phal. 1. t. 5.

Alb. Ins. t. 9 .

Esper. t. 2. t. I 0.

Habitat in Galio vero. Sub vesperum imago lecta ad flores Iasmini.

$$
\text { 362. S. O E N O T H E R A Ė. }
$$

S. alis eroso-virescentibus, fascia saturatiore; posticis fulvis apice atris. F. Mant. 93. 11. Sp. 141. 10.

Spbinx Oenotberae $W . V .239$. Tab. tit. praff.

Iuesl. magaz. 2. t. 1. f. 9. 10.

Esp. t. 2. t. 20. Suppl. 2.-t. 26. cont. 1. var.

Spbinx Proserpina. Pallas spicil. fasc. 9. t. 2. $f .7$.

Goeze I1. 212.29.

Erust. Ins. d'Eur. t. I 21. f. 166. le Sphinx de l'Epilobe. Habitat in Epilobio palustri. Lecta semel in horto sub Julii finem.

\section{S E S I A.}

Palpi duo reflexi. Lingua exserta truncata. Antennae cylindricae.

$$
\text { 363: S. C O N O P I F O R M I S. }
$$

$\mathrm{S}$. alis fenestratis apice fulvis, abdomine barbato nigro annulis quatuor flavis. Villers. 2. 104. 31 . 
Esp. tom. 2. t. 31. cont 6.

Habitat in floribus Umbellatis \& praesertim Sambuco.

364. S. I С H N E U M O N I F O R M I S .

$\mathrm{S}$. alis fenestratis: margine fasciaq. nigris puncto fulvo, abdomine cingulis albis nigrisq. alternis. F. Mant. 100. 19. Sph. Ichrienmoniformis Wien. Verz. 44. 7 .

Antennae in nostris basi luteae apice nigrae.

Habitat in silvestribus rarior.

$$
\text { * 365. S. A S E L L I F O R M IS. }
$$

S. alis tectis, fusco-grisea lucida unicolor.

Magnitudo Muscae domesticae. Statura gibba. Caput parvun collari tenuissimo albicante. Corpus crassiusculum. Antennae vix pectinatae. Etsi Sesiae admodum variationi subiectae, cum haec habeat alas omnes tectas, species indescricta videtur.

Habitat in silvestribus.

\section{ZYGAENA.}

Palpi reflexi. Lingua exserta setacea. Antennae saepius medio crassiores.

$$
\text { 366. Z. E P H I L T E S }
$$

$Z$. cyanea alis anticis punctis sex rubris, posticis unico, abdomine cingulo rubro. F. Sp. 158.5.

Sphinx Ephialtes. Linn. Syst. Nat. 806. 36.

Fuesl. Magaz. t. 1. f. E.

Esp. t. 2. t. 18. f. 3 .

Pap. d'Eur. t. 100. f. 144.

Panz. Fur. Germ. Hefi. Iv. 20.

Variat punctis albis baseos, uti \& cingulo abdominis nune flavo, nunc rubro.

Habitat in Medicagine falcata, rarior. 


\section{Z. T R 1 G O N E L L A E.}

$Z$. alis omnibus utrinq. atro cerulescentibus, superioribus maculis disci tribus albis, binis baseos flavis, inferioribus macula unica alba. Esp.t. 2. t. 33. cont. 8. f. 3. f. 4. var. Sibaeff. Icon. $t .165, f .3 .4 \% .4$.

Ernst. Pap. d' Eur. t. 101. f. 146. c. d.

Habitat in montuosis Florentiae.

\section{CLI. $B O M B Y X$.}

Palpi duo compreșsi, reflexi. Lingua brevis membranacea. Antenuae filiformes.

\section{B. T R I F O L I I .}

B. alis reversis ferrugineis : anticis striga, punctog. albis, posticis immaculatis. F. Mant. 112.46.

W. S. "1. 4. p. 57 .

Esp. t. 3. t. 15.

Wilkes t. 47.

Habitat in Trifolio capite purpurescente non rara.

$$
\text { 369. B. Q U E R C U S . }
$$

B. alis reversis ferrugineis, striga flava; anticis puncto albo. F. Sp. 175.39.

Frr. Etr. 2. 168.1074.

Larva polyphaga, \& a me plerumq. inventa subfinem Junii in Lauri cerasi folis, iisq. educata.

Habitat in Quercu.

\section{B. C I A V I s.}

B. spirilinguis dorso cristato, alis superioribus griseo-fuscis stigmate claviformi, fasciaq. marginali macularum nigrarum triangularium. Esper. tom. 3. t. 6.3. f. 5.

Berl. Magaz. 2. B. 426. S. $47 . \mathrm{m}$.

Naturf. 8. St. 109. S. 47. nF: $^{2}$

A nonnullis confusa cum $P$. B. Exclamationis Limn.

Habitat in silvis sat frequens.

Tom. II. 


\section{I. B. V E L I T A R I S .}

B. alis cinerescentibus denticulatis, strigis duabus albidis repandis, fusco marginatis. Esper. t. 3. t. $58, f .6$.

Naturf. 9. p. 129. n. 64 .

Magaz. de Berlin. p. 394. 23. 64 .

Goez. Ent. part. 3. t. 3. 193. 21.

Habitat in Quercu, lecta in locis silvestribus submontanis.

372. B. C O M P R S S A.

B. alis compresso-adscendentibus niveis : macula communi fusca centrali grisea: lunula alba. F. Mant. 124.137. Pyr. Bankiana. F. Syst. Ent. 645. 1.

Pbalaena Spinula $W . V .64 .6$.

P. G. Modesta. Naturf. xiI. St. p. vi. t. 3. f. 4. a. f. 4 . b.

Panz. Fn. Germ. 1. Heft. t. 6 .

Caret interdum macula grisea centrali.

Habitat in Pruno spinosa non rara.

\section{B. A E S C U L I.}

B. nivea, alis punctis numerosis caeruleo nigris, thorace senis. F. Mant. 116.85.

Hepialus Aesculi F. Sp. 208. 5.

Pbalaena Aesculi. Linn. Syst. Nat. 833. 83. Fin. Sv. 150.

W. S. t. tit. praef.

Poda Ins. 88. n. 16.

Reaum. Ins. 2. t. $38.8 f$. 1.4 .

Roes. Ins. 3. t. 48. f. 5. 6 .

Esp. t. 3. t. 62. f. onnzes.

Scbaeff. Icon. t. 3 1. $f .8$. 9 .

Antennae in masculo usq. ad dimidium pectinicornes pinnis utrinq. aequalibus.

Habitat in Aesculo Alno, Pyro, at etiam lecta in caudice Ulmi mens. Jun.

374. B. A N A C H O R E T A.
B. alis deflexis griseis: strigis albidis, macula apicis fuscoferruginea: striga undata alba. F. Mant. 120. 114. 
B. Anachoreta W. Verz. 55. 1.

Esp. t. 3. t. 51 . f. 5 .

Variat alis lutescentibus.

Habitat in Salice', Populo rarior.

375. B. A U R I F L U A.

B. alis deffexis albis: anticis subtus costa fusca, ano barbato luteo. F. Sp. 125. 145.

B. Auriflua Wien. Verz. 52.4.

Esp. t. 3. t. 39. f. 9.

Fuesl. Ins. p. 35. 81. 662.

Kleeman. p. 101. 3. 287.

Villers. Ent. 21. 153. 59.

Evist Pap. d' Eur. t. 136. f. 183.

Habitat in Pomona non frequens.

376. B. TES T U D O.

B. alis deflexis flavis, s. ferrugineis strigis duabus obliquis obscurioribus. F. Mant. 121. 116.

B. Sulphurea F. Sp. 189.86.

B. Testudo. W. V. 65. I.

Raro lecta in silvis.

\section{B. L U G U B R I S .}

B. alis deflexis flavis : rivulis punctisq. atris, posticis fuscis. F. Mant. 128. 16.5 .

Noctua Sulphurea Wien. Verz. 93. 6.

Geoffr. Ins. t. 2. 184 5. Inter Tineas.

Villers. Ent. t. 2. 434. 782 . Vera Tortrix Linn.

Schaeff. Ic. $t$. 9. f. 14.15.

Habitat in Convolvulo arvensi, frequentissima.

378. B. V E S T I T A.

B. alis incumbentibus nigris immaculatis abdomine subtus villoso albo. F. Sp. 204.146.

Reaum. Ihs. 3. t. 11, f. 7.8 .

Geoff. Ins. 2. p. 203. "1. 50 , 
De Geer t. 2. 307. t. 3. f. I 3. I 4.

T. Plumella $W . V$. 133.3.

Esp.t. 3. t. 44. f. 1:-5.

Villers. Ent. 2. 154.62.

Habitat in graminosis. E folliculo seu involucro graminibus foliolisq. aridis tecto, prodicrunt mihi domi plures $\mathrm{m}$. Sept. c larvis educatis lauri cerasi foliis.

\section{B. A P 1 F O R M I .}

B. alis incumbentibus, hyalino-nigris, abdomine ovato villoso rufo. Fn. Etr. t. 2. 178. 1105. t. 8. f. 2.

Variat, sed rarissime abdomine atro villoso.

Hujus singularis Bombycis plurium annorum spatio frustra investigavi exemplaria, deceptus fortasse volatu quo Apem mentitur, re vero explorata tandem captura facillor; sub Junii finem enim serenis diebus ante nonam horam matutinam occurrit iuxta sepes in silvis, numquam plantis insidens, sed statim ac visa primum obviam volans, volatu humili tremulo, quasi albo tibialium colore allecta, facillimeq. inde fugiens, ac rediens.

Habitat in locis silvestribus.

$$
\text { 380. B. O B S C U R A. }
$$

B. alis incumbentibus concoloribus fuscis, anticis, punctis tribus albis, posticis immaculatis. F. Sp. 206. 156.

Pb. Ancilla Linn. Syst. Nat. 835. 93.

N. Ancilla W. V. 69. 13.

Esper. t. 88. n. 6. f. 1. 2.

Antennae setaceae. habitu Tortrix.

Habitat in silvis frequens.

\section{B. $P$ U N C T A T A.}

B. alis incumbentibus concoloribus anticis fuscis albo-punctatis, posticis flavis apice fuscis. F. Sp. 206. 157.

Statura ac magnitudo praecedentis, cui valde affinis, \& forte varietas.

Habitat in locis iisdem minus frequens. 
Palpi duo reflexi. Rudimentum linguae bifidae inter palpos. Antennae noniliformes.

H. alis rufo lateis lineis duabus obliquis albis, antenn is serratis. F. Mant. 135. 6.

Statura $H$. Hecti, \& vix major. Alae luteae rufo mixtae lineis duabus obliquis albis ad marginem tenuiorem coeun. tibus. Posticae subtus obscuriores. Antennae breves serratae.

Semel lectus m. Jul.

\section{CLIII. $N$ OCTU:A.}

Palpi compressi, pilosi, apice cylindrici nudi. Lingua porrecta cornea. Anternse setaceae.

\section{N. Q U E R C U S.}

N. laevis alis incumbentibus griseis, strigis tribus fuscis. F. Sp. 214.24 .

Noctua Trilinea $W . V .84 .5$.

N. Trigrammica Esp. t. 123. 44. f. 6.

Villers. Ent. 2. 256.273.

Habitat in Quercu minus frequens.

N. laevis 384 . N. C O M P L A N A. posticis totis flavis. F. Mant. 139. 39.

P. Complana W. V. 68. 4.

Alb. Ins. t. 70. f. G. $H$.

Hubner. 1. 3. t. I. f. F.

Variat alis pallidis.

Habitat in Quercu non rara. 


$$
\text { 385. N. B A } T \text { I S. }
$$

N. laevis, alis deflexis: anticis fuscis; maculis quinque incarnatis, posticis albidis. F. Mant. I41. 56.

$P$. Batis W. V. 85. I.

Merian. Eur. 3. t. $21 . f$. I. f. 122.

Reaum. Ins. 1. t. 7. f. 2.

Roes. Ins. 4. t. 26.

Esp. t. 86. Noct. 7.f. 6.

Semel lecta in Rubo m. Jul.

\section{N. M A N I C A $\mathrm{T}$ A.}

N. lacvis alis purpurascentibus, strigis undulatis, pedibus maris manicatis. Vill. Ent. t. 2. 275. 349. t. 5. f. 22.

Magnitudo N. Rivularis. Pedes antici in masculo valde lanati.

Habitat in silvestribus frequens.

$$
\text { * 337. N. B E N G A L E N S I.S. }
$$

N. laevis alis deflexis anticis subauratis, fuscoq. variis, maculis subrotundis duabus aurato-argenteis .

Statura ac magnitudo fere $N$. Festucae. Alae anticae subauratae fusco-cinereoq. variae. In medio maculae duae argenteae subcontiguae minores quam in $N$. Festucae, ac rotundiores. Posticae basi flavo-cinereae, apice fuscae.

Noctua huic omnino similis, ejusdemq. sane speciei, a $D$. de Paykull transmissa sub nomine N. Bengalensis. nov. sp. Vespera adit flores; saepiusq. lecta in floribus Mirabilis Jalapae, ac Just. Adathodae.

388. N. N I G R I C O L L I S.

N. laevis alis deflexis margaritaceis, lunula difformi, collari atro. Vill. Ent. 2. 272. 337. t. 5.f. 12.

Magnit. media. Alae superiores albidae margine postico obscuriore. In medio alae lunula nigrescens male terminata. Alae inferiores subtus canae; collare atrum. V.

Habitat in Quercu non rara. 


\section{N.- L I V I D A.}

N. laevis, alis incumbentibus, atris nitidulis: posticis ferrtgineis; margine fusco. F. Mant. 138. 32.

N. Livida W. V. $85,13$.

N. Scotoplbila Hiibner. Heft. p. r. t. 4. f. $z$.

Habitat in Taraxaco rara .

\section{N. S P E C T R U M.}

N. spiril. crist. alis crenatis, superioribus ochraceis, fasciis supra fuscis, punctoq. in medio albo: inferiorioribus fuscis subtus dilutioribus. Esper. T. 100. 21. 21.f. 3. 4 .

$N$. Socrus spiringuis cristata, alae omnes griseac, superioribus strigis plurimis undatis obscurioribus; inferioribus immaculatis. Giorna Kalend. pag. 15.

Statura ac magnit. N. Pactae.

Habitat imago ruri muris insidens in cavis domorum, \& antris; m. Octob. frequens.

N. cristata, alis incumbentibus hepaticis, posticis flavis, lunula strigaq. postica fuscis. $F$. Mant 150.116.

Pap. d' Eur. t. cclxx. 434. k.

Hubn. t. 2. 4. 1. f. D.

Aliae occurrunt huic, sed magis $N$. Promubae affines, sane N. Subsequa Hubner p. 1. 4. f. $Y$.

Semel lecta in silvis.

\section{N. S E G E T IS :}

N. cristata, alis incumbentibus ferrugineis, strigis undatis obscurioribus, posticis albidis. F. Sp. 223. 78 .

P. Segetum. W. V. 252 . t. 1. a. 3. t. 1. b. 3.

Esper. t. 4. t. 150. f. 4. 5.

Habitat in segete radices devorans. raro lecta.

393. M. M A U R A.

N. cristata, alis incumbentibus dentatis cinereo-nigroq. variis, subtus margine albo. F. Sp. 224. 81 . 
P. Maura. Linn. Syst. Nat. 843. I 24.

P. Lemur. Naturf. 6. t. 5. f. 1 .

Esp. t. 107. 28. f. 1 .

Scbaef. Ic. $t$. I. $f$. 5. 6 .

Larva nuda obscure viridis flavolineata $m$. Jun. occurrit copiosa in Genista corticem ac flores comedens. Pupa folliculata. Quies 2. hebdomadum .

Habirat in Arni Valle superiori frequens.

394. N. D E N T I N A.

N. cristata, alis planis, cinereo fuscoq. variis macula marginis interioris, strigaq. postica flavis. F. Mant. 156. I 51 . N. Dentina $W . V .82 .8$.

Esper. t. 127. n. 48. f. 2. 3.

Habitat in silvestribus rara.

395. N. L. A L B U M.

N. cristata grisea alis incumbentibus 1. albo notatis. $F$. Sp. 226. 87. Linn. Syst. Nat. 850. 154.

Esp.t. 90. N. 11. f. 3. 4.

Hubn. Heft. 1. t. 2. $f$. $K$.

Schaeff. Ic. t. $92 . f .4$.

Margo posticus fuscus .

Habitat in pratis non frequens.

N. cristata, alis deflexis luteis: puncto medio fusco, strigaq. postica punctorum nigrorum. F. Masst. 161. 172.

W. S. и. 10. p. 87 .

Lecta in Salice.

$$
\text { 397. N. C I R C U M F L E X A. }
$$

N. cristata, alis deflexis: anticis fuscescentibus, charactere flexuoso argenteo. F. Mant. 162. 179. Limm. Syst. Nat. $884 . \quad 128$.

W. $V \cdot 93.4$.

Hubner. t. 1. t. IV. f. v. 
Esper. t. 4. t. III. f. 5. 6.

Habitat in Achillea millefolio, in silvestribus rarior.

N. cristata, alis deflexis dentatis brunneis: anticis puncto $\mathrm{fla}$ vo inter punctula duo alba. F. Sp. 230. 104. Limn. Syst. Nat. 855.176.

$N$. Satellitia $W . V .86 .5$.

Roes. Ins. 3. t. $5 \mathrm{C}$.

Habitat in Grossularia. rarissima .

\section{N. A B S I N T H I I.}

N. cristata, alis deflexis canis: fasciis, punctisq. in tetragonum positis nigris. F. Sp. 230. 109.

P. Absintbii Limn. Syst. Nat. 845. 133. Fu. S.v. 1182.

Geoffr. Ins. 2. 158.95 .

W. S. 73. 1.

Clerck. Iion. t. 8. $f$. 19.

Roes. Ins. 1. ph. 2. t. 61.

Esper. t. 4. t. 116. f. 1.

Habitat in Absinthio non frequens.

\section{N. O G C U L T A.}

N. cristata, alis deflexis nebulosis, apice cinereis : maculis tribus nigris. F. Mant. 166. 212.

$P$. Oiculta spirilinguis, cristata, alis deflexis fusco-nebulosis, inferioribus brevioribus: margine albis. Lim. Syst. Nat. 849. 247. Fm. Sv. 1.203?

Clerck. t. 1. f. 6.

Esper. t. 132. N. 53. f. 4 .

Hubr. tom. 2. p. IV. $t$. 2. f. L. larva.

Nostra specimina conveniunt cum descriptione $F$. $S_{v}$. Raro lecta.

401. N. P Y R M I D A.

N." cristata, alis fuscis, strigis tribus undatis, flavescentibus repandis; posticis ferrugineis. F. Sp. 232.119.

Tom. II. 
P. Pyramidea Linn. Syst. Nat. 856. 181 .

Geoff. Ins. 2. 160. 99.

W. S. n. 1. p. 71 .

Reaum. Ins. 1. t. 15,f. $1-5$.

Merian. Europ. 2. 23. t. 9 .

Roes. Ins. I. pbal. 2. t. II.

Habitat in Juglande, Quercu non frequens.

\section{N. A L C H Y M I S T A.}

$\mathrm{N}$. cristata, alis deflexis dentatis nigris atro undatis, apice cinerascentibus, posticis basi, maculisq. duabus marginalibus albis. F. Mant. 171. 240.

N. Alchymista W. V. 89. 5.

Naturf. 14. St. t. 4. f. 10.

Esp. t. 107. 21. 28.

Habitat in Populo alba rarior.

\section{N. TR I D E N S}

N. cristata, alis defexis cinereis, maculis atris trifidis, posticis albidis. F. Mant. 173. 254.

N. Tridens. W. V. 67. 1.

Roes. 1. t. 8.

Esp. t. 115. N. 36. f. 5.

Affinis $N$. Psi, at larva diversa.

Habitat in Pruno armeniaca non rara.

N. cristata, alis deflexis cinereis, maculis duabus fuscis. $F$. Mant. 173. 251.

N. Perla W. V. 70. 3 .

Schaeff. Ic. t. $263 \cdot f \cdot 4 \cdot 5$ ?

Habitat apud nos frequens.

$$
\text { 405. N. E U P H O R B I A E. }
$$

N. cristata, alis deflexis fusco undatis: maculis ordinariis; anteriore orbiculata, posteriori reniformi albidis. F. Mant. 1 74.260. 
N. Euploorbiae. W. V. 67. 4 .

Esp. t. 117. N. 38. f. 1 .

Roes. 1. $t .45$.

Habitat in Euphorbia. Semel lecta.

406. N. A T R I P L I C I S .

N. cristata, alis deflexis, anticis fusco-nebulosis, litura media flava bifida. F. Sp. 232.115.

P. Atriplicis Linn. Syst. Nat. 854. 173. Fn. Sv. 196.

Geoff. Ins. 2. 159.97.

Wilk. Pap. 3. t. 1. a. 2.

Roes. Ins. 1. ph. t. $3 \mathrm{I}$.

Habitat in Atriplice Rumice frequens.

\section{N. T R A G O P O G I N I S.}

N. cristata, alis deflexis: anticis fuscis; punctis nigris tribus approximatis, posticis lividis. F. Sp. 237.133 . Linn. Syst. Nat. 855, 177. Fur. St. 1189 .

De Geer. 2. 418 . t. 7. f: 15.

N. Tragopoginis. W. V. 85.14 .

Frisch. Ins. 11. p. 33. t. 7.

Habitat in Tragopogine, Spinachia, Runice sat frequens .

\section{N. H E P A T I C A.}

N. cristata, alis deflexis obscure griseis, macula fusca punctisq. tribus costalibus albis. F. Sp. 237. 134. Limn. Syst. Nat. 853. 169. Fr. Sv. 1209.

N. Hepatica W. S. 84. I.

Clerck. Icon. t. 8. f. 3 .

Villers. Ent. t. 2. 235.231 .

Lecta ruri.

409. N. P O L Y O D O N.

N. cristata, alis deflexis dentatis nebulosis, striga postica dentata alba. F. Sp. 237. 136. Limm. Syst. Nat. 853. 170. Fin. Sv. 1219.

N. Polyodon. W. S. 72. 1.

Goeze 111. 163. 170.

Habitat in Betula alba. Raro lecta. $\quad D_{2}$ 


\section{Io. N. NI G R I C A N S :}

N. cristata, alis deflexis nigricantibus, stigmatibus ordinariis pallidioribus. F. Mant. 178. 279.

$N$. Nigricans. $W . S .8$ I. I 9.

Alae inferiores colore variant.

Habitat in Cichorio lntybo.

411. N. H I P P O P H A E S.

N. spirilinguis antennis filiformibus ferrugineis, alis deflexis fusco rufescentibus nitidis, fascia ferruginea punctoq. rubro. De Geer. t. 2. p. 419. t. 7.f. 16.

Goeze III. 252. 37 1.

Villers. Ent. t. 2. 250.260.

Lecta in silvis, rara.

$$
\text { 412. N. CR A C A E. }
$$

N. cristata, alis striatis cinereis: puncto albido, lunula punctata, thoraceq. antice atris. F. Mant. $154.13 \%$.

N. Craccae. W. V. 94. 3.

Goeze IV. 224. 229.

Statura N. Lusoriae, at paullo minor.

Habitat in Vicia cracca.

$$
\text { 413. N. A R B U T I. }
$$

N. cristata, alis deflexis fuscis, posticis nigris fascia flava. F. Mant. 184.309 .

Naturf. 3.t. 1. f. 8. pag. 8.

Goeze nil. 236. 306. Lang. Verz. 3. II 34 . N. Policula. Paullo ninor $N$. Myrtilli.

Habitat in silvis frequens. 
Clas. VI. Glossata. Phalaena.

CLIV. $P H A L A E N A$.

Palpi cylindrici. Lingita porrecta membranacea. Antennae filiformes .

\section{P. P U N C T A R IA.}

P. pectinicornis, alis angulatis cinereis: striga ferruginea ordineq. punctorum nigrorum.F. Mant. 185. 9. Sp. 242. 7. Linn. Syst. Nat. 859. 200. Fiz. Sv. 1250.

W. S. n. 2. p. 107 .

Knoch. 1. 1 3.t. 1. $f .4$.

Clerck. t. 5. f. 11 .

Striga omnibus ferruginea in medio. Puncta interdum subtus obliterata.

Habitat in Quercu.

\section{P. EQUESTRARIA.}

P. pectinicornis, alis angulatis, anticis fuscescentibus, fascia lata flava, posticis flavis. F. Sp. 244. 15.

Goeze 111. 419.302.

Alae anticae angulatae fuscae in medio fascia flava. Posticae angulato-dentatae flavae apice obscuriores. Subtus anticae flavescentes puncto medio nigro, apice obscurae, margineq. flavo variegato. Posticae obscurae basi pallidae, punctoq. medio nigro.

Semel lecta .

$$
\text { 4I6. P. R O B OR A R I A. }
$$

P. pectinicornis, alis dentatis griseis, atomis, strigisq. numerosis fuscis. F. Mant. 187.23.

P. Roboraria $W . V .101 .1$.

Goeze III. 392. II 5.

Schaeff. Ic. $271 . f .3$ ?

Habitat in Quercu rarior.

$$
\text { 417. P. PA P I L I O N A R I A. }
$$

P. pectinicornis alis viridibus, subrepandis, striga sesquialte- 
ra repanda. F. Sp. 246. 26. Limn. Syst. Nat. 864. 225. Fr. Sv. 1247.

P. Papilionaria $W . V .97 .1$.

Roes. Ins. 4. t. 18. f. 3 .

Wilk. pap. 37. t. I.

Fuesly Arcbiv. 2, t. 3.

Schaef. Ic. t. 17.f. I.

Variat magnitudine. Apud nos minor.

Habitat in silvis non frequens.

\section{I8. P. F U R C A R I A?}

P. pectinicornis alis griseo-nebulosis: omnibus subtus puncto nigro; lunula alba. F. Syst. 624. 22? Sp. 247. 30.

Omnino diversa a P. Lunaria. Hubn. tom. I. t. I. f. C. I. 2. Magnitudo $P$. Abietariae. Antennae setaceae subdentatae. Caput, \& thorax cinerea, hic vero antice griseo-fasciatus. Alae omnes supra cinereae strigis variis undatis, obsolete nigris, fascia baseos seu potius striga duplicata obscuriori. In medio versus marginem exteriorem macula unica orbi culata albida nigro marginata tam in alis anticis quam posticis: subtus seu in pagina inferiori omnes albidae macula magis conspicua nigra, lineola in medio tenuissina alba. Apex anticarum postice obscurior apice ipso albido. Tarsi nigro annulati.

Pluries lecta quiescens in muro, alis patentibus .

P. pectinicornis, alis fuscis flavo-maculatis, subtus nebulosis, fasciis duabus fuscis. F. Sp. 247. $3 \mathbf{1}$.

P. Piniaria Linn. Syst. Nat. 86. 210. Fn. Sv. 1233.

De Geer. t. 2. 35\%. t. 5. f. 20.

W. $V .106 .7$.

Reaum. Ins. 2. t. $28 . f$. 6.

Ammiral. Ins. 1. t. 20.

Sepp. 6. st. t. 4 .

Clerk. Ic. t. 4. f. 11. ph. t. 1. f. 10.

Scbaeff. Ic. t. 1. f. 10. t. 159. f. 1. 2. Mas.

Habitat in pino, non frequens. 
420. P. B I P U N C T A R I A.

P. pectinicornis, alis anticis cinereis fusco-undatis: fascia media obscuriori; punctis duobus atris. F. Mant. 1 89. 48.

P. Pipunctaria W. V. 111. 5 .

P. Undulata Scop. Cam. 555.

Habitat in lolio perenni, sat frequens.

42I. P. M U R I N A R I A.

P. pectinicornis, alis griseis: strigis duabus, punctoq. medio fuscis. F. Mant. 190. 55.

P. Murinaria W. V. $105.4 \%$

Goeze 1II. 395. i 43.

Parva, tenera. Corpus griseum.

Lecta Florentiae in montuosis.

422. P. P I U M B A R I A.

P. pectinicornis, alis plumbeis: strigis tribus, punctoq. medio fuscis. F. Syst. Ent. 628. 44. Sp. 252.59.

P. Plumbaria W. V. 102. 7 .

Scop. 55 I. P. Cblorosata.

Goeze 1II. 415. 273.

Magnit. P. Elingturiae. Strigae tres luteolae.

Habitat in silvis, rarior.

\section{P. MAR G I N A R IA.}

P. alis lutescentibus angulatis ad basin littera $V$. notatis, margine postico late purpurascente. Villers. Ent. t. 2. 303 . 423. t. 6. f. 3 .

P. Vespertaria. Fab. Mant. 62?

P. Apiciaria Hubner. Heft. p. 1. t. 2. f. O.

Alae minus flavae quam in $P$. Parallelaria.

Pluries lecta in silvis umbrosis.

\section{P. H I R T A R I A.}

P. pectinicornis, alis cinereis, striga fusca undata albae innata. F. Sp. 249. 41. Limn. Fn. Sv. 1236.

De Geer. Ins. 1. 354. t. 22. f. 6. 
Clerck. Icon. t. 7. f. 1 .

Habitat apud nos rarior.

\section{P. C A I A B R A I A}

P. pectinicornis alis patentibus luteis fascia duplici communi rosea, anticis versus basin fascia tertia lineari. Petagna Sp. Ins. Calab. 199. t. 1. f. 23. Inst. Entom. to 2. 590. 79. Ph. Calabra.

P. Calabraria Hubuer. Heft. 2. 4. t. 2. f. M. mas.

$P$. Trifasciata Cyril. Ent. Neapol. Spec. $t$. $1 . f$. 5. Figura bona, at nomen improprium, antennae enim in masculo pectinatae.

Alae patentes omnes luteae. Fascia marginalis latior: ante marginem altera fascia communis priore angustior: parum distans a basi alarum anticarum tertia fascia linearis lunata, quae progreditur per costam ad basin usq.; omnes roseo laeto colore. Corpus totum luteo, \& roseo colore variegatum. Femora rosea uti \& frons. Tibiac luteae. Pet. l. c.

Affinis P. Vibicariae.

Habitat in silvestribus, Pisis.

P. pectinicornis alis anticis flavescentibus, fascia obliqua, atomisq. fuscis. F. Mant. 196. 95.

$P$. Gilvaria $W . V .102 .10$.

Goeze III. 394. 132.

Mabitat in Achillea millefolio.

427. P. M I N U T A R A .

P. pectinicornis, alis cinereis, strigis fasciaq. postica fuscis. F. Sp. 253.62.

Villers. Ent. t. 2. 320.459.

Parva, sed non minima.

Habitat in pratis non rara. 
* 428. P. F A s c I A T A R I A:

P. pectinicornis, alis angulatis, fusco-griseis, in medio obscurioribus, subfasciatis, strigosis, puncto nigro centrali . Magnitudo $P$. Piniariae. Alae superiores in parte antica, \& postica griseae, margine exteriori striga abbreviata, punctoq. nigris. In medio fascia obscurior, ad apicem nigra, anticeq. striga nigra terminata, postice sinuosa. Inferiores angulatae fere similiter pictae, omnesq. subtus pallidiores, atomis, striga, punctoq. medio nigris. Affinis. P. Lignariae.

Habitat in silvis sat frequens.

$$
\text { * 429. P. O C H R E A R I A. }
$$

P. pectinicornis, alis anticis squammoso-lutescentibus, posti. cis albidis: subtus omnibus, atomis, puncto, strigaq. repanda submarginali fuscis .

Magnitudo praccedentis. Antennarum costa alba, radii fusci. Alac ad costam atomis confertius aspersae praesertim inferius.

Habitat in silvis frequens.

\section{* Anten. setaceis.}

$$
\text { 430. P. D E M A N A T A. }
$$

P. seticornis, alis subangulatis lutescentibus, strigis tribus fascis, punctoq. medio atro. F. Sp. 254. 73.

Villers. Ent. 2. 335. 508.

Goeze III. 416.277.

Paullo minor P. Amataria, cui affinis.

Habitat in pratis \& hortis frequens.

\section{P. O B S C U R A T A.}

P. seticornis, alis dentatis griseis, strigis pallidioribus, undatis obsoletis. F. Sp. 255. 80.

Villers. Ent. 2. 336.509.

Goeze III. 396.153.

Media. Basis alae anticae fuscescit.

Habitat in Myrtillo. Lecta in silvis.

Tolm. II. 
432. P A D U S T A T A

P. seticornis, alis anticis albidis: fasciis duabus fuscis; po* steriore repanda cinereo undata. F. Mant. 205.172.

P. Adustata W. V. 114.9.

Gotze III. 402. 200.

Scbaeff: Ic. t. $112 . f$. 9 .

Media. Fascia altera baseos, altera fere marginalis.

Habitat in Evonymo.

\section{P. UN D U L A T A .}

P. seticornis, alis omnibus strigis confertissimis undulatis fuscis. F. Sp. 257.89 . Limn. Syst. Nat. 863. 239. Fn. Sv. 1272.

P. Undulata W.V. 109. 16.

Clerck. pbab. t. 6. f. 3 .

Goeze 11I. 321. 239.

Udm. Diss. 71 .

Habitat in Salice capraea, frequens.

434. P. O C E L L A T A :

P. seticornis, alis albidis fascia lata abbreviata fusca, puncto subocellari atro. F. Sp. 262. 118.

P. Ocellata Linn. Syst. Nat. 870. 258 . Fn. Sv. 1280.

P. Ocellata IV. V. I1 3.9.

P. Alstroemeriana Sulz. Hist. Ins. t. 23. f. 5.

P. Fasciata Scop. 550. Goeze III. 339. 258.

Habitat in Galio sylvatico.

\section{P. C H E N O P O D I A T A.}

P. seticornis, alis anticis testaceis, fascis tribus griseis, puncto prominulo, apicisq. lineola supra fusca. $F . S p .263$. 124. Linn. Syst. Nat. 868. 246. Fn. Sv. 1263.

$P$. Mensuraria $W . V, 112.2$.

Alb. Ins. t. $47 . f$. 79 .

Finesl. "7. 780. Goeze III. 328. 246.

Kleemann Ins. $t .37 . f .8 .9$.

Schaeff. Ic. $t .67 . f .5 \cdot 6$.

Habitat in Chenopodio, sat frequens. 


\section{P. L U C T U A T A.}

P. seticornis, alis anticis fusco-virescentibus: fasciis duabus albis, punctoq. centrali nigro. F. Munt. 208. 194.

Hubner. Hefi. 2. 4. t. 3. f. Y.

Habitat in silvis frequens.

\section{P. MON I L I A T A .}

P. seticornis, alis omnibus cinereis strigis nigris fasciaq. postica fusca; striga moniliformi cinerea. F. Mant. 209. 201.

P. Moniliata W. V. 117.10.

Goeze 1II. 402. 209.

Hubuer. Heft. 2. 3. 3. f. N.

Habitat silvas in sepibus.

P. seticomis alis rotundatis niveis: anticis puncto medio fusco, margineq. nigro punctato. F. Sp. 265.134.

P. Temerata $W . V$. i 16.7 .

Villers. Ent. 2. 375.603.

Hubner. Heft. 1. tab. iv. f. 5. P. Sylvestrata.

Colore niveo puncto fusco, punctisq̣. marginalibus facile dignoscitur .

Habitat in silvis frequens.

\section{P. I N C A N A T A.}

P. seticornis, alis omnibus canis, postice striga alba repanda, disco puncto margineq. nigro-punctatis. Frs. Sv. 1278.

Villers. Ent. 2. 350.538.

Clerck. phal. t. 3. f. 3 .

W. V. 117. 7. Hubn. n. 62. Goeze iII. 343. 263.

$\mathrm{Ob}$ maximam fragilitatem difficillime asservatur.

Lecta in silvis.

440. P. MEDIATA.

P. seticornis, alis omnibus griseo-undatis, puncto centrali fusco, margineque nigro punctato. F. Sp. 265.135.

P. Strigilata. W. V. 117,4 . 
Clerck. t. 5. f. 2. Goeze 111. 423. 319. Affinis P. Punctatae. Parva. Habitat in herbosis.

441. P. R U B R I G A T A F. Mant. 210.214.

P. Rubricata $W . V$. I 10.19.

Goeze III. 398. 169.

Parva. Strigae quatuor fuscae, quarta pallidior. Habitat in silvis, non rara.

P. seticornis, alis flavescentibus: strigis numerosis obscurioribus. F. Mant. 211.215.

P. Ocbrata Scop. Carn. 567. Geoff. Ins. 2. 153.87.

P. Oibreata $W . V .110 .20$.

Goeze III. 409. $2+4$.

Parva .

Habitat in Festuca duriuscula, frequens in herbidis prope aquas.

P. seticornis, alis niveis: posticis fascia terminali nigra: punctis quatuor albis. F. Sp. 269. 162. Limm. Syst. Nat. 874, 278. Fn. Sv. $130 \mathrm{I}$.

Hubn. 88. P. Gemmata.

Raj. Ins. 205. 102.

Reaum. Ins: 2. t. 12. f. 14. 15.

Goeze III. 353.278.

Harris. Ins. 15. t. 7. f. 1. p.

Magnitudo P. Moniliatae. Antennae corpore dimidio breviores, articulis singulis ab altero latere albo triangulo pictis, ince hinc visae annulis albis cinctae, \& quodammodo subserratae conspiciuntur. Alae omnes albae; posticaeq. fascia media undata fusca abbreviaca ad marginem internum, mox striga, deindeq. fascia terminalis atra monili- 
formis, auro circumducta, in qua secundum ejus longitudinem puncta quatuor argentea aequaliter distributa. Corpus pedesq. albidi.

Habitat imago prope aquas ineunte Octobri, \& larva fusco nigra capite albo inventa saepe affixa parieti vasis plantas aquaticas continentis, ubi collectis lemnae, vel Ienticulae palustris foliolis, iisdemq. involuta fere ad aquae superficiem metamorphosin subit, \& declaratur.

\section{P. C O R R I G A T A.}

P. seticornis, alis fulvis, strigis undatis fysco-ferrugincis . F. Sp. 265.140.

Parva. Alae omncs dilute fulvae, strigis plurimis undatis obscurioribus. Subtus concolores puncto centrali nigro.

Habitat in silvestribus.

445. $P . G \cap$ I S A $T A$.

P. seticornis, alis griseis anticis striga, fascia, punctoq. fuscis. F. Sp. 261. 119.

Goeze III. 422.315.

Media. Alae pone fasciam obscuriorcs .

Habitat in herbosis.

$$
\text { * 246. P. H A M A T A. }
$$

P. seticornis, alis anticis virescentibus, basi fasciaq. postice unidentata, niveis.

Vix major $P$. Lemzata. Caput thoraxq. alba. Alae anticae virescentes ad basin niveae spatio viridi intruso; in medio fascia nivea postice uncum seu dentem recurvum majusculum exserente, \& ad costam macula pariter nivea: subtus fuscescentes. Posticae fusco-cinereae margine albido: subtus albidae .

Habitat in silvis m. Jun.

447. P. $S$ U C C E N $T$ U R R I A $T$ A A.

P. seticornis, alis albidis puncto nigro limboq. obscuriore. F. Sp. 264. 130. Linn. Syst. Nat. 872. 267 . Fn. Sv. 1294. 
Geoff: Ins. 2. 141, 164.

IV. $V .110 .24$.

De Geer. t. 2. 459. t. 9.f. 8 ?

Scop. Carn. 578. P. Signata.

Clerck. t. 8. f. 8.-1 I.

Roesel. t. I. N. V. 3. Cl. t. 7.

Goeze III. 344. 267.

Habitat in silvis non frequens.

448. P. V E N T I L A B R I S.

P. palpis antennis pectinatis brevioribus, tibiis anticis, apice fasciculato-pilosis. F. Mant. 216. 267?

Varietates quas in Fn. Etr. (conf. P. Barbabis N. 1181.) adnotavimus, huc referendae videntur.

Habitat in silvis.

449. P. VE R B A S C A L I S .

P. seticornis, alis flavescentibus: anticis strigis tribus, punctoq. medio fuscis. F. Mant. 214 . 246. P. Verbascata.

Pbalaena Verbascalis Wien. Verz. 121. 5.

Hubner. Pyral. t. 9. $f .59$.

Statura P. Verticalis, at paullo minor.

Habitat in Verbasco tapso.

\section{* 450. P. L U T E A L I S .}

P. alis pallidis, primoribus punctis quatuor, strigaq. postica obsoleta nigris .

Statura ac magnitudo fere P. Verticalis. Alarum color cinereo-flavescens. Striga plerumq. obliterata. Variat alis immaculatis .

Habitat in Asclepiade Syriaca.

$$
\text { * 451. P. D } 1 \text { M E R A L I S. }
$$

P. palpis porrectis, thorace longioribus, alis ad basin fuscoviridibus, ad apicem griseis, lincola alba acqualiter in triangulum bipartitis. 
Statura ac magnitudo P. Verticalis. Corpus griseum. Antennae setaceae ad basin superius albae, \& in masculo pubescentes. Palpi porrecti, approximati apiceq. superius retorti thorace longiores. Alae omnes supra \& subtus griseae nitidulae, at anticae ad basin fusco-virides, ad apicem griseae, stria alba aequaliter in triangulum bipartitae, punctoq. minutissimo nigro prope marginem exteriorem ante medium notatae. Frons pilosa. Color fusco-viridis in aetate provectis plumbeus evadit, \& saepe omnino evanescit. Primum bis lecta insidens muro externo domestico m. Majo; mox vero ineunte Septembri in loco herbido inculto horti Acad. Pisani plures adinventae.

\section{P. NEMOR A L I S .}

P. alis anticis basi osseis, venulis paleaceis reticulatis limbo paleaceo, parte intermedia vinaceis, margine externo repando. Villers. Ent. 2. 447. 8I5.

IV. V. 123.34.

Scop. Ent. Carn. 618.

Goeze 1v. 68. 25.

Hiibro. Pyral. t. $15 . f .100$.

Habitat in silvis.

\section{P. F $\perp \wedge$ V $A$ I I :}

P. alis anticis sulphureis: strigis duabus maculaq. media veniformi fuscis. F. Mant. 221.302.

P. Flavalis $W . V .121 .7$.

Goeze iv. 70. 41.

Hubner. Pyral. t. 11. $f .69$.

Habitat in silvis frequens.

\section{P. U N D A L 15 .}

P. alis obscure cinereis strigis tribus obliquis undatis nigris . F. Sp. 272, 178.

Goeze 1v. 65. 10.

Vill. Ent. 2. 441. 797 .

Habitat ruri . 


\section{P. R E T I C U L A R I S .}

P. alis grisescentibus, punctis lineola, strigaq. flavis, margine ciliari variegato. Fu. Sv. 1355 .

Goeze IV. 62. 341.

Vill. Ent. 2. 438.790.

Habitat ruri frequens m. Septemb.

\section{P. P A L' E A L I S .}

P. alis anticis virescentibus immaculatis. F. Mant. 220. 295. Geoff. Ins. 2. I 66.112.

P. Palealis $W . V .123 .27$.

Goeze IV. 72. 55.

Hubner. Pyral. t. 1 . f. 70.

Alae antice albidae virore quodam luteo.

Habitat in Feniculo; larva nuda lutea nigro punctata fila dacens in umbellis. Pupa folliculata. Metamorphosis e larva in pupam tarda. Quies fere decem mensium.

\section{P. S T R I G A L I S .}

P. alis griseis: strigis duabus flavis, costaq. purpurascente. F. Sp. 274.191.

Goeze 1v. 65. I 3.

Villers. Ent. 2. 442. 800.

Subferruginea magnitudine fere. P. Forficalis. Habitat in silvis rara.

\section{P. C E N T R A I I S.}

P. alis albis, macula centrali ferruginea. Vill. Ent. 2. 450. 826 .

Inter medias minor. Macula fusco-ferruginea notatur punctis duobus minimis atris.

Habitat ruri frequens.

$$
\text { 459. P. P O R P H I R A L I S . }
$$

P. alis fuscescescentibus : macula costali fulva, posticis atris: striga albida. F. Mant. 223.317.

P. Porphyralis. Wien. Verz. 317. 50. 
Gozze IV. 74. 71.

Hubner: Pyral. t. 6. $f$. 36.

Statura \& summa affinitas $P$. Purpuralis, cujis forte varictas.

Alae anticae obscure fuscae.

Habitat in floribus praesertim labiatis frequens.

\section{P. P U N I C A L I S .}

P. alis purpureis : lineola baseos punctis duobus mediis flavis. F. Mant. 223. 318.

Pbalaena Punicalis Wien. Verz. 317. 49.

Hubrs. Pyral. t. 6. f. 34 .

Statura praecedentis, at paullo major, \& obscurior.

Habitat in floribus frequens.

$$
\text { 46I. P. CESP.I T A I IS. }
$$

P. alis anticis obscuris variegatis: posticis nigris, strigis deabus flavis. F. Mant. 222. 314 .

Phalaena Cespitalis Wien. Vers. 123. 32.

Hubu. Pyral. t. 6. f. 39 .

Magnitudo P. Purpuralis. Alae anticae colorc variant.

Habitat in plantis.

\section{P. $R$ U R A L IS.}

P. alis paleaceis strigis transversis undulatis fuscis. Vill. Ent.

2. 446.813.

Scop. Ent. Cann. 6.16.

Goeze IV. 68. 23.

Scbaef. Ic. $257 . f:$ 1. 2. an?

Habitat in hortis \& pratis silvestribus frequens.

$$
\text { 463. P. A T R ALI.S. }
$$

$P$. ais atris: omnibus maculis duabus niveis. F. Sp. 275.197. P. 8.-Maculata Linn. Mant. 540.

P. Funeraria Mull. Zool. Dan. 132. 1524.

P. Guttalis $W . V .124 .45$.

Schaeff. Ic. t. $275 . f .5 \cdot 6$. at major.

Thorax linea laterali flava.

Habitat in silvis rara.

Tom. II. 


$$
\text { 464. P. FERR U G I N A L I S . }
$$

P. palpis porrectis, alis superioribus ferrugineis macula fusca. Villers. $t .2$. p. 451.827.

Hubu. Pyral. t. 9. f. 54. P. Ferrugalis.

Est inter minores. Alae superiores ferrugineae macula centrali fusca. Inferiores albidae puncto fusco. Diversa omnino a $P$. Ferragali $\mathrm{E}$.

Habitat in pratis.

$$
\text { * 465. P. V I T R E A L I S . }
$$

P. alis albo-hyalinis immaculatis Iucidis; anticis costa seu margine fusco .

Statura ac magnitudo P. Palealis, at alae albae pellucidae costa obscuriori, neq. subtus ad marginem nigro venosae. Descriptam non inveni.

Lecta semel ruri.

\section{CLV. $P Y R A L I S$.}

Palpi nudiusculi, basi cylindrici medio dilatato ovati, apice subulati. Antennae filiformes.

$$
\text { 466. P. B R U N N I C H A N A. }
$$

P. alis fuscis, macula communi dorsali rhombea alba. $F$. Sp. 281.30 .

P. Brumichand Linn. Syst. Nat. 880. 319.

W. $V .132 .2$.

Geoff. Ins. 2. 187.12 ?

Villers. Ent. 2. 401. 683. Goeze Iv. 21. 319.

Alae omnes plumbeae, sed superiores obscurius griseae. Habitat in silvis.

$$
\text { 467. P. C H R I S T I E R N A N A. }
$$

P. alis anticis flavissimis, venis sanguineis reticulatis. $F$. Sp. 281.33 . 
P. Christiernana Limn. Syst. Nat. 877. 303.

W. V. 128.9.

Fuesl. 31. 805. Goeze iv. 15. 303.

Schaef. Ic. t. 2. $f .12$.

Habitat in silvis non rara.

468. P. A S P E R A A.

P. alis anticis, basi albis, apice fuscis scabris. F. Sp. 284.48.

W. $V .130 .9$.

Villers Ent. 2. 409. 708.

Goeze IV. 29. 23.

Habitat in silvis non rara.

469. P. Q UER C A N A.

P. alis anticis flavis, maculis duabus costalibus sulphureis.

F. Sp. 285.55 .

P. Fagana W. V. 28, 7. t. 1. a. b. 1. b. b.

Ent. Paris. 2. 199.

Goeze IV. 26. 11.

Antennae albae alis longiores.

Habitat in Quercu frequens.

470. P. CIN E R A N A.

P. alis exalbido-cinereis inmaculatis, capire fulvo. F. Sp. 281.27 .

Goeze IV. 31. 33. der Arbwickler.

Nimis $P$. Crucianae affinis at alae immaculatae.

Habitat in nemoribus frequens.

\section{P. P O M A N .}

P. alis nebulosis, postice macula rubra aurea. F. Sp. 286.67. P. Pomonella. Limn. Syst. Nat. 892, 401 . Fiz. Sv. 1418.

W. V. 126. 10.

P. P.omonella. Villers Ent. 2. 476.892 .

Reaum. Ins. 2. $t$. 40. f. 9. 10.

Roes. Ins. 1. phat. 4. t. 13.

Wilck. pop. 5. t. 1. a. 9. 
Scbaeff. Ic. $t=220$. f. I. 2.

Habitat in pomis frequens.

$$
\text { 472. P. W O E B E R A N A. }
$$

$P$. alis fusco, aureoq. varis: costa strigis argenteis numerosis. F. Mant. 230.52.

P. Woeberana. W. V. 126.9.

Goeze IV. 4I. 79.

Statura P. Amonacie. Striae argenteae in costa alarum.

Habitat in silvis rarior.

\section{CLV1. T I N E A,}

Palpi quatuor inaequales. Antermae sctaceae. -

\section{T. M E S O M E L L A.}

T. alis anticis pallidis, margine flavo, punctisq. duobus fuscis. F. Sp. 292.14.

P. Mesomelia Limn. Syst. Nat. 886. 356. Frz. Sy. 1362.

N. Eborina W. V. 68. 5.

Clerck. phal. t. 4. f. 14.

Thubner Heft. 1. t. 3. f. Q.

Habitat in gramine rarior.

474. T. O X Y A C A N T H E I L A.

I. alis fusco-nebulosis, striga albida, margineq. postico albido. F. Sp. 292. 15.

P. Oxyacantbella. Linn. Syst. Nat. 886. 3.57.

Goeze IV. 85. 357.

Striga postica undulata luteo albida.

Habitat in Crataego Oxyacantha.

475. T. C I IN E R E L L A.

$T$. alis fusco-cinereis nitidulis immaculatis. $F$. Sp. 299. 55.

P. Cinerella alis fusco-cinereis immaculatis nitidulis palpis 
corniformibus. Linn. Syst. Nat. 891. 392. Fn. St. 1445.

W. $V .138 .25$.

Palpi clavati recurvi apice setacei.

Habitat in plantis frequens.

$T$. alis anticis linearibus testaceis, punctis quatuor fuscis. F. Sp. 297. 46.

P. Punctella. Linn. Syst. Nat. 890. 386. Fu. Sv. 1437.

T. Alucitella.W. K. 144. 40.

Habitat in Pomaris, sedens apicibus alarum innititur.

477. T. PROLETEL L A.

T. alis albidis punctis duobus fuscis, lingua inflexa. Linm Ed. xiIr. p. 2594. 379.

Vallisn. Nat. Ed. Pat. $1726 . p$. 1 o1. Vulgo dicta Ovis Brassicae.

Rbeamm. Ins. 2. t. 25.

Minima, ac brevis respectu latitudinis. Alac incumbentes. An hujus familiae?

Habitat in Brassica frequens, at facile volat \& in aliis plantarum foliis occurrit.

\section{T. C O M P OSITELIA.}

$T$. alis fuscis macula communi dorsali argentea, strigis quatuor composita. F. Sp. 300. 62.

Goeze IV. 152. 209. der Ruckenfleck.

Parva. Frons alba. Antennae nigrae.

Habitat in silvis rara.

479. T. S T R O B I L E L L A.

$T$. alis fusco argenteoq. undatis, posticis fuscis margine albo. F. Sp. 298.50.

P. Strobilella Limn. Syst. Nat. 892. 402. Fn. Sv. 1419.

De Geer. Ins. 2. 490. 9. t. 9. f. 15.

W. V. i 35.24 . Fuesl. 839.

Magnitudo fere praecedentis. Alae fuscescente-griseoq. nebulosae pluribus striis transversis obliquis striatae. 
Habitat in Abietis strobilis .

$$
\text { 480. T. TR I G O N E L L A. }
$$

T. alis fuscis macula communi dorsali duplici alba trigona. F. Sp. 299. 57.

P. Trigonella. Linn. Syst. Nat. 891. 393. Fu. Sv. 1373. Villers. Ent. 2. 474. 884.

Habitat in Juniperetis non rara.

$$
\text { 481. T. L Y O N E T E L L A. }
$$

T. alis flavis, fasciis quatuor argenteis, tertia superne bifida. F. Sp. 302. 77 .

P. Lyonetella Linn. Syst. Nat. 897. 440. Fn. Sv. 1404. Goeze IV. 119. 440.

Habitat in silvis.

$$
\text { 482. T. A U R E L, L A. }
$$

T. alis auratis, postice atris fascia argentea. F. Sp. 305. 92 W. $V .142 .19$ ?

Goeze :1v. 139. 123.

Minima. Caput album fronte ferruginea.

Habitat in Pomonae arboribus.

$$
\text { * 483. T. B L O C K I E L L A. }
$$

T. alis cinereo-fuscis subnitidis fascia lata dorsali communi obsolete argenteo striata, posticeq. striga punctisq. duobus argenteis marginalibus.

Minuta. Alae omnes subtus obscuriores fere nigrae. Caput, abdomen, pedesq cinerescentes. Tarsi annulati .

Lecta saepius in Citri Medicae foliis, quae demisso capite, variatisq. assidue gyris ubiq. percurrit, aliquid lingua nutrimenti hauriens.

In honorem Cel. Viri lib. Bar. de Bluck Dresdensis qui Entomologiam summa lande colit, \& auget.

$$
\text { * 484. T. P R U N N E R E T L A. }
$$

T. alis sub-aureis cinereoq. fuscis albo-bifasciatis punctis ar- 
genteis sparsis, disco, apiceq. maculis atris argento-punctatis .

Minuta. Alae primores cinereo-fuscae, quasi ustulatae, fasciis duabus subnitidis albidis, quarum prima latior. In disco apiceq puncta, seu maculae tres atrae argento punctatae, sedenti, in circulum communem ad fasciam posticam distributae. Inferiores fuscae striga albida. Corpus cinereum. Pedes cinerei nigro annulati. Antennae corpore breviores, annulatae pilosae.

Habitat imago frequens in foliis Inulae Helenii, ibiq. sub vcsperum ineunte Augusto choreas agens, celebrat nuptias. In honorem illustris Viri mihiq. amicissini Leonardi de Prunnner, qui naturalem historiam Entomologiamq. Pedemont. Glossatorum Kalendario erudite locupletavit .

\section{CLVII. $A L U C I T A$.}

Palpi duo ad medium bifidi: lacinia interiorí acutissima. Antennae setaceae.

$$
\text { 485. A. B I P U N C T E L L A. }
$$

A. alis fuscis: vitta communi dentata alba, thorace niveo punctis duobus atris. F. Sp. 307.9 .

Tinea Ecbiella W.V. 140. 54.

Hubner Heft. 1. 3. t. 1. $f$. B.

Habitat in Anchusa.

$$
\text { 486. A. S U Z } Z \text { E L L A. }
$$

A. antennis mediocribus alis nigris, superioribus fascia aurea. F. Sp. 309, 20.

P. Silzella. Limu. Syst. Nat. 896. 427 .

$$
\text { W. V. 143. } 24 .
$$

Goeze IV. 115.427.

Antennae maris incrassatae usq. ad basin . Habitat in silvis frequens. 
A. antennis mediocr bus, alis nigris fascia alba. F.Sp. 309. 21.

Villers. Ent. 2. 485. 919.

Alae fascia aequali.

Habitat in silvis non rara.

488. A. E R X L E B E L L A.

A. antennis mediocribus unicoloribus, alis anticis fusco-aureis, posticis nigris capite fulvo . F. Mant. 256. 27 .

Affinis $A$. Caltbellae. Antennae subtus pallescentes, palpi \& caput fulva.

Semel inveni.

\section{A. X Y L O S T E I L A.}

A. alis cinereo-fuscis, vitta dorsali communi sinuata alba. F. Sp. 306. 1 .

P. Xylostella Linn. Syst. Nat. 890. 389. Fin. Sv. 1390. Geoff. Ins. 2. 195. 33.

Roes. ph. 4. t. 10. $f .4 .5$.

Fuesl. 835 .

Antennae niveae ad apicem nigro-annulatae, corpore paullo breviores, quas quiescens gerit horizzontales porrectas, \& simul junctas.

Larva viridis. Pupa tenuissime folliculata. Quies hebdomadis. Habitat in Lonicera Xylosteo, Cheiranthi floribus.

$$
\text { 490. A. } M A R G I N E L L A \text {. }
$$

A. alis fusco nitidis marginalibus niveis. F. S, 307.8.

Goeze IV. 159. 245. der Scbneerand.

Mabitat in Juniperetis non rara.

$$
\text { 491. A. FA S C I E L L A. }
$$

A. alis auratis fascia fusca antennis apice albis. F. Sp. 310,23.

$T$. Sibieffermyllerella $W . V^{\top}, 142.20$.

Goeze IV. 158.240.

Villers. Ent. 2. 50.5. 983.

Habitat in nemoribus. 
492. A. A R I S T E L L A :

A. albida, alis linea argentea. F.Sp. 308. 15.

P. Aristella Linn. Syst. Nat. 894. 416.

Goeze IV. 3: 416.

Villers. Ent. 26481.907.

Corpus teres longiusculum. Palpi porrecti capite longiores, aristati. Facile dignoscitur.

Habitat ruri minus frequens.

\section{A. O P P OS I T E L L A.}

A. alis fuscis, maculis duabus oppositis flavis, posticis fuscis . F. Sp. 3 1.0. 26.

Villers. Ent. 2. 506. 986.

Goeze Iv. 158. 242.

Affinis A. Sulphurellae, distincta tamen.

Habitat in silvis non rara.

CLVIII. PTEROPHORUS.

Pulpi duo lineares. Lingua exserta membranacea. Antennae setaceae.

494. P. MON O D A C T Y L U S.

P. alis patentibus linearibus indivisis. $F . S p .3$ ro. 1 .

Pbalaena Monodactyla Linn. Sist. Nat. 899. 453. Fur. Sv. 1452.

Rheaum. Ins. 1, t. 20. $f .12:-16$.

Villers. Ent. 2. 530.1083.

Habitat in Convolvulo.

495. P. TESSER A D A C T Y Z U S.

P. alis patentibus fissis cinereo-nebulosis, posticis fuscis. $F$. Sp. 311. 4 .

Ph. Tesseradactyla Limn. Syst. Nat. 900. 456. Fn. S*. 1454. Alucita Leviodactyla. W. S. I 4 6. 7?

Goeze IV. 177. 70.

Habitat in Pulmonaria officin.

To:n. II. 


\section{G L A S S I S S E P T I M A. $R \quad Y \quad N \quad G \quad O \quad T A$.}

CLX. $M E M B R A C I S$.

Os rostro inflexo. Labium corneum, elongatum apice menbranaceum subulatum. Antennae subulatae fronti insertae.

\section{M. G E N I S T A E.}

Thorace inermi fusco, postice producto, abdomine dimidio breviore. F. Sp. 318.17 .

Cicada thorace inermi pone producto. Geoff. Ins. 2. 224.19. $M$. Cormusta duplo minor, \& ab ea presertim distincta thorace inermi, obtuso, convexo.

Habitat in Genista. Lecta saepius in Spartio Junceo, m. Jul.

\section{TETTIGONIA.}

Os rostro vagina biarticulata gulae inserta. Antemne setaceae.

$$
\text { 497. T. M O N T A A. }
$$

Abdominis segmentis margine rubellis. Scop. Ann. bist. Nat. 5. p. 109. 23. 108.

Duplo minor T. Omi. Caret seriebus punctorum in alis quas habet $T$. Omi, a qua etiam differt corpore supra fuscocineree, oculis nigris, alis excoloribus, excepta basi quae rubet; tibiis anticis crassis tridentatis.

Habitat Florentiae in montuosis non frequens. 
CLXII. C.I C A D A.

Os labio rotundato apice setaceo. Antennae filiformes sub oculis insertae.

498. C. I N T E R R U P T A.

Elytris flavis, linea nigra duplici interrupta longitudinali. F. Sp. 325. 24. Limn. Syst. Nat. 710. 35. Fn. Sv. 889.

Petiv. Gazoph. t. 61. f. 10.

De Geer Ins. 3. 186. 7. t. 12. f. 6.

Geoff. Ins. 1. +19. 9.

Schrank. Enum. 494.

Fuesly. Ins. Helv. 24. 462.

Habitat in plantis rarior.

Flava unicolor, Vill. Enzt. 1. 463.21.

499. C. F L A V A.

Schrank. E. I. 497.

Gron. Zooph. 681.

Mull. Limzz. Nat. Cl. v. p. 463 .

Habitat in plantis.

$$
\text { * 500. C. F L A V E S C E N S. }
$$

Flavescens, fronte, thoraceq. punctis duobus nigris.

Minima. Oculi magni nigri. Abdomen fuscum. Alae aqueae margine exteriori flavescente.

Habitat in plantis.

$$
\text { * 501. C. P A L I I D A. }
$$

Pallida, capite punctis duobus atris, elytris pallidis nervis obscure anastomosantibus.

Parva.

Capta in Aro.

$$
\text { * 502. C. DES E R T R I x. }
$$

Alis hyalinis, nervis nigro punctulatis, bifasciatis; antennis apice globosis. 
Statura, ac facies C. Nervosae, at triplo minor. Frons plana fusca. Antennae capite breviores, sub oculis insertae constant articulis duobus globosis. Alae superiores albo-hyalinae praeter punctula nigra in nervis, gerunt quoque fascias duas, prima prope basin obliqua, altera media recta ad marginem internum diramata. Nervi pone hanc saepe fuscescentes. Alae inferiores albo-hyalinae immaculatae. Pedes omnes pallidi confertim nigro annulati. Proprii gcneris videtur.

Lecta saepius in plantis aq̣uaticis.

\section{CERCOPIS.}

Os labio abbreviato truncato emarginato. Antemnae filiformes, sub oculis insertae.

\section{C. C O L E O P T R A T A.}

Elytris totis coriaceis alas obtegentibus griseis, fusco irroratis. F. Sp. 330. 9 .

Villers. Ent. 1. 459. 10?

Panzer. Fann. German. Hefi. 11. t. 6.

Magnitudo C. Sanguinzolentae. Puncta duo fusca distincta in medio fere elytrorum. Variat elytris ad marginem crassiorem late fusco maculatis .

Habitat in plantis, saepeq. lecta quotannis m. Aug. \& Septemb. in horto Pisano Academico.

$$
\text { * 504. C. O S N I G R U M. }
$$

Testaceo-rufa capite pedibusq. nigris .

Statura, ac magnit. C. Unifasiciatae. Thorax ac elytra testaceo-rufa; caput vero \& pedes nigra. An proxima $C . O s$ album. Villers. I. 474. 75 ? Sed os in nostris nigrum.

Habitat in silvis frequens. 
Clas. VII. Rrngota. Cimex.

CLXIV: $N O T O N E C T A$.

Os rostro arcuato. Labiun conicum clongatum subulatum. Antennae sub oculis insertae.

505. N. MIN U TIS S I M A.

Long. 1. l. lat. $\frac{1}{2}$.

Grisea, capite fusco elytris truncatis. F. Sp. $33: 2.4$.

N. Minutissima, elytris cinereis maculis fuscis longitudinalibus. Linn. Syst. Nat. 713. 3. Fn. S2. 905.

Geoffriay. Ins. 1. 477. 2.

Fuesl. Ins. Helv. 24. 470.

Panzer. Fn. Germ. Hefi. 11. 14.

Habitat in aquis non rara.

\section{CLXVIII. $A C A N T H I A$.}

Rostrum sub capitis apice insertum. Labiun nullum. Antemnae ante oculos insertae.

$$
\text { 506. A. U M B R A U L A TA. }
$$

Ferruginea, thorace marginato, margine antice, scutelloq. apice albis. F. Sp. 337. 15.

Descriptio Fabricii optima, cui addendum, pedes antennaeq. albo nigroq. annulatae.

Habitat ineunte vere iuxta sepes, frequens in Aparine.

\section{C I M E X.}

Labium elongatum subulatum annulatum. Antesnne filiformes ante oculos insertae. 


\section{* 507. C. A P U A N U S .}

Oblongus, rubro nigroq. varius, thorace lunulis duabus nigris: elytrorum parte coriacea rubra, puncto medio nigro; membranacea nigra, puncto medio albo .

Statura, \& magnitudo omnino C. Italici Fn. Etr. 2. $241,1323$. t. 7. $f$. 1. cujus nomen a $D$. Gmelin usurpatum pro $C$. Bipunctato $F$. indicando permutandum. Caput nigrum. Antennae quadrarticulatae nigrae. Thorax antice, \& lateribus ruber, maculis duabus lunatis nigris antice vix disiunctis, latis, \& spatium trigonum rubrum in medio constituentibus. Scutellum nigrum. Elytri corium rubrum puncto medio rotundo atro. Apex membranaceus niger puncto marginis interioris albo, quod elytris iunctis unicum apparet. Alae nigrae. Subtus totus niger medio tantum abdominis rufo. Differt a $C$. Italico thorace diversimode picto; puncto elytrorum aibo; alis nigris (in Italico) albis; ano nigro; pedibus anticis non crassioribus.

Habitat Apuae ad Macram fluvium in Tusciae confinio.

$$
\text { * 508. C. P H O E N I C E U S. }
$$

Oblongus, niger, thorace postice, elytrisq. purpurascentibus; macula ad angulum corii internum atra.

Statura omnino ac magnitudo $C$. Pini, cui affinis. Caput antemnaeq. nigrae. Tharax antice niger, postice purpureomarginatus. Scutellam nigrum. Elytra purpurea, nacula ad angulum corii intcrnum ovato-oblonga atra, in singulo elytro singula. Pars elytrorum membranacea aterrima, alboq. subtilissime marginata. Alae albae. Subtus totus niger.

Habitat Florentiae .

$$
\text { 509. C. R O L A N D R I. }
$$

Oblongus ater, alis macula rhombea flava. F. Sp. 367. 175. Linn. Syst. Nat. 729. 98. Fn. Sv. 957.

Cimex oblongus atrofuscus, alarum macula flava. Geoff. Ins. 1. 45951 .

Cimex fulvo-maculatus. De Geer Ins. 3. 294.33. 
Clas. VII. Ryngota. Cimex.

Sulz. Ins. t. I 1 . $f: 76$.

Fuesl. Ins. belv. 26. $11 \mathrm{t}$.

Schaeff. Ic. t. 87. $f: 7$.

Habitat in silvis frequens.

$$
\begin{aligned}
& \text { 510. C. L } \mathrm{I} \mathrm{M} \text { в о } \mathrm{s} \mathrm{U} \mathrm{S} \text {. } \\
& \text { Long. 2. l. lat. I. l. }
\end{aligned}
$$

Ovatus, niger, elytrorum limbo exteriore albo. Villers. Ent. 1. 504. 78. la Bordeé.

Ent. Paris. 1. 217 . 74. Ia Punaise nuire is bordure blanche. Omnino similis statura, ac magnitudine C. Murioni Scbrankii, seu C. Fumoso Ent. Par. Differt tantum elytrorum limbo exteriore albo.

Habitat in sepibus primo vere frequens.

$$
\text { * 5II. C. TES T A C E U S. }
$$

Ovatus testaceus oculis, antennarumq. apicibus nigris.

Magnitudo A.Clavicornis. Corpus fere totum testaceum. Antennae quadrarticulatae, articulo ultimo nigro crassiori. Oculi nigri. Thorax punctulatus, inferne cirerescens. Elytrorum medium puncto minutissimo rufo notatum. Alae albae. Habitat in plantis .

$$
\text { * 5I2. C. P A L L I D U. S. }
$$

Ovatus pallide-rufus, capite, thorace, elytrorumq. apicibus fuscis, antennis setaceis pilosis.

Statura ac magnitudo ferc praecedentis. Antennae seraceae ad apicem praesertim pilosae. Caput parvam. Rostrum, pedes, antennae, elytra pallide-rufa: reliqua obscuriora. Alae albae. Magnitudine, statura, \& colore C. Pallidus, Testacels, ac Invidus Fn. Etr. inter sese non admodum differunt, at species omnes distinctae.

Lectus in fenestris. 
Clas. Vil. Ryngota. Coccus.

$$
\begin{aligned}
& \text { * 513. C. S A L T A T OR. } \\
& \text { Long. I. } \frac{1}{2} \text { l. lat. I. l. }
\end{aligned}
$$

Nigro-aeneus, apterus, saltatorius, elytris coriaceis, fronte, pedibus, antennisq. pallide flavis .

Affinis C. Saltatorio, cujus descriptio Geoffroyana Ins. I. 472. 76. in plurimis huic nostro convenire videtur. Statura C. Flavicollis, at triplo minor. Corpus magis ovatum, quam oblongum. Antennae flavae corpore longiores. Caput antice flavum. Oculi nigri. Thorax subquadratus aeneo-niger. Scutellum, elytra, pectus, abdomen aeneo-nigra immaculata. Elytra tota coriacea, ad apicem gibba Tetusa, \& paullulum dilatata. Pedes pallidi ungulis nigris" Postici longiusculi femoribus incrassatis nigris. Alae nul. lae. Salit. An sit ad C. Saltatorium Limm. referendus, judicent alii.

Raro lectus.

\section{CLXXIV: COCEUS.}

Rostrum vagina, setisq. pectoralibus. Antemae filiformes.

$$
\text { * 514. C. A R T E M I S I A E. }
$$

Testa grisea, clypeolis octo cincta marginalibus, albo-granulatis .

Femina testudiniformis octogona, superius cincta dypeolis octo marginalibus, centroq. granulo albo notatis; inferius fusca. Marem non vidi. Granula alba aetate obsolescunt C. Rusci affinis .

Habitat in ramulis Artenisiae campestris m. Septemb. 


\section{Clas. Vill. Antulata. Tipula . \\ C L A S I S O C T A VA.}

A A 'I L I A T A.

CLXXVII. TIPULA.

Haustellum absq. vagina. Palpi duo porrecti filiformes, ad basin proboscidis. Antentuae filiformes.

$$
\text { 515. T. R I v O S A. Alis patentibas. }
$$

Alis hyalinis, rivulis maculaq. nivea. F. Sp. 400. 2. Linm. Syst. Nat. 971. 2. Fn. Sv. 1738.

Tipula maxima alis majoribus fusco, \& albo variegatis.

Raj. Ins. 72. 2.

Tipula alis albis fusco variegatis. Geoff. Ins, 2. 554. 2.

Tipula Rivosa Scop. Ent. Cam. 846 .

Tipula Gigantea Scbrankii. E. I. 845 ?

Mea specimina exacte conveniunt cum descriptione Geoffroyana quae accuratissima omnium. Figura vero $T$. Rivosae a De Geerio exbibita $t$. 6. 341.2 . $t$. 19. $f$. 1. differt a nostris margine inferiore alarum immaculato.

Habitat in pratis.

$$
\text { 516. T. P I L I P E S? }
$$

Cinerea, alis striatis fuscescentibus tibiis anticis pilosis. $F$. Mant. 324. 33.

Media. Corpus cinereum thorace substriato. Anus rufus forcipatus in nostra, pedesq. omnes longi, flavescentes pilosissimi. Antennae nigrae, subpilosae, primis duobus articulis pallidis .

Habitat in hortis.

Toin . 11 . 


\section{T. $N$ I G R A .}

Alis fuscis, corpore atro. F. Sp. 404. 18. Limn. Syst. Nat. 972. 1 3. Fn. Sv. 1748.

Geoff. Ins. t. 2. 559. 10 :

Schrank. E. I. 864.

Fr. Fridr. 17. 673 .

Media. Alae fuscae vasis nigricantibus, punctoq. marginali. Habitat in pratis, \& hortis non rara.

\section{18. T. $P$ R A T E N S I S.}

Thorace variegato, abdomine fusco, lateribus flavo maculatis, fronte fulva. F. Sp. 403. 13.

$T$. Pratensis alis subcinereis, vasis fuscis, punctoq. marginali obscuro, fronte fulva. Limm. Syst. Nat. 972. 10. Fn. Sv. 1745.

Scop. E. C. 848 .

Habitat in herbidis prope flumina m. April.

* * Alis incumbentibas.

$$
\text { 519. T. P L U M O S A. }
$$

Thorace virescente, alis albis puncto fusco, antennis plumosis. F. Mant. 324. 37. Limn. Syst. Nat. 974. 26. Fn. Sv. 1758. $T$. fusca thorace virescente, alis pellucidis puncto nigro. Geoffr. Ins. 2. 560.16.

T. Ammaris, griseo-fusca, antennis filiformibus, maris plumosis, abdomine fasciis nigris, alis hyalinis puncto nigro.

De Geer I3s. 6. 379. 18. t. 19. $f$. 14.15.

Scop. E. C. 841 . Sibrank. E. I. 866.

Rheaumur Ins. 5. t. 5. f. 10.-4. t. 14. f. 12.

Villers Ent. 3. 373.50.

Habitat circa lacus, frequens.

$$
\text { 520. T. } \mathrm{H}_{\mathrm{I}} \mathrm{R} \mathrm{T} A \text {. }
$$

Hirsuta, alis deflexis, ovatis, ciliatis, albo, nigroq. tessellatis. F. Sp. 411. 61. Limn. Syst. Nat. 977. 48. Fu. Sv. 1772 . 
Bibio alis deflexis cinereis, ovato lanceolatis, nebuloso maculatis. Geoff. Ins. 2. 572.5 .

De Geer Ins. 6. 424. 31. t. 27. f. 10. 11 .

Similis $T$. Phalenoidi, at alae squammosae nigro maculatae apice albo, non acuto.

Habitat in Arctio lappa. Mihi lecta saepius in foliis Citri Medicáe ad muros.

\section{* 52I. T. C U P R I N E R V I S.}

Nigra, pedibus antennisq. pallidis; alis griseo-hyalinis, nelvis nebulosis cupreo viridibus.

C. Pipienzte paullo major.

Lecta in fenestris $\mathrm{m}$. Octob.

$$
\text { * 522. T. P E N I C I L L A TA. }
$$

Atra, nitens, alis albis; antennis penicillatis niveis, basi nigris .

Minutissima, \& Culice quadruplo minor. Corpus totum aterrimum. Antennae plumosae penicillo denso basi atro, apice niveo, quae ob corporis nigritiem eleganter apparent. Alae albae incumbentes.

Differt a T. Atra Geoff. Ins. 2. 567. 26. quae huic proxinia, antennis niveis.

Percurrit aestate folia juniora Quercus Roboris.

\section{B I $\quad B \quad I O$.}

Hanstellum setis tribus, vaginaq. univalvi. Palpi brevissimi. Antenane basi connatae acuminatae.

\section{* 523. B. I T A I I C A .}

Hirta, atra, thorace lateribus villis flavescentibus, abdomine lato fasciis, punctisq. villoso-argenteis: alis nigris ad marginem crassiorem hyalino-punctatis, margincq. tenuiori sinuato hyalino, absq. punctis nigris distinctis. 
Cum ad species jam descriptas minus referenda esse videretur, iconem exhibere curavi in Tab. I., ut judicent peritiores. B. Manrae, ac Aetbiopi proxima. Statura eadem; maguitudo variat. Abdominis fasciae argentene aetate, ac attritu saepe obliteratae. Ad costam alarum puncta quatuor duplicia, longitudinalia, hyalina. Schaefferi frgura Ic. t. 76. f. 9. a Fabricio citata in Syst. Ent. pro B. Manra indicanda, huic potius competere videtur, Matram enim exhibet Schaeff. fig. 8. t. 76. uti in Fab. speciebus emendatum. Habitat in silvis sat frequens.

\section{STRATIOMYX.}

Hatkstcllum seta tunica absq. vagina. Palpi breves, capitati. Antennae acuminatae, basi connatas.

$$
\text { * 524. S. C O N F U S A. }
$$

Scutello bidentato nigro, thorace aureo-pubescente; abdomine lateribus luteo-maculato, subtus toto flavo.

Statura $S$. Cbanacleontis, cui proxima, at dimidio minor. Caput nigrum immaculatum ore cinereo pubescente. Thorax niger aureo obsolete pubescens. Scutellum nigrum dentibus duobus flavis. Abdomen supra fascia lata nigra dorsali usq. ad ultimum segmentum producta, tres utrinq. maculas luteas subrotundas constituente, quarum ultima minor. Subtus totum flavescens. Anus flavus. Pedes flavi femoribus apice excepta, nigris. Alae margine crassiori flavescente. Differt a $S$. Chamaleonte magnitudine semper duplo minori, capite nigro immaculato, thorace aureopubescente, abdomine subtus toto flavo.

S. Splendens F. mihi ignota, at magnitudine aliisq notis distincta videtur.

Habitat in silvis m. Jun. \& Jul. frequens. 
525. S. TRILI N E A T A.

Scutello bidentato, corpore viridi, thorace lineis, abdomine fascies nigris. F. $S p .418 .9$.

Musća Trilineata Lizur. Syst. Nat. 2. 980. 6.

Strationys. Geoff. Ins. 2. 482. 7 :

Strationays Fasciata Furcroy. Ent. Par; 2, 7. 468 .

Panz. Fu. Germ. Heft. iv. f. I3.

Corpus viride magnitudine vix Muscae domesticae. Os antennacq. testaceae. Oculi aurato-virides fascia transversa testacea. Thorax lineis tribus longitudinalibus atris, postice connexis, mediaq. latiori. Abdomen ovatum fasciis quatuor nigris extrorsum angustioribus. Pectus nigrum. Pedes pallidi. Alae albohyalinae.

Habitat in aquosis rarior.

\section{S. $M U$ U I C A .}

Scutello inermi, atra, abdomine niveo, apice atro. F. Mant. 332. 20.

Musca Uliginosa antennis clavatis mucronatis, abdominis dorso albo: segmentis duobus penultimis striga alba. Limm. Syst. Nat. 2. 982.22.

Mussa Mutica Villers Ent. 3. 4.23. 45.

Statura S. Tritineatae qua paullo minor. Caput atrum puncto interdum sub antennis albido. Antennae nigrac. Thorax atro-violaceus nitidus. Halteres albi. Abdomen rotandum depressiusculum, laeve, nitidum, basi atrum, dorso album, \& in nostris, quasi myrininum lactei coloris: segmenta duo fere ultima linea transversa lata emarginata nigra. Subtus atrum, medio ac margine albis. Femora nigra geniculis albis. 'Tibiae tarsiq albidi. Alae albae.

Habitat in locis paludosis rartor. 
Haustellum setis quatuor absq. vagina . Palpi duo basi setarum exteriorum inserti. Antennae breves, subclavatae, setariae.

\section{S. MET A L L I N US .}

Antennis setariis, aeneus, nitens, antennis nigris. $F$. Sp. 431.52.

Frons, ac totum corpus aeneum nitidum ad plumbeum vergens. Antennae breves setariae nigrae, patellis inferius rufescentibus. Abdominis dorsum planum ovatum. Squammae halterum albae, ciliatae.

Habitat in plantis minus frequens.

528. S. L U G U B R I $S$.

Antennis setariis, niger immaculatus. F. Sp. 43 I. 50.

Villers Ent. t. 3. 121. t. 9. f. 19.

Statura S. Ruficornis, at paullo minor. Totus niger alis solis albis macula magna fusca. Antennae longiusculae.

Lectus in Chamomillae floribus, rarior.

\section{S. ROS A R U 。}

Antennis setariis, nudus, thorace aeneo nigro, abdomine atro: maculis duabus flavis. F. Mant. 341. 71.

Nostra specimina omnino conveniunt cum descriptione Fabricii . Habitat flores non rarus.

\section{* 530. S. C O N S T A N .}

Antennis setariis, ater, thorace, abdomineq. supra vellcre grisco-flavescente tomentosis; femoribus posticis dentatis, tibiisq. compresso-gibbis emarginatis, apiceq. ungulatis .

Statura, ac magnitudo $S$. Tenacis, cui valde affinis. Antennac nigrae fronte sub antennis cinerescente. Oculi fusci. Thorax, ac abdomen codem modo denso vellere griseoflavescente superius obtecta, inferius atcrima. Pedes onnes 
atri, posticiq. femoribus crassioribus valido dente armatis, tibiisq. compresso-gibbis, interius ad apicem emarginatis, apice ipso ungulato. Alae albae.

Quamvis $S$. Tethax admodum variet, tamen hic noster differt ab eo, colore, \& villo abdominis densiore, uti etiam diversa tibiarum posticarum structura. Addendum quod $S$. Tenax occurrit ubiq. \& nimis frequens, hic vero rarissimus, \& una vice tantum capti tres similes.

Habitat in silvis supra filices.

$$
\begin{aligned}
& \text { * 531. S. A C A N T H O D S. } \\
& \text { Long. 3. } \frac{1}{4} \text { l. lat. } 1 . \frac{\mathrm{x}}{3} \text { l. }
\end{aligned}
$$

Antennis setariis, tomentosus, fronte thoraceq. aeneis, abdomine atro nudiusculo, cingुulis tribus albidis interruptis: femoribus posticis crassioribus, apice interno spinosis.

Magnitudo, ac statura C. Acnei Siop. 967. Frons inter oculos aenea lata tomentosa. Antennae ferruginco-fuscae. Oculi fusci. Thorax aencus flavo-tomentosus, scutello concolori. Abdomen atrum fere glabrum, cingulis tribus albidis vix interruptis. Pedes subferruginei femoribus nigris, posticisq. crassioribus, apice interno multispinoso. Alae hyalinae.

Habitat in floribus.

\section{* 532. S. MEG A C E P H A U U .}

Antennis setariis subtomentosus, thorace lineato, abdominis segmentis primis duobus latere pallide-flavis pellucidis; capite, oculisq. magnis subflavis, fusco punctatis.

Statura, ac magnitudo S. Penduli, codemq. fere modo maculatum abdomen. Differt ab eo capire, oculisq. magnis flavescentibus, undiq. fusco punctatis, antennis ferrugineis, thorace a tergo lineis quinque albidis, \& quatuor aeneolucidis latioribus, alternantibus. Sternum nigrum. Caput magnum, \& uti in $T$. Italico conformatum. Frons, seu oculorum pars superior obscurior. Pedes aeneonigri tibiis ad basin flavescentibus tomentosis. Femora postica vix 
crassiora: Alae albae.

Lecti plures ad Pastinacae flores m. Jul.

$$
\text { * 533. S. P I S A E U S. }
$$

Antennis setariis nudus, ater; pedibus antennisq. flavis seta nigra.

Magnitudo fere S. Ichnetzmonei. Corpus elongatum gibbum. Antennae flavae deflexae seta porrecta crassiuscula nigra. Alae ad marginem crassiorem fuscae. Habitat flores in silvis rarus.

\section{CLXXXIL $M U S C A$.}

Haustellum seta unica absq. vagina. Palpi duo porrecti extrorsum crassiores. Antemnae breves clavatae seta instructae.

$$
\text { * Ant. plumatis. }
$$

534. M. MER D IANA.

Long. 5. l. lat. 2. l. \& ultra.

Antennis plumatis, pilosa nigra, fronte aurea, alis basi ferrugineis . F. Sp. 435. 3. Limm. Syst. Nat. 989. 63. Fn. Sv. 1827 .

Musca antennis plumatis, pilosa nigra, fronte flava, alis basi flavo-testaceis. De Geer Iis. 6. 55. 2.

Geoffr. Ins. 2. 495. 5 .

Musca Meridiana Siop. Ent. Carni. 867.

Scbaeff. Ic. t. 108. f. 7 .

Nigerrima, pilosa. Frons utring. aurea; alarum basis, \& halterum squammae ferrugineo-flavae. Halteres nigri.

Raro capta in silvestribus sub finem Septembris. Inveni in stercore bovino recenti . 
535. M. R U S T I C A.

Antennis plumatis, grisea, femoribus rufis. $F . S p .440 .26$. Magna, tota grisea, pilosa, femoribus solis rufis.

Habitat Florentiac.

536. M. T E S T A C E A.

Antennis pluniatis, cincrea, scutello, abdomine, pedibuscl. testaceis. F. Sp. 440. 22.

Villers Ent. $t .3 \cdot 481.180$.

Praecedente minor. Antennae nigrae brevissimae plumatae.

Habitat in plantis rarior.

\section{M. C A N I N A.}

Antennis plumatis, setaria, cinerea, thorace punctis, abdomine strigis nigris. $F . S p .+40.24$.

Magnitudo feminae, in nostris, paullo major quam in $M$. Pluviali; maris corpus tenujus. Antennae nigrae, uno tantum latere subplumatae, apiceq. setariae. Caput pilosum fronte nigra, ore cinereo, binis foliolis subrufis lucidis, ante labium porrectis. Thorax subtus cinereus, supra griseus pilosus, lateribus fusco-lineatus. Scutellum cinereum apice nigro-punctato, setoso. Squammae halterum albae. Abdomen cinereum vix pilosum, in femina, ovatzim crassiusculum segmentorum incisuris, lineolisq. obliquis dorsalibus, nigro nitidis, spatia triquctra albo-cinerca Pateribus, \& in medio ita costituentibus, ut totum supcrius albido maculatim appareat. Pedes nigri femoribus cinereo-nigris, tarsis anticis saepius subtestaceis. Abdominis apex terminatus puncto, seu spatio nigro inter duo lateralia alba. Allata descriptio competit praesertim feminae, in qua hace omnia evidentiora.

Lectae plures sub vesperum in muris Piscinarum horti Acad. Pis. prope aquam.

$$
\text { *538. M. L E E C O N Y X. }
$$

Antennis plumatis atra, alis fuscis, plantis albis.

Statura, ac magnitudo fere $M$. Domesticae. Plantae insolenTom. II. 
ter albac. Reliqua in definitione dicta. An M. Sepulcbralis var?

Habitat iuxta sepes.

539. M. A M E N T A R I A.

Antennis plumatis, abdomine aureo-fusco, basi truncato, thorace fusco setoso. Scop. Ent. Cam. 898.

Villers Ent. t. 3. 168.

Statura, ac magnitudo $M$. Caesaris.

Habitat in amentis salicis m. Mart.

$$
\begin{aligned}
& \text { 540. M. F U N G OR U M. } \\
& \text { Long. 1. } \frac{2}{3} \text { l. }
\end{aligned}
$$

Antennis plumatis, supra fuscescens, subtus, pedibusq. pallidioribus. Scop. Ent. Carn. 903.

M. antennis oblongis plumatis, pilosa, corpore ovato brevi, thorace griseo-cinereo, abdomine, pedibusq. flavo rufis. De Geer t. 6. 89. 89. t. 5. f. 5. 6?

Villers t. 3. 478.173.

Roesel. Musc. t. 8.f. 3 .

Habitat in boletis putrefactis frequens, copiosa.

$$
\begin{aligned}
& \text { 54I. M. C OL E O P T R A T A. } \\
& \text { Long. I. } \frac{3}{4} l \text {. }
\end{aligned}
$$

Antennis plumatis, nigra, alis arcuatis fuscescentibus, corpore nigro, ore, thorace subtus, pedibusq. albidis. Scop. Carnz. 907. Iners, superne nitens. Abdomen ellipticum. Alae pone basin costa obscuriores, rigidulac, arcuatae, gibbae. Genua postica nigra.

Semel lecta ruri.

* Antemis setariis.

542. M. R A D I C U M.

Antennis setariis, nigra, abdomine cinereo nigro fasciato. $F$. Sp. 443. 35. 
M. Radicum, ant. setariis pilosa, abdomine cinereo, linea dorsali, cingulisq. quatuor nigris. Limn. Syst. Nat. 992. 79. Frz. Sv. i 839 .

Villers Ent. 3. 488.197.

Simillima $M$. Domesticae, sed dimidio minor.

Habitat in radicibus Raphani.

\section{* 543. M. G A S T R O D E S.}

Antennis setariis, atra glabra, abdomine lato gibbo hemisphaerico, antennis, tibiis, tarsisq. pallidis; alis ad basin atro-nebulosis .

Paullo major $M$. Rorali. Caput parvum, nigrum glabrum septo medio, ac margine subnitido. Antennae livido-testaceac. Thorax ater laevis. Halteres nigri. Abdomen latum hemisphaericum, valde gibbum, atrum laeve, ano dehiscente. Femora nigra. Tibiae, tarsiq. albidi. Alae hyalinae expansae, prope basin obscuriores fascia nebulosa, interdum vix apparente.

Lectae plures in Coryli foliis m. Jun.

\section{M. T I G R I N A .}

Antennis setariis, pilosa cinerea, femoribus apice, tibiisq. ferrugineis. F. $S p$. 144. 42 .

Magnitudo M. Domesticae. Pilosa, tota cinerea. Thorax nigroptinctatus. Scutellum nigrum apice cinereum. Alae albae. Anus stylatus.

Habitat in plantis victitans rapina congenerum.

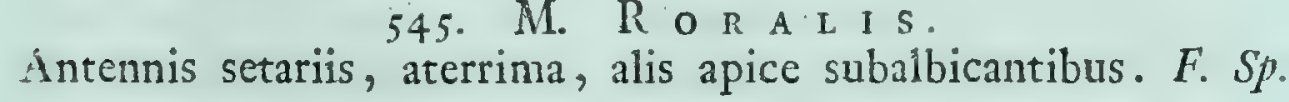
144. 44 .

M. Roralis, antennis setariis, pilosa aterrima. Linn. Syst. Nat. 993. 85. Fn. Sv. 1846 .

Scop. Ent. Carn. 890. Schrank. E. I. 941.

Geoff. I7zs: 2. 523.74 .

Minor M. Domestica. Subpilosa. Oculi brunnei. Antennae brevissimae. Halteres nigri. Alae apice albicante.

Habitat in plantis. 
Antennis setariis, nigra, abdomine pallidiore, oculis ferrugi546. M. C E L L A R I S . neis. F. Sp. 445. 48. Limn. Syst. Nat. 992.87. Fu. Sv. 1848. M. ferrugineo-fusca subpilosa, oculis ferrugineis, alis trineto viis. Geoff. Ins. 2. 536.85

M. Oenopota. Scop. Eut. Carn. 905.

Rheamm. Ins. 5. t. 8. f. 7. 11. 12.

Parvala, \& potias subrufa quam nigra. Oculi rubelli. Antennae subplumatae.

Habitat in cellis vinariis, etiam in fenestris.

$$
\begin{aligned}
& \text { 547. M. FENESTR A L I S. } \\
& \text { Long. 2. \% lat. } \frac{1}{3} \text { l. }
\end{aligned}
$$

Antennis setarïs, glabra arra, abdonine supra rugoso, sirigis albis, alis fuscis. $F$. Sp. 444. 45.

M. Fenestralis, antennis filatis, glabra atra, abdomine supra rugoso, strigis albis, pedibus ferrugineis . Limn. Syst. Nat. 981. 14. Fn. Si. 1845 .

Nemotelus Fenestralts niger, antennis cylindricis muticis, abdomine oblongo, fascirs quatuor albis, alis nigro-fuscis. De Geer Ins. 6. I89. 11.

Villers Ent. 3. 410.13.

Statura fere S. Metalini, at dupio minor. Corpus totum atro-aeneum, glabrum subnitidum. Caput parvum linea media frontis lucida. Antennae filatae, nigrae, breves, absq. seta Iaterali. Thorax antice angustatus . Halteres albi. Abdomcil oblongum, compressum, segmentis mediis dehiscentibus, saepe margine niveis, apice obtuso. Pedes rufi. Alae in nostris, albohyalinae incumbentes. Strigae niveae latera non attingant, \& omnino desunt in abdomine feminae ova gerentis. Animal tardum, hebes.

E descriptione quam dedimus, minime dubitari potest nostra specimina non esse huc referenda; at haec mox tantum, \& semcl lecta in fenestris, semperq. inventa insidens Foeniculi foliis, Scirpo, Festuca, aliisq., ubi m. Jul. coit cum femina coipore retrorsum verso, more Tipularum. In fe- 
nestris vero contra pluries capta sequens habitu, magnitudine, colore diversa:

$$
\begin{aligned}
& \text { * 543. M. A L B I C I N C T A. } \\
& \text { Long. 1. } \frac{1}{5} \text { l. lat. } \frac{1}{3} \text { l. }
\end{aligned}
$$

Antenmis filatis, cinerescens, glabra, ocalis, pedibusq. rufis, abdomine nigro, segmentis medris margine niveis.

Paullo major M. Flava. Oculi subrufi. Antennac filatae, breves muticae, supra fuscae, inferius rufescentes. Thora: cinereus. Scutellum albidum, flavescens. Abdomen obovatum, depressum, apice acuto, stupra nigrum segmentis tribus mediis margine late niveis; subtus cinereo-fuscum segmentis omnibus tenuissime niveo marginatis. Halteres albi. Pedes ferruginei tarsis saepe fuscis. Alac albae. Scutellum in hac semper flavescens, nota costans, ac optima. Habitat in ferrestris, \& locis umbrosis.

$$
\begin{aligned}
& \text { 549. M. } \mathrm{P} \text { E T R O N E L L A. } \\
& \text { Long. 3. l. lat. } \frac{\mathrm{E}}{2} \text { l. }
\end{aligned}
$$

Antennis setariis, livida, fronte rubra, pedibas eliongatis, testaceis, geniculis nigris. $F . S p .447 .57$.

M. Petronella, antennis setariis, pilosa glabra livida, fronte rubra, cauda incurvata, pedibus elongatis testaceis. Linn. Syst. Nat. 994. 96. Fin. Sv. 1856.

$$
\text { Schrank. E. I. } 946 .
$$

Habitat ad aquas, velociter cursitans supra aquas quietas proriores, \& facillime avolans.

$$
\begin{aligned}
& \text { 550. M. C O R R I GIOLATA. } \\
& \text { Long. 3. l. lat. } \frac{1}{6} \text { l. }
\end{aligned}
$$

Antennis setariis, nigra, pedibus elongatis luteis, femoribus nigro annulo. F. Sp. 447. 59. Lim. Syst. Nat. 995. 100.

$$
\text { Sabrank. E. I. } 949 \text {. }
$$

Statura accedit ad Tipulas. Corpus nutans, elongatum an- 
gustum nigrum. Pedes elongati nigri; femoribus luteis annulo ad apicem nigro. Caput singulariter conformatum galeae faciem exhibens, fronte tuberculosa, flavescente, cujus basi inhaerent antennac nigrae, seta alba terminali. OcuIi sublimes, posticeq. prominuli, \& disiuncti, antice vero immersi, lineaq. tenui alba ad os producta coaliti. Collum elongatum. Alae angustae, abdomine vix longiores. Halteres albi. Abdomen subtus flavescens apice, in masculo obstuso; in femina acuminato.

Lecta saepius in locis humentibus supra folia Viciae Fabae, ineunte Majo.

\section{M. S P I N I P E S.}

Antennis setariis elongatis, rufa, femoribus posticis crassioribus, longioribus, subtusq. spinosis, punctis duobus nigris supra, totidemq. sub antennis. Scop. Ent. Carn. 919. M. Rufifronti, \& Marginatae proxima, at magis S. Sphaegeo, cui statura, \& facie simillima. Differt tantum colore corporis, \& magnitudine fere duplo minori. Caput supra rufum, subtus tumidum, subargenteum, Oculi fasciis duabus rufis. Puncta duo nigra supra, totidemq. sub antennis. Antennae elongatae, ferrugineae seta alba porrecta. Thorax rufescens lineis obscurioribus parum conspicuis. Abdomen oblongum, rufescens, subtus pallidum. Pedes rufi femoribus posticis crassioribus, longioribus, subtusq. spinosis uti in S. Sphegeo. Alae puncto medio fusco.

Habitat in plantis; frequens in horto Acad. Pisano m. Septemb. $\&$ Octob.

552. M. 4-F A S C I A T A.

Antennis setariis, pallida, abdomine fasciis quatuor atris, alis albis. $F, S p .448 .69$.

Corpus statura omnino M. Rostratae, at paullo minus, pallidum fasciis quatuor abdominis atris. Alae albae imnaculatae. Pedes clongati pallidi. F. In nostris oculi subvirides; reliqua similia .

Habitat in plantis non frequens. 


\section{M. D I A P H A N A .}

Antennis setariis, thorace aeneo, abdomine cinereo, primo, secundoq. segmento lateribus diaphanis. F. Sp. 448. 70.

Statura, \& magnitudo M. Ungulatae. Antennae seta elongata. Oculi rubri linea fromtis argentea divisi. Thorax aeneocyaneus, holosericeus, pilisq. raris aspersus. Abdomen conicum, tenue, albo-sericeum, primo segmento, \& vix secundo (certa incidentia lucis) testaceo pellucidis. Pedes longiusculi, fusci, tibiis pallidis. Alac albae, inmaculatae. Thorax in altero sexu, colore differt minus cyaneo. Habitat in sepibus m. April.

\section{M. S T E L L A T A .}

Antemis setariis, cinerca, alis albis apice macula rotunda, radiata. Ent. Par. l'Asterisque. Villers Ent. 3. 335. 333.

Affinis M. Sonchi. Parva, cinerea. Thoracis, abdominisq. apex cinereus. Alae albac macula nigra radiata.

Habitat in Arctio lappa aliisq. haud infrequens.

\section{M. Q U A D R I P U N C T A T A ?}

Antennis setariis, flava, abdomine punctis nigris quatuor. F. Sp. 453. 93 ?

Statura, ac magnitudine cum $M$. 4-punctata $F$. convenire videtur, at in nostra, caput inter oculos, antennaeq. flavae patellis deflexis, setula longiuscula nigra. Oculi fuscorufi. Thorax cinereus, hirtus. Scutellum prominens. Abdomen flavum nudum fere pellucidum, postice ad latera punctis utrinq. duobus nigris, anticis multo majoribus, subquadratis, posticis minutissimis, \& rotundis. Halteres flavi. Pedes flavi tibiis, tarsisq. anticis nigris. Alae albae. Rar issime lecta in Quercus foliis.

\section{M. C E R A S 1.}

Antennis setariis, alis albis, fasciis fuscis inacqualibus, posticis exterius connexis. F. Sp. 453. 99. Limn. Syst. Nat. 998. 124. Frz. Sv. 1878.

Musca antennis setariis, pilosa rufa, pedibus flavo-testaceis, 
oculis viridibus, scutello luteo, alis albis fasciis inaequalibus flexuosis fuscis. De Geer Ins. 6. 50. 19.

Rbeaun. Ins. 2. $t .38, f .22 .23$.

Red. vivent. 264.

Magnitudo M. Heraclei, \& Cardui.

Habitat larva in Cerasorum nucleis.

\section{* 557. M. C O R $\mathrm{x}$ L T.}

Antennis setariis, alis nigro maculatis, basi, punctisq. tribus intermediis, albis.

Paullo minor praecedente. Caput ore antenuisq. pallidis. Ocali subvirides. Thorax ater laevis nitidus, scutello concor lori, pilis quibusdam raris hispido. Halteres albi. Abdomen ovatum atrum laeve nitidum, ano stylato in femina. Pedes testacei. Alae basi \& lateribus albae, macula magna nigra implicata, nexiformi, fere totam alam occupante, \& ramulos, seu strias angulatim e centro ad utrumc. marginem exerente, in cujus medio puncta tria alba longitudinaliter posita, ac aequali spatio distincta. Incedit alis expansis. Mas multo minor femina.

Tractu -temporis lectae tres, aut quatuor in Coryli foliis.

$$
\text { * M. 5.58. C I N E R A P I A. }
$$

Antennis setariis, cinerea, abdominis dorso, punctis duobus atris lucidis.

Paullo major M. Pluviali. Habitus M. Larvarum. Caput cinereum linea frontis, antennisq. rufis. Oculi nigri. Abdomen cincreum lateribus, \& apice subrufum punctis duobus atris lucidis in medio secundi, \& tertii segmenti positis. Pedes sibrufi tarsís nigris. Alae albae immaculatae. Captae duae in floribus.

\section{* 559. M. M A C R O C E P H A L A.}

Antennis setariis, atra nitens, glabra, capite thorace majore: tibiis, alarum basi, halteribusq. flavis.

Statura, \& magnitudo fere $M$. Domesticae. Antemnae nigrae prope os inhaerentes. Caput magnum atrum sabtuberculo- 
sum, fronte lata nigra, setulis quibusdam hirta. Thorax, \& abdomen atra nitida glabra. Halteres flavi. Femora nigra. Tibiac, tarsiq. flavi. Alac albae, basi flavae, apice miacula nigra triangulari, uti in $M$. Vibrante.

Habitat in plantis non frequens.

\section{* 560. M. G I B B A.}

Antennis setaris, aterrima gibba, abdomine rotundo coma presso, tarsis posticis rufis, alis puncto medio obscuriore. Magnitudo $M$. Roralis, at statura diversa, magisq. gibba, brevis, aterrima, nitens, etiam glabra exceptis pilis quibusdam frontis, scutelliq. duobus. Abdomen compressum, rotundum. Anus nen stylatus, Halteres albi. Pedes antici toti nigri, reliqui nigri tibiis, tarsisq. subrufis, ultimo nigro. Alae incumbentes, obscurae costa, punctoc nedio nigris .

Habitat in plantis.

* 561. M. H ELI I A IN T H 1 .

Antennis setariis, cinerea, pedibus pallide rufis, ano-stylato nigro, alis albis ad marginem obsolete punctatis.

Proxima M. Stellatae Ent. Par., at diversa.

Lectae plures in Heliantho tuberoso.

$$
\text { * 56z. M. G A L E A T A. }
$$

Antennis sctariis, obscure nigra, ore truncato biante: tibiis posticis apice appendiculatis.

Statura, ac magnitudo fere M. Celliris. Tota nigra obscura, praeter halteres qui flavi sunt. Antennae nigrae, patcllis rotundis, globulosis, apice sabcinereis, seta longiuscula. Caput subpilosum labio truncato patulo, certaq. Iucis incidentia, cinerescente. Pedes postici elongati, tibiis apice, seu tarso primo appendiculato. Alae immaculatae obscurae. In Muscis Aqtaticis saepe os patulum observatur.

Incedit super aquas impuras stagnantes, volatu brevi persequutorem evitans.

Tom. II. 


\section{* 563. M. H Y D R O P H I L A.}

Antennis setariis, abdomine aeneo, labio rotundato albolucido .

Statura fere $M$. Petronellae. Labium convexum, rotundatum, truncatum, argenteo-lucidum. Thorax subtestaceus. Alae obscurae puncto, seu potius anastomosi ante medium marginali nigra. Pedes, antennaeq. nigrae. Non confundenda cum M. Lacustri De Geer Ins. 6. 194. 15. t. 11. f. 19. 20. a qua diversissima.

Lecta cum ex aqua vasis plantas aquaticas continentis volasset ad marginem, w. Octob.

\section{* 564. M. P R O P E R A N S}

Antennis setariis, aterrima holosericea, alis albis, costa usq. ad medium nigra, pilosa, pedibus posticis elongatis.

Magnitudo fere $M$. Cellaris, ar tenuior. Corpus totum ater. rimum tomentosum. Frons nigra pilosa. Antennarum seta longiuscula. Pedes postici elongati crassiusculi. Alae albae hyalinae costa usq. ad medium atra, pilisq. brevissimis ciliata, \& eam prope venula ejusdem longitudinis, cum qua jungitur inferius, absq. puncto marginali. Magnitudo variat. M. Festinanti Scop. Carn. 946. affinis, \& forte eadem; at differt praesertim fronte nigra, non rufa, pedibus posticis elongatis, crassiusculis.

Habitat in plantarum foliis, quae velociter cursitando percurrit, numquam quieta.

$$
\text { * 565. M. P A L M I P E s. }
$$

Antennis setariis, nigra gibba, thorace fusco lineato, abdomine atro tomentoso, maculis cinerè-cerulescentibus: tarsis posticis magnis palmatis.

Statura praecedentis, at paullo major. Caput antennaeq. nigrae. Thorax fuscus, cinereo-lineatus. Abdomen gibbum, tomentosum, atrum, maculis utrinq. sex cinereo-cerulescentibus, ultimis quatuor in fasciam connatis. Halteres longiusculi, capitulo magno concavo albido. Pedes nigri. Tarsi postici dilatati, subtusq. albidi. Alae albae nervis fuscis. 
Agilis cursitat supra foliá, uti M. Properans.

Lecta in Phitolaccae foliis.

$$
\text { * 566. M. P r A E D o. }
$$

Antennis setariis, pilosa, abdomine cinereo, segmentorum marginibus nigricantibus; fronte aurea, pedibus, antennisq. nigris .

Statura, ac magnitudo fere $M$. Latcralis. Caput pilosum fronte, lineolaq. inter antennas aurcis. Labium albidum. Antennae deflexae nigrae, seta nigra. Oculi fusci. Thorax antice griseo-flavescens lineolis abbreviatis nigris, postice niger. Scutellum nigrum. Squammae halterum magnae albae. Abdomen nigrum subcylindricum apice obtuso, segmentis tribus late cinereo-fasciatis, variantibus, pilisq. longis atris ciliatis: subtus totum cum pedibus atrum. Alae fuscac. Proxima videtur $M$. Latroni $\mathrm{F}$.

Habitat in plantis non rara.

\section{CLXXXIII. $T A B A N U S$.}

Haustellam vagina univalvi, setisq. quinque. Palpi duo clavati, acuminati. Antennae emarginato-acuminatae.

$$
\text { * } 567 \text { T. M A c U L A T U S. }
$$

Oculis fuscis, tomentoso-cinereus, haustello exserto longiưsculo; alis nigro-obsolete maculatis.

Statura, \& color T. Tropici, cui athinis, sed differt magnitudine paullo minori, alis nigro-obsolete maculatis, longio. ribus, femoribus fuscis, tibiis, tarsisq. subferrugineis, haustello longitudine thoracis. Oculi modo coaliti, modo linea cinerea disiuncti.

Habitat in pratis, Florentiae. 
Hanstellam rectum bivalve basi gibbum. Antennae filiformes.

Ater, alis nigris; fronte alba. F. Sp. 462. $1 \mathrm{~L}$.

$$
\begin{aligned}
& \text { 568. A. D I A D E } \\
& \text {; fronte alba. F. Sp. } \\
& \text { stit. Entom. t. 9. f. } 15 .
\end{aligned}
$$

Villers Ent. 3. 599. 30.

Affinis A. Atro, sed paullo minor.

Habitat in pracis frequens .

\section{CLXXXVI. $C O N O P S$.}

Hulustelltum vagina univalvi abbreviata, setaq. unica. Probosits porrecta ultra basin geniculata. Antennae clavatoacuminatae.

$$
\text { 569. C. S E R I C E A. }
$$

Antennis filatis, abdomine postice sericeo albo. Villers. Enk. 3. $585.25 . t$. 10. f. 26 .

Ilabitat Pisis, in silvis, \& pratis, non frequens.

$$
\text { 570. C. LUTEA. }
$$

Antennis filatis, abdomine pedibusq. luteis. Vill. Ent. 3. 585 . 24. t. 10. $f .25$.

Statura, ac magnit. praecedentis. Occiput vesiculosum. Puncta

duo elevata ad basin thoracis, qui nigro-fuscus. Scutellum, abdomen, pedesq. Iutea. Alae flavescentes.

Habitat cum praecedente.

\section{EMPIS.}

Haustellum, \& proboscis inflexa: haustellum vagina univalvi, setisq. tribus. Palpi breves filiformes. Antenzae setariae.

$$
\text { 57r. E. C I L I A T A. }
$$

Nigricans, alis costa fusca, pedibus atris : posticis quatuor 
pennatis. F. Mant. 365.7.

Villers Ent. 3. 570.9.

Statura, \& magnitudo omninó E. Lividae.

Habitat in silvestribus.

Nigra, tarsis anticis incrassato-ovatis. F. Sp. $47 \pi .4$

Villers Ent. 3. 569. 6.

Parva .

Lecta saepius in fenestris, iuxta Arni aquas, m. April:

\section{* 573. E. F L A V E S C E N S.}

Acneo-nigta, thorace, pedibusq: subflavis, capitc atro, femoribus mediis reliquis multo crassioribus.

Vix major E. Forcipata. Antennae nigrae basi testaceae. $\mathrm{Ca}$ put nigrum parvum elongatum, ore attenuato. Oculi atri oblongi, capitis longitudinem aequantes, septo medio, seu fascia inter oculos argentea. Thorax nunc magis, nunc minus cincreo-flavescens, quasi testaceus, immaculatus. Halteres albidi. Abdomen nigro-acneum subnitidum , apice acuto bifido. Sternum nigrum, Pedes longiusculi flavescentes, subpilosi, tarsis nigro-annulatis. Femora secundi paris crassiora, tibiis apice unispinosis. Alae albae immaculatae.

Lecta saepius in foliis Amaranthi, Asclepiadis Syriacae, aliisq.

\section{* 574. E. A L B I C O R N I S .}

Atra nitida, femoribus ferrugineis, alis nigro-venosis; antennis albis.

Statura, ac magnitudo E. Maurae. Antennae longiusculae albae, basi nigrae. Caput thoraxq. nigra nitida. Halteres albi. Reliqua uti in diagnosi.

Lecta in floribus.

$$
\text { * 575. E. B I F A S C I A T A. }
$$

Atra nitida, femoribus anticis crassioribus pallide-rufis; alis albis late nigro bifasciatis. An E. Marginatae Fab. varietas? 
Pedes quatuor antici, in nostro specimine, pallide rufi, posticiq. nigri tarsis rufis. Femora antica crassiora. Alae magnae albae, in medio late, ac irregulariter nigro bifasciatae. Habitat in floribus.

\section{CXCI. $B O M B Y L I U S$.}

Hatstellum longissimum rectum, setaceum bivalve. Anteinae subulatae, basi connatae.

$$
\text { * } 576 \text {. B. E L O N G A T U S. }
$$

Cinereo-pilosus, rostro longitudine corporis; abdomine oblongo. Statura parvae Muscae, \& minor M. Sonchi. Corpus nigrum, pilis canis hirtum, at valde minus densis quam in congeneribus. Caput nigrum fronte inter oculos cana. Rostrum nigrum longitudine corporis. Thorax gibbus. Abdomen oblongum. Pedes cinerei. Alae albae immaculatae.

Habitat in pratis silvestribus rarior.

$$
\text { * 577. B. A E N E U s. }
$$

Nudiusculus niger, thorace abdomineq. aeneo-fuscis, subnitidis. Dimidio minor M. Domestica. Corpus vix tomentosum. Caput, antennae, rostrum nigra. Thorax, ac abdomen aeneofusca nitidula. Halteres albi. Pedes nigri. Alae obscurae. Accedere videtur ad B. Nudum Villers Ent. t. 3. 609. 12. at differt capite non barbato, alis fuscescentibus, pedibus nigris . Habitat cum praecedente non frequens. 


\section{$\begin{array}{llllllll}\text { A } & P & P & E & N & D & I & X\end{array}$}

1. Scarabaeus Hemisphaticus.

S. scutellatus, niger, hemisphaericus, thorace mutico, capite tuberculato, elytris laevibus. Oliv. p. 66. "2. 74. t. 2. f. 15. Similis S. Vernali, at major, \& latior. Totum corpus nigrum. Clypeus rotundatus. Caput tuberculo medio unico. Thorax laevis antice emarginatus, lateribus puncto impresso. Scutellum triangulare. Elytra laevia. An femina $S$. Vermalis? Habitat in stercore bovino, Pisis non rarus.

\section{Scarabaeus Arenarius.}

S. scutellatus, muticus, ater, elytris striatis, tibiis piceis. $F$. Mant. I1. 105.

Oliv. p. 96. t. 24. f. 206. a. b.

Statura, \& magnitudo $\mathcal{S}$. Porcati. Totus ater nitidus, tibiis solis piceis. Clypeus apice emarginatus. Elytra profunde striata. Tibiae anticae tridentatae.

Habitat in arenosis.

\section{* 3. Scarabaeus Flavidus.}

S. scutellatus, muticus, subpubescens; capite, thorace, elytrisq. pallide flavis: abdomine nigricante.

Fere duplo minor praecedente. Corpus oblongum. Caput flavescens, muticum, maxillis acutiusculis . Oculi nigri. Thorax rotundatus, inermis, flavescens. Elytra laevia flavescentia. Abdomen nigricans. Pedes flavescentes tibiis anticis 5-dentatis.

Habitat in floribus primo vere.

$$
\text { * 4. Dermestes. Birasciatus. }
$$$$
\text { Long. 2. 1. lat. 1. vix. }
$$

D. ovatus villosus, capite nigro, elytris subrufis: fasciis duabus undulatis cinereis. 
Statura, ac magnitudo $D$. Pellio. Caput nigrum. Antennae basi rufae, apice nigrae, capite vix longiores. Thorax fusco niger, villosus praesertim basi, ac lateribus. Elytra latitudine thoracis, subrufa, laevia, fasciis duabus undulatis pallide villosis, multo latioribus quam in $D$. Undato; punctoq. baseos ad suturam, alteroq. apicis utrinq. concoloribus. Subtus fusco niger. Videtur diversus a $D$. Trifasciato magnitudine, antennis, aliisq. notis.

Lecti duo in plantis m. Aug.

\section{* 5. Dermestes? Denticulatus.}

D. testaceo-fuscus, pubescens; thorace plano obscuriori denticulato.

Statura depressa, \& color uti in Calc. Flavipede, quo duplo minor. Caput exsertum, fuscum, denticulo pone oculos vix apparente. Antennae longitudine thoracis, articulis ultimis tribus majoribus. Thorax obovatus, planus, lineolis tribus prominulis, margineq. latcrali sexdenticulato. Elytra vix thorace latiora, \& duplo longiora, pubescentia, punctulata, striis in singulo tribus, aut quatuor laeviter elevatis; subtus omnia, ut supra testaceo-fusca. D. Unidentato proximus .

Lecti duo cursitantes in cistulis Insectorum d. 23 . Aug., \&e mox etiam alibi.

\section{* 6. Dermestes Sulcatus.}

$$
\text { Long. } \frac{2}{3} \text { 1. lat. } \frac{1}{3} 1 \text {. }
$$

D. niger, thorace elytrisq. marginatis: elytris profunde striatis, punctatise.

Magnitudo dupla Pediculi. Corpus ovatun. Càput nigrum, subrotundum, depressum, punctulatum. Antennae terrugineae clava perfoliata. Thorax niger fere latitudine capitis, subquadrat ${ }^{\prime}$, , lateribus, posticeq. depressus, marginatus, punctulatus, fcre scaber. Elytra nigra, thorace duplo latiota, integra, profunde striata, punctata, ac manifeste marginata. Pedes subferruginei. Preximus Sph. Atomario, at 
elytris marginatis plane distinctus.

Habitat in plantis.

\section{* 7. Byrreus Crenulatus.}

\section{Long. 1. I. vix.}

B. niger, elytris cxcavato-punctatis, apice acutiusculis .

Statura, ac facies B. Dorsalis, at quadruplo minor. Totus obscure niger. Elytra punctis majusculis longitudinaliter excavata, apice acutiuscula.

Lectus in silvis sub arborum cortice d. 6. Decemb.

\section{* 8. Byrrius Spinosus.}

B. ater, capite, thorace, elytrisq. sctulis albis brevibus raris aspersis .

Magnitudo seminis Milii. Corpus obovatum, globosum, uti in B. Pilnla, totum atrum subnitidum, ac superius setis brevibus, canis, raris, armato oculo tantum conspicuis, undiç. hirtum. Elytra vix striata.

Habitat in floribus, \& quisquiliis, m. Maj. rarus.

\section{Ptinus imperialis.}

P. fuscus, thorace subcarinato, coleoptris macula alba Aquilam expansam referente. F. Sp. 73. 5. Lim. Syst. Nat. 565. 4. Petagna Ins. Cal. 6. t. 1. $f: 27$.

Panzer Fn. Germ. Hefi. v. n. 7 .

Statura P. Germani, at duplo fere major, \& onnium nostratium maximus. Antennae corpori subaequales, cinereac. Frons cinereo-maculata. Thorax gibbus, postice subcarinatus, villosus, fuscus, lateribus cinereis. Scutellum cinereum. Elytra thorace duplo latiora, villosa, testacea fuscoq. varia, lineolis obliquis ad suturam in angulum convergentibus, fascia superius bilaciniata, postico margine, apiceq. late cinereis .

Lectus in Rubi floribus $m$. Jun 
"10. BRUCHUS GALEAE.

B. niger, corpore cinereo pubescente immaculato, elytris substriatis: antennis, pedibusq. testaceis.

Parvus, corpore nigro, pube cinerea undiq. obtecto. Antennae, ac pedes omnes toti testacei. Elytra substriata. Femora mutica, posticaq. interdum basi nigra.

Habitat in floribus Galegae officin. frequens, copiosus.

\section{Elophorus Minutus.}

E. fuscus, thorace rugoso aeneo, elytris pallidis. F. Sp. 77 . 3. Simillimus $E$. Aquatico, at magnitudo vix dupla Pediculi. Pedes subferruginei. Dantur nonnulli rariores corporis habitu Iongiusculo: an E. Elongatus: D. Schallers?

Habitat in plantis aquaticis frequens.

\section{* 12. SPHAERIDIUM. AsSimile.}

S. atrum immaculatum, thorace elytrisq. laevissimis, nitidis : antennis longiusculis, porrectis, pilosis .

An Tetratoma Atra D. Hertst?

Statura, ac magnitudine vix superat $S$. Haemorrboidale, adeoq. assimile $S$. Immaculato Fu. Etr. I. 48. I 18., ut nisi sedulo armatis oculis examinetur, pro illo indubie assumatur; differt enim ab eo tantum magnitudine duplo minori, antennis pedibusq. paullulum diversimode conformatis, thorace elytrisq. etiam laevioribus, scilicet non tenuissime uti in eo punctulatis. Corpus ovatum convexum, fere hemisphaericum : totum atrum nitidum, thorace elytrisq. laevissimis, vix marginatis. Antennae ad lentem subpilosae, thoracis longitudine, ante oculos positae, porrectae, longiores, clava tribus articulis composita, ultimo elongato. Palpi filiformes? Pedes omnes tarsis tribus, ultimo ungulato, paullo breviores quam in Spbaeridiis. Thorax latitudine elytrorum. Alae albae.

Habitat in plantis.

13. SPHAERIDIUM Bipustulatum.

S. atrum nitidum, elytris macula apicis rubra, pedibus piceis. F. Sp. 78. 2. 
Nimis S. Scarabaeoidi affine, mihic. mera varietas. Maculae apicis saepius albidae.

Habitat in stercore frequens.

\section{* 14. Spiaferidium Pellucidum. \\ Long. 1. l. lat. $\frac{2}{3}$ l. vix.}

S. atrum nitens, elytris flavis pellucidis: antennis, pedibusq. rufis .

Dermestes elytris corneis pellucidis, thorace obscuriore. Genff. Ins. 1. 108. 22. le Dermeste à etuis trasparens; qui variare videtur elytris nunc magis, nunc minus obscuris. Synonymia tamen D. Fenestralis Scopolii, \& Schrankii huic minime competit, caput enim in nostro laevissimum, nigrum, occipite destituto corniculis duobus a Scopolio observatis. Scbrankium conf.

Statura, ac magnitudo $S p h$. Melanocepbali. Antennae rufae clava perfoliata. Caput thoraxq. laevissima, nigra, nitida. Elytra flava fere pellucida, macula baseos communi triangulari, margineq. nigris. Pectus, \& abdomen obscura. Pedes rufi. Differt a S. Melazocepbalo F. antennis, pedibusq. rufis. Macula baseos, in nostris, non semper praesens.

Habitat in plantis.

* 15. Sphaeridium Testudineum.

S. ferrugineum glabrum nitidum, thorace laevi submarginato nigricante: elytris corneis, punctato-striatis.

Statura S. Ferruginei, at paullo minus. Caput nigricans ore paullulum acuminato, rufo . Oculi nigri. Antennae perfoliatac, basi rufae, clava ex articulis quatuor majoribus composita, fuscis, subrotundis, compressis. Thorax nigricans, gylaber laevissimus nitidus, submarginatus . Elytra ferruginea, glabra laevia nitida submarginata, ac punctato-striata. Tibiae spinosae. Alae albae. Differt a praecedente magnitudine paullo majore, statura diversa, clava antennarum non tribus, sed quatuor articulis majoribus composita, thorace, ac elytris submarginatis, hisce punctato-striatis. A $S$. Fer- 
mgineo vero diversum ntagnitudine paullo minori, elytris: corneis fere pellucidis glabris nitidis, \& diversimode punctato-striatis. Colore interdum paullulum variat.

Habitat in floribus, rarum.

\section{* ro. Sphaididim Pilosem.}

S. luteo-fuscum elytris pilosis punctato-striatis.

Magnitudo, statura, \& color fere S. Lutei, cui valde affine Differt tantam colore paullo obscuriori, thorace minus lato, minus convexo, magisq. marginato; elytris non pu bescentibus, sed pilosis, ac manifeste punctato-striatis; abdomine, ac alis subnigris.

Mabitat in plafitis, m. April.

\section{SCAPHIDTM IMMACULATUM}

$$
\text { Long. 2: } \frac{1}{3} \text { l. lat. 1. } \frac{x}{2} \text { l: }
$$

S. nigrum, nitidum immaculatum, elytris obtusis striatopunctatis. Oliv. Ent. 20. 3. t. 1.f. 3. a. b:

Magnitudo, \& statura Sc. Quadrimaculati. Corpus totum nigrum nitidum immaculatum. Elytra obtusa, abdomine paullo breviora, stria suturali, punctisq. impressis striatis. Ab. domen acutum. Tibiae posticae arcuatae.

Habitat sub arborum cortice frequens.

18. IPS RUTTCOR I S

I. nigra, antennis, pedibus, basiq: elytrorum ferrugineis: thorace striato. Oliv. Ent. 18, t.. 3. f. 1 8. $a . b$.

Magnirudo, ac statura $I$. Elongatae. Antennae ferrugineae. Corpus nigrum. Thorax quadristriatus. Elytra fusco-fer ruginea, apice nigra. Pedes ferruginei.

Habitat in ligno putrido:

T9. OpAtrum Gibium.

O. nigrum, elytris lineis elevatis plurimis obsoletis. $F$. $S p$ : 90. 3.

H. Cornuta D. Tbunb. Act. Soc. Ups. 
Iragnitudo O. Sabulosi, at magis oblongum, \& postice ma gis gibbum. Elytra obsoleta lineis elevatis striata. F. Thorax late marginatus margine parum serrulato, angulis anticis exsertis, posticisq. denticulo acuto .

Lectum in locis arenosis.

\section{Nitidula Marginata.}

N. ovata, elytris sulcatis: margine punctisq. disci punctatis。 F. Mant. 51. 4 .
Oliv: Ent. 1.3. t. 2. f. I 5. a. b.

Statura N. Bipustulatae. Corpus subtus piceum. Thorax niger margine late ferrugineo, Elytra marginata nigra margine, punctisq. aliquor disci ferrugineis. F. Caput auriculatum. Oliv. scilicet basis antennarum mobilis, demissis tantum antennis conspicua .

Habitat in plantis, \& sub arborum cortice.

\section{2r. Nitidula Litura.}

N. testacea, elytris litura arcuata nigra. F. Mant. 52. 15. Vix major N. Aestiva. Caput, \& thorax rufo-testacea immaculata nitida. Antennae rufae longitudine thoracis. Elytra armato oculo pubescentia, laevia, nitida, testacea, litura inaequali arcuata nigra. Abdomen nigrum. Pedes testacei. Lecta in plantis liliaceis, m. Maj.

\section{* 22. Coccinella Eláterit.}

C. rufa, pubescens, elytris maculis baseos quatuor distinctis, in medio decem connexis grandiusculis nigris.

Statura C. 7-punctatae, qua paullo major, hine maxima nostratium. Caput rufum, oculis nigris. Thorax rufus, convexus submarginatus. Scutellum minutum, rufum. Elytra rufa, maculis baseos in singulo duabus, distinctis, grandiusculis, nigris; in medio quinque duplici ordine longitudinali connexis, magnis, posticeq. coeuntibus: scilicet tribus ad marginem exteriorem invicem intrusis, binisq. ad suturam connexis, nigris. Alae albae. Abdomen in medio nigrum. Pedes rufi. 
Habitat in Elaterio Momordica Provinciae maritimae Senensis.

\section{* 23. CocGinella i 8-NOTATA.}

C. aptera, suborbiculata, rufa, elytris punctis octodecim nigris .

Magnitudo C. Bipustulatae. Caput rufum, oculis nigris. ThoIax rufus, convexus, submarginatus. Scutellum minutum, rufum. Elytra thorace dimidio latiora, latitudine parum longiora, valde convexa rufa, punctis utrinq. novem 1. 4 . 3. 1. minutis, nigris. Alae nullae. Pectus, abdomen, \& pedes rufa. Obs. Oculo acute armato supra pubescens. Habitat in plantis, rara.

\section{CocCinella IMMACULTA.}

C. aptera, suborbiculata, coleoptris flavo-rubris, immarginatis, puncto nullo: corpore concolori.

Statura, ac magnitudo fere praecedentis. Abdomine, pedibusq. concoloribus manifeste differt a C. Impunctata Linncci, aliaq. paullo majori alata, quae C. 4-pustulatae staturam habet, \& gaudet elytris magis rubris, marginatis, non adhuc satis bene distincta.

Raro lecta.

25. Coccinella QUAdRIMACULATA.

C. subvillosa, nigra, punctis quatuor luteo-rubris. Geoff. Inss. 1. 332 . 22. La Cocc. velue à points. Ent. Par. 1. 149. 22. C. Villosa.

Fn. Etr. 1. 71. 1 79. Confer:

Minime varietas $C$. Minntissimae uti dubirat $D$. Geoffroy, potius $C$. Bisbipustulata $F$. Frons modo lureo-rubra, modo non. Habitat in Umbellatis non frequens.

\section{Coccinella Frontatis?}

C. coleoptris nigris, punctis duobus rubris; fronte, pedibisq. anticis rubris. F. Mant. 1. 60. 86?

Variat punctis elytrorum quatuor. F. Hace nostra numquam: vídetur igitur nova species, cui C. Bimaculatae nomen ans magis proprium? 
Specimina quae sane habeo plurima, eodemq. tempore, ac loco lecta in Lauri Cerasi foliis, aliisq. plantis, differunt a praecedente elytris antice tantum bimaculatis, fronte thoraceq. fere semper nigris. Femora etiam omnia nigra; tibiae anticae fere semper rufae, interdum tamen etiam mediae, ac posticae. Tarsi rufi. Ne credam praecedentis vatietatem, obstare etiam videntur punctorum color in hac magis ruber, habitationis diversitas, copula observata similis cum simili, aliaq. Corpus in hac etiam subvillosum. Habitat in plantis variis, \& Jul. \& Aug. mens. frequens copiosa in Lauro Ceraso :

\section{Coccinella Minutissima.}

C. subvillosa nigra, fasciis duabus transversis rubris. Geoff. Ins. 1. 332. 21. La Cocc. velue à bandes. Ent. Par. 1. 149. 21. Coccinella Fasciata. Villers Ent. 1. 115. 64. Cocc. Minutissima. Variat admodum magnitudine, forte etiam specie. Habitat in plantis variis. M. Jun. \& Jul. frequens in Quercus ramulis, Lauro Ceraso, Citro medica \&c.

\section{Coccinella Marginalis.}

C. subvillosa nigra, elytris basi macula magna utrinq. rufa, marginali.

C. subvillosa nigra, coleoptrorum basi fascia transversa rubra, interrupta . Geoff. Ins. 1. 333. 23. C. Interrupta.

C. Austriacae. Villers Ent. 1. 115.63.

Statura, ac magnitudo plerumq. C. Minatissimas, at dantur individua majora. Differt a Coccinella sub dubio nomine Frontalis exhibita, cum qua frequens cohabitat, elytrorum punctis, quae in hac maculae majores, ad basin positae, triangulares, marginemq. externum occupantes. Etiam in hac specie frons, thorax lateribus, pedesq. interdum colore variant, \& in masculo saepe toti rufi.

Habitat in plantis variis, m. Aug. \& Septemb. frequens. 


\section{CoCCINELLA ANALIS.}

C. coleoptris atris, apice rubris immaculatis. F. Mant. 6c. 8ฐ. Paullo major C. Minutissina. Caput rubrum immaculatum . Thorax rufus basi ad scutellum nigra. Elytra pubescentia laevia atra, apice late rufa. Pedes rufi. Abdomen in nostris nigrum, ano rufescente. Obs. Insecta quae Halae saxomm indigena sunt, saepe etiam nobis communia.

Habitat in plantis rarior.

\section{* 3o. Coccinelia Arcuata.}

C. nigra, pubescens: elytris strigis duabus arcuatis, albidis. Insectum minutum elcgans, mihiq. memorabile ob vitam sublimi lapsu in eo legendo-periclitatam. Caput albido-nigrum nitidum. Oculi nigri. Thorax albus nitidus, in medio niger, emarginatus. Elytra nigra, pubescentia, strigis duabus caput versus arcuatis albis, armato praesertim ocuto manifestis, \& in elytrorum medio duplicem semicirculum efformantibas, quorum prior nagis in gyrum protractus, posticus latior. Alae albae. Pedes allbidi. Corpus hemisphaericum, subglobosum.

R. C. pubescens, elytris corneis fere pellucidis: puncto ad suturami utrine. nigro.

Statura, ac magnitudo omnino praecedentis, cujus alter sexus, scilicet mas. Caput album. Oculi nigri. Thorax albus, emarginatus. Abdomen basi nigrum, apice rufum. Pedes albi. Puncta suturae interdum striga subcirculari flavescente clauduntur. Elytrorum color testudineas.

Habitat in foliorum Citri Medicae pagina plerumg. inferiore, ibiq. lecta constanter, mens. Sept. \& Octob. in plantis parieti innixis, locis dissitis.

37. Coccinetia PYGMAEA.

C. subvillosa, nigra, thorace utrinq. macula rubra. Geoff. Ins. 1. $333 \cdot 24$.

Magnitudo fere C. Minntissinae. Pedes rufi.

Habitat in plantis rarior. 


\section{* 32. Coccinelia? Minima.}

C. nigra pubescens, antennarum clava, tibiis, tarsisq. rufis. Magnitudo seminis Milii. Nigra, pubescens, immaculata. Corpus hemisphaericum subglobosum. Thorax emarginatus . Occurrit alia, rarissime lecta in Coryli foliis, quae a praecedente differt tantum magnitudine paullo majori, \& capite flavo.

Habitat in Lavaterae arboreae foliis non rara, sed etiam cum. congeneribus in Citro medica, aliisq. plantis.

\section{* 33. Coccinela Lutea.}

C. rotunda lutea, elytris basi puncto utrinq. minutissimo nigro.

An C. Pallida D. Thunb. Diss. Ekelierg. 1785 ?

Magnitudo C. J2-punctatae. Tota lutea crocei coloris, exceptis oculis, punctoq. minuto in medio baseos singuli elytri, nigris. Alae luteae. Variat elytris immaculatis puncto scutellari minutissimo nigro.

Habitat in Chaenopodio viridi, rara.

\section{CASSIDA VIBEX.}

C. virens, sutura dorsali sanguinea. F. Sp. 108. 4. Linnn. Syst. Nat. $575 \cdot 5$.

Schrank. E. I. 89 .

Villers Ent. 1.92. 5.

Variat magnitudine, \& apud nos saepe minor mensuris a Scbrankio datis .

Habitat in Carduis.

\section{CASSIDA TIGRINA.}

C. viridescens, elytris nigro confertissime punctatis, corpore subtus nigro, thorace basi punctis duobus albidis.

C. viridis punctis nigris, corpore subtus nigro, thorace maculis binis albis. De Geer 5. 168. 1. t. 5. f. 15. 16. La C. Tigrée.

C. Affinis Fal. at, in nostris, thorax punctis duobus albis distinctis.

Toin. II. 
Villers Ent. I. 92. 7.

Sibaeff. Icon. t. $27 . f .4$. a. b.

Statura, ac magnitudo $C$. Viridis. Antennae nigrae basi albidae. Elytra punctato-sublineata. Pedes albidi. Alae obsct: rae ad marginem tenuiorem pallidae. Puncta alba thoracis post mortem obliterantur.

Habitat in Chacnopodio hybrido.

\section{Chrysomelä Holsatica.}

C. saltatoria, nigra nitida, elytris apice puncto rubro. $F$. $S p$. 136. 112. Linzz. Syst. Nat. 995.67. Fn. Sv. 544.

Altica Holsatica Syst. Ent. I I5. 118.

Villers Ent. I. 143. 88.

Magnitudo majoris Pediculi. Tota atra nitida. In apice Utriusq. elytri punctum rubrum .

Habitat in oleribus.

\section{Chry Somela Moderi .}

C. saltatoria, viridi-aenea elytris macula postica pedibusq. anticis flavis. F. Mant. 77.134.

C. Modeeri saltaroria, aeneo-nitida elytris apice flavis, pedibus anterioribus, tibiisq. posticis luteis. Limn. Syst. Nat. 594. 57. Fn. Sv. 539.

Corpus Pulice minus, aeneum, nitidum. Elytra striata, apice late flava. Antennae basi luteae. Limn. Subrotunda, globasa, \& apud nos Pulice major.

Habitat in plantis non frequens.

* 38. Cryptocephalus Stragula.

$$
\text { Long. 2. } \frac{\mathrm{x}}{2} \text { l. lat. } 1 . \frac{\mathrm{x}}{3} l \text {. }
$$

C. nigro-aeneus, elytris flavis: margine, fasciaq. late nigra dorsali ad suturam communi.

C. Quadro, \& C. Marginato Fn. Etruscae proximus, at major, \& distinctus fascia, seu macula late nigra dorsali elytrorum communi, ad apicem fere producta; elytris irregulariter punctulatis; tibiis anticis testaceis. Antennae longae ni- 
grae quatuor primis articulis rufis. Thorax lacvissimus, ater nitidus. In C. Marginato Fn. Etr. ( scilicet femina C. Flavilabris. $F$.) elytra striato-punctata.

Habitat Florentiae rarus.

* 39. Cryptocephalus Blockir.

$$
\text { Long. 2. l. vix lat. } 1.1 .
$$

C. niger, antennis longis, thorace rufescente, elytris luteis, punctis duobus nigris.

Insectum rarissimum quod D. lib. Bar. de Block Dresdensis nomini mihi caro consecratum volo.

Statura, ac magnitudo $C$. Laeti $F$. at magis etiam affinis $C$. Thoracepunctato ipsius $D$. de Block, a quo tantum differt thorace immaculato. Antennae nigrae filiformes longitudine corporis . Caput nigrum. Thorax saturate luteus, quasi rufeseens immaculatus. Scutellum nigrum. Elytra laeviter punctatostriata, glabra, lutea: in singulo punctum nigrum baseos ad marginem exteriorem, alterumq. simile fere in medio elytrorum positum. Subtus totus niger subpubescens. Lectus ruri.

40. Cryptocephalus Vititatus.

$$
\text { Long. 1. } \frac{1}{2} \text { l. lat. } \frac{3}{4} \% \text { vix. }
$$

C. niger, elytris margine, striaq. abbreviata flava: $F . S p$. 144. 36.

Cryptocepbalus elytro singulo duplici linea longitudinali flava . Geoff. Ins. 1. 233. 4. descr. optima .

Chrysumela Vittata. Vill. Ent. 1. 157. 146.

Thorax antice, ac lateraliter flavo marginatus. Elytrorum margo exterior flavus, \& in medio suturam versus singulo elytro stria abbreviata, cuspidata, flava. Pedes flavi. Antennae basi flavae, apice nigrae.

Figura Schaefferi Ic. t. $260 . f$. 3. a D. de Villers citata, aut falsa, aut male picta.

Habitat in graminosis silvaticis, m. Jun., \& Jul. saepiusq. lectus in Hieracio. 
* 41. Lagria Linearis.

$$
\text { Long. 2. } \frac{1}{2} \text { l. lat. } \frac{1}{3} \text { l. vix. }
$$

L. fusco-viridis, thorace elytrisq. subpunctatis: corpore Iineari .

Corpus langiusculum, lineare, dimidio minus quam in $L . N_{5}$ gra, \& angustum ratione longitudinis.

Habitat in plantis raia.

\section{Curculio Anguinus?}

C. longirostris, cylindricus, canus, fusco-lineatus . Linn. $E \bar{d}$. Gmelin 4. 1751.35.

Villers Ent. I. 183.30.

Corpus tota structura C. Paraplectici fuscum, subtus canum, nigro-punctatum. Rostrum magis arcuatum. Thorax lineis quatuor exalbidis. Elytra lineis quinque canescentibus parallelis, exteriore latiore, longitudinaliter punctata duplici serie punctis excavatis, vix conspicuis. Apices elytrorun mucronati, nec dehiscentes. Pedes cani mutici nigro-punctati. Antennae clavatae acutiusculae.

Lectus in Artemisia campestre, m. Jul.

$$
\begin{aligned}
& \text { 43. Curculio Jaceae. } \\
& \text { Long. 2. } \frac{1}{2}, 4 . \text { l. lat. 1. } \frac{1}{3}, 2 . \text {. }
\end{aligned}
$$

C. longirostris, niger cinereo irroratus, elytris pancto baseos distincto. F. Sp. 164. I5?

Geoff. Ins. 1. 281. 8. le Charanson tacbetè de tete de Chardon. Junior super atomis plurimis villoso-cinereis aspersus; aetate glaber, \& niger evadit.

Habitat in Carduis, Cirsio, Centaurea, frequens.

\section{Curculio Guttula.}

C. longirostris, femoribus dentatis, thorace tuberculato niger, elytris striatis puncto postico albo. F. Mant. 107. 124. Magnitudo, ac statura fere C.. Pseudacori. Rostrum porrectum incurvum nigrum. Thorax fusco-niger inaequalis, 
antice utrinq. emarginatus, acute angulatus, tuberculosus, linea dorsali impressa. Margo anticus parum elevatus. Elytra fusco-nigra puncto apicis albo. Corpus subtus cinereum .

Raro lectus in silvestribus.

\section{* 45. Curculio Gris.}

C. brevirostris, griseo-murinus, antennis fractis, elytris leniter punctato-striatis.

An C. Palliatus. F. Mant. I I 3. 178. qui mihi ignotus?

Magnitudo, ac statura omnino C. Viridis. Color totius corporis uti in dorso $C$. Viridis, at minus nitens, magisq. ad griseo-murinum vergens. Antennae fractae, nigro-cinereae, articulo primo magis quam in antennis $C$. Viridis elongato, \& elytrorum apex minus acutus . Reliqua omnia similia : Elytra punctato-striata. Femora inermia. Alatus .

Habitat in locis paludosis.

* 46. Curculio Barbatus.

Long. 8. l. lat. $3 \cdot \frac{1}{4} l$.

C. brevirostris, niger, elytris lineis rugoso-elevatis, antennis brevibus fractis: rostro bisulcato, apiceq. inferius barbato. Statura C. Morionis, \& C. Tenebriodis D. Pallas, at paullo minor. Corpus totum fusco-nigrum: subnitidum. Antennae fractae, rostro paullo longiores. Rostrum crassum bisulcatum, lateribus, apiceq. inferius pilis brevibus rufis barbatum. Oculi subimmersi. Thorax convexus subrotundus, punctulatus, subcarinatus . Elytra rugosa punctulata, lineis 5, aut 6. rugoso-elevatis, unde quasi porcata, admodum convexa, connata. Femora omnia clavata.

Lectus Floientiae.

47. Curculio Tamarisci.

C. brevirostris, viridi-nitens, elytris viridi nigro aureoq. variis. 
C. brevirostris, viridi-nitens, elytris viridi ferrugineo nigro cinereoq. variis. F. Mant. 11 3. 18 $\mathbf{i}$.

Fabriciana descriptio C. Splendiduli huic etiam quodammodo competit, at Insecti habitatio huc nostra specimina referenda esse suadet.

Statura, ac magnitudo fere C. Argentati. Caput aurato-fuscum, squammulis paucioribus cinerescentibus. Rostrum thorace brevius, supra planiusculum, non valde crassum, apice subtestaceo. Antennae fractae, basi testaceae, ad apicen cinereae. Oculi nigri rotundi prominuli. Thorax vix longitudine angustior, viridis, nitens, squammulis cinereis dorsi rarioribus. Scutellum nullum. Elytra thorace dimidio latiora, \& duplo longiora, ovata, convexa, oculoq. acute armato substriata, viridia pallide-luteo nigroq. varia, maculis in singulo praesertin distincta duabus majusculis auratis, nigroq. marginatis; posticis ad suturam communibus. Sternum, abdomen, pedesq. viridia. Tibiae, ademta pube aurata, testaceae. Femora nutica. Alatus. Obs. C. Tamarisci Villers Ent. to 1. 217. 195. t. 1. f: 25. ab hoc distinctissimus.

Habitat in Tamarisco. D. Strave Svecus, Entomologus peritissimus, cum Pisis esset sub Julii finem an. 1794., tres invenit in Tamarice Gallica, mihiq. unum benevole communicavit. Mox vero ineunte Septembri, primis horis matutinis, a me eciam reperti quamplures in nonnullis tantum Tamaricibus paludis rarius inundatae.

\section{* 48. Curculio Thaumaturgus. Long. 2. l. lat. 1. l.}

C. brevirostris, oblongus fuscus; thorace elytrisq. punctis fasciculato-villosis, fiavescentibus .

C. Antiodontalgicus brevirostris, oblongus, fuscus, thorace punctato, elytris punctato-striatis, supra maculis villosis aureis undig. aspersus: subtus luteo villosts. Gerbi Storia Naturale d' mn muovo Insetto. Firenze 1794. cum descriptione, fig., \& accuratissima historia, qua guidem amplior nulli unquam Insectorum contigit. 
Magnitudo C. Argentati . Fusco-niger, pilis flavescentibus undiq. asperses. Rostrum crassum, planum, brevissimum. Antennae vix longitudine thoracis, clava cinerea. Thorax longitudine fere duplo latior. Elytra laeviter punctato-striata, pilis crebrioribus huc illac accumulatis. Femora mutica. Alatus. Differt a C. Villoso Geoff. 52. magnitudine paullo majori, thorace non elongato, elytris fasciculato-villosis . Hic quemadmodam Attel. Baccbus, \& Betuleti (1) a D. Gerbi pro optimo in Odontalgia a carie derivante remedio habetur, ac praedicatur; scilicet confricato dente digitis, quibus nor minus quam tredecim, aut quatuordecim larvae contrectatae, \& contusae fuerint; sic enim digitus humore, seu sanguine larvae contaminatus, ac veluti imbu-

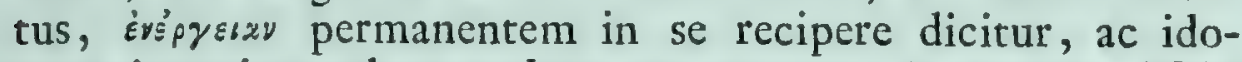
neus invenitur ad sanandum per menses, \& annum. Mihi adhuc experientia non constat (2).

Habitat in floribus Cardui spinosissimi (3), \& C. Eriophori spurii. Limn: Invenitur larva in receptaculo floris intra gallas lignosas. Obs: Cavendum ne confundatur cum aliis quae interdum ibidem cohabitant, nam Cardui fere omnes in receptaculo floris, \& medulla caulis domicilium praebent larvis non paucis e genere Muscarum, Curculiomum, atq. Tenthredinum.

49. Rhinomacer Curculioides?

Long. a cap. ad anum 3. $\frac{1}{2}$ l. lat. 1. $\frac{2}{3}$ l.

R. villoso-griseus, antennis pedibusq. nigris. F. Mant. 123. I. Sp. 199. I.

(1) Confer Dissert. DD. Comparini, i Carradori italice scripe, ac edit. Florent. ans. 1294.

(a) A D. Gerbi in notis alia Insecta antiodontalgica numerantur, scilicet Iarva M. Cardui Haemorrhoidalis, larva Ichneumonis in C. Spinosissimo hospitantis, Curc. Jaceae, Carab. Chrysocephalus Fin. Etr., \& Carab. Ferrugineus Fabricii?

(3) Plantam hanc $D$. Gerbi 1. c. exhibet tanquam indescriptam, \& diversam a $C$. Eriophoro spurio Linnaei cui valde affinis. 
Statura Cumcrlionis. Palpi quatuor extrorsum crassiores, articulo ultimo oblique truncato, quorum antici longiores. Antennae setaceae rectae, medio rostri insidentes, thoracis longitudine. Thorax dorso planiusculo. Obs: magnitudo, in nostris, major, \& pedes colore omnino corporis, hoc est albo-cinerescentes.

Habitat Pisis rarus.

\section{* 50. Notoxus Ruficolis.}

N. niger, ore, thorace, antennis, pedibusq. rufis.

Duplo minor N. Trifasciato, seu Pedicslo aequalis. Caput inflexum ore rufo, fronte, oculisq. nigris. Antennae rufae longitudine dimidii corporis, articulis novem brevibus subpilosis, ultimo acuminato majore, uti in $N$. Monocero. Palpi quatuor securiformes. Thorax teretiusculus glaber, rufus, latitudine capitis, \& fere duplo longior. Elytra glabra nigra, tenuissime punctulata, thorace duplo latiora. Abdomen nigrum. Pedes rufi. Color elytrorum interdum subniger.

Habitat in Citro medica per folia discurrens, m. Jul.

* 5i. STENOCORUS LURIDUS.

$$
\text { Long. 8. l. lat. } 2 \cdot \frac{1}{4} l \text {. }
$$

S. apterus, lividus, antennis subserratis, compressis: elytris mollibus, abbreviatis .

Statura quodammodo Calopi, sed facies, pracscrtim si corpus, ac elytra respiciantur, omnino Melois. Apterus, \& corpore toto livido, seu sordide flavescente. Caput pone elongatum uti in Attel. Coryli, collo angustiori, valde a thorace disiunctum. Antennae mediocres articulis decem subserratis, compressis, ante oculos positae. Palpi quatuor, antici filiformes, longiusculi; postici breves, subclavati. Maxillae exsertae acutae. Oculi non lunati, sed subrotundi, magni, nigri. Thorax rotundatus, elytris antice angustior, semiovalis. Scutellum majusculum subtriangulare. Elytra clevata, flexilia, subrugosa, valde abbrevia- 
ta, dehiscentia, apice attenuata. Pedes crassiusculi femoribus, tibiisq. compressis: Numerus tarsorum, ac conformatio uti in Stenaconis. Differt a Calopo Serraticomi colore lurido, qui in co griseo-fuscus, palpis anticis filiformibus; antennis ab oculo distantioribus; maxillis magis exsertis; oculis majoribus; capite pune elongato; collo praelongo angustiori; thorace convexa, semiovali g elytris mollibus abbreviatis; abdomine obeso; pedibus non teretibus neq. exilibus, sed crassiusculis, femoribus tibiisq. compressis; tarsisq. in pedibus omnibus quatuor. Obs: In Calopo Serraticomi tarsi pedum anticorum quinque. Conf. etiam fig. D. Panzeri Fr. Germ. 1. Hefi. m. 15.f. 15. qua satis exacta, colorem si exceperis nimis rutescentem.

Inseelum idem quod forma antennarum, aliisq. notis deceptus, dedi in Fr. Etrusca sub falso nomine Calopi Serraticornis, a quo, facta tandem utriusq. comparatione, ita distinctum inveni, ut diu dubitaverim an ad novum genus esset referendum. Ac ne iterum in errorem induduceremur, transmissione Insecti, aut figurae accuratissimae, Entomologas peritiores per litteras consulendos esse censui, sed eorum pars, quos inter, dolore commemoro Cl. viros $D$. Schwarz, \& D. Panzer Norimbergenses, nullam responsionis grariam fecit, etsi prior hoc singulare Insectum, alter figuram una cum plus quam ducenis ab co mihi efflagitatis specicbus rarioribus accepcrit: altera pars vero novitatem Insecti admirata, incertitudinem, observationibus propris dubiaq. nostra augere magis quam imminuere visa est.

Habitat Florentiae, \& Pisis, in locis silvestribus rarus. Metamorphosin subire videtur non in ligno cavato, ut fere genus omne Cerambycum Limnaei, sed in terrae latebris.

\section{Saperda: Sicaris.}

$$
\text { Long. 5. l. lat. 1. } \frac{\mathrm{I}}{4} \text { l. }
$$

S. coleoptris linea suturali dentata, punctisq. favis, antennis mediocribus, F. Sp. 231.2. Tom. IL. 
Cerambyx Scalaris thorace mutico subcylindrico coleopteris linea suturali dentata punctisque flavis, antennis mediocribus. Linn. Syst. Nat. 632. 55. Fn. Sv. 697.

Cerambyx favo-viridis. De Geer Ins. 5. 77. 14.

Scop. Ent. Carn. 175. Cer. Scalaris.

Ann. bist. nat. 5. 102. 77. Lept. Scalaris.

Schaeff. 16020 t. 38, $f .5$.

Variat margine elytri interiore albo. Antennarum articuli, in meis speciminibus, grisei apicibus nigris.

Raro inveni in ligno Pruni Cerasi exsiccato.

\section{Saperda TEStacea:}

S. thorace cylindrico nigra, elytris testaceis. F. Sp. 235. 23. Statura, ac magnitudo fere S. Cylindricae. Antennae longitu* dine corporis nigrae. Corpus totum nigrum, elytris solis testaceis.

Lecta m. Maj. in pratis.

\section{Callidium Praeustum.}

C. thorace subtuberculato testaceum, elytris apice violaceis . F. Sp. App. 500. 17-18. Mant. 153. 27.

Differt a $C$. Testaceo elytris tantum a medio ad apicem violaceis, quasi praeustis. Antennae corpori, in masculo, subaequales: Femora omnia clavata. Variat magnitudine. Habitat in plantis frequens.

\section{* 55. Callidium Lividum.}

C. thorace subtuberculato nudo, elytris obscure-testaceis, ore, thorace, pedibusq. flavo-lividis, antennis fuscis pilosis, longitudine corporis .

Magnitudo fere duplo minor quam in praecedente, \& a $C$. Lurido distinctissimun. Variat elytris nigricantibus. Habitat ruri frequens, \& in muris hortorum. 


\section{LEPTURA TOMENTOSA.}

Long. 5. l. lat. 2. l. \& ultru.

L. nigra, elytris flavo-testaceis, apice nigris, pedibus posticis corpore brevioribus. De Geer 5. 136.13.

Stenocortus niger elytris luteis apice nigris. Geoff. Tus. 1. 227. 8. Le Stencore noir à etuis jaunes.

L. Melanura Scop. Ent. Cam. I 49?

Atfinis L. Melanutue. Elytra apice nigra truncata. Pedes postici corpore breviores. Subtus, quadam incidentia lucis, holosericeo-nitens.

Habitat in rubo.

\section{* 57. NeEYdalis? CERAMBOIDE.}

$$
\text { Long. 3. l. lat. } \frac{\pi}{2} l \text {. }
$$

N. fusco-aenea hispidula: thorace rereti, antice angustato.

Paullo major $N$. Viridissima. Corpus rotum fusco-aeneun, irregulariter punctulatum, pilis rariusculis albidis aspersum. Antennae filiformes, mediocres, in oculis positae, subrufae articulis nigris. Thorax haud tuberculosus, teres convexus, magis clongatus, magisq. antice angustatus, quo paullulum recedit $a b$ aliis, unde generis incerticudo. Elytra minus attenuata, integra, lineola nedia prominula. Femora omnia aequalia, simplicia, mutica, ad basin rufescentia. Alae fuscae.

Lecta in silvis ineunte Majo.

$$
\text { * 58. Elater Flexuosus. }
$$

E. niger fasciis duabus undatis albis. Oliv. Ent. 3 . 77. t. 8. f. $84 . a . b$.

E. Pulchello paullo minor. Caput thoraxque nigra. Elytra brevia fasciis duabus undatis pallidis, prima ante, secunda pone medium . Corpus subtus nigricans pedibus pallidioribus .

Habitat Pisis sub arborm cortice, \& foliis disiectis. 
59. Elater Buprestoides.

Long. 4. $\frac{1}{6}$ l. lat. I. $\frac{1}{4}$ l.

E. cylindricus, niger immaculatus, capite retracto. F. Mar 175.55 .

E. Buprestoides Linn. Syst. Nat. 656. 36. Fn. Sv. 746.

Antennae, in meo specimine forte femina, non pectinatae; sed serratae, paullo thorace longiores. Color totius corporis ad castaneum vergens. Caput majusculum in tho. racem retractum. Thorax gibbus. Elytra tenuissime striara. Pedes breves.

Lectus in Agro Liburnensi.

\section{6o. Elater Dermestoides.}

E. subvillosus cinereus, elytris striatis, capite retracto. $F$. Mant. 175.56.

E. Dermestoides. Limn. Syst. Nat. 656. 37.

Elater fuscus antennis serrato-clavatis. Geoff. Ins. 1. 137. 16. Magnitudo saepe Pediculi, at dantur duplo majores. Corpus totum castanci coloris pube cinerescente obrectum. Antennae serrato-clavatae articulis ultimis tribus majoribus. Elytra, ademta praesertim pube, leniter striata. Etsi antennarum forma recedat ab aliis Elateribus, genus tamen haud dubium.

Habitat in silvis. Reperi plerumq. sub arborum cortice.

\section{Buprestis LURIDA.}

B. elytris bidentatis obscura, ano tridentato. $F$. Sp. 274. 8. B. elytris bidentatis, corpore obscuro, ano tridentato. Oliv. Fnt. 32. 21 . t. 8. f. 83 .

Nostra specimina omnino conveniunt cum descriptione $F_{G-}$ bricii, ac Encyclop. Meth. Paris. 23. 23.

Habitat in silvis non rara.

\section{* 62. Buprestis Fabricit.}

B. elytris serratis integris fusco-aenea, thorace elytrisq. subrugosis punctatis, fronte impressa sulcata; scutello nullo, aut vix apparente. 
Maxima nostratium, \& B. Mariana oblongior. Color totius corporis obscure purpurascenti-aeneus. Antennae nigrae. Caput in thoracem magis retractum, fronte late excavata, sulco medio impresso. Oculi fusco-nigri. Thorax subcanaliculatus, undiq. punctulatus punctis minutissimis confluentibus. Scutellum fere nullum, puncto vix apparente excavato. Elytra laeviter rugosa, ad apicem serrulata, integra. Abdomen sub elytris obsçure inauratum. Alae fuscae. Proxima B. Marianae, at distincta magnitudine, statura, colore : caput angustius, fronte diversimode impressa; oculi magis approximati obscuriores; thorax, ac elytra laeviora, neq. excavata rugis longitudinalibus, latis, cavitatesq. efformantibus .

In honorem summi Entomologiae instauratoris Fabricii.

Habitat in silvis Pisanis, rara.

\section{* 63. Buprestis Pisana.}

B. elytris subbidentatis, corpore supra aureo-viridi, subtus aeneo-nitido pubéscente.

Magnitudo B. Rusticae . Caput aeneo-viride, punctulatum, subpubescens. Oculi fusci. Antennae aureo-virides, capite duplo longiores. Thorax aureo-viridis, rotundatus, vix marginatus, punctulatus. Scutellum puncto elevato lucido prominet. Elytra aureo-viridia, punctulata, serrulata, apicibus subtruncatis, subbidentatis. Subtus tota aeneo-nitida, cinereo-pubescens. Species omnino diversa a $B$. Aenea $F$. Habitat in silvis Pisanis, frequensq. exclusa mihi domi est e lignis combustioni asservatis.

\section{* 64. Buprestis 10-Maculata.}

B. elytris tridentatis viridibus: singulis, maculis quatuor subrotundis, thoraceq. duabus impressis, cyaneis.

Statura B. Rutilantis cui affinis, at minor, \& distincta thorace postice maculis duabus impressis cyaneis, elytris totis viridibus, maculis in singulo quatuor cyaneis, subrotundis, \& in crucem digestis.

Lecta in Cardui foliis. 
* 65. Carabus Megacephalus.

Long. 6. 7. l. lat. 2..

C. niger nitidus, thorace subquadrato, postice angustiori, ab elytris parum disiuncto: capite magno, fronte rotundata, laevi .

Magnitudo fere $C$. Tenebrioidis, codemq. modo convexus, at starura diversa. Caput magnum nigrum, parum in thoracem retractum, sub fronte utrinq. impressum, mucha convexa laevissima. Oculi nigri. Palpi, antennaeq. subrufae. Maxillae validae. Thorax niger, haud capite latior, subquadratus, laevis, lineola longitudinali absq. punctis ordinariis, antice emarginatus, posticeq. angustatus. Elytra latitudine thoracis, ab eoq. parum disiuncta, nigra, laevia, convexa, striata, punctis discoidalibus nullis, capite thoraceq. paullo longiora. Sternum nigrum, porrectum, tuberculosum. Abdomen nigrum. Pedes nigri. Alae albae. Differt a C. Tenelarioide, capite multo majore, thorace postice angustato, \& ab elytris disiuncto. A C. Intempto Fal. vero distinctissimus magnitudine dupla; fronte magis convexa rotunda laevi; thorace minus ab elytris remoto, neq. postice rotundato, scilicet non lunato, neq. ita brevi respectu latitudinis; sterno tuberculoso, aliisq. Obs: In :C. Interrupto $F$. frons, thorax, ac elytra punctulata, punctis etiam majoribus supra strias sparsis longitudinalibus excavatis. Hujus descriptionem videre est in Sc. Clypeato $D$. d'Antic. conf. Fu. Etr. t. 1. p. 228. n. 57c. qui sane est verus Car. Intermptus Fabricii.

Habitat in terra, \& sub arborum cortice in silvis frequens.

66. Carabus SUbGiobosus.

$$
\text { Long: I. } \frac{\pi}{4} \text { l. lat. } \frac{1}{3} l \text {. }
$$

C. niger, thorace obscare subaeneo subgloboso, postice angustato, elytris punctato-striatis, maculis quatuor pallidis discoídalibus. D. de Paykull Mon. Car. 32. 54.

Cucindela Qudamarulata Fu. Sv. 151. 
Magnitudo C. Meridiani. Caput nigrum nucha obscure subaenea. Oculi prominuli. Antennae saepius basi ferrugineae. Thorax supra obscure subacneus, globosus, vix marginatus, glaberrimus, postice angustatus, lineola nulla longitudinali . Elytra thorace latiora, nigra nitida, subtilissime punctatostriata; maculis utrinq. duabus discoidalibus minoribus orbiculatis, altera baseos, altera apicis. Tibiae pallidae. Femora nigra. $M$. $C$.

Habitat in putridis minus frequens.

\section{Pimelia Glabia.}

P. atra, thorace rotundato, elytris glaberrimis $F . S p .319 .23$. Tenebrio laevis apterus nitens, thorace suborbiculato marginato, elytris laevibus, marginatis. Forsk. Descr. Animal. 78. 7 .

Duplo minor P. Carinata. Tota atra nitida. Thorax orbiculatus, latitudine brevior, Jaevis, marginatus. Elytra connata, obtusa, glaberrima, laevia, marginata .

Habitat Pisis, rarior.

\section{* 68. Mordella fasciolata.}

M. nigra caudata, thorace elytrisq. maculis aureo-villosis.

Valde affinis M. Fasciatae, cujus forte varietas. Facies, statura, color idem. Differt tamen ab ea magnitudine minori, elytris aureo nitidiori villo aliter pictis, antennisq. totis nigris, quae in M. Fasciata, ad basin rufae. In reliquis omnibus vix, ac ne vix quidem diversa.

Habitat in plantis rarior.

\section{* 69. Mordella Biguttata.}

M. nigra, elytris basi flavo maculatis .

Statura, ac magnitudo $M$. Flavae. Antennae nigrae, basi flavae, Iongiusculae. Tibiae tarsiq. flavi. Elytra basi macula flava suturam non attingente. Reliqua nigra .

Descriptio $M$. Dimidiatae cum hac omnino non convenit. Occurrit alia etian habitu, ac magnitudine similis, tota nigra thorace, \& pedibus flavorufis, forte varietas $M$. Tho- 
racicae, at caput constanter in meis speciminibus, atrum. Habitat in floribus frequens.

7o. Staphylinus Porcatus.

S. niger thorace abdomineq. porcato, elytris quadrisulcatis, pedibus piceis. Paykull Mon. Staph. n. 50.

Facies quodammodo Silphae; magnitudo majoris Pediculi. Corpus ovato-oblongum, depressum apice attenuato. Sternum fossula profunde excavatum. Tibiae anticae pallidae. Reliqua uti in descriptione Mon. Stapl. l. c.

Lectus pluries in Tritici aristis, \& in Rubi foliis, at acquisitio difficilis ob immobilitatem, \& colorem quo frustula, \& quisquilia mentitur .

71. Locusta Thymigola.

Long. 12., 13. $\%$

L. thorace tetragono laevi, elytris sublinearibus, fusco punctatis, ala brevioribus. Petagna Instit. Entom. 1. 313.1. $t$. I o. $f .18$.

An haec nostra sit vera $L$. Tbymifolia Fal. Syst. Ent. 283.5 . non certus; convenit tamen cum descriptione, \& figura a Cl. Petagna l. c. exhibitis.

Habitat apud nos non frequens.

$$
\text { * 72. Grilues Giornae. }
$$

Masc. long. 6. l. lat. 1. l. Fem. long. 8. l. lat. 2. l.

G. apterus, griseo-fuscus, femoribus posticis intus nigro bifasciatis, abdominis basi ( in mare) linea alba obliqua laterali.

Facies larvae, seu potius pupae, at perfectum animal. Femina fere magnitudine $G$. Rufi; mas duplo minor. Color totius corporis, in femina griseo-fuscus, in masculo obscurior, interdum fere niger. Caput antice lineis quatuor elevatis. Antennae filiformes, longitudine capitis. Thorax carinatus. Abdomen in femina griseum, atomis nigris inter- 
dum aspersum, lateribus obscurioribus: in masculo, fuscum linea bascos alba obliqua laterali ad femorum posticorum juncturam perducta. Elytrorum rudimenta in statu adulto tantum brevissima, concolora. Alae nullae. Femora postica abdomini subacqualia, intus nigro quasi bifasciata, nervisq. nigro-punctatis. Tibiac posticae ad basin macula pallidiori intus notatae.

Quamvis Gryllus hic diu mihi notus, semperq. visus apterus, ac saepissime copula junctus cum femina pariter aptera, attamen indescriptus videtur non mihi tantum, sed etiam ill. viro D. Gioma Entomologo egregio, cujus nomine insignitus nunc prodit.

Habitat ubiq. in locis apricis, m. Aug. \& Septemb.

\section{* 73. SEMBLIS Farinosa.}

S. alba, alis farinosis, deflexo-compressis, posticeq. adscendentibus; collo elongato, oculis nigris.

Longiuscula, \& minuta. Facies Tinzeae, at antennae hujus generis, annulatae, filiformes, fere longitudine corporis. Yalpi breves, occultati. Oculi nigri. Thorax clongatus. Corpus totum albo farinosum.

Habitat imago frequens sub Viburni Tini foliis, ms. Septemb. in locis umbrosis humentibus.

\section{Hemerobius Striatulus .}

H. fuscus, flavo-maculatus, alis fusco-striatis posticis immaculatis. F. Sp. 394. 10.

$$
\text { Villers Ent. 3. 53. } 15 .
$$

Habitat in plantis.

\section{Cynips Adonidum.}

$$
\text { Long. 2. } l \text {. }
$$

C. nigra gibba, oculis lacte rubris, abdomine compresso cordato, apice acutissimo, geniculis, tarsisq. albidis .

C? Adonidum. Fr. Etr. 2. 79. 854 .

Magnitudo, ac statura fere Cyn. Geoff. Ins. 2. 298. 5. t. 15. Tom. 11 . 
f. r. c. Caput totum punctulatum, fere scabrum nigrum, punctoq. majore inter oculos supra antennas excavato, lucido. Antennae breves, fractae, 7 -articulatae, nigrae. Thorax niger, gibbus, punctulatus. Abdomen nigrum nitens, ad latera compressum. Femora nigra geniculis, tarsisq. albis. Alae aqueae puncto minutissimo concatenato, \& a margine distanti, uti in Ichn. Muscarum. Conf. De Geer t. 1. p. 607. t. 32. $f .22$. Aculeus rufus longitudine abdominis, cujus sub fornice latet, basi inhaerens.

Lecta in plantis Hesperidum, \& mox etiam saepius in Quercu, \& Lauri cerasi foliis.

* 76. Curips Scuteliaris.

\section{Long. 2. $l$.}

C. atra nitens, tibiis subferrugineis: scutello punctis tribus excavatis .

Statura, ac magnitudo C. Quercus folii. Diplolep. Geoff. Ins. 2. 309. 1. t. 15. f. 2. cui affinis. Corpus totum nigrum nitidum, tibiis exceptis subferrugineis. Antennae nigrae filiformes 14-articulatae, longitudine abdominis. Scutellum porrectum punctis tribus distinctis impressis. Abdomen globosum, ad latera compressum. Alae aqueae: anticae abdomine sesquilongiores puncto, nervisq. duobus fuscis ante medium cruciformiter anastomosantibus.

Habitat in plantis.

\section{* 77. Cynips Ruficornis.}

Long. 2. l. vix.

C. nigra, gibba, abdomine brevi obtruncato nitido, antennis tibiisq. rufis : scutello obtuso, porrecto, tricarinato.

An Diplolepi Geoff. Ins. 2. 311. 5. affinis?

Paullo minor praecedente, a qua etiam differt antennis Iongioribus rufescentibus, basi seu primo articulo nigro, abdomine breviori, anticeq. obtruncato; scutello tricarinato. Occurrunt aliae huic fere similes, abdominis apice minus obtuso, quae forte feminae. 
Primum ruri inveni Araneae tela irretitam, mox lecta etiam in Quercu.

\section{* 78. Cynips Affinis.}

$$
\text { Long. } x_{3} l \text {. }
$$

C. nigro-viridis nitens, alis ad marginem nigro bimaculatis. Antennae fractae, 7-articulatae, nigrae, basi rufae.Caput, thorax, abdomen nigro-viridia. Abdomen cordiforme, ad latera compressum, apice acutum. Tibiae pallidae. Alae albae ad marginem nigro binaculatae. Diversa a $C$. Geoffr. Ins. 2. 307. 30. (quae primac familiae) antennis septemnodiis, alisq. non tripunctatis, sed tantum bimaculatis.

Lecta in Lauri cerasi foliis.

\section{Cynips Plumata.}

C. nigra, antennis plumatis; abdomine reverso, petiolo longiori .

Eadem quam dedimus in Fn. Etr. 2. 79. 853. sub dubio nomine Cbryseos Plumatae. Magnitudo C. Rosae. Antennae subdentatae articulis septem quadrangularis, primo articulo, seu basi praelonga, \& caput versus deflexa, plumatae tenui villo albo sericeo. Tota nigra exceptis oculis, tibiis, \& digitis rufis. Abdomen breve nitens, ad latera compressum figura cordis reversi, fornicati, lunati, basi prona terram respiciente, petiolo longo uti in E. Appendigastro, at non dorso thoracis imposito. Alae hyalinae
Primum lecta in plantis Hesperidum, mox in Quercu.

$$
\begin{aligned}
& \text { * 8o. Cynips? Dubia. } \\
& \text { Long. 2. } \frac{1}{5} \text { l. lat. } \frac{3}{3} \text { l. }
\end{aligned}
$$

C. nigra nitens, villosula, abdomine sessili, pedibus ferrugineis, capite in pectus retracto, ore acuminato.

Genus mihi dubium. Facies Icbnetumonis, aut Sphaegis. Antennae moniliformes, 14-articulatae, nigrae. Caput nigrum in pectus retractum, ore acuminato, uti in Cbell. Hlesperi-

$\mathrm{O}_{2}$ 
dum . Oculi sublimes. Thorax niger nitidus, pilis raris cinereis aspersus. Abdomen obovatum, longitudine thoracis, nigrum nitidum, cinereo-subpilosum. Pedes omnes ferruginei, tenues, subpilosi. Alae albae immaculatae. Lecła ruri in plantis.

\section{* 8x. Ichneumon Apparitorius.}

I. seutello flavicante, capite, thorace, pectoreq. nigris, abdomine pedibusq. fulvis. Villers Ent. 3. 143. 29.

Omnino bicolor. Antennae nigrae albo annulatae. Abdomen, pedes scutellumq. fulva, reliqua nigra. Vill. l. c. Statura, ac magnitudo I. Sarcitorii. Aculeus niger brevissimus.

Habitat ruri non frequens .

\section{ICHNEUMON IRRISORIUS.}

\section{Long. 4. l. lat. $\frac{1}{2}$ l.}

I. scutello albo, thorace maculato niger, abdominis segmentis margine albis.

Antennae nigrae, fere longitudine corporis. Caput nigrum orbita oculorum alba. Thorax albo variegatus, puncto utrinq. baseos, tribus sub alis, macula scutelli lunata, $\delta$ pone lineola, dein fascia angulum in medio efficiente, \& ad latera extensa, albis. Abdomen nigrum, subsessile, segmentis omnibus albo marginatis. Aculeus niger longitudine abdominis. Pedes ferrugineo-flavi patellis, tarsisq. posticis nigris. Alae hyalinae.

Lectus in silvis.

\section{* 83. Ichneumon Flagitator.}

I. niger, thorace ferrugineo, postice bidentato; abdominis apice albo.

Magnitudo I. Exbortatoris. Antennae basi, \& apice nigrae, albo-fasciatae, longitudine abdominis. Caput nigrum immaculatum. Thorax ferrugineus scutello concolore, postice utrinq. denticulo armatus. Petiolus ferrugineus. Abdomen subfalcatum, nigrum, apice albo. Aculeus niger, 
dimidio minor abdomine. Pedes nigri tibiis anticis vix pallidis. Alae hyalinae puncto nigro marginali.

Lectus in plantis.

* 84. ICHNeUmon InVEStigator.

Long. 6. l. lat. $\frac{x}{2}$ l.

I. niger, thorace obsolete rufo-maculato, abdomine subfalcato, tenui longo obtuso, tibiis anticis pallide rufis .

Statura fere, ac magnitudo I. Sigittatoris. Mant. I. 122. 268. eiq. affinis. Antennae nigrae, tenues, abdomine breviores. Corpus totum nigrum, thorace excepto maculis quatuor oblongis ferrugineis, anticis vix manifestis, quae in mortuo fere omnino evanescunt. Aculeús ninime apparet, at ano subhiante latet. Alae albae, breves, erectae, puncto nigro marginali. Variare videtur thorace immaculato. Obs: ne vitio laboret judicium de sexu, examinandi in vita Icbnetumones, nonnulli enim adeo brevem, \& occultatum gerunt aculeum, ut nonnisi molestati exserant conspiciendum.

Habitat in Quercu, aliisq. plantis festinanter ramulos, \& folia perscrutans.

* 85. Icheneumon Sanguinator.

$$
\text { Long. 4. l. lat. } \frac{2}{3} \text { l. }
$$

I. rufus, abdominis apice nigro; ano albo.

Medius. Statura I. Incubitoris. Antennae nigrae articulis brevibus, albo-fasciatae, longitudine abdominis . Caput rufum oculis nigris, palpis, lineaq. ante oculos, albis. Thorax rufus scutello concolore. Abdomen petiolatum rufum, apice nigrum, segmentis tribus ultimis albis. Aculeus brevissimus vix exsertus, niger. Pedes rufo fuscoq. varii. Sternum, femorum apophyses, ac femora postica nigra. Alac albae puncto marginali nigro. I. Exbortatore paullo major, $\& \mathrm{ab}$ eo omnino diversus.

Habitat in Quercus. 
86. ICHNEUMN VIATOR.

Long. 5. $l$.

I. niger, femoribus fulvis. Scbrank. E. I. 715 :

Scupoli Ent. Carin. 747.

Geoff. Ins. 2. 340. 43.

Villers Ent. 3. 163.88.

Antennas in morte spirales gerit Scop. Tibiae posticae puncto, seu annulo albo dimidiato notatae.

Habitat in plantis. Inquietus migrans de loco in locum. Scop.

* 87. ICHNEUMON IDOLON.

I. abdomine supra flavo annulis atris, capite, antennarumq. apicibus flavis: alarum margine exteriori luteo.

Statura, \& facies Sir. Pygmaei, at major, \& hujus generis . Antennae nigrae apice tantum flavae. Thorax antice flavus. Tibiae tarsiq. primi, \& secundi paris nigra. Alae fuscae costa lutea.

Lectus Florentiae.

* 88. ICHNEUMON RUBIDUs.

$$
\text { Long. 2. } \frac{1}{2} \text { l. }
$$

I. rufo nigroq. varius: alis albis nigro bifasciatis .

Statura, ac magnitudo I. Mutillarii. Antennae rufae longitudine dimidii corporis. Caput rufum . Oculi fusci. Thorax rufus, macula scutellari nigra. Petiolus, ac primum abdominis segmentum rufum, reliqua nigra. Aculeus niger abdomine brevior. Pedes rufi. Femora postica nigra. Alae albae, anticae fasciis duabus transversis latis, marginesq. attingentibus nigris, postica duplo majore. Occurrit alius simillimus aculeo destî́utus, qui difiert tantum antennis longioribus, alisq. praeter fascias puncto magno marginali nigro notatis. An mas?

Habitat in Quercu robore, Corno sanguinea, aliisq. 
* 89. Ichneumon Auratus.

1. viridi-aeneus nitens, abdomine ovato, tibiis flavis; antennis, tarsisq. posticicis nigris .

Fere duplo major I. Bedeguaris, \& I. Chrysi Fal. affinis. Antennae nigrae longitudine thoracis. Caput, thorax, abdomen aureo viridia nitida, immaculata. Abdomen ovatum. Femora nigra. Tibiae flavae. Tarsi postici nigri. Alae aqueae puncto nigro a margine distanti. Differt ab I. Chrysi magnitudine minori, colore capitis atq. thoracis, aliisq. notis .

Lectus in Quercu.

* 9o. Ichenuon Calcaratus.

1. aeneo-ignitus nitens; femoribus posticis cyaneis, denticulo armatis .

Magnitudo praecedentis, at statura diversa. Antennae fractae, basi rufae, apice nigrae. Caput aureo-ignitum, punctulatum. Oculi rufi. Thorax aeneo-ignitus, gibbus, valde punctulatus. Abdomen aeneo-ignitum, laevissimum, gibbum, lateribus compressum. Aculeus niger paullo longior abdomine. Pedes primi, \& secundi paris rufi femoribus nigris: postici rufi, femorum apophysibus antice aeneo-nitidis, posticeq. cyaneis. Femora postica crassiuscula cyanea, \& ad apicem internum denticulo instructa. Alae hyalinae puncto nigro marginali.

Lectus in foliis Coryli Colurnae.

\section{* 91. Iohneumon Infidus.}

\section{Long. I. $\frac{x}{2} l$.}

I. niger, antennarum basi, fronte, pedibusq. rufis; scutello flavo, apice bifurcato.

C. Infida. Fri. Etr. 2. 80. 855.

Facies parvae Muscae, \& vix duplo major I. Muscarum. Antennae nigrae, fractae, clavatae, articulo primo rufo flavescente. Caput postice nigrum, punctulatum. Thorax ad scutellum bifurcatus, maculaq. magna flava instar lunulae in- 
cisa. Abdomen parvum, rotundum nigrum petiolo brevissimo. Tibiae posticae nigrae. Alae hyalinae puncto nigro, \& apice fuscae.

Lectus in Citro medica.

* 92. IChNequon Crassicornis.

Long. I. $\frac{1}{5} l$.

I. niger, antennis basi rufis, crassis, septemngdiis, longitudine corporis .

Statura I. Muscainm. Caput nigrum subrotundum. Oculi magni prominuli. Antennae nigrae basi rufae, crassae, longitudine corporis, articulis septem extrorsum crassioribus, compressis, ultimo longiore attenuato, quas antrorsum inflexas gerit, \& agitat. Thorax magnus, gibbus, ater. Abdomen thorace minus, ovatum, nigrum, aculeo non apparente. Tibiae anticae rufae. Alae albo-hyalinae puncto marginali nigro .

Mabitat in plantis.

\section{ICHNUMON RAMICORNIS.}

I. viridis, antennis ramosis. $F . S p .441 .125$.

De Geer Ins. 1. 589 . t. 35. f. 3. 4. 5 .

Eulophus. Geoff. Ins. 2. 313. I. t. I 5. $f .3$

Villers Ent. t. 3. 212.252.

Minor I. Bedeguaris. Antennae uti in figuris De Geerii, or Geoffroy l. c. ramosae, nigrae. Oculi in femina praesertim subrufi, post morten fusci. Caput, thorax, abdomen auro viridia. Abdomen in masculis basi albo-hyalinum. Pedes omnes albi, at postici femoribus, tibiisq. apice nigricantibus. Alae albae immaculatae. Femina fere duplo major masculo, antennis simplicibus, aculeo vix, aut ne vix quidem exserto. Mca specimina conveniunt cum Iibnewsnone a De Geerio descripto 1. c., \& differunt ab Eulopho Geoff. antennarum colore semper nigro, abdomineq. basi albo-hyalino: An varietas? An species?

Habitat in Quercu, ibiq. etiam lectus, at prodierunt mihi 
plures ineunte Novembre e fructibus infectis Oleac Europeae ad cxclusionem Muscarum in vase asservatis.

\section{I CHNEUMON RUEESCEN .}

1. pallide-rufus, antennis fractis clavatis, thorace postice, abdomineq. nigris, macula alarum mágna fusca. De Geer Ihs. 2. 882, t. 30. f. 22 . mala .

Statura, ac magnitudo praecedentis. Antennae fractae, clavatae, nigrae, articulo primo praelongo rufo. Caput nigrum laevissimum. Oculi atro-aenei . Thorax pallide-rufus, fascia nigra postica cinctus. Abdomen postice nigrum. Aculeus niger longitudine abdominis. Alac pone medium. ad apicem maculatae, puncto atro marginali macula intruso. Pedes pallide rufi tibiis basi albo-fasciatis, tarsisq. posticis nigris. Saltat.

Quemadmodum $D_{e}$ Geerio contigit, mihi ctiam domi ante oculos obviam se dedit, digitisg. apprehensus bis fugam saltu adeo celeri petiit, ut nonnisi diligenti, ac improba perquisitione recuperare potucrim.

I. rufus, capite, antennisq. apice nigris .
IS.

Est inter minimos. Nigra sunt caput, antennarum apices, $\&$ aculeus, reliqua rufa. Antennae longitudine dimidii corporis. Aculeus abdomine brevior. Alae incumbentes, puncto elongato majusculo nigro marginali. Non confundendus cum I. Melanocepbalo Scbrainkii qui omnino diversus. Pluries lectus in fenestris.

\section{I. A gilis.}

I. apterus niger, pedibus rufis.F. Sp. 44I. I 25.

Ichmetumon apterus niger, corpore oblongo, antennis pedibusq. bruneis. De Geer t. 2. 2. p. 903. 21. 17. t. 31. f. 18.

Villers Ent. 3. 215.266 . I. Fusciconis.

Magnitudo minoris Formicae. Niger. Antennae subrufae longitudine corporis. Caput latitudine dupla thoracis. Thorax in duos labos fere aequales divisus. Abdomen oblongum.

Tonin. II. 
Alae nullae. Aculeus longitudine dimidii abdominis. Pedes subrufi .

Lectus in Lauro Tino. Ponit ova in larvis Icbnenmonis Apbidum. De Geer l. 6 .

\section{Nov. Gerr. CXV. XENOS.}

Labiam breve medio setigerum. Palpi duo filiformes, compressi articulis inaequalibus. Oculi exserti, manifeste compositi. Thorax antice utrinq. appendiculatus pedunculo halteriformi. Antemane breves, vix capite longiores, duplici ramo instructae, ramis aequalibus, deflexis, compressis, quasi ensiformibus.

\section{* 97. Xenos Vesparum.}

$X$. ater, antemnis brevibus, furcatis compressis: thorace 12 . teribus antice appendiculato.

Missus ad Societ. bist. natur. Paris. ann. I 794. publici juris fecit. Confer: Soc. Pbilom. de Paris. Bull. May, o Jum 12. 23.24 . descr. 21. 22. Icon. male exbibet.

Insectum novi generis, Icbncumoni proximum. Totus ater fuliginosus. Caput parvum. Oculi valde prominuli, sphaerici, manifeste compositi. Labium breve, medio setigerum. Palpi duo filiformes longiusculi articulis duobus inaequalibus, primo brevi rotundo, altero elongato, compresso. Antennae breves vix capite longiores, in utroq. sexu duplici ramo instructae, ramis aequalibus, deflexis, compressis, quasi ensiformibus. Thorax lobo antico in collum veluti protractus, \& singulariter utrinq. ad basin appendiculatus membranula, seu pedunculo instar halterum porrecto, cochleariformi; in medio latior, convexus, inaequalis, posticeq. admodum elongatus. Abdomen fere cylindricum, neq. petiolatum, neq. aculeatum. Femora, tibiaeq. posti: cae depressae, \& breviores. Tarsi quatuor fusci, sabtus albidi. Alie quatuor albae, longitudine abdominis. 
Habitat in $V$. Gallica, proditq. declaratus Vespa adhuc superstite; Haec per aestatem apud nos frequens invenitur inter annulos occupata hoc singulari aninialculo, scilicer abdominis segmento fere semper quarto irregulariter elevato, ac turgido una, \& saepe binis, etiamq. tribus interpositis pupis. Hac pupae si acus ope, e loco penitus extrahantur, abruptoq. tegumento leniter deinde tunica, seu veste alba propria exuantur, mens. Aug. \& Septemb. exhibent Insectum non raro jam efformatum, ac vivum, cui Vespac larva antequam cellulas clauderentur, forte incunabula dedisse videtur (a). Mirum quidem Vespas abdominis annulis unam, vel plures pupas gerentes, etiam post Insecti exclusionem manere posse superstites, at certum, transacto enim co tempore ordinario exclusionis, Vespac fere omnes quae tum sacpissime occurrunt, etsi satis alacres, dati domicilii fidem, tegumentis in annulo permanentibus indubiam faciunt. An larvae status in hoc Insecto brevissimus, thoracisq. Vespae inoffensio eam forte $a b$

(a) Hactenus frustra tentatum id a me investigare non minus excubias longas agendo Vesparum nidis incubationis tempore, quam repetita larvarum puparumq. sectione; immo vidi saepius quod si Insectum aliquod, \& Formica praesertim etiam minima forte nidum propinquaret, illico Vespa una alterave insurgens, eam morsibus in fugam praecipitem adigebat. In nido tamen quo plures convenetant Vespae jam e cellulis exclusae, deprehendere datum individuum masculum gerentem in abdomine larvam, quae mihi se commonstravit e quarto segmento tantum post mortem Insecti. Mares huic molestiae magis obnoxii videntur quam feminae; ac de is, uti alio etiam malo subiectis, liceat mihi opportune heic ludicram observationem referre. Cum eorum exta inspicerem, oculosq. acute armatos obverterem in appendices genitalia amplexantes, cochleariformes, ciliatas, apiceq. aculeato, (conf. Rheaumurium, \& De Geer t. 2. 2. $t$. $26 . f .8 .9$.) quas Vespa irritata exserere solet $a b$ ano, non secus, ac si veri essent aculei pungentes, quanvis ad feriendum ineptae; contigit videre saepius admiratione quadam eas cum genitalibus infestari ab Acaris minimae speciei, albiq. coloris, quasi pellucidis, $\mathbb{E}$ in eo tantum loco hospitantibus. Conf. $V$. Gallica $1 l-$ listrat. in calce. 
interitu absolverent? Molestantur vero simili hospite etiam $V$. Sexfasciata, aliaeq. Vespae minores, sed rarius, proindeq. non uti $V$. Gallica accurate ad examen redactae.

Quamvis hoc meum Insectum antennarum forma differat $\mathrm{ab}$ aliis omnibus huc usq. cognitis, tamen nota haec unica, uti etiam (contra D. Geoffroy opinionem) in I. Ramicom animadvertit $\mathrm{Cl}$. De Geer, minus videri posset sufficere ad novum statuendum genus, si masculorum tantum propria esset, \& characteres alii peculiares non simul concurrerent, inter quos omnino singularis est nota thoracis q180damodo antice balterati.

\section{Chalcis Sispes.}

$$
\text { Long. 2. } \frac{3}{4} \% \text {. }
$$

C. nigra, femoribus posticis incrassatis, serratis, flavis, nigro maculatis, scutello piloso bidentato.

C. Sispes Frr. Etr. 2. 58.802 .

Sulzer. t. 27. $f$. 1. Sphex Myrifex.

C. Sispedem petiolo flavo Fab. numquam vidi. Haec quae nostratium omnium major, non satis adhuc recte descripta. Caput nigrum immaculatum, punctulatum, cinereo pubescens. Antennae nigrae. Thorax punctulatus, pubescens, niger, callo alarum flavo, scutello pilis canis penicillato, subtusq. bidentato. Petiolus brevissimus, niger. Abdomen nigrum, breve, subrotundum, apice retusun, primo segmento majori, glabio nitidissimo, reliquis cinereo subpilosis. Pedes quatuor antici flavi, ungulis, femoribusq. apice excepto, nigris. Postici flavi apophysibus elongatis nigris, femoribus incrassatis, serratis, macula magna nigra circumducta. Alae albae anastomosi, ac puncto marginalibus nigris. Mas variat abdominis apice minus retuso, femoribus posticis pro macula media, basin nigram fere usq. ad cjus medium gerentibus. Variat etiam, sed rarissime abdominis primo segmento, \& macula media femorum posticorum rufis. Obs. C. Minuta $F$. hac duplo minor est, \& mediae magnitudinis inter hanc, \& Pusillam. 
Habitat in plantis variis, \& frequens in Pastinacae floribus.

\section{* 99. Chalcis Rufipes.}

C. nigra, antennarum basi pedibusq. rufis, albo geniculatis, femoribus posticis incrassatis serratis.

Statura C. Clavipedis Fab., seu Sispedis Linn., at paullo major, antennaeq. nigrae basi, seu articulo primo subtus rufo. Pedes omnes rufi femoribus, tibiisq. albo geniculatis; reliqua omnia similia. An varietas? An species? Coloris diversi, ac vix magnitudinis notae unicae, in hoc genere species determinabunt? Certe apex abdominis in hac nostra etiam magis quam in C. Clavipede obtusus, sed proprius feminarum esse videtur, unde alia suspicio de femina Clavipedis:; tempus declarabit.

Habitat cum aliis rara.

100. Chalcis Hesperidum.

$$
\text { Long. } 2 . \frac{1}{3} l \text {. }
$$

C. atra, vertice capitis bifido, ore acuminato, femoribus posticis clavatis.

Cbr? Hesperidum Frn. Etr. 2. 78. 852.

Facies, \& habitus singularis. Magnitudo C. Clavipedis. Tota nigra punctulata. Antennae hujus generis, filiformes, in medio fractae, ad apicem paullo crassiores, deflexae, quae a scissura capitis emergunt. Caput nigrum punctulatum obscurum, vertice profunde diviso in duas partes, \& in pectus retractum. Os acuminatum, eo modo ut exhibeat imaginem faciei indutae caputio poenitentiae. Oculi magni, prominuli, sublimes. Frons lata. Thorax angustior capite, elongatus punctulatus, obscurus. Abdomen sessilc ovatum nitens, subtus fornicatum petiolo brevi. Femora omnia nigra nitida, posticaq. clavata globosa. Tibiae arcuatae apice acutissimae. Tarsi tenues, breves rufi. Actleus sub fornice reconditus, ac reflexus. Alae hyalinae immaculatae. Volatus gravis uti in Cbalcidibus.

Lectae primum tres, aut quatuor in plantis Hesperidum pa- 
rieti innixis media aestate: mox per plures annos frustra investigatae; aliae demum non paucae in Coryli Colurnae foliis rutsus adinventae.

\section{* 101. Sphex Thoracica.}

S. atra laevis, thorace postice ferrugineo, abdominis segmento primo puncto utrinq., secundo macula fere in fasciam connata, ferrugineis.

Statura S. Fuscae, at paullo major. Atra laevis. Antennac nigrae undecim articulis. Caput atrum. Thorax ater lobo postico laete ferrugineo. Abdomen sessile oblongum atrum nitidum, segmento primo puncto utrinque, secundo macula magna fere in fasciam connata, ferrugineis. Pedes nigri. Alae atro-caeruleae, apice obscuriores.

Habitat in silvis rara.

\section{* 102. SPHEx LaEvigata.}

S. atra, thorace postice, tertioq. abdominis segmento albopunctatis; corpore cylindraceo laevissimo .

Fere duplo minor S. Rufpede. Corpus atrum cylindricum, scilicet ubiq. cjusdem latitudinis. Caput deflexum fronte convexa laevi. Thorax elongatus, laevis, posticeq. ad imum marginem utring. albo-punctatus. Abdomen laeve subincurvatum tertio segmento albo-punctato. Alie apice fuscae. Habitat in silvis.

$$
\begin{aligned}
& \text { I03. SCOITA BresNTA. (A) } \\
& \text { Long. 5, 6, 8, 10. l. lat. 1, 2, 2. } \frac{3}{3} l .
\end{aligned}
$$

S. hira, atra, abdomine fasciis duabus flavis, alis cyaneoatris. F. Sp. 453.11 .

(a) Cum ob multiplices quae in hoc genere occurrunt varietates, non parum. mihi allaborandum fuerit, ut nonnullas adhuc non satis bene perspectas species certius determinare potuerim, operae pretium duxi eas rursus heic exhibere non minus a me recens factis observationibus illustratas, quam \& iconibus auctas. 
Frr. Etr. t. 2. 71. 836 .

Descr. masculi. Antennae nigrae, prismaticae, basi tenuiores, longitudine thoracis. Lingua trifida. Caput, \& thorax atra immaculata. Abdomen sessile hirtum atrum, bifasciatum, fasciis duabus luteis ad basin secundi, tertiiq. segmenti, $\&$ in medio marginis superioris sinu unico, nunc magis, nunc minus excissis, abdomen haud subtus cingentibus. Anus trispinosus. Pedes nigri, hirti, tibiis atro-spinosis, anticis ad apicem pedunculo rufo instructis. Alae atro violaceae. Variat admodum magnitudine, fasciisq. magis minusve in medio sinuatis; variat fascia tantum unica postica, alteraq. interdum vix puncto indicata. Fascia antica semper paullo angustior postica, \& lateribus interdum emarginata. Inter tot specimina a me examinata, unum tantum habui lunula lutea, quasi rudimento fasciae in quarto segmento notatum, sed tum etiam thorax semper immaculatus, ne confundatur cum masculo $S$. Bifasciatae satis admonet. Descr. feminae. Major. Antennae nigrae breviores, apiceq. retortae. Fasciae abdominis fere numquam in medio sinuatae, sed prima semper brevior, \& lateribus emarginata. Anus non trispinosus, sed retusus, aculeatus. Reliqua. omnia similia. Vix, aut ne vix quidem: variat.

Habitat in hortis, \& silvis frequentissima.

104. SCOLIA INSUBRICA.

Long. 7. 8. l. lat. 1. $\frac{2}{3}, 2$. l. vix.

S. hirta atra, abdomine fasciis maculisq. binis ovalibus luteis, alis apice hyalino-violaceis. Scop. Del. Fl. O Fn. Ins. fasc. 2. p. 58. t. 22. f. 1 .

Fro. Etr. t. 2. 72. 837. Mant. 1. 131. Obs.

Descr. masculi. Caput nigrum immaculatum. Oculi reniformes. Antennae rectae longitudine thoracis. Thorax niger macula utrinq. scapulari lutea. Abdomen oblongum maculis binis ovatis subconnexis luteis, posticeq. fasciis duabus concoloribus, prima latiori in medio excavata, alteraq. interdum labriformi. Pedes nigri hirti tibiis anticis ad 
apicem pedunculo rufo instrùctis. Anus trispinosus. Alae ad basin, \& costam ferrugineae, ad apicem violaceae. Variat interdum segmento etiam quarto puncto luteo notato, \& macula lutea thoracis quandoq. fere inconspicua.

Descr. feminae. Caput pone oculos macula lutea saepius interrupta notatum. Antennae nigrae retortae, capite vix longiores. Thorax immaculatus. Anus retusus, aculeatus absq. spinis. Reliqua omnia uti in masculo. Maculae luteae primi segmenti paullulum diversae, scilicet in hac lateribus emarginatae. Variat fronte immaculata, aut punctis vix aspiciendis $(a)$.

Habitat ruri, \& in hortis frequens.

$$
\begin{aligned}
& \text { * io5. Scolia Bifasciata. } \\
& \text { Long. 7. 8. l. lat. 1. } \frac{2}{3} 3 ., 2 . l \text {. }
\end{aligned}
$$

S. hirta, atra, abdomine fasciis duabus, strigaq. oblique excavata luteis, alis cyaneo-atris.

Descr. maris. Statura, ac magnitudo masculi S. Bicinctae. Caput nigrum immaculatum. Antennae rectae longitudine thoracis. Thorax niger macula utrinq. scapulari lutea. Abdomen oblongum nigrum, segmento $10^{\circ}$ puncto utrinq., $2 .^{\circ} 39^{\circ}$ fasciis in medio excavatis. $4 .^{\circ}$ striga nunc integra, \& superius sinuosa, fere uti in masculo Insubricae, nunc interrupta, luteis. Pedes nigri hirti, tibiis anticis ad apicem pedunculo rufo instructis. Anus trispinosus. Alae cyaneo-atrae. Obs: cavendum ne confundatur cum masculo S. Insubricae, a quo pracsertim differt segmento secundo fascia, non macalis; alisq. non ad basin, \& costam

(a) Haee a nonnullis habetur pro masculo S. 6-maculatae, at mihi nunc omnino distincta, et, sane alter sexus prioris cum qua frequens cohabitat. S. 6-maculata occurrit tantum in certis silvarum locis, ubi frequentem vidi, et copiosam, at semper adeo similem ut in ea non minus quam in ' $S$. Bimaculats, et Hortorms sexum alterum suto determinare non datum. 
ferrugineis, sed totis atro-cyaneis. Tibiarum etiam spinae in eo ferrugineae, in hoc nigrae $(a)$.

Descr. feminae. Antennae breves retortae. Caput nigrum stria frontis laciniata, \& ad oculi sinum perducta, punctoq. altero pone oculos minutissimo luteis. Maxillae exsertae arcuatae. Thorax niger immaculatus. Abdomen nigrum primo segmento punctum utrinq. luteum minimum, ac non semper praesens: secundo, fascia lutea lateraliter puncto nigro marginali, interdum intruso: $30^{\circ}$ fascia lutea similis, absq. puncto in medio sinuata: $4 .^{\circ}$ striga lutea late interrupta, oblique sinuosa, ac superius recurva. Anus retusus, aculeatus, absq. spinis . Reliqua similia . Variat fronte immaculata, seu tantum punctis tribus; variat quarto segmento sacpe immaculato, seu tantum strigae rudimentis notato, sed tum etiam satis distincta a femina $S$. Bicinctae segmentorum marginibus minus ciliatis, ac puncto laterali fere intruso fasciae anticae, quae in hac numquam brevior postica.

IIabitat in silvis mens. Aug. sat frequens, at mas rarior femina.

io6. Chrysis Fervida.

C. glabra aurea nitida, abdomine subtus atro. F. Mant. 283.14.

(a) Nota haec quae constans est, aliis adiuncta optime inservire videtur non modo ad sistendam hanc speciem, sed etiam quodammodo ad confirmandam in hoc genere sexus differentiam, ab antennis, et ano desumtam. Videtur etiam magis, cum insuper observata sit constans coloris relatio inter tibiarum spinas, et alas minime variationi subiectas; scilicet tibiis atro-spinosis instructas esse tantum eas Scoliarum species quibus alae atro-violaceae sunt, uti a S. Bicinctn, cui tantum haec nota communis cst, comprobatur. In aliis speciebus, quibus alae aut rotae ferrugineae sunt, aut in parte; etian tibiarum spinae, saltem si adversa luce attente inspiciantur, rufac inveniuntur. Datam deniq. sexus distinctionem evincunt ova saepius inventa in abdomine earum quae gaudent ano retuso aculeato, antennisq. brevibus, retortis.

Tom. II. 
Nostra specimina magnitudine fere aequant C. Ignitam, \& gaudent capite, thorace, pedibusq. viridibus. Abdomen subtus atrum, in medio subcarinatum; anus integer.

Habitat in plantis rarior.

\section{Chabro Subterraneus.}

C. thorace maculato, abdomine utrinq. maculis quinque fiavis, pedibus ferrugineis. F. Syst. Ent. 374. 4. Sp. 470. 4.

Panz. Fn. German. Heft. 111. 21.

Habitat flores in silvis.

$$
\text { * 108. Crabro Calceatus. }
$$

C. niger, antennis, abdominisq. segmentis margine flavis: pedum omnium tarsis ultimis inter ungulas membranula fusca insolenter aucta palmulatis.

Statura, ac magnitudo C. Spinosi. Caput nigrum labio, antennisq. flavo-rufis. Oculi glaucescentes. Thorax niger laevis, dorso admodum convexo, linea antica, puncto sub alis, lineola loco scutelli, punctisq. duobus ad latera postica flavis. Abdomen nigrum nitidum, segmentis margine flavis, subtus etiam continuatis. Pedes flavo-rufi femoribus primi, \& secundi paris exterius nigra macula, omnesq. tarsis ultimis inter ungulas membranula fusca palmari insolenter aucta instructì. Alae subferrugineae ad marginem crassiorem versus apicem interdum obscuriores. Variat antennis nigris basi subtus flava, \& femoribus omnibus nigro maculatis. Punctum ad latera postica thoracis non semper praesens, ultimumq. abdominis segmentum margine flavum, plerumq. occultatum. Differt a $V$. Sexfasciata magnitudine paullo minori, antennis brevioribus, oculis non lunatis \&c.

Habitat in plantis, frequens sub vesperum in Artemisia campestre, Foeniculo, aliisq. m. Jul. \& Aug. 
* 109. Crabro ANNulatus.

Long. 4. \%. lat. $\frac{3}{4} \%$

C. niger, abdomine flavo fasciato, geniculis nigris, antennarum apicibus flavis :

Magnitudo C. Vagi. Caput nigrum labio flavo. Antenmae nigrae basi, \& apice flavae. Thorax niger lineola antica posticaq. loco scutelli, punctoq. ante alae callum minutissimo flavis. Abdomen atrum nitidum segmento primo angustiore annulo flavo interrupto, reliquisq. omnibus flavo marginatis. Femora nigra. Tibiae basi flavae apice exterius nigro, interius flavo. Tarsi flavi geniculis nigris, ultimo toto nigro. Optima, ac constans nota est linca antica thoracis quac continuatur, \& jungitur cum. puncto flavo laterali sub alis.

Habitat in silvis.

* rro. Crabro Bicinctios.

C. ater laevis, abdomine fasciis duabus, primo segmento puncto utrinque, flavis.

Medius. Caput nigrum fronte sub antennis, ore, palpisq. flavis. Antennae supra nigrae, subtus ferrugineae, articulo primo flavo. Thorax niger linea antica, puncto sub alis, binisq. fere contiguis loco scutelli flavis. Abdomen atrum nitidum primo segmento coarctato, punctis duobus majusculis flavis: $20^{\circ}$ flavo fasciato fascia per medium excurrente: $3:^{\circ}$ flavo marginato: reliquis immaculatis. Pedes flavi, antici femoribus nigro maculatis; postici, femoribus nigris, tibiis ferrugineis. Alae macula fusca. An affinis C. Tricincto Fab?

Raro lectus.

* Ili. Crabro Ceraunius.

C. niger, laevis, fronte flava, abdomine ferrugineo, luteo variegato; antennis cochleatim retortis.

Magnitudo C. Unighmis. Caput nigrum fronte ore orbitaq. oculorum, flavis. Antennae nigrae, basi, \& in medio subtus flavae, capite paullo longiores, compressae, attenua- 
tae, ac in modum cochleae valde contortae. Thorax niger linea antica, puncto sub alis, lineolisq. binis subconnexis loco scutelli, flavis. Abdominis segmenta 1. 2. 3. rufescentia maculis utrinq. tribus luteis obsoletis: 4. fascia nigra, reliqua flava. Pedes primi, \& secundi paris flavi femoribus nigro maculatis. Postici flavi femoribus nigris. Alae apice fuscae.

Lectus in silvis.

\section{* 112. Crabro Pygmaeus.}

C. niger laevis, thorace maculato, pedibus, maxillis, antennarumq. basi flavis.

Parvus, \& $C$. Clypeato duplo minor. Antennae nigrae, basi flavae, capite breviores. Labium argenteum. Maxillae flavae. Thorax niger linea antica, scutelloq. flavis. Abdomen gibbum ovatum nigrum. Pedes flavi, femoribus, tibiarumq, apicibus nigris. Alae albae puncto marginali nigro. Habitat frequens in Quercus roboris foliis.

\section{* II3. ApIs Furax.}

Long. 5. $l$.

A. nigra, fronte, thorace, tibiisq. griseo-villosis, abdomine subdepresso, segmentis duobus ultimis albo-fasciatis, tertio, \& quarto tantum latere albis.

Magnitudo fere $A$. Lagopodae. Caput nigrum fronte, ac ore cinereo-pilosis. Thorax villo griseo magis tectus. Abdomen nigrum ovatum basi subpilosum, dorso depressiusculo glabro, segmentis quatuor ultimis albido-ciliatis, seu fasciatis, tertio, \& quarto fascia late interrupta. Pedes nigri tibiis griseo-villosis. Affinis $A$. Bicinctae $D$. de Paykull, at diversa.

Adit flores, m. Maj. \& Jun. frequens.

\section{* 114. Apis Glaucocincta.}

A. griseo-pubescens, ore abdominisq. segmentis quatuor margine glaucis . 
Magnitudo $A$. Pubescentis. Antennae breves nigrae, subtus fulvae. Caput nigrum pubescens ore glauco maculato. Thorax niger griseo-pubescens. Abdomen subdepressum segmentis quatuor apice nigris, glauco marginatis. Pedes nigri tibiis griseo-pilosis.

Habitat silvas.

\section{* il 5. Formica Mortuorum.}

F. ferrugineo-flavescens, oculis, antennarumq. apicibus nigris . Longitudine vix Pediculo aequalis, at multo angustiot. Tota flavescens praeter oculos antennarumq. apices nigros. Capue thorace duplo latius. Abdomen ovato-oblongum apice acutissimo. Aculeus niger. Glabra, laevis :

Habitat in arculis Insectorum, ibiq. tantum lecta saepius, ac semper visa eadem.

\section{MUTHLE LAEVIS.}

M. glabra nigra, dorso pedibusq. rufis, abdominis segmento secundo, quintoq. margine a!bis. Alata. D. Latreille. Act. de la Soc. d' Hist. Natur. de Paris. amm。 1792. t. 1. p. I. pag. II. n. 12.

Parva, \& fere dimidio minor Sph. Concinna Frz. Etr. 2. 66. 825. quae huc referenda. Antennae supra nigrae, subtus obscurae, capite paullo longiores, articulo primo baseos crassiori, \& inferius albido. Caput nigrum laeve, ore lineolaq. ante oculos albidis. Oculi pallidi. Thorax rufus. Abdomen oblongo-ovatum, apice acurum nigrum, laeve, nitidum. primo segmento puncto uerinq. albo: $20^{\circ}$ majori, margine albo fasciato, fascia in medio attenuata, seu lateraliter aucta; quinto vix albo marginato. Pedes antici rufi, fernoribus basi nigris: medii rufi femoribus nigris: postici nigri tarsis rufis. Alae superiores obscurae. Variat magnitudine minori, thorace nigro antice albo lineato, segmentis primis duobus abdominis rufis; reliqua omnia similia. Mas? Quamvis haec nostra paullulum variare videatur a Mat. Laevi descripta a $D$. Latreille l. c. tamen de identitate, aut affnitate summa minime dubitari potest; differt enim tan- 
tum segmento abdominis primo, in meis speciminibus, albo punctato. Assentior autem Cl. viri opinioni Sph. Concimnam Fn. Etr. onnino hujus generis esse, \& una cum hac affinitatem mediam habere inter Mutillas, \& Crotrozes. Differentia enim maxima in capitis, oculorumq. forma consistit, qua magis ad Crabrones accedic.

Habitat $\mathrm{m}$. Jul. in locis iisdem arenosis ubi inveniuntur. M. Europaea, \& Maura.

\section{* I17. Mutilla Catanensis.}

M. nigra, thorace rufo, abdomine maculis sex albis distinctis. Statura, ac magnitudo omnino $M$. Maurae. Caput antennaeq. nigra. Thorax rufus immaculatus. Abdomen nigrum maculis duabus secundi segmenti majoribus, rotundis; posticisq. quatuor lateralibus oblongis, quasi in fasciam late interruptam connatis, albis. Subtus tota nigra.

Misit vir egregius $D$. Hieronymus Recupero Catinensis.

\section{Mutilia Calva.}

$$
\text { Long. 5. } l \text {. }
$$

M. hirta nigra; occipite, thoraceq. rufis, abdominis segmentis margine albis. (aptera). Latreille Act. de la Soc. d' bist. nat. de Paris. 1792. t. 1. p. 1. pag. Io. 8.

M. Calva, occipite thoraceq. rubris. Villeg's Ent. 3. 343.9. t. 8. f. 34 .

Statuia M. Maurae, uti in descript. D. Latreille l. c., at mea specimina magnitudine accedunt ad $M$. Europaeam. Antennae subnigrae. Caput hirtum (in meis) majusculum rufum labio nigro, mandibulis nigris apice late tridentatis. Tuberculum nigrun acutum utrinq. ad basin antennarum. Thorax hirtus rufus. Abdomen nigrum hirtum basi utrinq. denticulo instructum, segmentis margine albis, $20^{\circ}$ \& $30^{\circ}$ fasciis latioribus. Anus aculeatus. Pedes subnigri apophysibus femorum posticorum denticulo subtus armatis. Habitat Pisis non frequens. 


\section{O P E R I S}

\section{EMENDATIONES AG ILLUSTRATIONES \\ F. E. indicat Faunam Etruscam, M. Mantissam sigaificat.}

F. E. t. 1. p. 2. G. 2 .

Luc. Capreolus?" "Nota "Luc. a D. Herbst exhibitum Natur. S. t. 33. f. 4. 5. sub nomine L. Hirci credit Celeberr. Hellwig in annot. Frz. Etr. ed. Helnnst. a Fleckeiseni 1794. at mihi nullo modo pro var. min. L. Cervi, assumendus.

F. E. E. r. p. 7. . 26. Synonymon Sc. Moeris, \& conf. Sc. Furriferum M. t. 1.p. 7. 9.7. Vide etiam quae heic relata subiungimus.

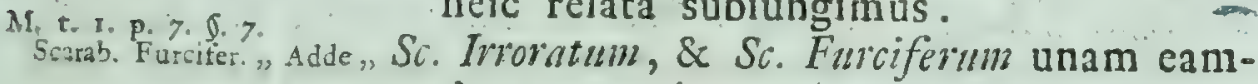
demq. speciem esse ex observationibus nuper factis evidenter mihi nunc constat, ideoq. nomen Sc. Furciferi excludendum, retinenduinq. tantum illud $S c$. Irrorati. In Sc. Furcifero scil. var. masculi, notae constantes sunt pedes antici longiores femoribus bidentatis absq. tarsis; caput muticum; tibiae medii paris latere externo emarginatura notatae. In Sc. Irrorato seu femina pedes antici non longiores, sed tibiis validioribus, fenioribus inermibus, tarsisq. brevissimis in. structi; capitis clypeus corniculo semper armatus. Furca pectoris ( quae tantum propria masculi ) character valde inconstans. Nota vero utriq. communis est pulvinar, seu penicillus ex pilis atris compositus, qui inesse observatur latere 
F. E. t. I. p. 4. \$. 6 . Scarab. Dispar. "Adde; M. t. 1. p. 9. 6. 12.

Trox niger. "Nota " interno fenorum anticorum ad juncturae sustentandum attritum destinatus. $\mathrm{Ma}$ xillae membranaceae latera oris inclu. dentes post esum facile apparent magnae, subrufae. Color corporis in utroq. sexu saepe niger, at plerumq elytra, non thorax, rufo submaculata. Pro lamina cuneiformi in masculo, plerumq. dens simplex. An Sc. Clizias Fab. qui mihi ignotus? Obs: Pedes antici longiores femoribus dentatis ad arctiorem copulam sustinendam idonei, notam systematicam suppeditare videntur ad dignoscendum sexum masculinum. Mox saepe lectus uterq. mens: Jul. in locis arenosis sub stercore bovino recenti.

Sc. Dispar. Oliv. p. 58. t. 3. f. 20. a. b.c. Missus e Saxonia sub nomine T. Arenarii, sed descriptio a Fabricio data parum convenire videtur, \& in Svecia judicatus novus. F. E. t. x. p. 39. "Adde" Melol. Castanea Herbst N. d. k. III. 27.35. tab. 23. $f$. 2. Statura, ac magnitudo fere M. Ruficornis, qua obscurior, clypeo ni₹. E. t. s. p. 25. 5. 57. gricante. Habitat Pisis frequens Maj. m. Cet. Speciosissind "Not., Cet. Fastuosa Fab. Ent. Syst. i. 1 27.9.

F. E. t. 1. p. 26. §. 59.

Cet. Eremita "Nota, Scbwarz. Nomencl. Roesel. Iirsect. 64. 27.

M. t. 1. p. 22. 1. 20. qualem bilaciniatam notantur latere antico puncto majusculo nigro. Semper lectus in arboribus putrescentibus, etsi erFore dictum in Mantissae l. c. occurrere in stercore bovino.

M. T. 3. P. 17.9 .25 . Hist. Picipes. F.

in. t. 2. App. p. 8o. 8. 8. D. Sexdentattus F. Ent. System. t. I. p. 232. 26. Ips 6-dentata Herist Arch. t. 20. f. 21? Insectum adhuc dubii generis. 


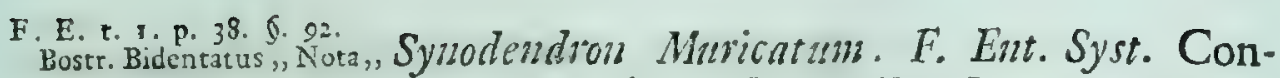
fer Not of Add. Fu. Etr. Iconem exhibet

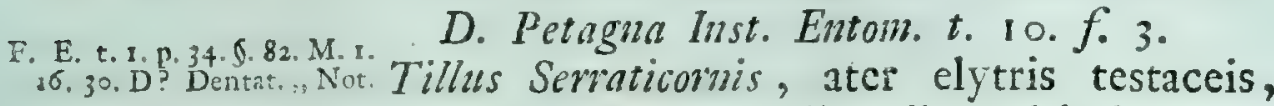
antennarum articulis tribus ultimis serratis. F. Oliv. Ent. 22. 2. t. 1. f. 2. a. $b$. c. d. Similis T. Elongato, at minor. Antennae nigrae, basi filiformes, articulis tribus ultimis majoribus serratis. Caput subvillosum nigrum. Elytra testacea. Insectum cum aliis quamplurimis a me primum transmissum ad $D$. D'Antic. Bosc. Paris.

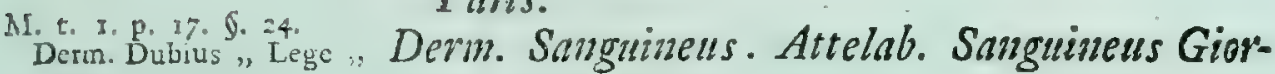
na Kalend. 48. 10.

F. E. t. 1. p; 45. 6. 110. Antennae quasi pedunculatae, crassae nigrae basi rufae. Thorax antice attenuatus lateribus cinereis. Elytra substriata nigra, cinereo veluti bifasciata, paullulum abbreviata. Ani regio, \& abdomen cinerea. Pedes mutici, antici quatuor rufi. Long. 1. l. Iconem exhibet D. Vitlers Ezat. t. 1. f. 19. Aliud habeo specimen magnitudine vix praecedentis, scilicet niger, clytris obscuris, antennis sertatis, pedibusq. quatuor anticis rufis, scutello albo; forte $B$. Serraticomis $D$. Quensel. Saepe lecti in foliis Viburni Tini, m. Aug. \& Septemb.

F. E. t. 1. p. 42.121 .

Ips Crenata "Adde",

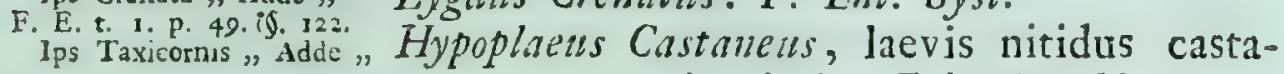
neus antennis nigris. Fab. Act. bist. Nat. Paris. 1792. p. 34. 1. Hispa Picipes Fab. Mant. Ips Taxicomis Oliv. Cemiterius Her-

F. E. t. 3. P. 50. 5. 123 . bit. Arch. t. 2 1. f. 6.

Ips Lineans "Adde "

Tom. II.

Colydiun Elongatum, atrum pedibus ferrugineis. F. Act. bist. Nat. Paris. 1792. 
M. t. X. p. 22. \$. 50. Ips Fallax "Nota"

F. E. t. I. p. $52 . \oint .128$. Hisp. Testacea "Adde, F. E. t. 1. p. 52. \$. 130 . Hispa Pomaticor. "Nota , I

F. E. t. 1. p. 55. 5. 136 . Silp. Russica" Adde,

F. E. t. 1. P. 58. 9. 142. Nit. Punctata "Adde, F. E. t. 1. p. 68. \&. 171 . Cocc. 4-pustul. "Adde ",

F. E. t. 1. p. 83. \&. 208 . Chrys. Dytiscoid. ", Nora, M. t. I. p. 30. 6. 72 . Chrys. Gemell." "Adde "

F. E. t. 1. p. 99. \$. 252. Crypt. 4-pustul. "Nuta,
Bostr. Elongatus F. Mant. Ips Linearis Oliv. 2. 18. 53. t. 2. f. 17. Panz. Fn. Germ. I. Heft. t. I 7 .

Lygdus Nitidus. F. Ent. Syst. Panzer Fr. Germ. vi. Heft. t. I 8.

H. Testacea Petagna Inst. Ent. t. I. f. 10.

In multis convenit cum H. Mutica Linns. of Fab. Panz. Fn. Germ. Hefi. vi. to 8. an esse posset varietas?

Ips Nigripemis, rufa antennis, elytris pectoreq. nigris. F. Erotylus Russicus Oliv. Iizs. 89. t. 1. f. 1. Herbst. Arch. t. 43. f. 9. Confer Act. Soc. hist. Nat. Paris. amm. 1792. p. 29.

N. Lunata Oliv. Ent. 22. t. 3. f. 26. a. b. Vidi \& ipse saepius copula connexam cum femina C. 2-punctatae.

Diaperis Violacea F. Ent. Syst.

Colore variat acneo, \& atro-caerulescente. Habitat in Hyperico perforato.

Chrys. 4-pustulata Linn., of Ips Ruffirons Fab. insectum idem designant quod variat apud nos sed rarissime elytris rufo octo-pustulatis, scilicet I. puncto baseos majusculo, 2. in medio ad marginem exteriorem, 3. ad apicem ex duobus comcosito, 4. rotundo apicis. Variat etiam admodum magnitudine. Antennarum forma hoc Insectum a Cryptocepbulis removet, \& ad genus Ips amandare videtur.

F. E. t. 1. p. 100. \$. 256 . Cist. Gigas "Nota "

F. E. t. 1. p. 111. $\} .2 s_{3}$. Curc Pulverul. "Adde,

F. E. t. 1. p. 125. \$. 320 . Curc. Salicis "Nota"

F. E. t. 1. p. 127.0 .323 . Cebrio Longicornis F. Ent. Syst. 2. 1. 4 I. Curc. Bardanae $F$.

Variet. F. Mon. Curcul. D. de Paykzll. Habitat etiam in Populo alba.

Brachycerus Barbarus. F. Ent. Syst. Petagn. Ins. Entom. to 2. f. 3. C. Barbaris.

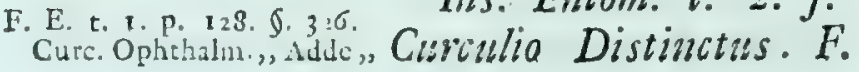


F. E. t. 1. p. 132 . \$. 339.

Curc. Latirostris ,"Nota ",

M. to s. p. j6. 6.88 .

Curc. Bardanae " Dele ",

F. E. t. 1. p. 112. S. 286.
Cutc. Bacchus, Nota,

Curc. Bacchus "Nota"

Curc. Betulae "Nota",

F. E. t. 1. p. 116. \$. 297 . C. Pseud-acori "Nota ",

M. t. 1. p. 44. g. 111.

Antbribus Latirostris. F. Ent. Sysi.

In boc elytra, \& sequentia.

Attelabus Bacchus. F. Ent. Syst.

Attel. Betuleti. F. Ent. Syst.

Var. colore elytrorum subtestaceo fusco, plerumq. mas.

Attelab bicolor "Lege, Attel. Aequatus. F. Curc. Aequatus Limm. Syst. Nat. 607. 9. Geoff. Ins. 1. 270. 4. le Becmare dore' à etuis rouges. Synonymon Geoffroyanum ab auctoribus tributum C. Baccbo huic competit, uti videre est in Monnog. Curcul. Sueciae D. de Paykull 32. 126.

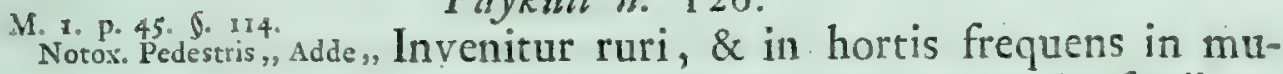
M. t. x. p. 48. $5 .{ }_{12 \pi}$ ris prope terram, numquam in floribus. Notox. 4-guttat. "Nota" Maculae elytrorum potius albidae quam obscure flavae, eaeq. baseos plerumq. in fasciam connatae.

F. E. t. I. p. $142 \cdot$. 360 . Cer. Varius "Nota"

F. E. t. 1. ก. 144. ๔. 363 . Lam. Textor. "Lege"

Ineunte Julio sub vesperum inveni quamplures, omnesq. copula connexos in $\mathrm{pa}$ lis Vitibus adjunctis. Mas omnino feminae similis.

L. Tristis quae variat magnitudine, elytris submaculatis, antennis brevibus, ac longissimis.

F. E. to 1. p. 148. \$. 372., Et conf. in Mant. t. 2. App. 5 1. Stenoc. Luridus.

F. E. r. . P. 149. 373. Callid. Salicis. Alter sexus variat elytris thoraci concoloribus. Rbagii genus minime apud nos habitare videtur; occurrere tamen saepius in Alpium summitatibus supra Larices ab ill. Viro Entomologiae amantissimo $D$. Petro Goanta observatum. Ex speciebus quas mihi benevole communicavit amicus noster $D$. Giona Taurinensis co magis statuere datum est $R b$. Cursorem unam eamdemq. speciem esse cum $R b$. Noctis uti a $F a-$ 

Rh. Cursor fem.
M. t. r. p. 152, g. 38.
Saperda Linearis "Adde "Magnitudo S. Clavicornis, \& duplo longior bricio dubitatum; scilicet $R b$. Noctis $\mathrm{m}$.

S. Cylindrica. Nigra, pedibus margineq. baseos elytrorum exteriore luteis. Pan-

F. E. t. 1. p. 152. . 380 . Sap. Filum "Adde"

F. E. t. i. p. 194.6 .383 . Callid. Omega "Nota"

M. t. 1. p. 53. 6. 131 . F. E. t. 1. p. 16 \%. \&. 400 . Lept. Villica "Adde ", zer Fn. Germ. Hefi. vi. 14.

Antennae tenuissimae articulis praelongis, primo elongato reliquis duplo crassiore. Plantae non semper albidae, sed tota unicolor. Lecta etiam in horto quiescens in Festuca elatiori.

Varietas C. Liciati Linn. Femora postica abdomine longiora. Mox quoque lectum in Gramine prope Junii finem .

Lectum deinde etiam Pisis in Rubo.

Variat elytris antennarumq. articulis primis quatuor etiam in provectiori aetate thoraci concoloribus: scilicet ferruginea oculis, pectore, antennisq. pone medium nigris. Lept. Revestita Limn.

F. E. t. . p. 1.52. 502.4 Lept. Villosa Vill. t. 1. f. 31. Callid. Qua* dripunctatum $F a b$. at elytra constanter punctis sex nigris.

M. t. 1. p. 54. 9. "33. "Nota "L. Nigrofasciata Petagna Instit. Entom. I.

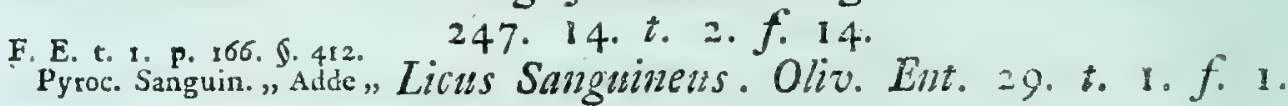

F. E. t. 1. p. 169.0 .421 a. b. C.

Canth. Biguttata "Adde" Statura, ac magnitudo C. Pallidae. Antennae nigrae primis duobus articulis rufis. Elytra admodum abbreviata, apice flava sulphurea. Tentacula abdominalia, segmentorumq. imi margines flava. Variat thorace toto rufo. A nonnullis confusa. Long. 2. $\frac{1}{4}$ l. Lat. $\frac{2}{3}$ l. Occurrit in Graminum summitatibus.

F. E. t. Y. P. 173. S. 43\%. Necyd. Ruf." "Nota"

Quoad N. Atram, \& Rufam conferenda sunt quae asserere non dubitavimus in prima 
Mantissae parte 1. 56. 139. \& nunc ex observationibus factis in individuis copula connexis confirmamus, scilicet speciem unicam esse, cujus mas rufus variare videtur clava femorum posticorum nunc rufa, nunc nigra, antennarumq. colore.

F. E. t. X. p. 175. 9. 434 . Nec. Humural. "Adde ,

F. E. c. 1. p. 180. \$. 446 . Elat. Ferrugin. "Adde,

F. E. t. 1. p. 180.8 .447 El. Prolifericorn. "Nota,"

F. E. t. 1. p. 183. 9. 456 . Bup. Mariana "Adde "

F. E. E. 1. p. $184 \cdot 6.450$. Bup. Tencbricos. $\beta$. Nota, , M. t. 1. p. 62. 6. 152.
Bup. Pygmaea "Adde,

F. E. t. 2. p. 343 . Cicind. 4-punct., Nota , Cic. Nemaralis. Oliv. Ent. 3.3. 10.t. $3 \cdot f \cdot 36$. Mydrop. Pallidus „Adde "Hydr. Minutus. F. Forster N. I. S. 52 . An Hydrop. Pallidus "Adde, Hydr. Minutuls.

M. t. 2. p. 69. $6 .{ }^{367}$.
Dyt. Bipunctat.? , Nota,

F. E. t. 1. p. 208. 6. 513 Carabus Ruficornis .

F. E. t. I. p. 233 . 9. 520 . Car, Interruptus.

F. E. t. I. p. $2 \pi 1$. 5.528. Car. Ferrugineus , Adde ,C

Non dubitandum, $a b$ aliis deinde lectis
Antennae in masculo longiores. Vix volat, semperq. lecta supra terram in herbidis .

Mas variat thorace toto nigro. Mox saepe lectus in salicis ramis humorem stillantibus.

Parmus Prolifericomis. F. Ent. Syst.

Variat capite thorace elytrisq. superne nigris .

Bup. Tenebricosa Oliv. 62. 82. t. 5. f. 48 . Occurrit frequens copiosa in Lavaterae arboreae foliis quibus vescitur, \& in Althen Cannabina, aliisq. Malvaceis. certior factus, assero.

Deleatur.

Dele, \& confer C. Megacepbalum Mant. App. 23. 65.

C. Ferrugineus, latus brevis ferrugineus, oculis nigris, thorace punctis ordinariis duplicibus : elytris striatis disco impunctatis. Mon. Carab. D. de Paykull n. 76. Diagnosis optima, amplioriq. descriptione ad determinandam speciem minime indigens. Obs: Primum de nympha nuper declarata dubitatur, at elytra transfixioni inventa durissima Insectum perfectum declarant. Nostrates majores mer- 
F. E. t. I: p. 213. 6. 525 . Car. Limbatus ., Nota,

F. E. t. I. p. 2 I $3.5 .5=6$.

Car. Pulverulent. „, Lege

F. E. t. I. F. 214.9 . 527.

Car. Madidus.

F. E. t. 1. P. 215 . 5. 53 I.

Car, Pilicorns.

F. E. t. 1. p. 216.5 .533 . Car. Carbonasus "Nota",

E. E. t.t.221. $\$ 548$. Car. And M. t. 1.p. 91. 205 . C.Etratus

F. E. t. I. p. 224 . \%. 557 .

Carr. Pedestris ,. Corrige ,

F. E. t. 1. p. 227. 0. 566 . Car. Nou plus uitra "Cor

M. t. 1. p. 83 . \&. 190. Car. Dentatus "Nota "

F. E. t. 1. p. 228 . 5. 570 .

Scarit. Clypearus "Nota,

F. E. t. 1. p. 23 1. 5.576 . Blaps Mortisaga ", Nota,"

F. E. t. I. p. 232.5 .578 . Terieb. Affinis "Nota,

F. E. t. \$. P. 232 . 579 . Teneb. Maurit. , Adde,

F. E. t. 1. p. 234. 9. 583 . Teneb. Dubius "Adde "

M. t. 1. p. 92. ${ }^{207 .}$. Ips Haemorrboidalis, rufa elytris nigris apice rufis. F. Act. Soc. bist. Nat. Paris. 1792. p. 29. D. de Paykull. Statura omnino I. Nigripemis, at corpus totum rufum. Mas cornubus duobus erectis capitis. D. Scbneider. An Hispa Comigera antemnis serratis, thorace rufo, elytris caeruleis capite bicorni F? Nostra specimina cum descriptione I. Haemorrboidalis absq. dubio conveniunt, at antennae moniliformes sunt articulis tribus ultimis paullo crassioribus .

F. E. t. s. 2. 238. 6. 591. Meloe Tuccia "Adde"

F. E. t. I. p. 241 . (. 5 5 Mylab. Algivina, "Áúc,

suris a $D$. Geoffroy exhibitis .

Panz. Fn. Germ. Hefi. Iт. 9.

Deleatur.

Deleatur.

C. Holosericeus verus Fab. Caput etiam in nostris nigro-aeneum .

C. Crux minor verus Linn. Fn. Sv. minime Fabricii, \& Paykalii qui omnino diversus. Notoxus Pedestris. M. 1. 45.114.

Not. Non ptus ultra M. I. 47. a. $b$. plialum M. App. n3. 65.

B. Gages si species distincta est a MortiTen. Cutruipes F. Ent. Syst.

Trogossita Mauritanica. Oliv. Confer M. I. 93. 208.

Cebrio Brevicomis. Oliv. M. I. 34. 84. Mense Majo ponit ova innumera oblonga flava. Lecta etiam saepius m. Octob. Habitat in Scabiosis, \& Carduis frequens. 


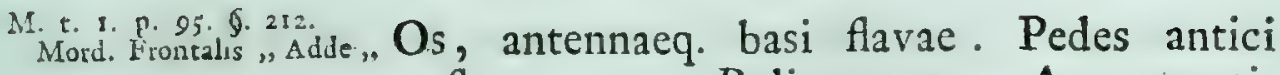
flavescentes. Reliqua atra. Anus muticus. Variat magnitudine.

F. E. t. r. p. 249. 614., Staph. Edentulus, ne confundatur cum St. Morsitante D. de Paykull. Mon. Staph. mox saepe lectus.

M. I. P. 28. \$. 220 . guttatus tamen qui a DD. Geoffroy, \& Paykull pro varietate hujus habetur, a

F. E. T. 1. p. 254.6 .627 . me numquam lectus.

Paed. Impressus,"Currig. Staph. Canaliculatus. M. 1. 98. 2 I 9.

I. E. t. Ialica "265ide" Ach. Italica Cyrill. Ent. Neap. Specim. t. 7 . f. 5. non vero fig. sexta quae ad aliam pertinet. Ach. Italicae femina statura, \& habitu a masculo non dissimilis.

M. t. I. p. 105.9 .232 . Phrsg. Evitata, Adde, Notae constantiores in insecto recens excluso, ac deinde attentius pluries considerato, sunt caput hirtum; oculi fuscorufi; alae anticae pallide flavae, nigroq. reticulatae, basi tantum hirtae; abdomen constanter supra nigrum, subtus flavescens. Color aetate paullulum variat. Habitat frequens in fenestris ad Arni

F. E. t. 2. p. 34. 8. 737. aquas, m. April. \& Maj.
Sir. Dromedarius "Adde , Pone scutellum lateribus puncta duo minutissima alba. Mox sub Julii finem saepe lectus primis horis matutinis quiescens in salice, at semper inventus femina.

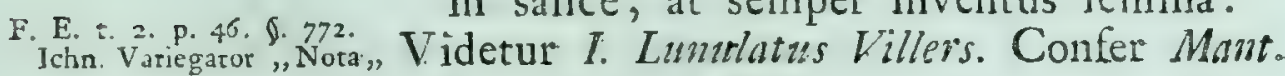

F. E. t. 2. p. 52. f. 789 . p. 1. 122. 269 .

Ichn. Argiolus "Adde" Pedes postici longissimi.

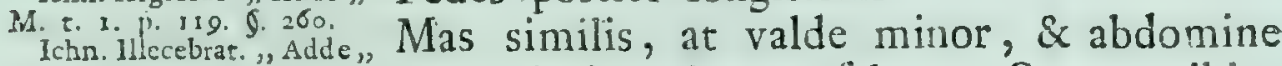
tenuiori, minusq. falcato. Saepe mihi e

M. t. .. p. 221. 5. 267 . Phryganeae folliculis uterq. sexus exclusus. Ichn. Guspidator ,Adde " Mas omnino similis.

F. E. t. 2. P. 57. 8 . 80. Variat magnitudine duplo minori, \& corpore nunc albo; nunc luteo maculato. 
F. E. t. 2. p. 57 . 9. 801 .

Evan? Ediogast."Nota "De genere adhuc haereo. Forte Cymips, aut

F. E. t. 2. p. 64. 5. 821 . Ichneumon.

Sph. Varabils "Nota" Hace nostra Sphex quam ob maximam affinitatem dubitative coniunximus cum S. Rufipede. F. \& S. Versicolore Scop. gaudet plerumq. tarsis anticis extrorsum valde ciliatis, quae nota communis etiam S. Pectinipedi, ac Rufipedi, distinctio se-

M. t. I. p. 127. 5. 882 . xus videtur.

Sph. Maculata , Adde, Thorax ad latera postica denticulo instructus, \& interdum etiam primum abdominis segmentum rufum lineola alba utrinq. notatumi.

F. F. t. 2. p. 67. 9. 828. W Wariat pedibus nigris, scilicet tota nigra F. E. t. 2. P. 73. 9. 839 unicolor.

Scol. Sexcincta?" Lege, Sc. Sexfasciata, nigra cincreo-hirta, abdomine atro strigis sex flavis. Species nova, cui competit descriptio allata 1. c. Obs: Thorax in medio dorsi linea tenuis-

M. t. 1. p. 130. §. 288 . sima flava transversa notatus.

Scol. Sexpunctata "Nota "Ex observationibus nuper factis constat spe.

F. E. t. 2. p. 75. 9. 483 . Chrys. Carnea "Adde"

M. t. 1. 1. 133. §. 293. Chrys. Micans "Nota,

F. E. t. 2. F. 77 . 9. 849. Chrys. Dubja "Adde

F. E. t. 2. p. 83.0 .862 . Vespa Gallica "Adde " ciem esse distinctam a Si. 4-punctata.

Proboscis longa recta subrufa apice bifido, valvis nigris duabus. Color viridis cupreo mixtus. Femora potius viridia, quam nigra. Mox inventa sacpius $m$. Jul. in canzis sabulosis silvaticis volans prope areham, eaq. identidem insidens, at cum a longe persequutorem videat, \& fugiat, captura difficilis.

Variat capite thoraceq. interdum viridibus. Mox semel inventa pernoctans in culmis fruticum exsiccatis. Insectum a me primum descriptum, rarissimum, \& novi generis .

Hae Vespae in nidis domum propriam allatis incubationis tempore, fame, ut vi- 
dentur, vexatae, quaeritant in cellulis larvas, abrosoq. operculo pupas etiam $\mathrm{cx}^{-}$ trahunt, ac vorant. Mas differt a femina abdonine subtus 5 -fasciato, oculis interdum glaucescentibus, macula frontis ad os continuata, maxillis, pectore, femorumq. apophysibus extus flavis. In femina abdomen subtus tricinctum, pectus nigrum, striga frontis supra antennas $\mathrm{fla}$ va, mox spatium nigrum, \& deinde macula subrotunda flava puncto medio nigro. Maxillac apice nigrae. Occurrit varietas minus obvia, cujus femina tantum differt a priore abdomine subtus quadricincto, macula oris flava saepitis absq. puncto, maxillisq. nigris. Hanc, etsi mera varietas praccedentis, tamen numquan vidi societate coniunctam cun ea connubia miscere. Nidificat pari modo, at nidus compositus e cellulis paullo capacioribus, \& materie minus rudi, minusq. , obscura confectis. Vespae quae post paucos dies in eumdem nidum conveniunt, omnes similes, ejusdemq. faniliae inveniuntur.

F. E. โ. 2. p. $8+\S .863$.

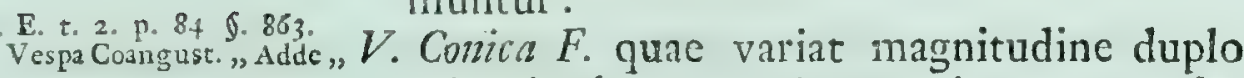
minori, thoraceq. nigro antice tantum fla-

r. E. t. 2. F. S5. S. 864. vo-punctato; mas. Conf. M. I. 35. 299. Vespa Oculara "Nota" Scolia Mutabilis Cyrill. Ent. Neapol. Specim. t. 2. $f$. 8. figura bona, at nomen im-

F. E. t. 2. p. 88. \$. \$74. proprium.
Vespa Annulata "Nota Oculi nullo modo reniformes inter Crabrones amandare videntur. Conf. $\mathrm{Cr}$. $\mathrm{An-}$

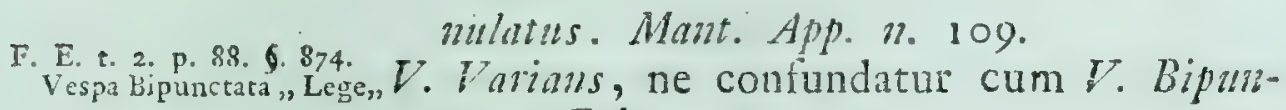
ctata Fab.

F: E. E. 2. P. 22. $9.884 . "$ Variat magnitudine paullo majori, abdoTom. II. 
F. E. t. 2. p. 94. 5. 889 .

Crab. Verustus "Nota,

mine maculis utrinq. quatuor albis, pedibusq. omnibus totis ferrugineis basi excepta femorum anticorum nigra. Variat tibiis flavis, interdum etiam posticis nigris. Frons cinereo-lucida.

Medius inter Crabrones, \& Vespas. In individuis mox lectis, oculi sinum visi sunt exhibere, at vix conspicuum. Alae non plicatae. Variat antennis subtus flavis. Punctum flavum in fronte nota constans.

F. E. t. 2. p. 95. 9. 892 .

Crab. 3-maculat. "Nota "Species omnino distincta a C. Spinoso aliisq. Statura C. Uniglumis, at paullo major.

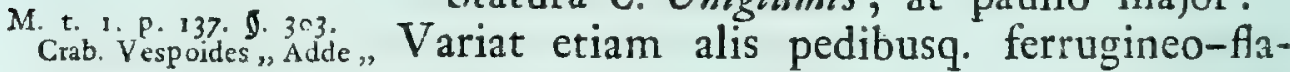
vis, ano flavo-maculato, ac punctis duobus ante lineam scutelli flavis: habitus tamen, fasciae abdominis, \& oculi semper glauci facile distinguunt ab aliis.

M. r. 1. p. 138. 8. 305. viori, quasi puncto elongato, abdomineq. fere toto flavo. Caput pone oculos ferrugineum. Antennae in medio multo crassiores. Alae planae.

F. E. t. 2. p. 345 , in fine. Andr. Discincta, Adde, Inveni etiam effosso cuniculo in arena la-

F. E. t. 2. p. 101. 6.208. A pis Garrula "Adde,"

F. E. t. 2. p. 106. \&. 922 . Ap. Longicornis "Adde",

F. E. t. 2. p. 104. 5. 915. Ap. Maculata "Adde"

I. E. t. 2. p. 102. 9. 228 . Ap. Conica, Adde" tentem.

Oculi glauci. Incisurae abdominis aetate cinereo-tomentosae evadunt; sp. nova.

Non fortuito haec Apis interdum gaudet fronte appendiculata; plures habui hac eaden nota instructas.

Vidi hanc saepius sub Julii finem occupatam in abradenda lanugine paginae inferioris foliorum Pyri cydoniae, eac. accumulata inter pedes, abire. Anus semper destitutus -aculeo punctorio.

Apis quam sub nomine Conicae cum $A$. 4-dentata $F$. in $F$ r. Etrusca coniunxinus, 
certe una eademq. species est, cum dif. ferant tantum abdominis apice quadridentato, \& semper cohabitare observentur, simul pernoctantes in culmis fruticum plerumq. exsiccatis, summis eorum. apicibus maxillis inhaerentes, corpore anoq. sursus porrecto, antennisq. junctis, demissis, extensis. Somnus gravis. Magnitudo variat.

II. t. I. P. 139. 5. 309. Ap. Pascuorum "Nota,

A. Fulva Scbrankii E. I. 400. 805. Cyrili. Ent. Neap. Specim. t. 2. f. 2. 2.

Inter apes a Gallis nuncupatas les Abeilles maçonnes, heic altera est recensenda species hactenus indescripta, quae nidum pyriformem ex arenula agglutinata componit quemadmodum $A$. Varians. Diwos enim nidos imperforatos integrosq. mihi e Sicilia benevole communicavit illustris vir D. Hieronymus Recupero naturalis historiae peritissimus, materie, ac forma similes is $A$. Variantis, etsi magnitudine dimidio minores; quorum unus cultro divisus exhibuit tantum cellulas quatuor repletas melle ad syrupi spissitatem redacto, subdulci ac insuavi, \& omnino intacto, forte co quod ova (uti excrementorum in ima cellularum parte defectus comprobare visus est) ante exclusionem perierant. Alter vero quatuor suppeditavit Apes jam mortuas, quae specie palam distinctae ab $A$. Variaute compertae sunt: nempe,

\section{* Apis Sicula.}

Atra hirsuta fronte, thoracis dorso, pedibusq. saturate fulvis; alis atro-violaceis. Statura, ac magnitudo masculi A. Varianz$\mathrm{S}_{2}$ 
M. t. I. p. 143. 9. 323 .

tis, a quo manifeste differt corpore subtus toto atro, antennis brevioribus, villo frontis thoracisq. fulvo saturatissimo lucido, abdomine etiam supra toto atro, pedibus fulvis vix pilosis, alis atro-violaceis. In $A$. Variante caput barba albida vestitum, in hac atrum, subnudum. Ap. Cucurbitina "Nota" Evacuata medulla, intrat Rubi ramulos exF. E. t. 2. p. 228. \$. 264 . siccatos obtruncatosq., ibiq. hospitatur. Aran. Phragmis "Adde , Ar. Formosa Vill. Ent. 4. 130. 125. t. 11. F. E. t. 2. p. 129. 9. 266 . Aran. Palustris "Adde"

F. E. t. 2. p. 132. \$: 974 Aran. Tarantula , Adde ${ }_{20}$ f. 10.

Variat fascia laterali modo nivea, modo flavescente.

Oculi octo rufi, medii majores cornea post mortem depressa. Forceps robusta conica apice aculeata, aculeo mobili articulato: huic subiacent maxillae duae nigrae corneae duas lineas divisorias cum forcipe efformantes, \& os in quatuor veluti partes cruciformiter dividentes, ex. qua partitione concludi posse videtur $T a$ rautulam esse Tetragnatium Aetii \& Plisiii, pariterq. unam eamdemq. speciem esse cum $A$. Solifuga Veterum. Ad maxillarum basin alia insidet pars quasi labium inferius, quod linguae officium praestat ad exsugendam praedam. Thorax fere duplo major abdomine, cinerescens areis nigris in centrum concurrentibus, fascia laterali, mediaq. albidis. Abdominis dorsum cinerescens maculis trigonis nigris, strigis arcuatis albidis intersectum: subtus laete croceum fascia transversa nigra. Pedes atro-fasciati. Colore admodum vaF. E. t. 2. p. 135. 5. 278 . riat.

Aran. Quatuotgut., 19 Add. A. Monilifera Villers Ent. 4. 128. 119. t. 1. $f .8$. 
F. E. t. 2. p. 138. 6. 983 . Aran. Sauvagii "Nota"

F. E. t. 2. p. 159. 6. 1046 . Sph. Ocellata , Nota,,

F. E. t. 2. p. 165 . 6. 1062 . Sesia Asiliformis," Adde,

F.E. p. $169 \cdot 8 \cdot 1078$. Boinb. Muri "Notá,

F. E. t. 2. 0. 875. \$. 10,6. Bomb. Grammica, Adce,
E. t. 2. p. 176.6 .1100 . Bomb. Furcula "Adde "

F. E. t. 2: P. 184. 9.1130. Noct. Pisi "Adde",
Novissime admiratione mea maxima detecta habitare etiam Pisis, in loco montuoso vulgo dicto Palaja, ubi domicilium struit e terra arenosa confectum operculo mobili quemadmodum Corsicana, \& Monspeliensis, intruditq. sacpius in muris externis antiquis aedium rusticorum, prope terram.

Mox lecta saepius.

M. Jul. occurrit alia huic fere omnino similis a $D$. Hubuer descripta sub nomine $S$. Rlbingiaeformis. Beitr. $G, t, 2$. th. 4. $t$. 2. $f$. $I$ quae differt tantum a $S$. Asiliformi $F a b$. antennis flavis, cingulisq. abdominis quinque. Nota haec admodum variationi subiecta .

In hac specie non raro mas \& femina in eodem simul contexto folliculo metamorphosin subeunt, ac inde exclusi pacta connubia persolvunt .

Variat alis flavis absq. striis.

B. Furcula. Panz. Fn. Germ. Hefi. 11. t. 20. Mox saepius inventa.

Pupa nuda brunnea ano bispinoso: larva flavo nigroq. varia, punctis nigris verrucosis piliferis fascia laterali, lineisq. dorsalibus flavis. Occurrit etiam in sili-

F. E. t. 2. p. 196. 5. 176. qua Coluteae vesicariae, aliisq. plantis. P. Nympheata "Adde "Hubner Pyral. t. 13. $f$. 85. P. Nympbealis.

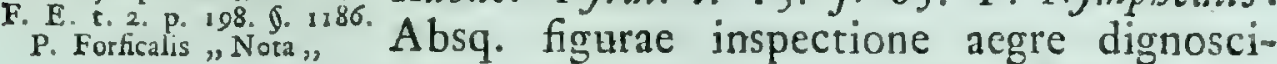
tur : Iconem dedit Hubner Pyral. t. 9. f. 58 .

F. E. 2. 2. p. 199. \$.1190. P. Extimalis Scop. P. Erucalis Hubn. Pyral. t. 9. f. 55.

M. t. 2. p. 41 . S. $46_{3}$.

P. Atralis "Nota "

P. Atralis Hubner Pyral. t. 5. f. 27. ab hac distinctissima.

M. 8.2. p. 16. §. 366."Add. "Sesia sub nomine minus certo $S$. Haemor 
roidalis $F$. a Cyrillo exhibita in Fn. Neap. Specim. $t$. 4. $f$. 3. Adde etiam suo loco $N$. Fuscula W. S. 89. 6. N. Cubicularis W. S. 72. 6. Ph. Permutataria Hubr. Heft. 2. 1v. t. 1. f. F. Pb. Ulmata $F$. Sp. 94. 258. Panz. Fn. Germ. Heft. IIr. t. 22. Pb. Flammealis $W . S$. n. 35. p. 123. Hubn. Pyral. t. 15. f. 99. Tin. Cribrumella. Lang. n. 1479. Hubn. 1. Hefi. t. 4. $f . W$. quae omnes habitant apud nos .

F. E. t. 2. p. 282. I. 3247.

Fulg. Europaea "Nota,

M. Jul. \& Aug. occurrit frequens in horto Pisano Acad. semper in foliis Asclepiadis Syriacae.

F. E. t. 2. p. 218.9 .1265 . Cicada Pusilla „, Adde

Elytra venosa hyalina maculis ferrugineis irrorata, margine exteriore punctis duobus nigris. Abdomen nigrum segmentis margine albidis. Pedes albi tibiis posticis spinulosis. Antennae albae longiusculae. Caput fronte 4 -punctata punctis in quadratum positis. F. E. t. 2. p. 222. J. I293. Cim. Globus F. Ent. Syst.

F. E. t. 2. p. 229. 6. 1294. Cim. Scarabaeoides. F.

F. E. t. 2. p. 235. 1310 . Jun. m. frequens copiosus in spicis florifeCimex 2-punctatus "Add. ris Teucrii Scorodoniae. C. Fucatus Fn. Etruscae $\%$. 1311 . an hujus mera varietas?

F. E. t. 2. p. 237. ${ }^{2315}$ C. Carbonaritts Ent. Paris. magnitudine majori a Scbrankio distinctus a C. Morio, seu C. Fumoso Ent. Paris.

F. E. t. 2. p. 238. ${ }_{\text {Cim. Familiaris, Nota, Mox saepe lectus, semperq. in Asclepiade }}$ Syriaca .

F. E. t. 2. p. 249. 9.1344. Sane C. Spissicornis F. Panz. Fu. Germ. Heft. II. $t$. 16. Habitat etiam in Populo alba.

F. E. t. 2. p. 250. 5. 1345. Mox lectus saepius in Populo alba \& tremula. 

F. E. t. 2, p. 25\% \$ 349. Oculi corpori concolores. Antennae apice rufescences. Pedes longiusculi praesertim. postici. Lineae duae longitudinales interdum percurrunt abdomen. Specimen habeo longum lin. $5 \cdot \frac{1}{2}$. F. E. t. 2. p. 268. 6. 443. In determinando hoc Oestro Valisneritis,
Oest. Bovis "Nota" Rbenumurius, De Geer assignant pro charactere alas immaculatas; Limnaeus vero Geoffroy, Fabriciusq: alas maculatas, \& e contra in O. Equi . Observationes nostrae convenire videntur cum descriptionibus priorum, \& cum fig. Schaefferi Elem. t. 91. f. 1. at cum O. Equi admodum variet caussa loci \& sexus, confusio non aliter depellenda nisi ab eo cui datum feliciter erit observare, \& comparare simul plures Oestros tum Bovis, tum Equi sub oculos natos.

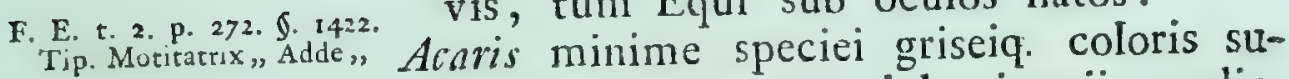
biecta. Vidi saepe abdomine is undiq. obtecto.

F. E. t. 2. p. 278.9 .1437 .

Bib. Satyrus, Notz, Mox capta saepias.

Syrph. Intricarus, Add. Mas differt abdomine villis thoraci concoloribus omnino vestito, scilicet rufo lutescentibus, oculisq. non uti in femina disiunctis .

F. E. t. 2. p. 289. 61463. S. Silvarum Fab.

F. E. t. 2. p. 291. 0.1468 . Prope finem Augusti occurrit frequens in Syrph. Sphegeus, Adde "Plantis palustribus; an larva in aqua? M. t. 2. p. 63. 5. 531. Not. Nomen S. Spinipedis t. v1. f. 1. in hoc per-
mutatum. F. E. t. 2. P. 314. $\$ .1529$.
Musca Clandestina " Not. M. Ammulata Sebrankii; antennis setariis, oculis violaceis, fasciis purpureis sex, pedibus annulo albo. Mitsca thorace viridi nitente, abdomine aeneo, tarsorum annulo albo. Geoff. Ins. 2. 527.63.

Caput inter oculos, antennaeq. rubrae. 
F. E. t. 2. P. 315. 0. 1532. Musca Cynipseä , Nota

F. E. to 2. p. 317. 9. 1538 . Musca Oleae "Adde "
F. E. t. 2. p. 319.8 .8544 . Tab. Tropicus "Nota ",

F. E. t. 2. p. 321. \$. 1549 . Tab. Pluvialis "Adde "
Oculi violacei fasciis purpureis. Thorax viridi-aeneus. Pedum omnium tarsi basi annulo albo. Alae tenuissimae albae longiusculae, una supra alteram fere incum. bentes. Anus stylatus in feminis. Habitat frequens in Quercu plantisq. variis folia percurrens, ac victitans rapina. Infestatur Sc. Cancroide qui pedibus ejus chela tantum unica firmissime inhaeret: saepe legi molestatam etiam pluribus.

M. Octob. occurrunt aliae in plantis, \& fenestris huic omnino similes, quae alas habent immaculatas absq. puncto .

Facies ac habitus $M$. Heraclei, eodemq. modo incedens alas patulas gerit, \& agitat. Corpus subrotundum. Hujus infestissimi Insecti immensa damna certe imminuerent, si magis curae esset colonis studium colligendi, \& removendi a plantis olivas, statim ac deciderunt; sic enim Muscae maximam partem alibi declaratae, incunabulis propriis ad anni posterioris jacturam parandam deficerentur. Confer. etiam Opusc. Rev. Canonici Giovene Melfictensis edit. Neap. an. 1792.

Antennae lunulatae fulvae apicibus nigris . Tibiae ferrugineae.

Occurrit sed rarissime oculis contiguis absq. fascia ordinaria frontis, punctisq. nigris, \& tum oculi observantur fusco-virescentes extremo tantum latere inferiori purpureo, lineolisq. duabus tenuissimis undulatis viridi-argenteis tranverse fasciato. Antennarum basis in hoc nigro lucida, \& punctum minutissimum album distinctum utrinq. in dorso thoracis. Va. rietas haec singularis, quac plerumq. ha- 
bitat in hortis, de diversitate speciei dubium promoveret, nisi in reliquis omniF. E. r. 2. p. 327 . 9.1565 . bus nimis $T$. Pluviali similis esset. Asil. Glaucius "Adde" Variat pedibus nigris, plerumq. mas. Affinis A. Nigro Scop. a quo differt oculis fuscis praesertim, \& segmentis abdominis glauco-maculatis. Thorax in hoc magis quam in $A$. Nigro griseo-pilosus, \& alae ferrugincae. Statura, \& magnitudo eadem .

Tis wain to hope in Nattere's things quick knouledge.

POPE's 'essay on criticism. 


\section{$I N D E X$ \\ GENERUM， ET SPECIERUMT}

Quae in Mantissa continentur.
G. I. Lueanus .
20. Macuilatus.*
39. Varius.
I. Viresceils .
21. Minor.*
40. Ater.*
G. ili. Scarabaeus :
22. Decemstriatus. *
$G$. Xv. Aмовium .
2. Punctulatus .
23. Duodecinustriatus?*
41. Punctatum.*
3. Fossor.
24. Sulcatas.
G. xvi. Ptinus .
4. Sordidus.
25. Parvulus.* 42. Longipes .*
5. Rubidus. *
26. Pusillus *
6. Irroratus.
27. Atomos.*
43. Variegatus.*
7. Furcifer.*
$G$. x. Dermestes .
44. Latro.
8. Rufipes.
9. Plagiatus.
10. Fuscuss, *
II. Lunaris.
G. IV. Trox .
I2. Niger.*
G. v. Mezolontifa .
13. Ruficornis.
14. Abdominalis.
I5. Argentea .
28. Vulpinus.
Marginatus. Thunb.
29. Trifasciatus.
30. D? Dentatus .
Tillus Serraticornis.
3i. Fornicatus.
32. Fuliginosus. *
G. XiX. SPhaEridium.
33. Bicolor.
34. Dubius.*
Sanguineus .
45. Finnetariun .
46. Pulicarium.
47. Luteum.
G. XX. TRITOMiA.
16. Squanosa.
17. Dubia.*
G. vin. Hister.
18. Major.
G. Xir. Bostrichus.
48. Bipustulata.
49. Sericea.
G. XXI. Ips .
50. Fallax.*
5r. Testacea.*
52. Atra.*
35. Caliographus.
G. XXIV. Sifpha.
36. Pygmaeus.
53. Laevigata.
3\%. Crenatus.
G. xxvi. Nitidula.
19. Cyaneus .
38. Ligniperda. 54. Maculata.* 55. Strigata. 
56. Discoider.

5\%. Chrysonzeloides.*

58. Haemorrhoidalis.

G. xxvil. Coccinella.

59. Tripunctata.

6о. Nigrofasciata.

61. 23-punctata.

62. Is-pinctata.

63. I 4-maculata.

64. I4-gattata.

65. 14-pustula:a.

G. Xxvill. Cassida. 66. Margaritacea?

$G$. xxx. Hrysomera .

67. Goettingensis.

68. Fastuosa.

69. Violacea.*

7̧०. Nigricornis.*

z. Gloriosa.

72. Gemellata. *

33. Vulgatissima.

64. Armoraciae.

65. Pyritosa.*

76. Ruficollis.

7\%. Nemorum.

78. Pulex.*

79. Violaceo-punctata.

80. Dorsalis .

G. XXXI. CryptocephaLUS .

8r. Moraei.

82. Tricolor.*

a. XXXit. Celrio.

83. Longicornis.

84. Brevicornis.*
G. XXXir. Criaceris .

85. Capreae.

G. XXXV. LAgRIA .

86. Aenea.

$8 \%$. Viridis. *

G. Xl. Curculio .

88. Bardazae.

89. Sanguineus.*

90. Cuprirostris.

9r. Caerulescens.

92. Timidus. ${ }^{*}$

93. Perpenszzs. *

94 Rumicis.

95. Infidus.*

96. Cinctus .

97. Binotatus. *

98. Tigratus .*

99. Bipustzilatus. *

I00. Canescens.*

10 1. Caudatus *

102. Costatus.

I03. Viator.*

104. Scabriculus.

105. Erevirostris.

106. Limosus.*

$10 \%$ Visus: ${ }^{*}$

108. Armadillo *

109. Sulcalus,*

G. XLI. Rhinomacer.

IIO. Brentoides.

G. xlir. Attelabus.

III. Bicolor .

G. Xlin. Clerus .

112. Univittatus.*

$G$. xLIV. Notoxus.
II 3. Trifasciatus."

1 I4. Pedestris .*

I 5. Cinctellus.**

I 16. Hispidus .*

II . Myrmicocephalust

118. Hispidulus .

119. Non plus ultra."

120. Termicollis.*

I2I. 4-guttatus.*

I22. Bifasciatus .*

G. xlvii. Cerambyx.

123. Fasciculatus,

G. xevin. Lamia.

124. Unifasciata.

G. LiI. Saperda.

125. Erythrocephala.

126. Linearis .

12\%. Lineola.

G. hiir. Callidium. 128. Salicis.

129. Clavipes.

I30. Variabile.

131. Gibbosam :

132. Pirsillman.

G. Iv. Leptura.

133. Elongata.

$G$. Lvis, PyrochroA.

134. Coccinea.

G. ixi. Cucujus .

135. Testacess.

G. Lxil. Cantharis .

I36. Pallida.

I37. Plumbea.

G. Ixiv. Necydalis .

I $3^{8}$. Hybrida.* 
139. Flavesceizs.

G. LXv. Elater.

140. Litigiosus *

I41. Lineatus.

I42. Cylindricus .*

I43. Thoracicus.

144. Binotatus."

G. LXVI. BUPRESTIS .

145. 9-maculata.

146. Cyanicormis.*

14\%. Deaurata.

I8. Rusilans.

149: Elata.

150. Laeta.

I5 1. Caerulea.*

152. Pygmaea.

153. Minuta.

154. Nitida.*

G. Lxvin. Elaphrus .

155. Caraboides.

${ }^{15} 6$. Nebulosus. .*

${ }^{15}$. Pyritosus. *

$G$. LXix. Hydrofhilus.

I58. Caraboides.

159. Orbiculatus .

160. Pallidus.*

G. Lxx. Dytiscus .

161. Dissinilis .

162. Bipustulatus.

${ }^{16} 3$. Trassversalis .

164. Pustulatus. *

165. Hylneri.

166. Taeniatus.*

16\%. Bipunctatus.

$167{ }^{2 i}$ Uliginosus.
168. Minutus .

G. lxxir. Carabus . róg. Purpurascens.

I ${ }^{\circ}$. Hortensis .

I I. Corvexus.

172. Paykullii.*

173. Granulatus .

174. Leucophthalmus.

175. Auropunctatus.

1 6 6. Terricola.

177. Punctulatus.

I 7 . Striatus .

179. Cinctus.

180. Ruficornis .

$18 \mathrm{r}$. Vestitus .

182. Spoliatus.*

183. Nigricorsis .

184. Rufus.*

185 . Humeralis .

186. Smaragdulus **

187 . Sexpunctatus.

188. Tenebrioides . *

189. Dentatus .

190. Distinctus . *

191. Germanus .

192. Exhalans.*

193. Psammodes .*

194. Aterrimus.

195. Proteus.

196. Assimilis.

197. Obscurus.

19S. Infidus. *

199. Agilis.

200. Ovatus.

sor. Votivus.*
202. Velocipes."

203. Rufipes.

204. Dorsalis.

205. Erratus.*

C. Crat minor. Fin. Sy.

G. LXxin. Scarites. 206. Dama.*

G. LXXv. Tenebrio :

207. Cornifrons .

v. Emendat.

208. Mauritanicus .

G. Lxxyiv. Mylabris .

209. Testacea.

210. Fulva .

G. Lxxxvi: Mordella.

2.I I. Abdominalis .

212. Frontalis.

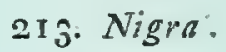

$G$. Lxxin. Staphylinus.

2r4. Hirtus.

2i5: Cyaneus.

2.6. Bicinctuss **

2ir. Pubescens.

II8. Tomentosus :

219. Conaliculatus .

220. Clavigornis.

221. Pollidus.**

222, Orbicklatus.

223. Singuineas.

G. IXXXix. Paederus .

224. Elongatus .

$G$. xom. Mantis .

225. Rossia.

226. Spallanzania.*

G. CXvi. Locusta. 
227. Tuberculata.

G. civ. Phryganea. ¿28. Binaculata.

229. Grisca.

230. Longicornis.

23 I. Obscura.*

232. Evitata.*

G. cv. Hemerobius.

233. Pulsatorins.

G. CVi. Termes.

234. Lucifugum 。*

G. cvir. Myrmeleon.

235. Pisanus:

G. Cxir. Tenthredo.

236 . Padi.

237. Nigra.

238. Viga.

239. Viridis.

240. Hacmatodes.

24I. Rubi Idaei.

242. Rapae:

243. Depressa.

G. cXIv. ICHNEUMON.

244. Qunesitorius.

245. Inflictorius. *

246. Machinatorius.*

247. Vacillatorius.*

248. Sarcitorius.

249. Fanereus?

250 . Oblatorius.*

25I. Motatorius.

252. Luctatorius.

253. Perfusorius.*

254. Laetatorizs.

255. Praedator.*
256. Occultator : *

257. Exhortator.

258. Amator" "

259. Insimuator * *

260. Illecebrator" .

26I. Turionellac.

262. Resinellae.

$26_{3}$. Bifasciatus.

264. Oculator.

$26_{5}$. Cuniculator.*

266. Terrefactor.

26\%. Cuspidator.*

268. Sagittator.*

269. Lunulatus.

270. Anictus .

27. C. Cinctus *

272. Crassipes.

273. Lenocinator.*

274. Mutillarius.

265 . Cyniformis.*

$2{ }^{2} 6$. Rodophthalmus. *

І67. Muscarum.

278. Mortwormm.*

G. cxvi, Chalcis .

279. Immaculata."

G. cxvil. Sphex.

280. Plumbea?

281. Notata.*

282. Maculata.

283. Carbonaria.

284 . Boops.*

G. cxix. Scolia .

285. Flavifrons.

286. a-maculata.

28\%. Hortensis.
288. Sexpunctata.*

289. 8-punctata.*

G. Cxx. Chrysis.

990. Roser.*

291. Bidentata.

292. Fulgida.

293. Micans. *

294. Ederatula.*

295. Integra.

296. Aurata.

G. CXXII. Leucospis.

297. Dorsigera.

298. Gallica.

G. cXXiv. VESPA .

299. Coangustata.

300. Bipunctata.

G. Cxxv. Crabro.

301. Flavipes.

30工. Affinis."

3०3. Vespoides.*

3०4. Lunulatus. .*

305. Androgynus **

306. Albofasciatus."

3०\%. Quinquefasciatus."

308. Spinostts.

$G$. cxxvi1, Apis .

309. Pascuormm.

310. Bicornis.

311. Pilipes.

312. Aemula.*

313. Palmipes.*

314. Regalis.

3.5. Subterranea.

3I6. Albopunctata.*

3I\%. Varians.* 
318. Obsoleta. *

319. Leucozoris.

320. Albipes.

321. Subaurata.*

322. Lingularia?

323. Cucurbitina.*

G. cxxvrir. Nomada.

324. Fabriciana.

325. Gibba.

326. Cingulata:

327. Cincta.*

32S. P. Psilla.*

G. CXXix. Formica.

329. Fusca.

33o. Flavipes .

G. cxxx. Mutilla. 33I. Coronata.*

332. Stridula:*

333. Ephippiann.*

334. Nigra.*

G. cxlin. Trombidium.

335. Trimaculatum .

G. CXL1v: Aranea.

336. Viridissima.

33\%. Phalangioides.

338. Catesbaei.

339. 4-punctata.*

340. Litterata. *

G. cxlv. Phalanglum.

341. Opilio.

G. cXlvis. PapiLio.

342. Cleopatra.

343. Phicomone.

344. Iris.

345. Fillig.
346. Fanna.

347. Maera.

348. Ida.

349. Aglaia.

350. Athalia.

35I. Euphrosyne.

352. Boeticus .

353. Amyntas.

354. Corydon.

355. Dorylas.

356. Cyllaris .

35\%. Paniscus .

G. CXLVi11, SphinX.

358. Atropas.

359. Lineata.

$3^{60}$ Galii.

361. Porcellus .

362. Oenotherae.

$G$. cxily. Sesia.

$3^{6} 3$. Conopiformis .

$3^{6}$. Ichnemmoniformis.

$3^{6} 5$. Aselliformis .*

G. CL. ZYGaena.

266. Ephialtes.

$3^{6}$. Trigonellae.

G. CL1. Bombyx.

368. Trifolii.

369. Quercus.

37o. Clavis.

3 I. Velitaris.

372. Compressa.

373. Aesculi.

374. Anachoreta.

375. Aurifuse.

3-6. Testudo.
37\%. Lugubris.

378. Vestita.

379. Apiformis.

380. Obscura.

381. Punctata.

G. cli1. Hepialus.

382. Crux.

G. Clini Noctua.

$3^{8} 3$. Quercus .

384. Complana .

$3^{8} 5$. Batis .

396. Manicata.

$3^{8} z$. Bengalensis .*

388. Nigricollis.

389. Livida.

390. Spectrum.

391. Orbona.

392. Segetis .

393. Maura.

394, Dentina .

395. L. Album :

396. Gilvago .

397. Circmaflexa.

398. Satellitia .

399: Absinthii.

400. Occulta.

401. Pyramidea.

402. Alchymista.

4०3. Tridens.

404. Perla.

405. Euphorbiae.

406. Atriplicis.

40\%. Tragopoginis.

408. Hepatica.

409. Polyodon?. 
410. Nigricaiss:

4 II. Hippophaes.

4I2. Craceac.

4I3. Arbuti.

G. cliv. Phalaena.

414. Punctaria.

4I5. Equestraria.

4I6. Roboraria.

417. Papilionaria.

418. Furcaria?

419. Piniaria.

420. Bipunctaria.

42 I. Murinaria.

422. Plumbaria.

423. Marginaria.

424. Hivaria.

425. Calabraria.

4ะ6. Gilvaria:

42\%. Minntaria.

428. Fasciataria.*

429. Ochrearia .*

430. Demandata.

431 . Obscurata.

432. Adustata.

433. Undulata.

434. Ocellata.

435. Chenopodiata.

436. Lustuata.

437. Moniliata.

438. Punctata.

439. Incanata.

440. Mediata.

441. Rubricata.

442. Ochreata.

443. Lemuata.
444. Corrigata.

445. Grisata.

446. Hamata.*

447. Succenturiata.

448. Ventilabris.

449. Verbascalis.

450. Lutealis .*

45 I. Dimeralis :

452. Nemoralis.

453. Flavalis.

454. Undalis.

455. Reticularis.

456. Palealis.

45\%. Strigalis.

458. Centralis.

459. Porphyralis.

560. Punicalis.

461. Cespitalis.

462. Ruralis.

${ }_{4} 6_{3}$. Atralis.

${ }_{4} 6_{4}$. Ferruginalis.

465. Vitrealis. *

G. clv. Pyealis.

466. Brunnichana.

467. Christiernana .

468. Asperana.

460. Quercana.

470. Cinerana.

471 . Pomana.

472. Woeberaina.

G. CIVI. TINEA .

473. Mesomella.

474. Oxyacanthella.

475. Cinerella.

476. Punctella.
47\%. Prolezella.

478. Compositella.

479. Strobilelli.

48o. Trigonella.

48I. Lyonnetella.

482. Aurella.

$4^{8}$. Blockiella .*

484. Prumerella.*

$G$. Clvid, Alucita :

$4^{8} 5$. Bipunctella.

486. Sulzella.

487. Podaella.

488. Erxlebella.

489. Xylostella.

490. Marginella.

49r. Fasciclla.

492. Aristella.

493: Oppositella.

G. ClVill. PTERophorus.

494. Monodactylus.

495. Tesseradactylus.

G. Clx. Membracis.

496. Genistac.

G. ClX1. T'ettigonia :

497. Montana.

G. clxil. Cicada.

498. Interrupta.

499. Flava.

500. Flavescens: *

50 I. Pallida.*

502. Desertrix.*

G. ClXI11: Cercopis .

503. Coleoptrata.

504. Os nigrum.*

G. clxiv. Notonecta. 
5०5. Minutissina.

G. Clxvin. Acanthia. 506. Umbraculata.

G. CLXIX. CrMEX . 507. Apuanus. * 508. Phoeniceus.* 509. Rolandri. 5 ro. Limbosus. 5II. Testaceus.* 512. Pallidus.* 5'3. Saltator?* G. ciXXiv. Coceus . 5I4. Artemisiae * G. Clxyvir. Tipula. 5I5. Rivosa. 516. Pilipes? 51\%. Nigra. 518. Prateinsis. 519. Plumosa. 520. Hirta. 52 I. Cuprinervis. ${ }^{*}$ 522. Penicillata.*

G. CLxxvili. Biblo . 523. Italica.* G. clyxix. Strationys. 524. Confusa. ${ }^{*}$ 525. Trilineata. 526. Mutica. G. CLXYXi. Syrphus. 527. Metallims.
528. Lugubris.

529. Rosaruan.

530. Constans .*

53 I. Acanthodes . ${ }^{*}$ (a)

532. Megacephalus *

533. Pisaeus. *

G. CLXXX11. Musca.

534. Meridiana.

535. Ristica.

536. Testacea.

537. Caxina..

538. Lenconyx .*

539. Amentaria.*

540. Fungorum.

541. Coleoptrata.

542. Radicum.

543. Gastrodes .*

544. Tigrina.

545. Roralis.

546. Cellaris.

547. Fenestralis.

548. Albicincta.*

549. Petronella.

550. Corrigiolata.

$55^{x}$. Spinipes.

55\%. Quadrifasciata.

(a) Nomen S. Spinipedis, conf. tab. VI. f. $L$ in hoc permutatuin, ne confundatur cum M. Spinipede.
553. Diaphana

554. Stellata.

555. Quadripunctata.

556. Cerasi.

557. Coryli.**

558. Cineraria."

559. Macrocephala . 560. Gibba.*

$5^{6 \text { I. Helianthi.* }}$

56.2. Galeata.*

$5^{6}{ }_{3}$. Hydrophila. *

564. Properans: *

565. Palmipes.*

566. Praedo.*

G. ClXxxi11. TABANUS. $5^{6} \%$. Maculatus.*

G. Glxxxv. Asilus . 568. Diadema.

G. Clxxxv1. Conops . 569. Serivea. 570. Lutea.

G. CXg. EMPIS . 561. Ciliata. 572. Maura. 573. Flavescens." 574. Albicornis.* 565. Bifasciata. * G. CXCi, Bombylus . 576. Elongatus . * 5:-. Aeneus * * 


\section{$I N D \quad E \quad X$}

\section{GENERUM, ET SPECIERUM}

\section{Quae in Appendice continentur.}
G. 111. Scarabaeus.
G. xy. Opatrum.
39. Blockii.*
I. Hemisphaericus.
19. Gibbam .
40. Vittatus.
2. Arenarius.
G. xxvi. Nitidula .
G. XXY. LAGRIA.
3. Flavidus.*
20. Marginata .
41. Linearis.*
G. X. Dermestes .
21. Litsra.
G. XL. Curculio .
4. Bifasciatus. *
5. Denticulatus.*
G. xxuir. Coccinella.
42. Angtinus?
6. Sulcatus.*
22. Elaterii. *
23. I8-notata.*
G. Xis. Byrrhus .
7. Crenulatus.*
8. Spinosts .*
24. Immaculata.*
43. Jacease.
44. Guttula.
45. Glis .*
25. Quadrimaculata.
46. Barbatus.*
26. Frontalis?
47. Tamarisi.
G. xvi. Ptinus.
27. Minutissina.
9. Imperialis.
G. xvi. Bruchus .
10. Galegae .*
G. Xvili. Elophorus .
II. Minutus .
28. Marginalis .*
48. Thatmaturgus .*
29. Analis.
30. Arcuata.*
3r. Pygmaea.
32. Minima.*
G. xix. Sphaeridium.
33. Lutea. *
12. Assimile *
G. Xxvin. Cassida.
13. Bipustulatum.
34. Vibex.
14. Pellucidum.*
I5. Testudineum .*
35. Tigrina.
G. XXx. Chrysomela.
I6. Pilosum.*
56. Holsatica.
G. xx. Scaphidium .
I\%. Immaculatum.
G. XXI. Ips .
37. Modeeri.
$G$. XXX1. CRyptocepha-
18. Raficorpis .
AUS .
38. Stragula.*
$G$. XL1. RHINOMAcer .
49. Curculioides?
50. Ruficollis .*
G. XLix. Stenocorus .
51. Luridus.*
$G$. LII. SAPERDA .
52. Scalaris.
53. Testacea.
G. liit. Callidium.
54. Praeustum.
55. Lividum.
G. Liv. LePtura . 56. Tomentosa.
G. LXIV. Necydalis .
57. Ceramboides * 
G. ixv. Elateg. 58. Flexalosas. * 59. Buprestoides. 60. Dermestoüdes.

G. IXv. BUPRESTIS .

61. Lurida.

62. Fabricii.*

63. Pisana. *

64. Decemmacalate. *

G. LXXII. Carabus .

6. Megacephalus. ${ }^{*}$

66. Sulbglubosus.

G. LXxv. Pimelia.

6\%. Glabra.

G. LXXXvi. Mordelia. 68. Fasciolata .*

69. Biguttata."

G. Lxxxvi1. StaphyL1Nus.

zo. Porcatus.

G. Ixxxxv1. LocustA.

7\%. Thymifolia.

G. Ixxxxvil. GryLLUs . 72. Giomae.*

G. chis. Semblis . 73. Farinosa.*

G. cv. Hemerobius .

74. Striatulas.
E. CX!. CYNips .

65. Adonidam .*

66. Scutellaris.*

77. Ruficornis."

78. Affinis .

79. Plumata.

So. Dubia. *

$G$. CXIV. ICHNEUMON .

8.1. Apparitorizs.

82. Irrisorius. *

83. Flagitator.*

84. Investigator. ${ }^{*}$

85. Sangunator. ${ }^{*}$

86. Viator.

87. 1dolon.*

88. Rubidus..*

89. Auratus.**

9o. Calcaratus.*

91. Infidus..*

92. Crassicornis .*

93. Ramicomis .

94. Rufescens.

95. Fenestralis. * 96. Agilis.

Nov. Gen. cxv. Xenos .

9\%. Vesparum :

G. cxvi. Chalcie . 98. Sispes.
99. Ruffipes, * 100. Hesperidums .

G. Cxvi1. Sphex. Ior. Thoracica. * I02. Laevigata.*

G. cxix. Scolia . 103. Bicincta. 104. Insubrica. 105. Bifasciata, *

G. cxx. Chr ysis . 106. Fervida.

G. cxxu. Crabro. I07. Subterraneus. 108. Calceatus .* 109. Annulatus. * I 10. Bicinctiss.* II I. Ceraunius ** II. Pygmaells.*

G. CXXYil. Apis. II3. Furax.* I14. Glaucocincta.*

G. exxix. Formica. 115. Mortuorum.* G. cxxx: Mutilla. 116. Laevis. 117. Catancusis.* 118. colson.

Praeter has nonnullae aliae species inveniuntur descriptae vel in Fn。 Etruscae Not. \& Add, vel in Operis Emend: ac Illustr. 


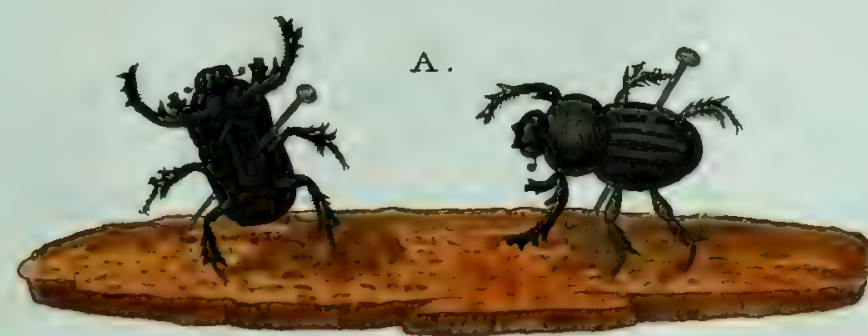

B .

N.

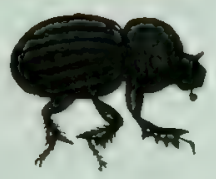

D.

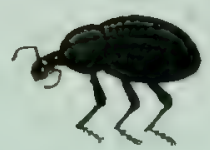

E .

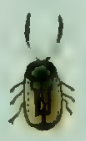

G .

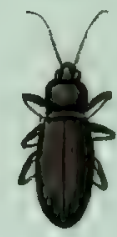

H.

0.

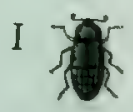

M.

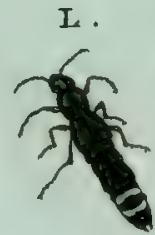

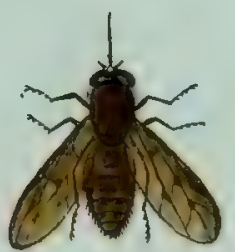

I.

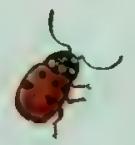

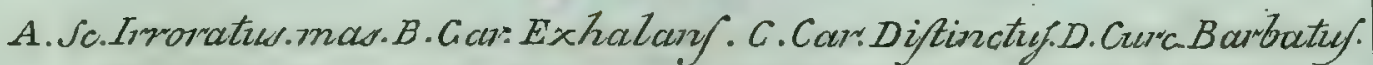
E.Crypot. Stragula. F. Derm. Dubiue. G. Hel.Chalibery. H.Bib. Italica. I.Hist. Maculatu. K. Crypt.Tiricolor: I. Staph. Bicinctus: M.Tab. Maculatuy. N.Sc.Imoratus: fom. O. Staph. Porcatus. 

- B .

A.

c.

E.

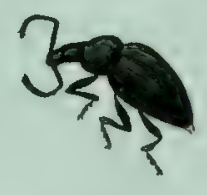

H.

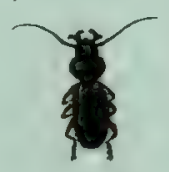

K.

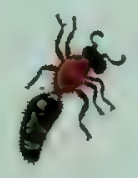

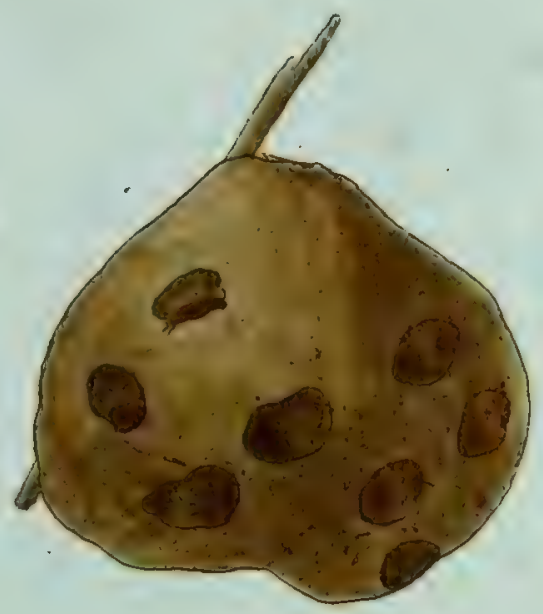

D.

年 $a$.

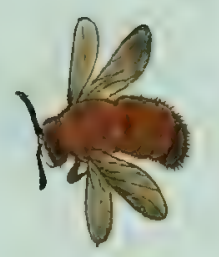

G.

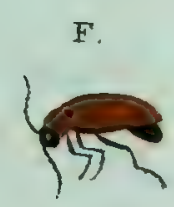

h.

I.

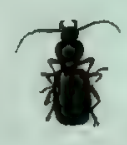

M.

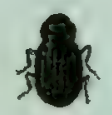

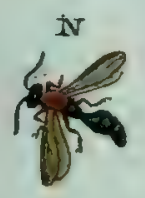

A.a.Ap.Varians. B. Nichy. a.Variantif. C. Not.Pedeforw. D.not.Cinctelluy.

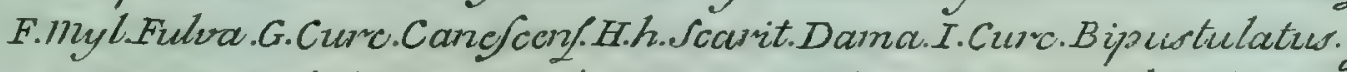

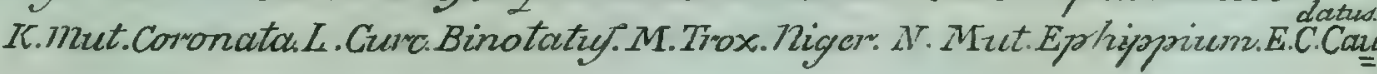


UIRRARY

DF THE

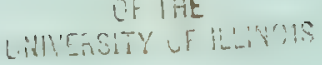




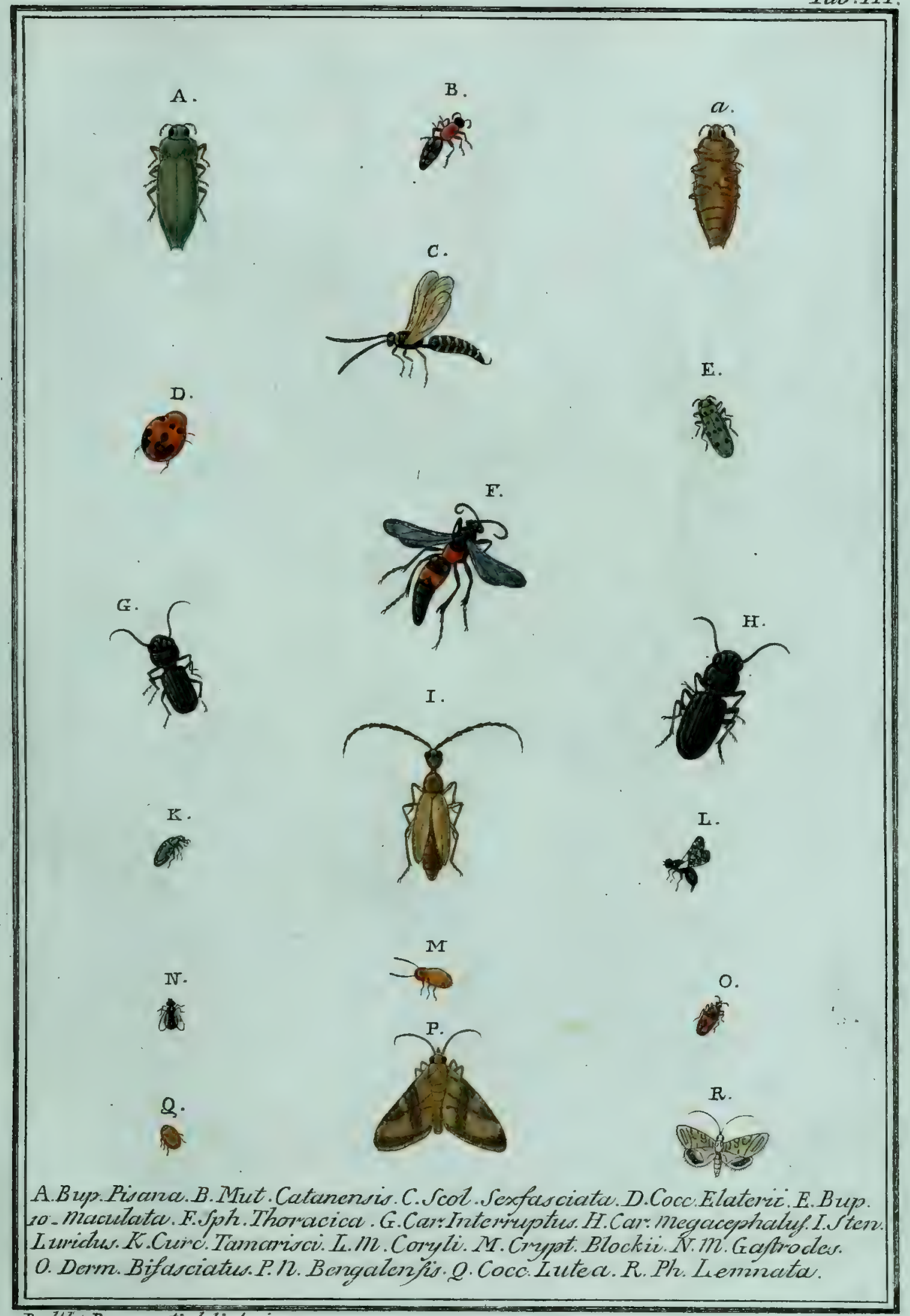

Balth: Bomenute delict.poins. 


$$
\begin{aligned}
& \text { LIRRARY } \\
& \text { UHW CI THE }
\end{aligned}
$$




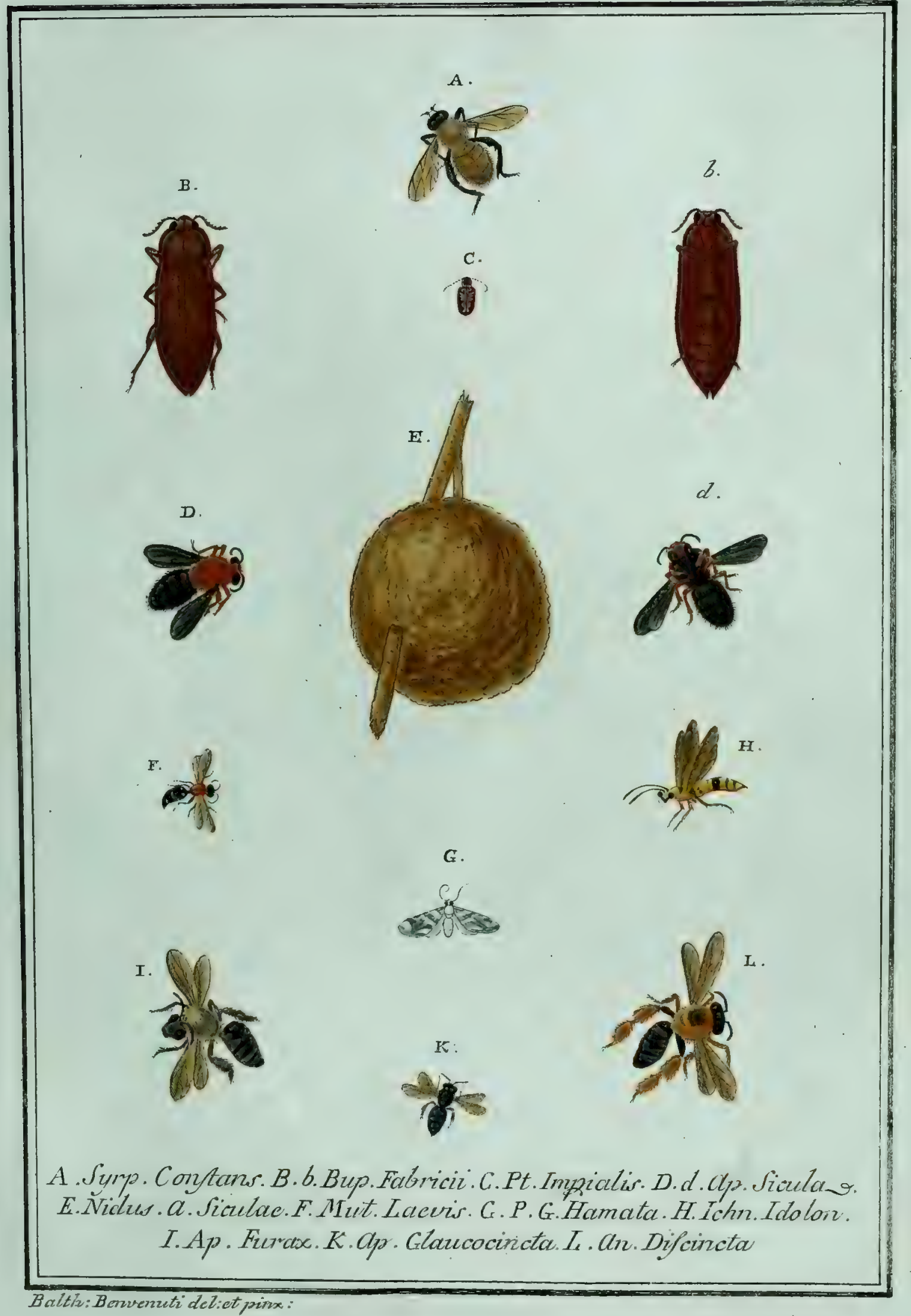




\section{IIBRARY \\ of THE}

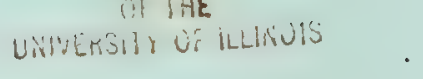




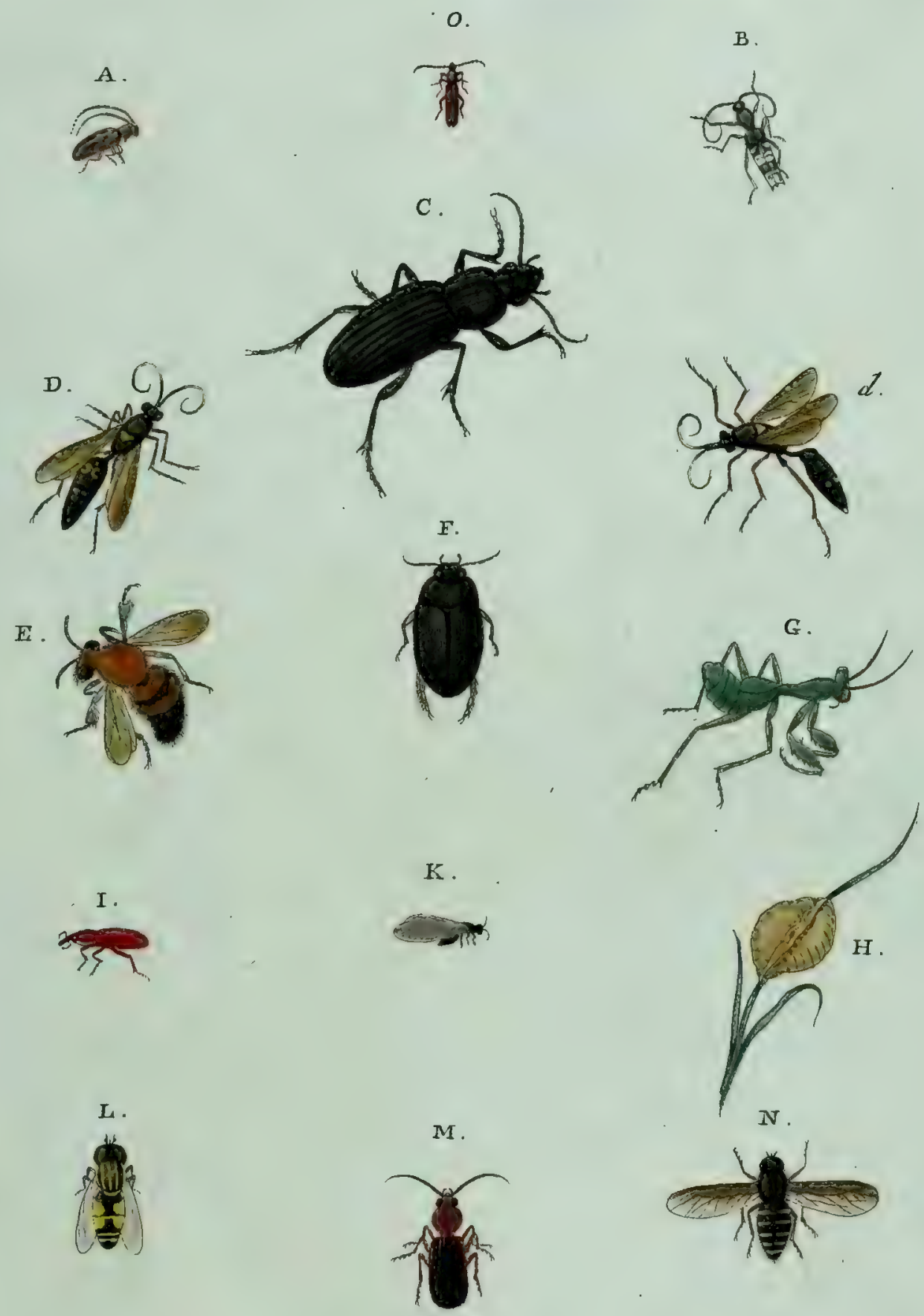

A .Cer. Quercus. B . Call. Gibbofum. C. Car. Paykulliz. D. d. Ichn Inflictorizes. E.Cap. Palmipas. F. Dy t. Pufulatues. G. Manf Spallanzania. H. Ejusd. Ovas I.Cure. Sanguincus. K. Iom. Lucifugun. L. Syrop. Negacephalus. II. Car. Psammodef N.Bib. Sabacut. O. Necyd. Cerranboides. 
LIBRARY

$$
\text { OF THE }
$$

VIVIERSITY ĆF ILLANOIS 
A .
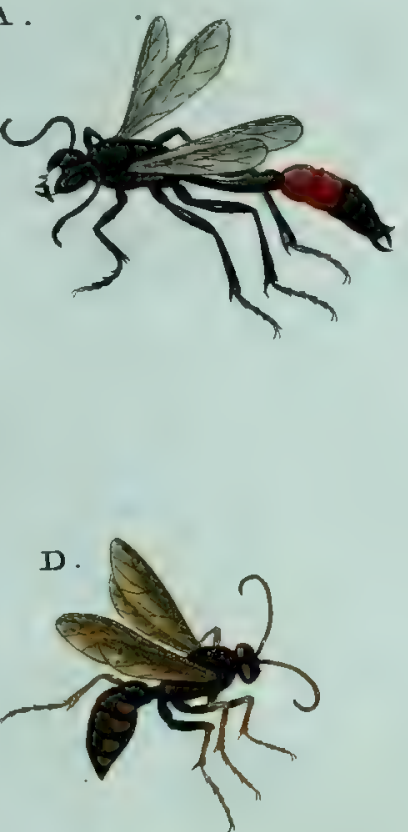

I.

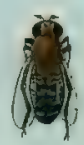

G .

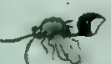

Sil
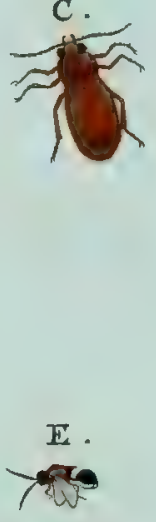

B .
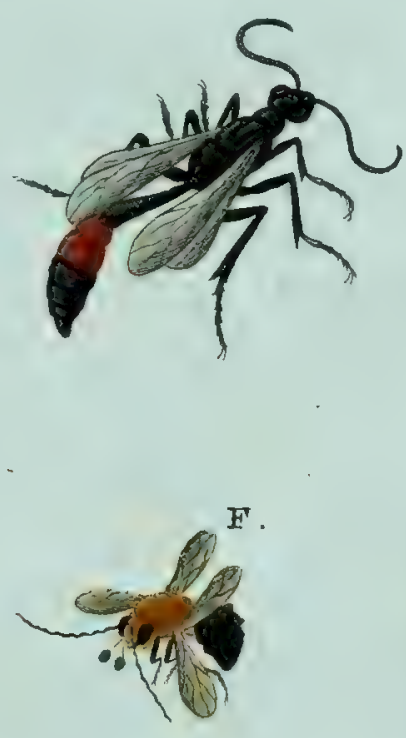

I

त्रिजि

$M$.

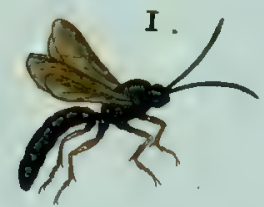

P.

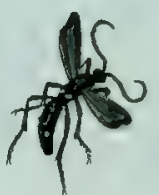

A.Sph. Sabulora major Etmusca,may. B. S. Sabulara majo; fem. C. Car:

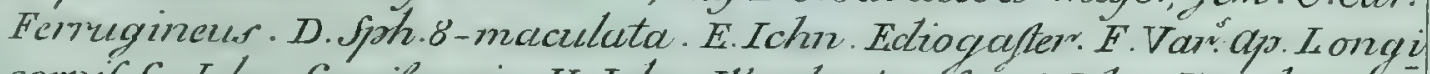
com if. G. Ichn . Cyniformis. H. Ichn. Illecebrator" fem . I.Ichn. Illecebrator"

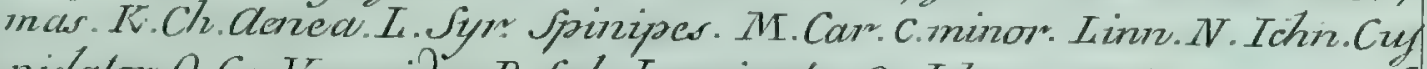
pidalor. O.Cr. Vespoides. P. Splz. Iacviqata. Q. Ichn anuatur. 



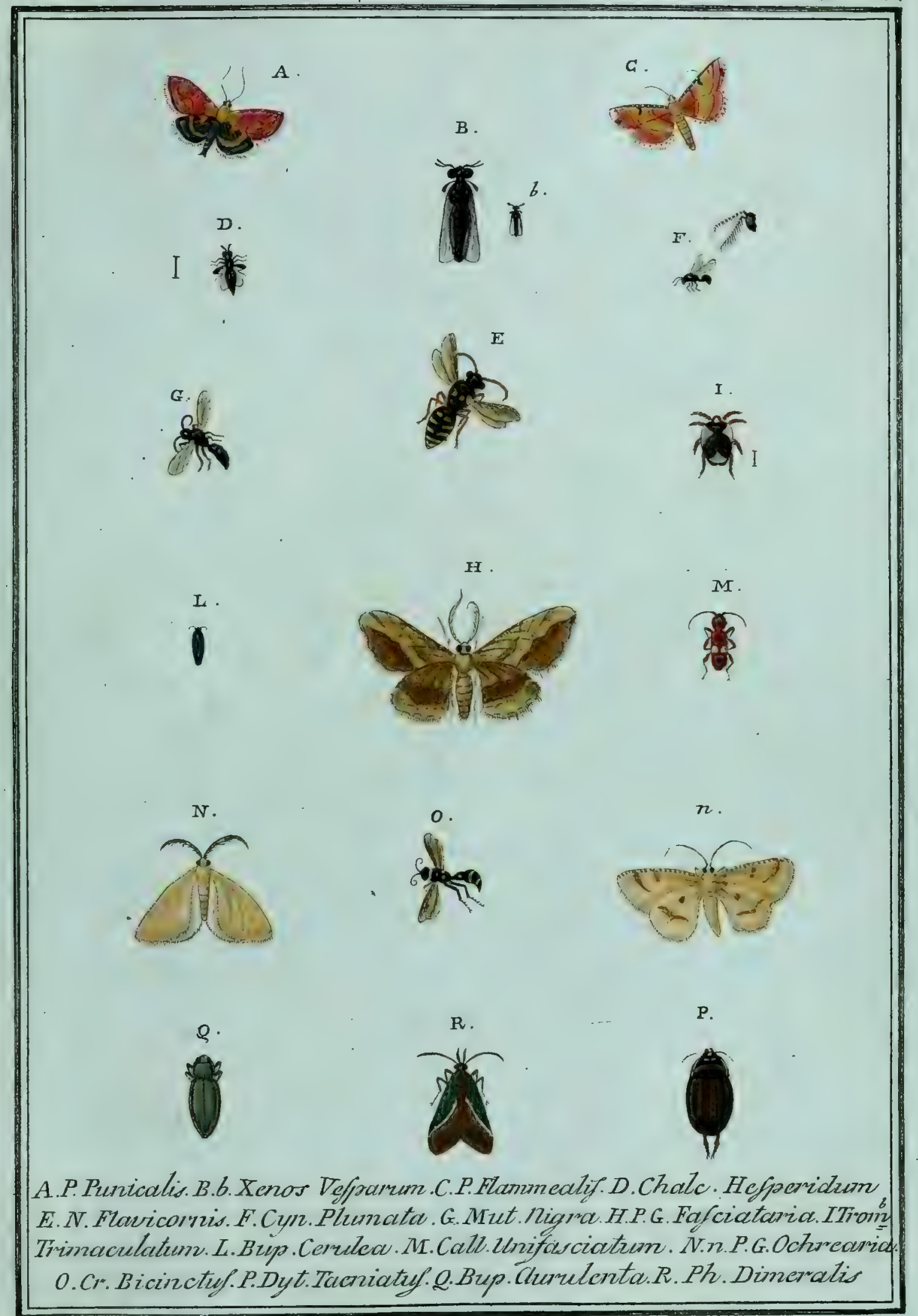

Balth. Benvenuti doli: at pinx. 



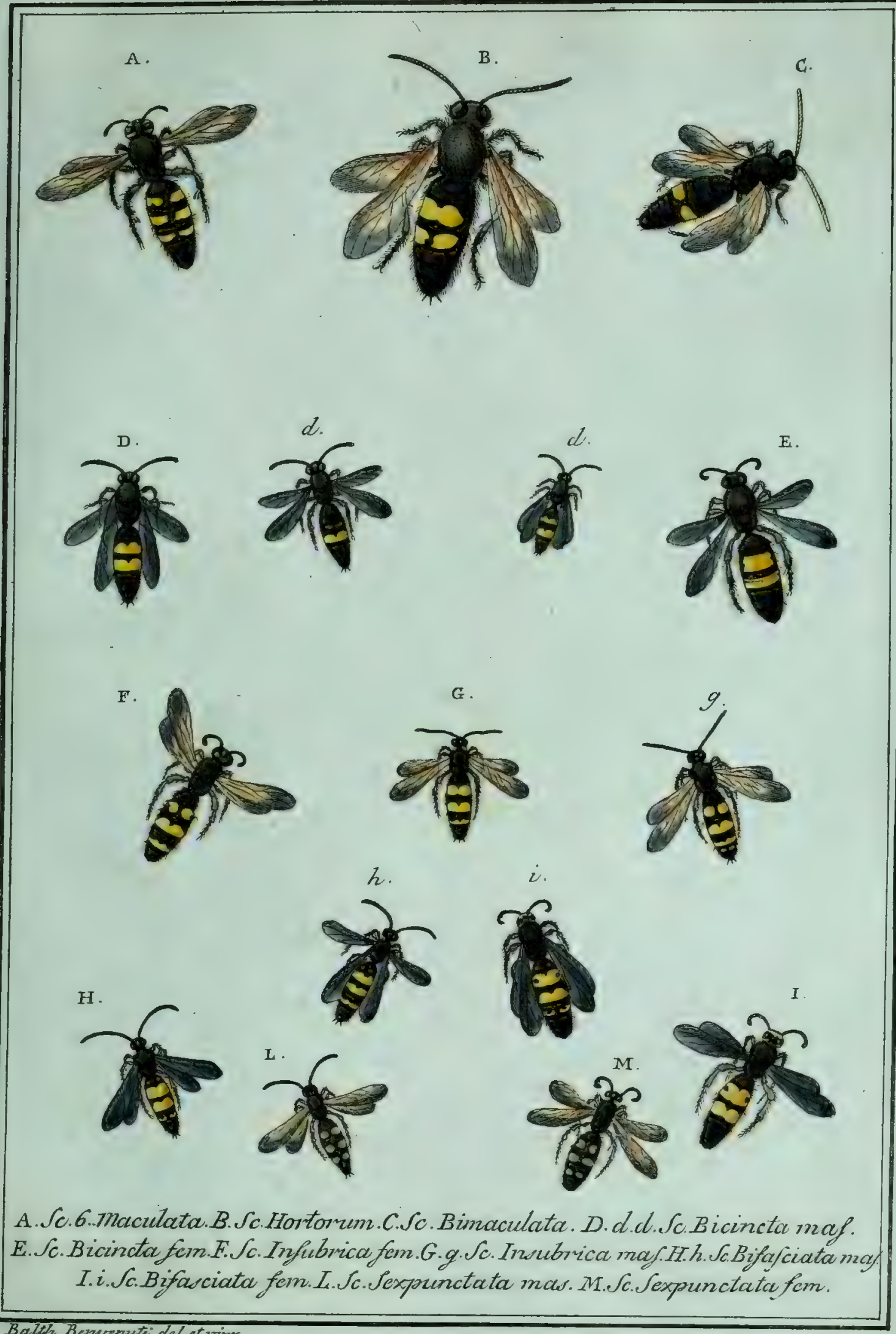






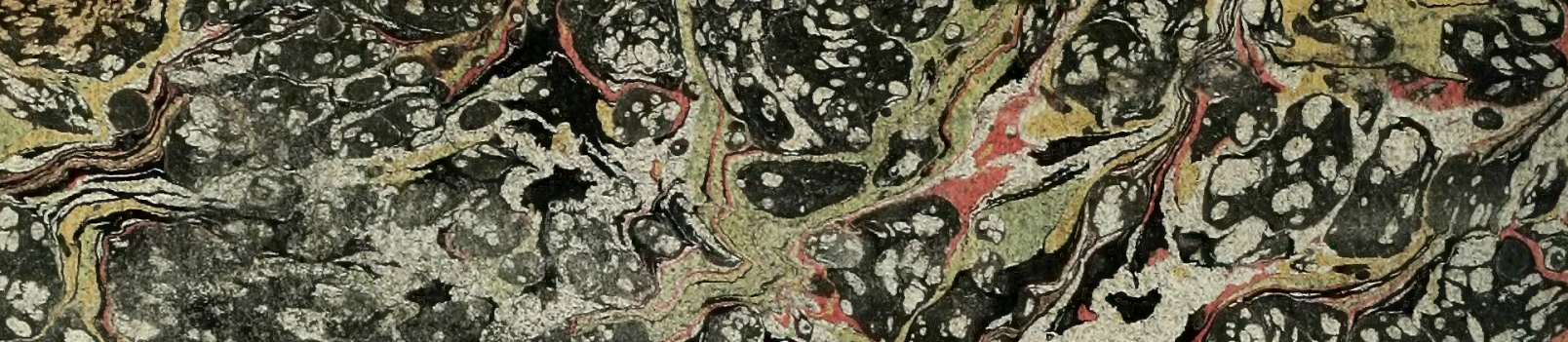

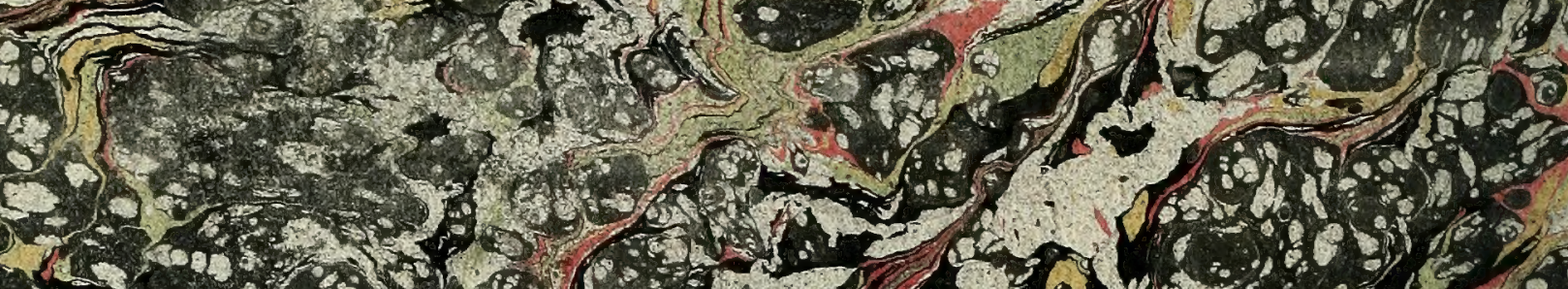

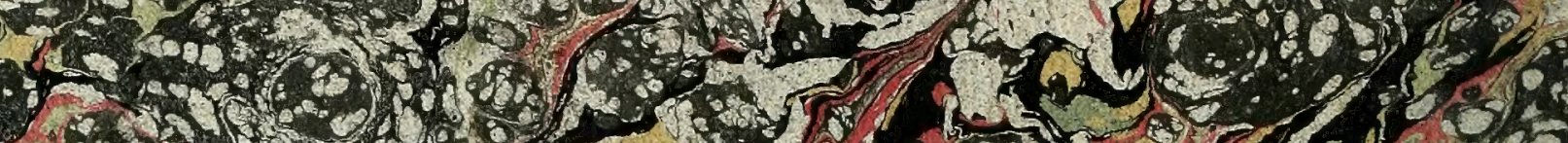

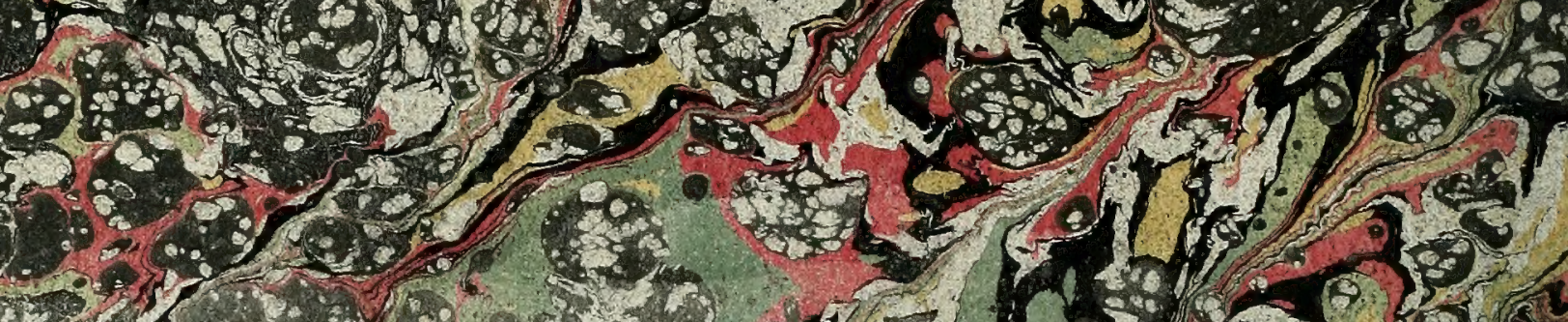

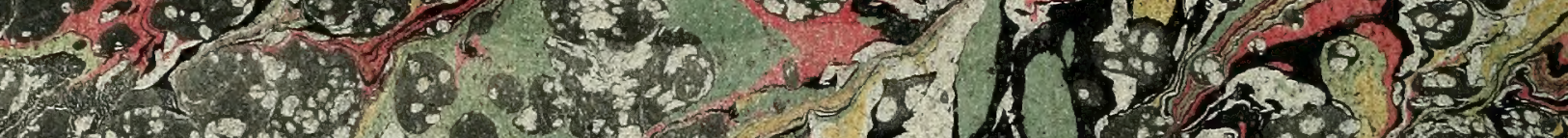

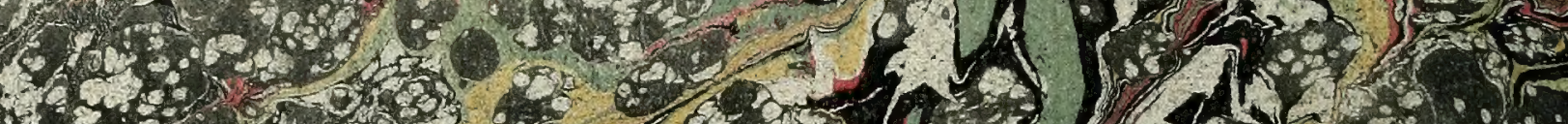
20.6-20.

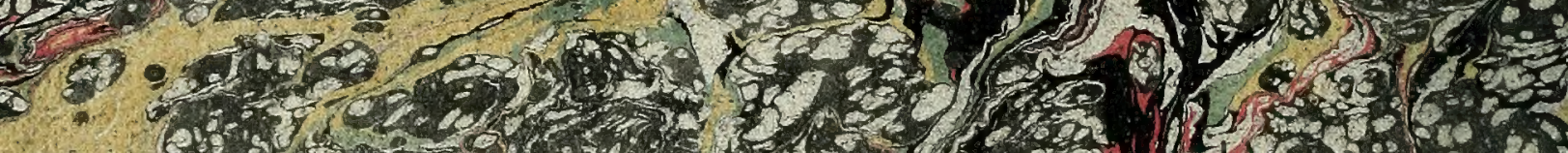

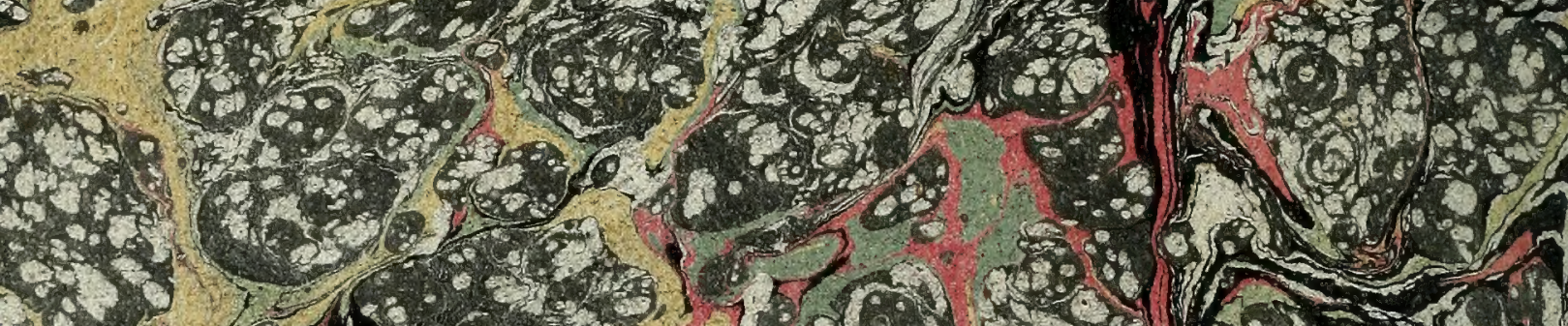
10. 165,30193

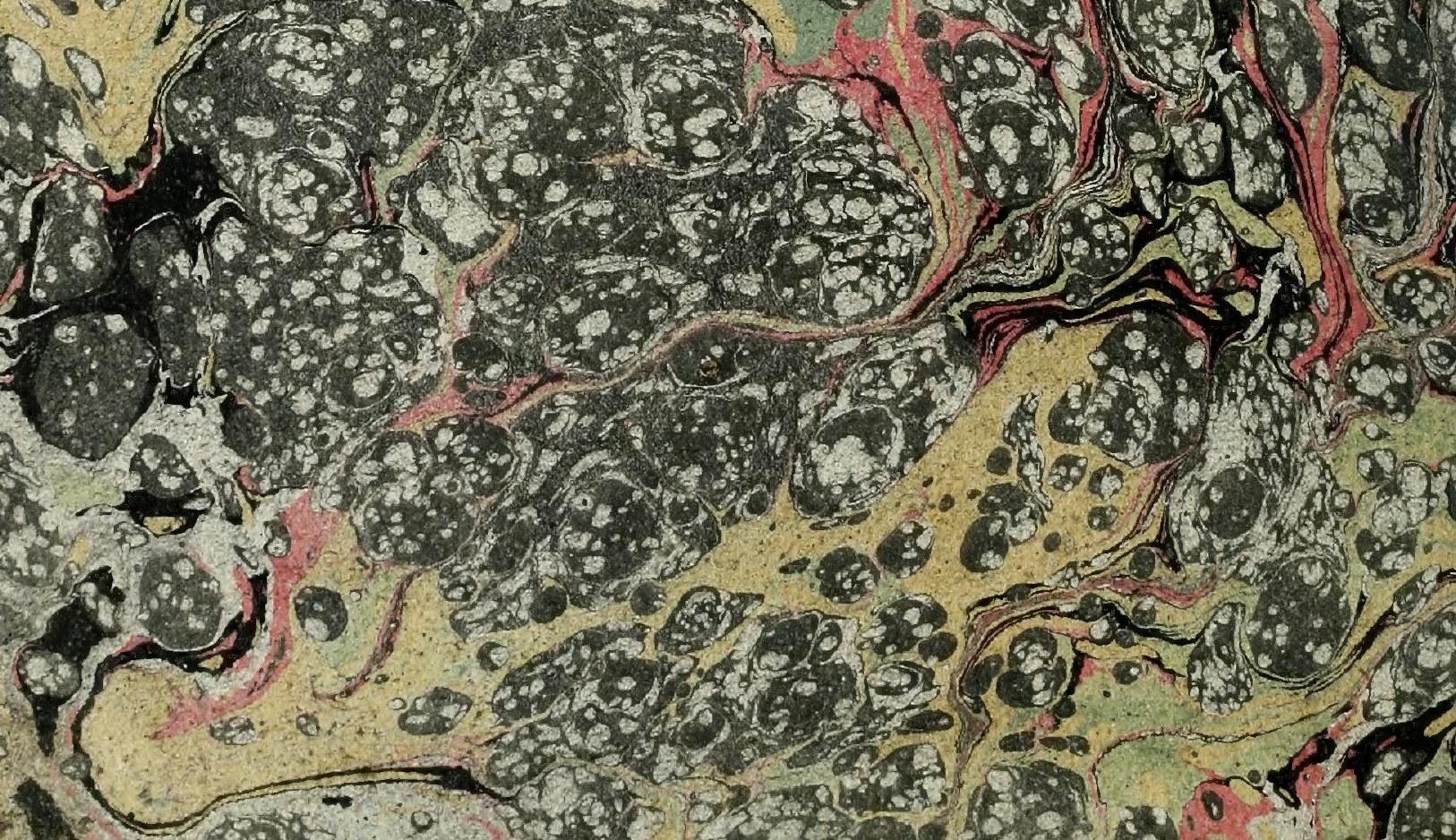





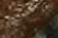

$\sin 30$.

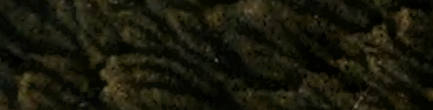

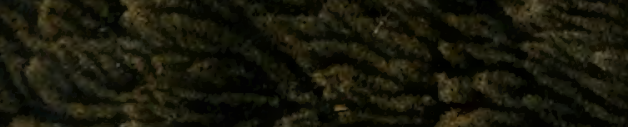

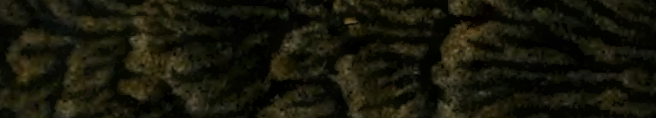

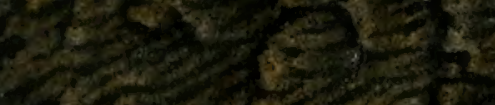

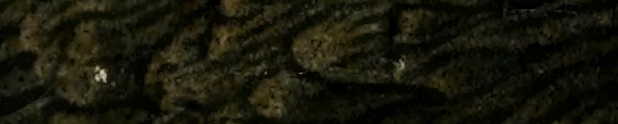

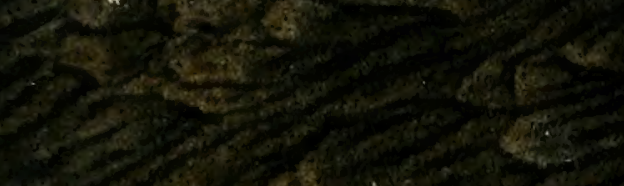

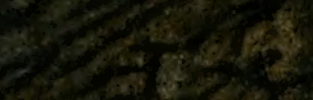

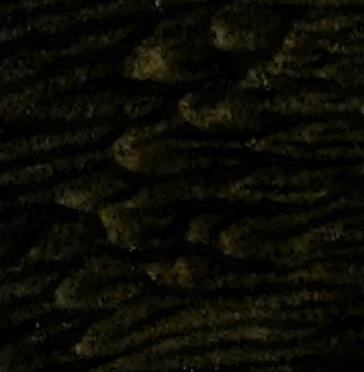

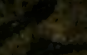

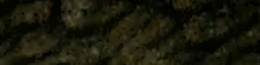

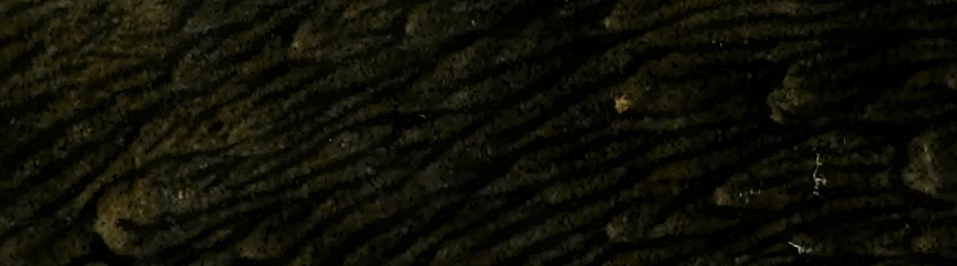

$\frac{3}{3}$

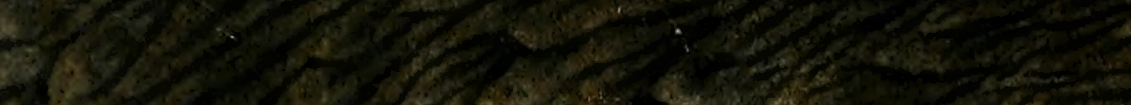

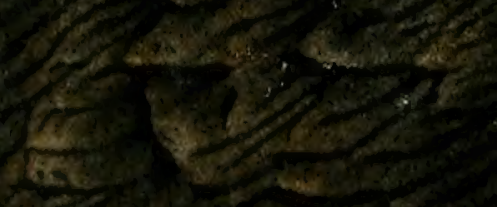

sinetro

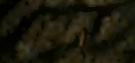

2.

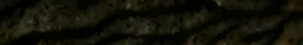

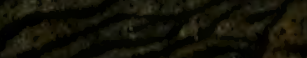

का when

Ear. 